\title{
Excessive aggression, ADHD- and ASD-like phenotypes in TPH2- and brain ganglioside-deficient mice
}

Citation for published version (APA):

Svirin, E. (2022). Excessive aggression, ADHD- and ASD-like phenotypes in TPH2- and brain ganglioside-deficient mice: mechanisms and gene-by-environment interaction. [Doctoral Thesis, Maastricht University]. OneBook.ru. https://doi.org/10.26481/dis.20220111es

Document status and date:

Published: 01/01/2022

DOI:

10.26481/dis.20220111es

Document Version:

Publisher's PDF, also known as Version of record

\section{Please check the document version of this publication:}

- A submitted manuscript is the version of the article upon submission and before peer-review. There can be important differences between the submitted version and the official published version of record. People interested in the research are advised to contact the author for the final version of the publication, or visit the DOI to the publisher's website.

- The final author version and the galley proof are versions of the publication after peer review.

- The final published version features the final layout of the paper including the volume, issue and page numbers.

Link to publication

\footnotetext{
General rights rights.

- You may freely distribute the URL identifying the publication in the public portal. please follow below link for the End User Agreement:

www.umlib.nl/taverne-license

Take down policy

If you believe that this document breaches copyright please contact us at:

repository@maastrichtuniversity.nl

providing details and we will investigate your claim.
}

Copyright and moral rights for the publications made accessible in the public portal are retained by the authors and/or other copyright owners and it is a condition of accessing publications that users recognise and abide by the legal requirements associated with these

- Users may download and print one copy of any publication from the public portal for the purpose of private study or research.

- You may not further distribute the material or use it for any profit-making activity or commercial gain

If the publication is distributed under the terms of Article 25fa of the Dutch Copyright Act, indicated by the "Taverne" license above, 


\section{MAASTRICHT UNIVERSITY}

Excessive aggression, ADHD- and

ASD-like phenotypes in TPH2- and brain

ganglioside-deficient mice: mechanisms

and gene-by-environment interaction

Evgeniy Svirin 
Excessive aggression, ADHD- and ASD-like phenotypes in TPH2- and brain ganglioside-deficient mice: mechanisms and gene-by-environment interaction / Evgeniy Svirin, - M.: LLC «SAM Polygraphist», 2019. - 302 p., ILL

Excessive aggression, ADHD- and ASD-like phenotypes in TPH2- and brain ganglioside-deficient mice: mechanisms and gene-by-environment interaction

ISBN 978-5-00166-525-0

Cover: Cortex in Red and Gold, fragment

Greg Dunn, 2021. www.gregadunn.com

Signed to print 25.11 .2021

Number of copies: 18

Order \# 105027

Printed by «OneBook.ru» LLC "Sam Poligraphist"

129090 Moscow, Protopovsky lane 6

www.onebook.ru

All rights reserved. No parts of this book may be reproduced or transmitted in any form or by any means, without prior permission in writing by the author, or when appropriate, by the publishers of the publication. 
Excessive aggression, ADHD- and

ASD-like phenotypes in TPH2- and brain ganglioside-deficient mice: mechanisms and gene-by-environment interaction

\section{DISSERTATION}

to obtain the degree of Doctor at the Maastricht University, on the authority of the Rector Magnificus,

Prof. dr. Rianne M. Letschert

in accordance with the decision of the Board of Deans,

to be defended in public

on Tuesday, January $11^{\text {th }}, 2022$, at $16: 00$ hours

by

Evgeniy Svirin 


\section{Supervisor:}

Prof. K.-P. Lesch

\section{Co-supervisors:}

Dr. T. Strekalova

Prof. E. Ponomarev, School of Biomedical Sciences, Faculty of Medicine, the Chinese University of Hong Kong, Shatin, Hong Kong

\section{Assessment Committee:}

Prof. J. Prickaerts (Chair)

Prof. E. Budygin, Sirius University of Science and Technology, Sochi, Russia, and Wake Forest School of Medicine, Winston-Salem, USA

Dr. J. M. Mey

Prof. M. V. Pletnikov, Jacobs School of Medicine and Biomedical Sciences, SUNY, University at Buffalo, USA

Prof. K. Schruers 


\section{List of contents}

Propositions ....................................................................... 7 -

List of abbreviations ................................................................ 9 -

Chapter 1. General introduction................................................. - 13 -

1.1 Emotional dysregulation and aggression in neurodevelopmental disorders......................................................................... 13 -

1.2 Aggression in females ................................................. - 15 -

1.3 Neuroanatomical basis of aggression and associated impairments in humans and rodents ..................................... - 16 -

1.4 Brain monoamine system in neurodevelopmental disorders - 21 -

1.5 Neuroinflammation and myelination in the pathogenesis of neurodevelopmental disorders and excessive aggression .......... - 24 -

1.6 Role of serotonin in mechanisms of neurodevelopmental

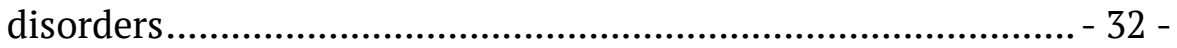

1.7 Gangliosides in the CNS pathology and neuroinflammation - 38 -

1.8 Gene $\times$ environment interaction and stress in neurodevelopmental disorders ............................................ - 42 -

1.9 Mouse models of pathological aggression .......................... - 45 -

Hypothesis and aims.............................................................. 49 -

Chapter 2. Altered behaviour, dopamine and norepinephrine regulation in stressed mice heterozygous in Tph2 gene .................................. - 84 -

Chapter 3. Predation stress causes excessive aggression in female mice with partial genetic inactivation of tryptophan hydroxylase-2: evidence for altered myelination-related processes ..................................... - 134 -

Chapter 4. ASD-like behaviours, a dysregulated inflammatory response and decreased expression of PLP1 characterise mice deficient for sialyltransferase ST3GAL5 ....................................................... - 180 -

Chapter 5. General discussion ................................................... - 239 -

5.1 Genetic and environmental factors in the pathogenesis of neurodevelopmental disorders and excessive aggression ........ - 239 - 
5.2 Alterations of monoamine metabolism and changes in the expression of 5-HT receptors, distress, and plasticity markers as well as myelination-related proteins in stress-related aggression of Tph2 heterozygous mice .......................................................... - 243 -

5.3 ST3GAL5-deficient mice as a model of neurodevelopmental disorders: social behavior abnormalities, molecular changes, and effects of inflammatory stress.......................................... 250 -

5.4 Dysregulated myelination and neuroinflammation as putative common mechanisms of neurodevelopmental disorders and pathologic aggression...................................................... 254 -

5.5 Conclusion ............................................................ 259 -

Summary .................................................................. 275 -

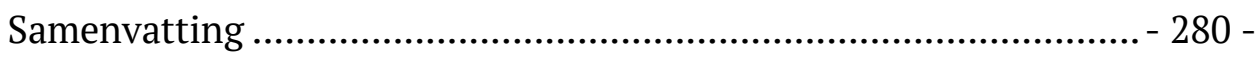

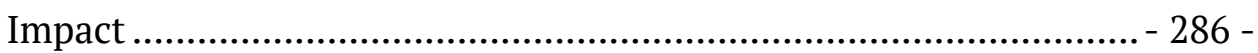

Acknowledgements ............................................................... 290 -

About the author ................................................................ 294 - 


\section{Propositions}

1. Partial deficiency of neuronal serotonin following heterozygosity in the Tph2 gene $\left(T p h 2^{+-}\right)$causes abnormal aggression and sociability in stressed male and female mice (this thesis).

2. These behavioral changes are accompanied by alterations in dopamine and norepinephrine metabolism, aberrant expression of myelination proteins, markers of stress, and plasticity (this thesis).

3. Downregulation of myelination marker PLP1 in St3gal5 $5^{-1-}$ mice deficient for brain gangliosides is associated with dominant behavior, and behaviors reminiscent of autism spectrum disorders (this thesis).

4. Inflammatory stress in St3gal5 $5^{-/}$mice leads to aberrant expression of pro-inflammatory cytokines in the brain and in the periphery, and aggravated aggressive/dominant behavior (this thesis).

5. Abnormalities in myelination and neuroinflammation may constitute common molecular mechanisms leading to behavioral abnormalities in the $\mathrm{Tph}^{+/-}$and St3gal5 $5^{-/-}$mice (this thesis).

6. Modeling of gene-by-environment interaction rather than of genetic or environmental factors alone is useful for animal studies of neurodevelopmental disorders (impact). 
7. Different types of environmental adversities may lead to similar pathological changes contributing to neurodevelopmental disorders.

8. Multiple risk genes act on early stages of neurodevelopment and the formation of brain circuits, thus conferring broad liability to psychiatric disorders.

9. Validation of experimental animal models of behavioral features related to psychiatric disorders requires the use of multiple tests and a variety of experimental conditions.

10. "It's not stress that kills us, it is our reaction to it." - Hans Selye 


\section{List of abbreviations}

$\begin{array}{ll}\text { 5-HIAA } & \text { 5-hydroxyindoleacetic acid } \\ \text { 5-HT } & \text { 5-hydroxytryptamine (serotonin) } \\ \text { 5-HTP } & \text { 5-hydroxytryptophan } \\ \text { 5-HTT/SERT } & \text { serotonin transporter } \\ \text { ADHD } & \text { attention-deficit/hyperactivity disorder } \\ \text { ALS } & \text { amyotrophic lateral sclerosis } \\ \text { ANOVA } & \text { analysis of variance } \\ \text { ASD } & \text { autism spectrum disorders } \\ \text { B4GALNT1 } & \text { beta-1,4 N-acetylgalactosaminyltransferase 1 } \\ \text { BH4 } & \text { tetrahydrobiopterin } \\ \text { cAMP } & \text { cyclic adenosine monophosphate } \\ \text { CNS } & \text { central nervous system } \\ \text { COMT } & \text { catechol-O-methyltransferase } \\ \text { COX } & \text { cyclooxygenase } \\ \text { CREB } & \text { cAMP response element-binding protein } \\ \text { DA } & \text { dopamine } \\ \text { DAT } & \text { dopamine transporter } \\ \text { DBH } & \text { dopamine beta-hydroxylase } \\ \text { DCC } & \text { deleted in colorectal carcinoma } \\ \text { DISC1 } & \text { disrupted in schizophrenia 1 } \\ \text { DLB } & \text { dark-light box } \\ \text { dlPFC } & \text { dorsolateral prefrontal cortex } \\ \text { dmPFC } & \text { dorsomedial prefrontal cortex } \\ \text { DOPAC } & \text { 3,4-Dihydroxyphenylacetic acid } \\ \text { DRD2 } & \text { dopamine receptor D2 } \\ \text { DRN } & \text { dorsal raphe nuclei } \\ \text { DTI } & \text { diffusion tensor imaging } \\ \text { EAE } & \text { experimental autoimmune encephalomyelitis } \\ \text { fMRI } & \text { functional magnetic resonance imaging } \\ \text { FST } & \text { G×E }\end{array}$


GSK-3 $\beta$

HO-1

HPLC

Hsp70

HVA

HPA

IDO-1

IFN- $\gamma$

iNOS

LC

MAG

MAO

MAPK

MBP

MHPG

MRI

NE

NMDA

OCD

OFC

OL

PLP1

PNS

PTSD

RIPK1

RIT

SIRT

SN

SNP

SSRI

SNRI

ST3GAL3

ST3GAL5 glycogen synthase kinase 3 beta heme oxygenase 1

high-performance liquid chromatography

heat shock protein 70

homovanillic acid

hypothalamic-pituitary-adrenal axis

indoleamine-2,3-dioxygenase

interferon gamma

inducible nitric oxide synthase

locus coeruleus

myelin-associated glycoprotein

monoaminoxidase

mitogen-activated protein kinase

myelin basic protein

3-Methoxy-4-hydroxyphenylglycol

magnetic resonance imaging

norepinephrine

$\mathrm{N}$-methyl-d-aspartate

obsessive-compulsive disorder

orbitofrontal cortex

oligodendrocyte

proteolipid protein 1

peripheral nervous system

post-traumatic stress disorder

receptor-interacting protein kinase 1

resident-intruder test

sirtuin

substantia nigra

single nucleotide polymorphism

selective serotonin reuptake inhibitor

selective serotonin-norepinephrine reuptake inhibitor

beta-galactoside- $\alpha 2,3$-sialyltransferase-III

lactosylceramide alpha-2,3-sialyltransferase 
TNFR1

TLR4

TPH1

TPH2

vHPC

VMAT2

$\mathrm{VMH}$

VmPFC

VTA

wt
TNF receptor 1

toll-like receptor 4

tryptophan hydroxylase 1

tryptophan hydroxylase 2

ventral hippocampus

vesicular monoamine transporter 2

ventromedial nucleus of the hypothalamus

ventromedial prefrontal cortex

ventral tegmental area

wildtype 


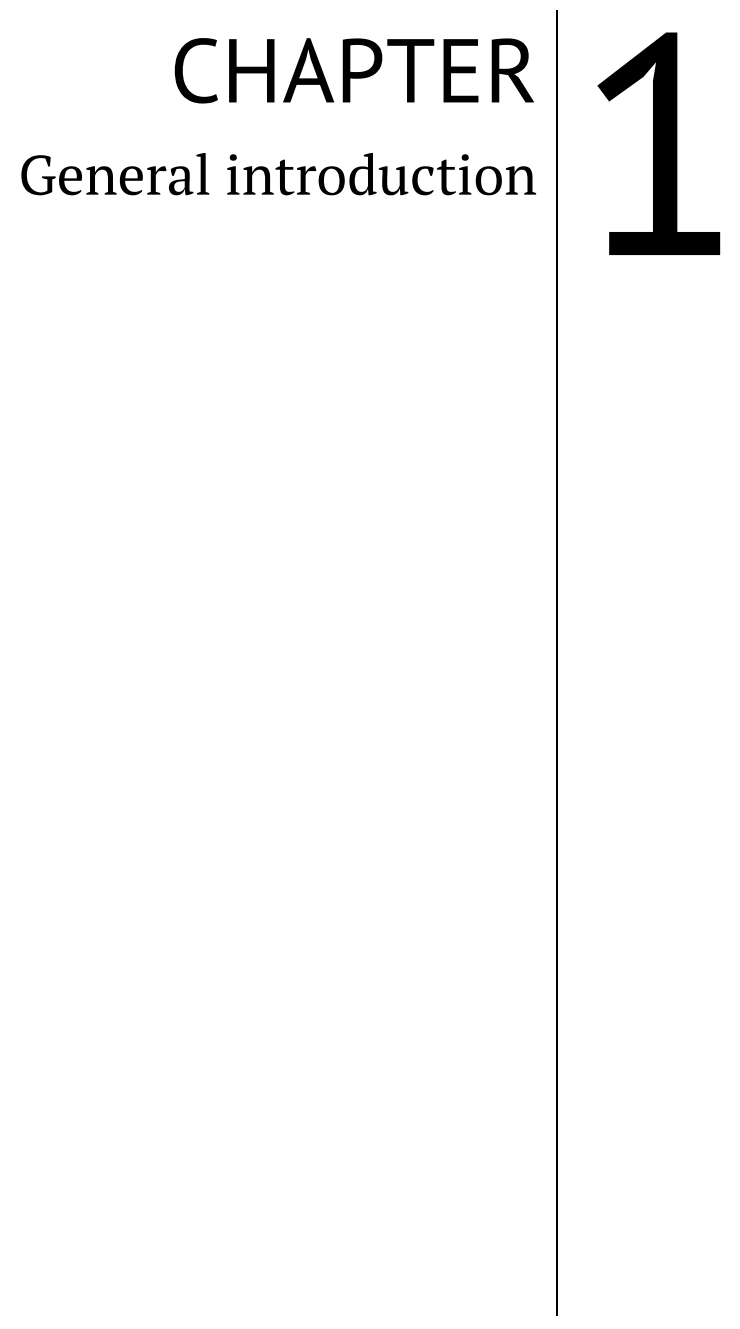




\section{Chapter 1. General introduction}

\subsection{Emotional dysregulation and aggression in neurodevelopmental disorders}

Aggression is an adaptive social behavior with multiple possible causes; most of them arise over limited resources where there is a conflict of interests between two or more individuals. The adaptive role of aggression comprises the defense of territory or resources, social position, or group identity (Covington et al., 2019). However, when brought to the extreme, aggression may become maladaptive or pathological. Such forms of aggression may be represented by an overreaction to provoking social stimuli, eventually leading to excessive harm, injury, or death.

Aggression in humans tends to be overrepresented in some individuals affected by mental disorders. Marked aggression often accompanies neurodevelopmental disorders, with the rate of aggression varying across different conditions. According to epidemiological research, the prevalence of abnormal aggression is estimated in the range from $5.7 \%$ in attention-deficit/hyperactivity disorder, where children with mostly hyperactive-impulsive presentation show more aggression than children with the inattentive endophenotype (González et al., 2013; Slaughter et al., 2020), to about 68\% in autism spectrum disorders (Mazurek et al., 2013). Aggressive behaviors are also overrepresented in bipolar disorder and major depressive disorder (Ballester et al., 2014; Pulay et al., 2008), schizophrenia (Fazel et al., 2014; Rund, 2018; Soyka, 2011), intellectual disability with comorbidities (Tsiouris et al., 2011), 
and neurodegenerative disorders such as Alzheimer's disease (Yu et al., 2019) and other forms of dementia (Kunik et al., 2020).

Stress-related disorders are also associated with aggressive behavior, e.g., patients with post-traumatic stress disorder are known to experience sudden uncontrollable bursts of anger and have difficulties with controlling aggressive urges (Van Voorhees et al., 2014). Last but not least, violent behavior is significantly increased among individuals suffering from drug and/or alcohol abuse (Pulay et al., 2008; Rund, 2018) - conditions, which are often comorbid with neurodevelopmental disorders (Gold et al., 2018; Hunt et al., 2018; Weissenberger et al., 2017). Aggression is a complex heterogenous behavior, which can be qualitatively differentiated into subtypes by several criteria. In light of current views, human aggression is most often categorized as impulsive (reactive) or instrumental (proactive), for which the underlying neurobiological mechanisms differ (Lesch and Merschdorf, 2000).

Besides aggression, other symptoms occur across various neurodevelopmental disorders, including emotional dysregulation (Faraone et al., 2019; Sagar-Ouriaghli et al., 2018), anxiety (Katzman et al., 2017; Rakofsky and Dunlop, 2011; Schatz and Rostain, 2006; Temmingh and Stein, 2015; Vasa et al., 2016), and increased impulsivity (Hoptman, 2015; Najt et al., 2007; Rund, 2018; Saddichha and Schuetz, 2014). Correlations between these symptoms and aggression were studied in both patients and healthy individuals. Suicide risk and risk of violent behavior were shown to be positively correlated with impulsivity, anxiety, and measures of anger in acute psychiatric inpatients (Apter et 
al., 1990). A link was also shown between impulsivity and violence in schizophrenia (Rund, 2018).

Correlations between aggression and other psychometrical measures were also shown for non-clinical groups. Measures of aggression were correlated with depressive symptoms in adults (Bjork et al., 1997). In children attention scores negatively correlated with both anxiety and aggression, while aggression was positively correlated with anxiety (Meesters et al., 2007). Some of the authors speculate that such a high degree of comorbidity between these disorders is due to shared neurobiological mechanisms and neuroanatomic substrates, while the brain serotonin $(5-\mathrm{HT})$ system receives much attention as the main candidate for intervention.

\subsection{Aggression in females}

Female aggression and violent behavior are particularly understudied, as there is a common misconception that aggression lies outside of female behavioral repertoire in many mammalian species, and it has been regarded as self-evident that men are more aggressive than women (Lindberg et al., 2009). However, this view is challenged by research suggesting that while boys are more physically aggressive than girls, boys and girls are virtually equal in scores of verbal and indirect aggression (Björkqvist, 2018). Regarding psychiatric pathology and aggression in women, a meta-analysis showed that about $42 \%$ of female prisoners had some personality disorder, and about one in five antisocial personality disorder (Fazel and Danesh, 2002). 
In animals, several types of female aggression were proposed. Maternal aggression is a defensive behavior against a potentially dangerous intruder, intended to protect the offspring. In mice and rats, such aggression is triggered by stimuli from pups, i.e., suckling stimulus, and the presence of an intruder (Bosch, 2013; Bosch et al., 2005). However, rodent maternal aggression is an example of female aggression less applicable to modeling human psychiatric pathology. Social aggression, as intermale territorial aggression, is much less common in female mice (Angoa-Pérez et al., 2012a). The prairie vole (Microtus ochrogaster) has recently emerged as a new animal model for investigating the neurobiology of escalated aggression and violence, since ethologically their mating is accompanied by aggressive behavior directed toward both male and female conspecifics (Gobrogge, 2013). Another highly recognized model of female territorial aggression is a Syrian hamster (Mesocricetus auratus), as in this species both males and females are highly territorial and females tend to be aggressive and dominant over male intruders (Been et al., 2019; Gutzler et al., 2010). Still, while there are rodent models of female aggression, they represent ethologically adequate behaviors, and little research is directed towards female aggression in pathology, including neurodevelopmental disorders.

1.3 Neuroanatomical basis of aggression and associated impairments in humans and rodents

Data from both human and animal studies highlighted several brain regions implicated in aggression. Multiple studies point out an 
essential role of the amygdala in emotional regulation and, in particular, in aggression (Cupaioli et al., 2021; Haller, 2017). The amygdala consists of several regions: basolateral nuclear complex, centromedial nuclear complex, and cortical nucleus. The basolateral complex is a structure that receives most of the amygdalar inputs from multiple brain regions, including the prefrontal cortex (PFC) and thalamus. It also receives dopamine (DA) projections from the ventral tegmental area (VTA) and substantia nigra (SN), norepinephrine (NE) projections from locus coeruleus (LC), and 5-HT projections from dorsal raphe nuclei (DRN) (Deal et al., 2021; Sharp, 2017). The centromedial complex, in turn, is the main output of the amygdala, including projections into the thalamus, hypothalamus (Keifer et al., 2015), and brainstem regions of 5-HT, DA, and NE systems of the brain (Fadok et al., 2018). Moreover, the basolateral complex also sends efferent projections to prefrontal and striatal regions (Rosell and Siever, 2015).

The amygdala was shown to play a major role in the integration of sensory and motivationally salient stimuli. There is a remarkable body of evidence from animal and human studies implicating the amygdala in aggression. Enhanced amygdalar activity upon presentation of threatening facial stimuli was shown in aggressive individuals with intermittent explosive disorder compared to healthy controls (Coccaro et al., 2007). Several studies in humans have shown that total amygdalar volume negatively correlates with psychometric scores of aggression (Matthies et al., 2012; Pardini et al., 2014). The latter study also showed volumetric changes, i.e., a decrease in the volume of the gray matter, of 
only the dorsal part of the left amygdala in more aggressive individuals (Gopal et al., 2013). In another study, the volume of the dorsal part of the left amygdala correlated negatively with self-reported measures of aggression. Lower activation of the left dorsal amygdala was also shown in aggressive compared to non-aggressive individuals. In the same study, it was also shown that the amygdala of more aggressive individuals is more reactive to neutral stimuli (Bobes et al., 2013). Involvement of the dorsal but not ventral amygdala suggests that observed changes may arise from the altered amygdalar output.

One of the major amygdalar outputs projects to the medial (m) PFC, which was also implicated in aggression in humans. The mPFC is reciprocally connected with the amygdala and is a pivotal region for the integration of information about the motivational value and affective valence of stimuli, as well as for decision-making and determination of adequate responses and their outcomes (Rudebeck and Murray, 2014; Walton et al., 2007). In more aggressive individuals, volumetric studies showed lower volumes of the gray matter in several regions of the ventromedial (vm) PFC (Ducharme et al., 2011; Gansler et al., 2009). Reciprocal activation was found between the vmPFC and amygdala. Coccaro et al. (2007) showed that in control non-aggressive individuals, who were presented with threatening faces, activity of the amygdala negatively correlated with the activity of the vmPFC, suggesting functional coupling of these structures. Such a relationship was not evident in the aggressive group with intermittent explosive disorder (Coccaro et al., 2007). 
Impulsive aggression is thought to develop when the amygdala is released from inhibition by the PFC (Haller, 2017). However, this point of view is questioned, as there is evidence that lesions in the vmPFC not only lead to a higher risk of impulsive aggression (Grafman et al., 1996), but also have a protective effect on the risk of post-traumatic stress disorder (PTSD) development (Koenigs and Grafman, 2009). Moreover, in a study using rats, lesions of the vmPFC led to reduced amygdala activation during decision-making tasks (Saddoris et al., 2005). Blair (2016) hypothesizes that vmPFC does not inhibit the activity of the amygdala, but rather provides information for optimal response choice. Thus, increased aggression accompanying the vmPFC-amygdalar dysconnectivity may arise not from disinhibition, but from the lack of adequate estimation of possible consequences of engagement in impulsive aggression (Blair, 2016).

Notably, neuroimaging studies showed that anxiety, which is often co-morbid with defensive aggression, may predict dysfunctional dorsomedial (dm) PFC- and vmPFC-amygdala connectivity in psychiatrically healthy humans both in goal-directed tasks and during resting state (Kim et al., 2011). Vice versa, in healthy individuals, trait anxiety was predicted by the structural integrity of the amygdalaprefrontal pathway (Kim and Whalen, 2009). The dorsolateral (dl) PFC and orbitofrontal cortex (OFC) receive inputs from the amygdala and other areas that may integrate sensory information and affective signals (Schoenbaum et al., 2006) as part of a network processing emotionally salient stimuli and mediating goal-directed behaviors. Dysfunction in 
these structures also may result in impaired emotional regulation and contribute to behavioral disinhibition, leading to aggression and impulsivity (Schoenbaum et al., 2006; Winstanley, 2007). Again, OFC is implicated in a number of anxiety-related disorders. Hypoactive medial OFC is implicated in phobias and panic disorder, as medial OFC fails to properly inhibit inappropriate fear and anxiety. Hyperactive lateral OFC is found in obsessive-compulsive disorder (OCD), which is also characterized by maladaptive behavioral stereotypes guided by anxiety (Milad and Rauch, 2007).

The striatum, especially the Nucleus accumbens, is one of the structures essential for the motivational effects of emotionally salient stimuli. It receives projections from the amygdala and the PFC and is seen as a "limbic-motor" interface, which plays a role in amygdalamediated behaviors as well (Ambroggi et al., 2008; Cardinal et al., 2003). Lesions in the Nucleus accumbens provoked excessive aggression and muricide in male Wistar rats (Lee and Ueki, 1986; Pucilowski and Valzelli, 1986). In patients, deep brain stimulation in the Nucleus accumbens region led to a reduction of symptoms in anxiety disorder and OCD (Sturm et al., 2003).

The hippocampus also plays a role in abnormal aggression. Disruption of the prefrontal-hippocampal circuitry may result in emotional dysregulation and impaired contextual fear conditioning (Raine et al., 2004). In mouse studies, stress-induced attack behavior was shown to be associated with the activation of ventral hippocampus neurons (Chang and Gean, 2019). Additionally, activation of pyramidal 
neurons in the CA2 region of the hippocampus, which are important for social memory, promote social aggression in mice (Leroy et al., 2018).

\subsection{Brain monoamine system in neurodevelopmental disorders}

Three main monoaminergic systems of the brain, characterized by 5-HT, DA, and NE transmission, mediate the functions of structures involved in the pathogenesis of aggression, impulsivity, and anxiety in neurodevelopmental disorders. The 5-HT system of the brain received particular attention in relation to these behavioral aspects in the past decades.

The main source of brain 5-HT are raphe nuclei located in the brainstem. Diffuse fibers arising from the raphe project to many cortical and subcortical areas. 5-HT receptors are abundant in the brain, and they are present in structures associated with emotional control and aggression, such as the PFC, amygdala, and striatum (Rosell and Siever, 2015). DRN projections to the PFC modulate its activity and thus may contribute to top-down control of impulsive aggression (Rosell and Siever, 2015). 5-HT is widely acknowledged as one of the most important regulators of aggression. In humans, dysregulation of the 5-HT system was associated with self-directed aggression and suicide (Mann, 2001). Human and animal studies linked aberrations in 5-HT signaling and metabolism with aggression and interpersonal violence (Glick, 2015; Virkkunen et al., 1995, 1987). Excessive aggression, muricide, and hyperemotionality were also shown upon pharmacological destruction or 
electrical lesioning of DRN in rats (Kostowski et al., 1975; Yamamoto and Ueki, 1977).

Genetic modification of components in the 5-HT system is widely known as a factor underlying excessive aggression in both animals and humans. Both male and female mice with Tph2 gene inactivation exhibit excessive aggression (Angoa-Pérez et al., 2012b; Gutknecht et al., 2015; Mosienko et al., 2020). Moreover, partial Tph2 inactivation in mice was shown to result in increased aggression after subjection to stressful conditions (Gorlova et al., 2020). In humans, variants in the TPH2 gene were also associated with aggressiveness, suicidal behavior, and risk of development of borderline personality disorder (Pavlov et al., 2012). Strikingly, allelic variants of the TPH1 gene were also associated with anger-related traits in suicide attempters and suicidal behavior itself, while TPH1 is not present in the brain and is responsible for peripheral 5 HT synthesis only (Pavlov et al., 2012).

Another gene of the 5-HT system implicated in aggression is the 5-HT transporter (5-HTT/SERT, SLC6A4). Mice deficient for 5-Htt showed lowered aggression (Holmes et al., 2002). In humans, homozygosity for the short allele of $5-H T T$ was shown to be associated with increased hostility in women (Sysoeva et al., 2009). Deficiency of monoamine oxidase A (MAOA), which is an enzyme catabolizing monoamines, including 5-HT, leads to excessive aggression in animals and humans (Bortolato et al., 2013; Godar et al., 2016). A rare MAOA mutation in humans causes Brunner syndrome, whereby symptoms include elevated impulsive behavior including pyromania and violence (Hunter, 2010). 
The DA system of the brain is implicated in the processing of both pleasurable and aversive stimuli (Budygin et al., 2012), as well as in social stress (Deal et al., 2018), and aggression. DA pathways are an integral part of the brain reward system, and lowered sensitivity of the reward system may cause pathological aggression. Alterations in genes of DA pathways were hypothesized to be involved in its etiology (Chen et al., 2005). Polymorphisms in DA receptor D2 gene (DRD2) were shown to be associated with aggression in men (Butovskaya et al., 2013). In an epistatic model, interactions associated with aggression were also found between DRD2 and dopamine transporter (DAT), as well as between DAT and catechol-O-methyl transferase (COMT) (Butovskaya et al., 2013). Lower availability of D2/D3 receptors in the VTA, which leads to enhanced DA release in striatum was shown to be associated with higher impulsivity in humans (Buckholtz et al., 2010).

In mice, agonists of $\mathrm{D} 2 / \mathrm{D} 3$ receptors were shown to potentiate defensive behavior and reduce aggressive behavior (Gendreau et al., 2000). D1 receptor inhibition in the Nucleus accumbens was shown to decrease aggression-seeking behavior in mice (Golden et al., 2019). Dat knockout mice showed excessive aggression (Rodriguiz et al., 2004), and repeated aggression in male mice led to elevated expression of the Dat gene in VTA (Bondar et al., 2009). COMT variants with lowered enzymatic activity in humans were associated with psychiatric abnormalities and predisposition to aggression (Brennan et al., 2011; Kulikova et al., 2008). Comt heterozygous knockout mice show increased aggressive behavior as well (Gogos et al., 1998). Alterations in DA 
signaling may induce impulsivity and aggression through weakening inhibitory pathways (Pavlov et al., 2012). As COMT and MAOA also participate in NE metabolism, there might also be a link between the NE system and aggression. Furthermore, in mice, knockout of dopamine beta-hydroxylase (DBH), which is involved in NE synthesis from DA, led to almost complete absence of aggression (Marino et al., 2005). Allelic variants in $D B H$ gene were also shown to interact with aggressiveness traits in humans (Hess et al., 2009).

\subsection{Neuroinflammation and myelination in the pathogenesis of} neurodevelopmental disorders and excessive aggression

While inflammation, in general, is a protective mechanism, intended to remove pathogens and affected cells and stimulate regenerative functions (Kulkarni et al., 2016), negative effects of prolonged inflammation are evident, including those of neuroinflammation in particular. Pro-inflammatory signals and subsequent neuroinflammation may affect CNS function in several ways. First of all, neuroinflammation may lead to neuronal death. Through activation of the death receptor TNF receptor 1 (TNFR1), TNF may induce apoptosis and necroptosis, which are implicated in many human CNS diseases (Yuan et al., 2019). Downstream to TNFR1 activation, receptorinteracting protein kinase 1 (RIPK1) mediates not only necroptosis but also inflammation itself (Ofengeim and Yuan, 2013). In mice, administration of LPS led to elevated apoptotic marker expression and decreased cell survival in the cortex and hippocampus (Khan et al., 2018). 
Neuronal cell death in brain structures implemented in aggression may lead to behavioral alterations, e.g., increased aggression in Alzheimer's disease may partly be attributed to monoaminergic neuron loss (Palmer and DeKosky, 1993; Weinshenker, 2008).

There are also more subtle pathways by which neuroinflammation may contribute to behavioral changes. CNS inflammation may affect monoaminergic transmission by altering monoamine synthesis and reuptake. Depressive-like behavior in mice caused by LPS administration was accompanied by activation of indoleamine 2,3-dioxygenase (IDO), an enzyme catabolizing tryptophan into kynurenine, thus possibly lowering tryptophan availability for 5-HT synthesis (Couch et al., 2013; O’Connor et al., 2009). Deactivation of IDO prevented depressive-like behavior (O’Connor et al., 2009). It was shown that IDO may be activated by interferon- $\gamma(\mathrm{IFN}-\gamma)$ and TNF, while cyclooxygenase (COX) inhibitors prevent IDO induction (Wirleitner et al., 2005). IDO effect, however, may be independent of 5-HT metabolism, as the kynurenine pathway also generates substances that act as either agonists or antagonists of the NMDA (N-methyl-d-aspartate) receptor, which also may contribute to behavioral changes (Dantzer et al., 2008).

Inflammation may lead to non-enzymatic oxidation of tetrahydrobiopterin (BH4), which is a co-factor of tryptophan- and tyrosine hydroxylases, thus lowering the activity of 5-HT and DA/NE synthesis rate-limiting enzymes (Haroon et al., 2012). Inflammation also affects DA metabolism by altering levels of vesicular monoamine transporter 2 (VMAT2) and DAT (Kazumori et al., 2004; Tien et al., 2013). 
DAT availability is also regulated by mitogen-activated protein kinases (MAPKs), which participate in the cellular response to pro-inflammatory cytokines (Morón et al., 2003). Exposure to pro-inflammatory cytokines may also reduce the expression of glutamate transporters in glial cells (Matute et al., 2006) and stimulate glutamate exocytosis from astrocytes (Ida et al., 2008) leading to elevated extracellular glutamate levels and, consequently, glutamate excitotoxicity. This excitotoxicity may lead to alterations in myelination by triggering excitotoxic oligodendrocyte (OL) death (Takahashi et al., 2003).

Myelination is one of the major postnatal CNS developmental milestones that provide efficient neuronal circuit connectivity. Myelin sheaths are electrically insulating structures consisting of a lipid-rich substance wrapped around axons in both the CNS and PNS (Figure 1.1).

A

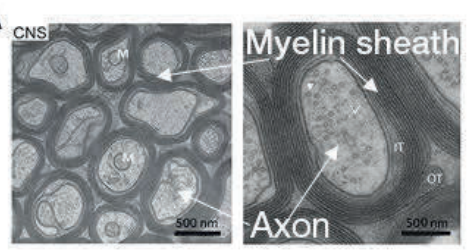

C Intrinsic myelination

C occurring after birth
B

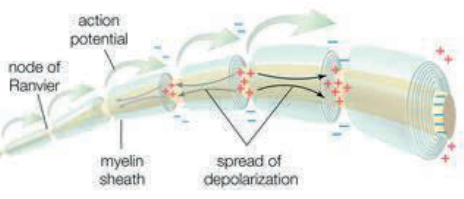

Adaptive myelination dependent on activity

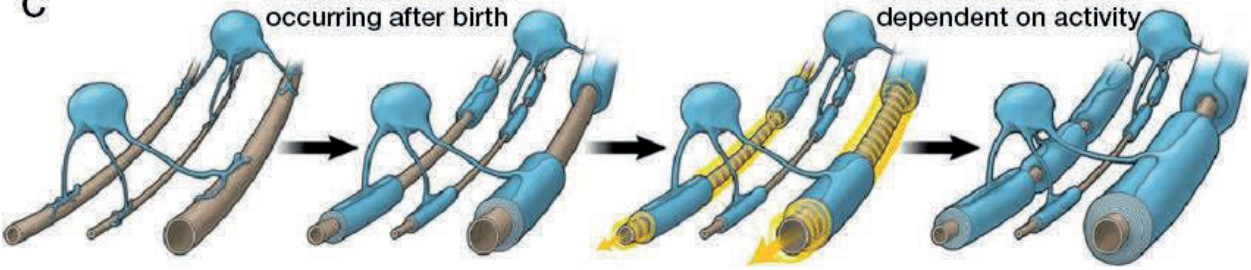

Figure 1.1. Myelination in the CNS. A. Myelin sheaths enwrap axons in the CNS and the PNS. B. Saltatory conduction in myelinated axons speeds up the propagation of the action potential. C. Two phases of myelination: intrinsic myelination after birth and activity-dependent myelin remodeling (adapted from Stassart et al., 2018; Encyclopædia Britannica, 2012; Bechler et al., 2018; also see the text). 
In the CNS, it is produced by OLs, while in the PNS Schwann cells are responsible for myelin sheath formation (Salzer, 2015). Myelin sheaths enwrap segments of an axon, forming internodal segments (or internodes), and individual internodes are separated by gaps, so-called nodes of Ranvier, where axonal membrane ion channels are concentrated (Arancibia-Cárcamo et al., 2017). Such structure of myelinated axon provides so-called saltatory propagation of action potential, ensuring faster signal conduction (Huxley and Stämpeli, 1949). For a long time, it was thought that the main functions of myelination are increasing maximum conduction velocity and decreasing axonal energy consumption (Stadelmann et al., 2019). However, growing body of evidence suggests that myelinating OLs are involved in other processes such as supporting axonal energy metabolism via myelin sheaths (Saab et al., 2013). There is also evidence that in the absence of one of the major myelin proteins, proteolipid protein 1 (PLP1), axonal degeneration is observed independently from demyelination and neuroinflammation (Garbern et al., 2002).

Until recently, the prevailing view assumed that myelination processes occurring around birth and in postnatal development result in topographically fixed myelination that remains static in adulthood. Recent discoveries, however, shifted this view. Now CNS myelination is thought to occur in two phases: genetically predefined intrinsic stage, which meets the idea of developmental myelination in early life stages, and adaptive phase. The adaptive phase implies constant de novo formation of myelin in the nervous system (Ye et al., 1995) and 
remodeling of the myelin sheaths, which was shown to be dependent on neural activity and now is thought to participate in learning and longterm neuroplasticity (Fields and Bukalo, 2020). It was directly shown that inhibition of OL proliferation and new myelin formation while preserving existing myelin sheaths, impairs memory consolidation and retrieval (Pan et al., 2020). Myelin plays multiple roles in the CNS function, and to no surprise, dysregulated myelination may lead to pathology.

Deficits in myelination are observed in numerous neurological and neuropsychiatric disorders. In addition to well-known demyelinating diseases such as multiple sclerosis and leukodystrophies, neurovisualization studies found myelination deficits in late-onset neurodegenerative diseases such as Alzheimer's, Parkinson's diseases and amyotrophic lateral sclerosis (Bartzokis, 2011; Dean et al., 2016; Han et al., 2019; Kolind et al., 2013; Nasrabady et al., 2018), neurodevelopmental disorders such as autism spectrum disorders and ADHD (Gozzi et al., 2012; Lesch, 2019; Onnink et al., 2015), and schizophrenia (Takahashi et al., 2011). In addition, factors such as prenatal SSRI exposure or social isolation, which are detrimental for the CNS development and function, lead to myelination abnormalities, as well as inflammatory disease, e.g., necrotizing enterocolitis in children (Shin et al., 2016).

It was found that social isolation impaired remyelination in the brain of male C57BL/6J mice (Makinodan et al., 2016). Social isolation in juvenile mice led to hypomyelination in the mPFC and lowered mPFC activation when exposed to a stranger mouse, while re-socialization 
reverted hypomyelination (Makinodan et al., 2017). Psychological stress, e.g., chronic social defeat stress, was also shown to affect myelination in a strain-specific and region-specific manner. In essence, stresssusceptible B6 mice showed thinner myelin sheaths in vHPC and downregulation of myelination genes in the mPFC, while stress-resilient mice had thicker myelination in the mPFC (Laine et al., 2018). Also, in mouse model of necrotizing enterocolitis, inflammatory disease of the digestive tract, impairments in myelination and changes in myelin protein expression were found (Nino et al., 2018).

Diffusion tensor imaging (DTI) (Chang et al., 2017) studies in children with perinatal exposure to SSRIs had shown that such exposure might lead to abnormalities in the brain white matter (Jha et al., 2016) and may contribute to affect-related behavioral alterations observed in some of these children (Misri et al., 2006; Oberlander, 2012). Such abnormalities in myelination were also evident in rodents perinatally exposed to the SSRI treatment. These rodents displayed behavioral abnormalities, such as increased emotional reactivity and altered social behavior (Jha et al., 2016). It was shown that exposure to SSRI in rodents alters the expression of myelination-related genes. Notably, the effect of SSRI on the expression of these genes depends on the age of the animal. While exposure to SSRI of adult rats led to the upregulation of myelination-related gene expression in the hippocampus, perinatal exposure led to the downregulation of such genes in adult rats (Kroeze et al., 2015). 
Such an effect of SSRIs on myelination in the CNS may link 5-HT to myelination processes. Another line of evidence of 5-HT implication in myelination comes from recent research, in which polymorphisms in the TPH2 gene were associated with alterations in white matter integrity in depressed patients (Ping et al., 2019) and the severity of multiple sclerosis (Natarajan et al., 2012). Ultimately, it was shown in vitro that 5HT directly affects OL development and myelination (Fan et al., 2015). But the list of factors affecting myelination is not limited to 5-HT (Figure 1.2). Other neurotransmitters, such as glutamate and DA, also promote differentiation of OLs and myelination via receptors expressed by oligodendrocyte precursor cells OPCs and OLs. Gangliosides GD1a and GT1b were identified as functional receptors for one of the crucial myelination proteins MAG, and they regulate axon-myelin interaction and axonal stability (Schnaar and Lopez, 2009). In turn, proinflammatory cytokines released by reactive microglia can impair Glu uptake and trigger excitotoxic OL death (Takahashi et al., 2003). Finally, glycogen synthase kinase 3 beta (GSK-3 $\beta$ ) suppresses myelination, and its inhibition promotes myelination by suppressing inflammation and Notch signaling (Dohare et al., 2018).

Complex evidence suggests the contribution of altered myelination to a broad spectrum of CNS disorders, which may lead to behavioral and cognitive alterations. As it will be shown in the next sections, 5-HT and gangliosides may affect inflammation and myelination in different ways. Thus, some of the deficits of mouse models used in our work may result from inflammation and 
demyelination involved in the pathogenetic mechanisms of neurodevelopmental disorders.

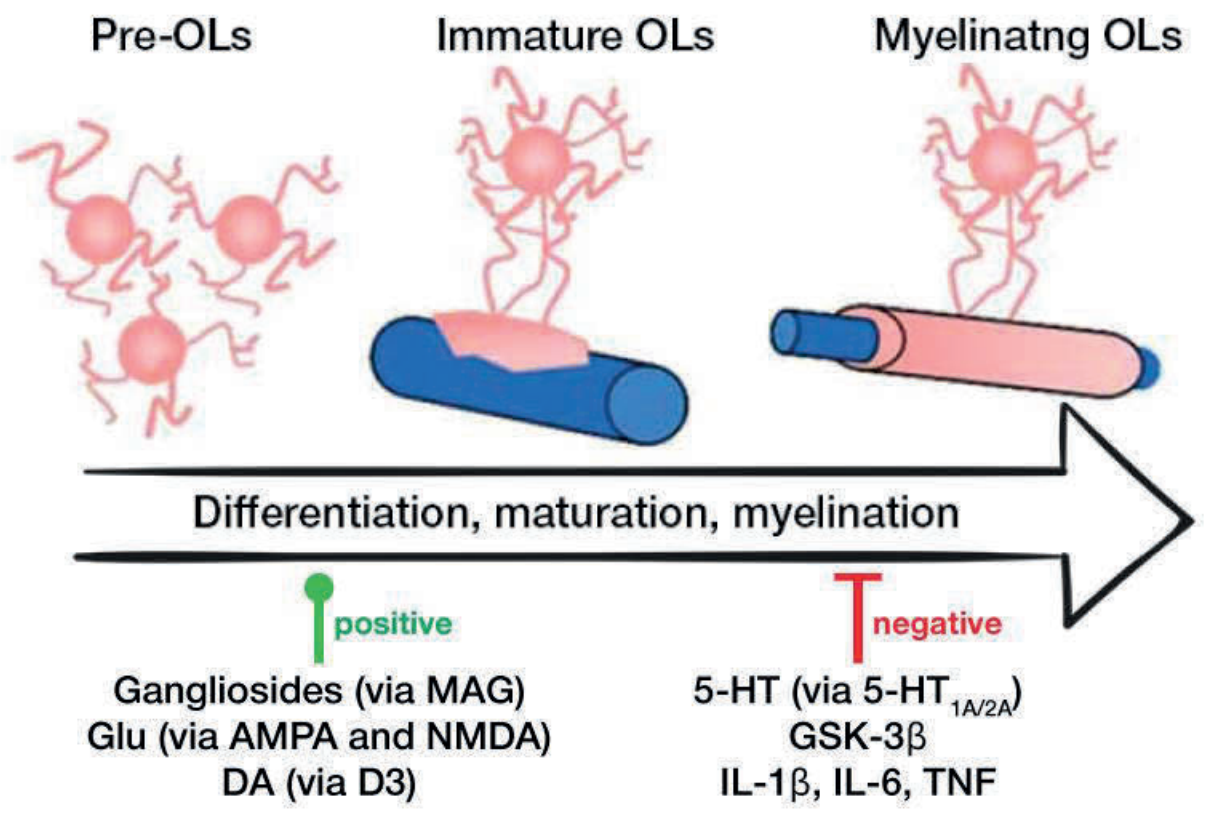

Figure 1.2. Factors affecting myelination. Cells of the $\mathrm{OL}$ lineage respond specifically to factors that regulate proliferation, migration, differentiation, and survival. A- and $b$ - series gangliosides interact with MAG and are crucial for myelin stability. Activation of AMPA receptors promotes Pre-OL differentiation into mature OLs, and activation of OL NMDA receptors enhances myelination. DA exerts a protective effect on OLs and may participate in differentiation via activation of D3Rs. High levels of extracellular $5-\mathrm{HT}$ acting through $5-\mathrm{HT} 1 \mathrm{~A}$ and $5-\mathrm{HT} 2 \mathrm{~A}$ may adversely affect OL development and/or myelination. GSK-3 $\beta$ negatively affects OL differentiation and myelination, and its ablation was shown to improve oligodendrocyte precursor cell differentiation and subsequent myelination. Pro-inflammatory cytokines like TNF and IL-1 can impair glutamate uptake and trigger excitotoxic OL death (adapted from Marinelli et al., 2016; also see the text). 
1.6 Role of serotonin in mechanisms of neurodevelopmental disorders

5-HT action is not limited to neurotransmission in the CNS. 5-HT is widely present in the immune system and also in the intestine. 5-HTP, the precursor of mucosal 5-HT, is synthesized by TPH1 present in mast cells and mucosal epithelium cells. In turn, TPH2 is present in neurons of the enteric nervous system and is involved in neuronal 5-HT synthesis (Israelyan et al., 2019). There are several links between 5-HT and inflammation (Figure 1.3). Studies have shown that lack of mucosal 5HT following Tph1 knockout leads to an anti-inflammatory effect in a model of experimental colitis. In contrast, Tph2 knockout leads to an elevated inflammatory response in the intestine, and colonic levels of pro-inflammatory cytokines interleukin 1 beta (IL-1ß), interleukin 6 (IL6), and tumor necrosis factor (TNF) were found elevated in $\mathrm{Tph}^{-/-}$mice compared to wt littermates (Gershon, 2012). Peripheral circulation of pro-inflammatory cytokines may affect the brain by several pathways. Circulating cytokines may gain access to the brain through cytokine transporters at the blood-brain barrier (Banks, 2009) and activate IL-1 receptor type 1 located on macrophages and endothelial cells of brain venules, inducing prostaglandin E2 synthesis (Konsman et al., 2004). These two pathways lead to the induction of pro-inflammatory cytokines by microglia (Dantzer et al., 2008). Thus, systemic inflammation caused by inactivation of TPH2 may contribute to central inflammation.

Another mechanism that may trigger neuroinflammation in TPH2 deficiency arises from the shift of tryptophan metabolism pathways. Both in the brain and the periphery, tryptophan undergoes utilization by the 


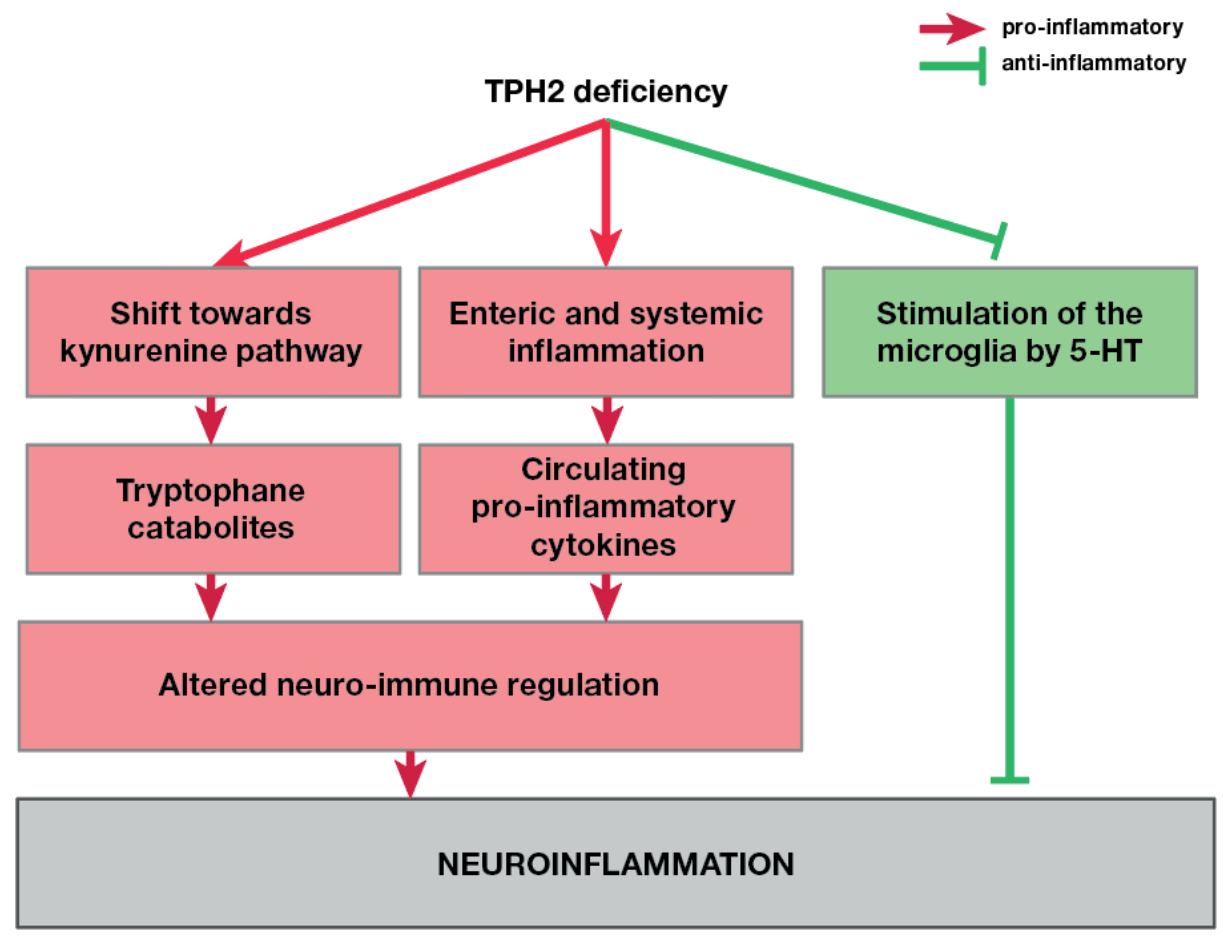

Figure 1.3. Complex interactions between the Tph2 deficiency and neuroinflammation. Possible ways by which $\mathrm{TPH} 2$ deficiency affects neuroinflammation include both pro- and anti-inflammatory pathways. $\mathrm{TPH} 2$ deficiency may lead to a shift of the balance between methoxyindoles pathway and kynurenine pathway towards the latter, producing tryptophane catabolites, which alter neuro-immune regulation. TPH2 deficiency in the enteric neurons leads to colonic inflammation and subsequent systemic inflammation, associated with an elevation of circulating pro-inflammatory cytokines. Cytokines enhance neuroinflammation by being transported through the blood-brain barrier and activating prostaglandin E secretion from the circulating macrophages. On the other hand, deficiency of the neuronal 5-HT may ameliorate its stimulating function on exocytosis from the microglia, thus lowering the levels of pro-inflammatory factors (see the text).

kynurenine pathway. Indoleamine-2,3-dioxygenase (IDO-1) is the ratelimiting enzyme of the kynurenine pathway in the brain (Lovelace et al., 2017). Metabolites of this pathway include both neuroprotective and 
neurotoxic compounds playing a role in neuroimmune regulation. The imbalance of tryptophan metabolites in the kynurenine pathway may lead to neuroinflammation and induce 5-HT deficiency (Kim and Jeon, 2018). In turn, deficiency of TPH2, the rate-limiting enzyme of the concurring methoxyindoles pathway, may shift the balance towards the kynurenine pathway. The associated decrease in 5-HT levels and the inflammatory reactions associated with another TPH2-associated pathway described above may shift the kynurenine pathway towards toxic tryptophan catabolites.

Brain 5-HT itself appears to modulate the neuroinflammatory process by affecting microglial function. Microglia were shown to express several classes of $5-\mathrm{HT}$ receptors, including $5-\mathrm{HT}_{2 \mathrm{~A}}, 5-\mathrm{HT}_{2 \mathrm{~B}}, 5-\mathrm{HT}_{4}$ (Glebov et al., 2015), 5- $\mathrm{HT}_{5}$, and 5- $\mathrm{HT}_{7}$ (Krabbe et al., 2012). The data on whether 5-HT affects pro-inflammatory cytokine exocytosis from microglial cells is inconclusive. Krabbe and coworkers (2012) have shown that in microglial culture pretreated with LPS application of different concentrations of 5-HT does not affect the release of IL-6 or TNF, while complex modulation of LPS-induced cytokine exocytosis by 5-HT was found in blood monocytes (Herr et al., 2017). In cultured human microglial MC-3 cells, activation of $5-\mathrm{HT}_{7}$ receptors was shown to elevate the Il-6 mRNA levels, and this effect was blocked by a selective antagonist of this receptor (Mahé et al., 2005).

Later it was shown that 5-HT stimulates microglial secretion of exosomes via activation of $5-\mathrm{HT}_{2 \mathrm{~A}}, \mathrm{~B}, 5-\mathrm{HT}_{4}$ receptors, but in this particular study exocytosis of pro-inflammatory cytokines, which is 
associated with the release of exosomes, was not investigated (Glebov et al., 2015). The link between microglia-derived extracellular vesicles and neuroinflammation, however, is present. In microglial activation caused by LPS-induced inflammatory response in mouse microglial BV2 cell culture, the level of pro-inflammatory IL-6 and TNF in extracellular vesicles was significantly elevated (Yang et al., 2018). Thus, while 5-HT itself was found not to increase exocytosis of pro-inflammatory cytokines, it promotes the release of extracellular vesicles by microglial cells, which, together with neuroinflammation, may increase levels of extracellular pro-inflammatory cytokines.

5-HT was also shown to demonstrate neuroprotective properties. Indirect evidence of such action comes from the well-established antineuroinflammatory effect of treatment with selective 5-HT reuptake inhibitors (SSRIs) in several conditions associated with neuroinflammation. There is evidence of a neuroprotective effect of SSRIs against multiple sclerosis in patients (Grech et al., 2019). It is of note that SNPs in the TPH2 gene in humans were associated with the severity of disability in multiple sclerosis (Natarajan et al., 2012). In a mouse model of diabetic neuropathy, selective 5-HT/NE reuptake inhibitor (SNRI) duloxetine treatment was associated with a lowered number of astrocytes and microglia in the spinal cord. In the sciatic nerve of these mice, treatment with SNRI duloxetine ameliorated axonal degeneration (Tawfik et al., 2018). Administration of SSRI fluoxetine decreased cell death and microglial activation and reduced proinflammatory cytokines $I l-1 \beta, I l-6$, and $T N F$ mRNA levels in the brain of a 
rat model of early brain injury after subarachnoid hemorrhage. Also, in this model, fluoxetine administration decreased protein levels of toll-like receptor 4 (TLR4) (Liu et al., 2018). In a mouse model of Parkinson's disease, administration of norfluoxetine inhibited microglial activation and oxidative stress, thus reducing the degeneration of nigrostriatal DA neurons (Kim et al., 2018).

Further evidence for the implication of the brain 5-HT system in neuroinflammation comes from a mouse model of experimental autoimmune encephalomyelitis (EAE) mimicking human multiple sclerosis. Knockout of Sert in mice leads to enhanced 5-HT transmission, markedly reducing susceptibility to EAE (Hofstetter et al., 2005). This finding is in line with reduced inflammatory responses in EAE upon treatment with SSRIs and MAO inhibitors (Grech et al., 2019).

The findings described above show an interaction between neuronal 5-HT and peripheral inflammation, namely enteric inflammation in $\mathrm{Tph}^{+/-}$mice, which may ultimately lead to central inflammation. Strong evidence of complex interaction between microglial cells and 5-HT further underpins the 5-HT system's role in regulating neuroinflammation in the CNS. Thus, we hypothesized that alterations in 5-HT transmission caused by partial or full genetic lack of TPH2 might have a complex effect on neuroinflammation, affecting behavior and contributing to neuropsychiatric disorders.

Striking evidence of direct cellular protective effects of 5-HT was found in the work of Hornedo-Ortega and associates (2018). Treatment of PC12 pheochromocytoma line cells with 5-HT-containing medium 
greatly improved cell viability under $A \beta$ cytotoxicity. The authors also found that treatment with 5-HT enhanced expression of Sirtuin 1 and 2 (SIRT1,2), Heat shock protein 70 (Hsp70), and Heme oxygenase 1 (HO-1) (Hornedo-Ortega et al., 2018). These proteins are known for their neuroprotective properties.

Activation of SIRT1-proliferator-activated receptor-gamma coactivator (PGC)-1alpha axis via $5-\mathrm{HT}_{2 \mathrm{~A}}$ receptors was found in rodent cortical cultures and in vivo (Fanibunda et al., 2019). Protective effect of SIRT1 was observed in a plethora of neurodegenerative and acute neurological disorders (Zhang et al., 2011). Anti-inflammatory effects of pharmacological SIRT1 activation were described in vitro and in vivo, in particular through inhibition of matrix metalloproteinases and reduction of cytokine synthesis (Zhang et al., 2020). In experiments with a rat model of hypoxia, pharmacologically enhanced expression of SIRT1 improved the learning and spatial memory of the animals and promoted neuronal survival (Barhwal et al., 2015).

Opposite to SIRT1, inhibition or lack of SIRT2 protein was found to exert a neuroprotective effect in models of Huntington's and Parkinson's diseases (Luthi-Carter et al., 2010; Outeiro et al., 2007), as well as in cellular and mouse models of ischemic stroke (She et al., 2018). One of the major functions of SIRT2 is carried out in OLs. SIRT2 overexpression facilitates OL differentiation and process outgrowth and elevates MBP expression (Ji et al., 2011). It also plays a role in axonmyelin interaction (Li et al., 2007). Hsp70 was also shown to protect neurons and glia in ischemia (Kelly and Yenari, 2002), neurodegenerative 
disorders with aberrant protein aggregation, i.e., Parkinson's, Alzheimer's, Huntington's diseases, and some forms of amyotrophic lateral sclerosis (Witt, 2010). Anti-inflammatory properties of this protein after brain injury were also found (Kim et al., 2012). Inducible HO-1 in the brain is usually expressed in glial cells in response to stress. It may protect neurons from oxidative stress; however, chronic overexpression of HO-1 may be detrimental and promote cytotoxicity in neurodegenerative diseases (reviewed in Chen 2014).

Thus, by activating the expression of SIRT1,2, Hsp70, and HO-1, brain 5-HT may activate a plethora of neuroprotective mechanisms, including those involved in myelination-related processes. Loss of 5-HT signaling with genetic deficiency of TPH2 may lead to impairments in these pathways, promoting neuroinflammation and impaired myelination.

\subsection{Gangliosides in the CNS pathology and neuroinflammation}

Impairments of brain ganglioside metabolism are known as a cause of rare severe neurodevelopmental disorders (Trinchera et al., 2018). However, recent studies show the role of genes involved in brain ganglioside synthesis in less pervasive disorders, i.e., ADHD and schizophrenic psychoses (Hall et al., 2020; Klein et al., 2020; Zhao et al., 2018a). Gangliosides or sialoglycolipids are molecules consisting of glycosphingolipid and one or more sialic acid residues. They are ubiquitous in cell membranes in all vertebrates, performing many functions, including protein organization, signaling, and cell adhesion 
(Schnaar, 2016). Gangliosides are predominantly found in the CNS, where they play critical roles in development and function (Bowser et al., 2019; Galleguillos et al., 2020; Schnaar et al., 2014). The majority of brain gangliosides consist of derivatives of ganglioside GM3 (Ishii et al., 1999).

Impairments in ganglioside metabolism are associated with several human disorders, most of which are ganglioside catabolic disorders, while only several families with disorders of ganglioside biosynthesis are known (Schnaar et al., 2014). Catabolic disorders include Tay-Sachs disease and Sandhoff disease, arising from dysfunctional hexosaminidases. Both are child-onset disorders, usually rapidly progressing and leading to child death before the age of four (CachonGonzalez et al., 2018; Fernandes Filho and Shapiro, 2004; Sandhoff, 1969). Much more rare disruptions of ganglioside biosynthesis lead to catastrophic neurological deficits, including severe cognitive impairments, seizures, and motor and sensory dysfunctions (Indellicato et al., 2019; Trinchera et al., 2018). These ganglioside biosynthesis disorders arise from mutations in genes encoding GM-3 synthase (ST3GAL5) (Bowser et al., 2019; Lee et al., 2016) or GM2/GD2 synthase (B4GALNT1) (Boukhris et al., 2013; Harlalka et al., 2013). Loss-offunction mutations in both proteins lead to the complete absence of major brain gangliosides (Trinchera et al. 2018; Schnaar 2010, Figure 1.4).

Besides severe neurological phenotypes following the abovementioned disruptions in ganglioside metabolism, changes in ganglioside profile in the brain were also associated with Alzheimer's 


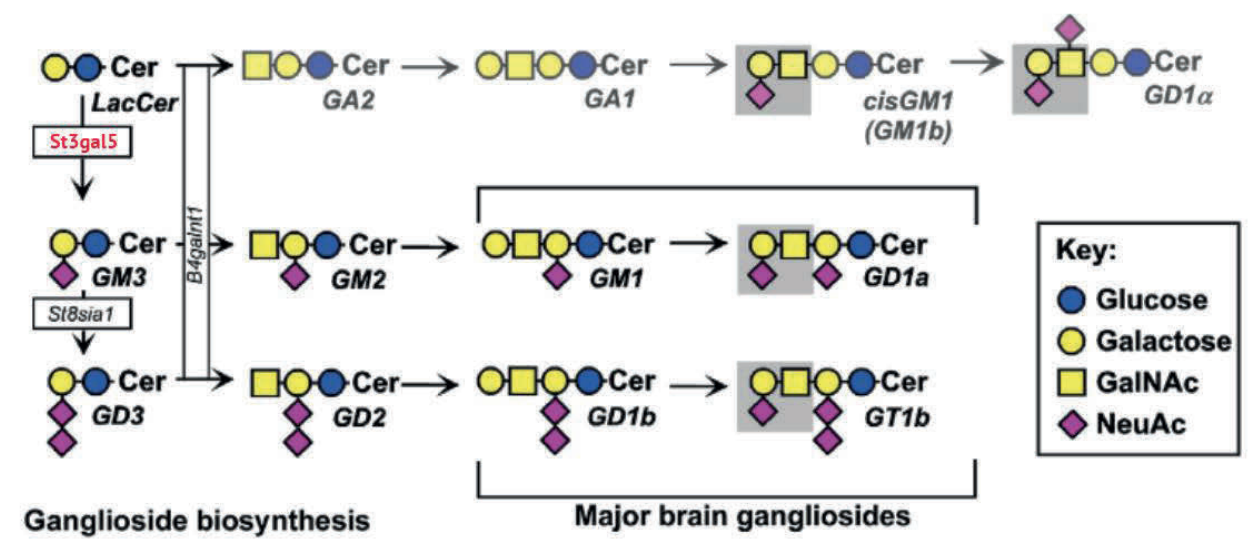

Figure 1.4. Brain ganglioside structure and biosynthesis pathways. Knockout of the St3gal5 (in red) gene leads to a complete absence of major brain gangliosides (adapted from Schnaar 2009; also see the text).

disease and amyloidosis (Ariga, 2017; Bucciantini et al., 2020), Parkinson's disease (Ledeen and Wu, 2018), Huntington's disease (Maglione et al., 2010), and amyotrophic lateral sclerosis (ALS) (Dodge et al., 2015), neurodegenerative conditions which have a well-established link to neuroinflammation.

Indeed, gangliosides in the CNS have an anti-inflammatory effect. Knockout of B4galnt1 or GD3-synthase (St8sia1) in mice led to elevated infiltrating microglia, and double knockout of these genes led to upregulation of inflammation-related genes in the brain, including $\mathrm{Il}-1 \beta$ and TNF (Ohmi et al., 2011). Neurostatin (O-acetyl GD1b) (AbadRodríguez et al., 2002) and several other $O$-acetylated gangliosides were shown to reduce inducible nitric oxide synthase (iNOS) and Il-6 expression in LPS-activated microglial culture and promote neuronal survival in co-cultures (Yanguas-casás et al., 2019). In rats, GM1 administration relieved negative consequences of developmental lead 
exposure, reverting cognitive deficit and cell death in the hippocampus via antioxidant effect, as well as activation of SIRT1 / cAMP response element-binding protein (CREB) / brain-derived neurotrophic factor (BDNF) and anti-apoptotic pathways (Chen et al., 2019; Meng et al., 2016). On the other hand, major brain gangliosides were shown to play a role in platelet activation in case of traumatic brain injury or neurodegeneration, leading to enhanced inflammation upon disruption of the blood-brain barrier (Dukhinova et al., 2018; Kopeikina et al., 2020).

Finally, participation of gangliosides in myelination processes was shown in many cases. One of the major myelination proteins, myelinassociated glycoprotein (MAG), is located on the surface of myelinating glial cells and interacts with neuronal membrane gangliosides to inhibit neurite outgrowth (Vinson et al., 2001). Gangliosides GD1a and GT1b, which are ligands of MAG, are absent in B4GALNT1 deficiency, and B4galnt1 knockout mice display axonal degeneration in the CNS and PNS, as well as motor deficits similar to those in Mag knockout mice (Pan et al., 2005). We may speculate that aberrant myelination may also play a role in human pathology associated with the loss of brain gangliosides. Notably, despite displaying motor deficits, B4galnt1- and Mag-knockout mice show motor hyperactivity (Pan et al., 2005). Finally, interaction of ganglioside GM1 and myelin basic protein (MBP) stimulates Schwann cell proliferation in the PNS (Tzeng et al., 1999).

The prominent role of gangliosides in neuroinflammation and myelination suggests that disruption of ganglioside metabolism may be a contributing factor in neuropsychiatric diseases. Moreover, gangliosides 
also regulate the function of G-protein coupled receptors, e.g., pharmacological depletion of gangliosides led to lowered 5-HT binding to human $5-\mathrm{HT}_{7}$ receptors (Sjögren and Svenningsson, 2007). Interaction between $\mathrm{GM} 1$ and $5-\mathrm{HT}_{1 \mathrm{~A}}$ receptors was modeled in molecular dynamics simulation, and authors speculate that such interaction in vivo may facilitate the entry of 5-HT (Prasanna et al., 2016). Thus, brain gangliosides may also contribute to the regulation of the 5-HT system.

1.8 Gene $\times$ environment interaction and stress in neurodevelopmental disorders

Alongside contribution of genetic predisposition to the risk of neurodevelopmental disorders and excessive aggression, environmental factors contribute to the pathogenesis of these conditions (Lesch et al., 1996; Lesch and Merschdorf, 2000; Lesch and Mössner, 2006). There is a remarkable body of evidence indicating that there is a combined contribution of genetic background and aversive life experiences during childhood, adolescence, and adulthood to the development of antisocial behavior and schizophrenia (Thapar et al., 2007), ADHD (Lesch et al., 2012), autism (Modabbernia et al., 2017), depression (Landrø, 2014), and substance abuse (Lesch, 2005). Family studies of aggressive behavior suggest that in both males and females $50 \%$ of the variance in aggressive behavior parameters is explained by environmental factors (Tuvblad and Baker, 2011).

Such aversive experiences include emotional stress, a form of stress evoked by processing negative mental experiences and primarily 
triggered by the perception and cognitive evaluation of adverse events rather than a disturbance of physical nature (Fontes et al., 2014). Emotional stress is of particular interest in the context of social interaction. It may contribute to different psychiatric disorders, e.g., emotional neglect, loss of a parent, or child abuse are risk factors for the development of violence and abnormal aggression, depression, and anxiety disorders (Barnow et al., 2001; Heim and Nemeroff, 2001).

In animals, emotional stress was also shown to lead to behavioral abnormalities and aggression (Costa-Nunes et al., 2020, 2014; Gorlova et al., 2019; Pavlov et al., 2019). Maternal separation at a young age and social isolation led to increased aggressive, anxiety- and depressive-like behaviors in mice (Ieraci et al., 2016; Matsumoto et al., 2005; Takeda et al., 2012; Veenema, 2009; Veenema et al., 2007). Recently, increased aggressiveness and depressive-like behavior were reported in BALB/c mice subjected to chronic ultrasound stress (Gorlova et al., 2019).

Brain structures crucial for aggression, impulsivity, and anxiety also play a pivotal role in stress response (Tottenham and Galván, 2016). Chronic restraint stress in $\mathrm{C} 57 \mathrm{BL} / 6$ mice was shown to enhance amygdala-PFC transmission, and optogenetic activation of this pathway led to elevated anxiety-like behavior and hyperactivity in unstressed C57BL/6 mice (Lowery-Gionta et al., 2018). Rats subjected to a singleprolonged stress paradigm, which is considered as a model for posttraumatic stress disorder, showed hypoactivation of the PFC associated with elevated activation of the amygdala and striatum (Piggott et al., 2019). Such stress-related changes in the activity of these 
structures may be due to modulation by monoaminergic pathways.

The role of the brain monoamine systems in stress response was studied extensively during the past decades. Acute and chronic stress were shown to affect monoamine metabolism in various brain areas in a manner dependent on the stress parameters. Alterations in metabolism of 5-HT, DA, and NE during and after exposure to physical or emotional stress were shown in rodent amygdala, frontal cortex, hippocampus, striatum, as well as midbrain and brainstem structures (Britton et al., 1992; Heinsbroek et al., 1990; Tanaka et al., 2000). Indeed, stress leads to changes in monoamine levels in the PFC (Arnsten, 2015; Feenstra, 2000; Van Bockstaele et al., 1998), which is, as discussed above, crucial for topdown control of aggression, emotional regulation, impulsivity, and anxiety. When the activity of the PFC is altered by monoamine influx, disinhibition of these behaviors may occur. Altered monoaminergic modulation in the striatum (Dunn and File, 1983; Gorlova et al., 2020; Heinsbroek et al., 1990), in turn, may lead to inadequate processing of social stimuli, which also may contribute to excessive aggression. Another mechanism that may contribute to neurodevelopmental abnormalities provoked by stress is impaired myelination, as was discussed above (Lane et al., 2011; Makinodan et al., 2017, 2016).

Another environmental factor widely known for its detrimental effect on neurodevelopment and mental health is systemic inflammation. Prenatal immune challenge, maternal immune activation, is known to be a contributing factor for the risk of autism spectrum disorders in children, as well as for high risk of schizophrenia (Boulanger-Bertolus et 
al., 2018; Minakova and Warner, 2018). In a mouse model of maternal immune activation, its interaction with expression of mutant human disrupted in schizophrenia 1 gene $(m h D I S C 1)$ resulted in anxiety, depression-like responses, and altered social behavior (Abazyan et al., 2010).

Notably, infectious diseases in childhood were also shown to be associated with increased risk of these disorders (Hadjkacem et al., 2016; Karlsson and Dalman, 2019), and also OCD and other mental disorders (Orlovska et al., 2017). Pre- and postnatal immune challenges, such as LPS treatment, viral mimic polyriboinosinic-polyribocytidylic acid (poly I:C), or streptococcal antigen exposure are used as models of neurodevelopmental abnormalities arising from immune mechanisms (Cardoso et al., 2015; Haddad et al., 2020; Mora et al., 2020; Piontkewitz et al., 2012). Exposure to prenatal maternal stress was also proven to be detrimental for child neurodevelopment, and implicated mechanisms include inflammation (Manzari et al., 2019; Polanska et al., 2017). Convergent mechanisms may underlie the contribution of pre- and postnatal stress and systemic inflammation to the risk of neurodevelopmental disorders besides genetic factors.

\subsection{Mouse models of pathological aggression}

Pathological aggression is a common feature of neurodevelopmental disorders; however, effective treatment is challenging. Mouse models can be a powerful tool for the investigation of the pathophysiology of excessive aggression and finding new therapies 
(Bortolato et al., 2013). Currently, several approaches are used for modeling excessive aggression in rodents (Figure 1.5).

As it was discussed above, stress may contribute to aggression and other behavioral abnormalities both in humans and in rodents. Different stressful conditions are usually used to provoke elevation in aggressive behavior in conventional mouse lines. One of the most used manipulations to provoke excessive aggressive behavior in male mice is social isolation. Socially isolated mice demonstrated alterations in the function of the hypothalamic-pituitary-adrenal (HPA) axis, which makes evident the stressful nature of such isolation (Ieraci et al., 2016), and tend to be more aggressive in the resident-intruder test (Brain et al., 1971; Pinna, 2010). Another stress paradigm potentiating aggression is chronic mild stress, which was shown to provoke increased aggression in male BALB/C mice, as shown in the resident-intruder test (Malki et al., 2016; Mineur et al., 2003; Mutlu et al., 2012; Strekalova et al., 2011). Rat exposure, which is an ethologically valid stressor, as rats are natural predators for mice, caused elevation in aggressive behavior in male C57Bl mice (Costa-Nunes et al., 2014; Vignisse et al., 2017). A novel model of ultrasound emotional stress was also shown to potentiate aggression in male BALB/C mice (Gorlova et al., 2019).

Stress may cause not only an immediate and short-term but also a persistent effect on aggression. In rats, maternal separation during the first two weeks of life significantly increased intermale aggression at 1416 weeks of age and lowered maternal aggression (Veenema et al., 2006). Interestingly, in mice, such maternal separation stress was shown to 


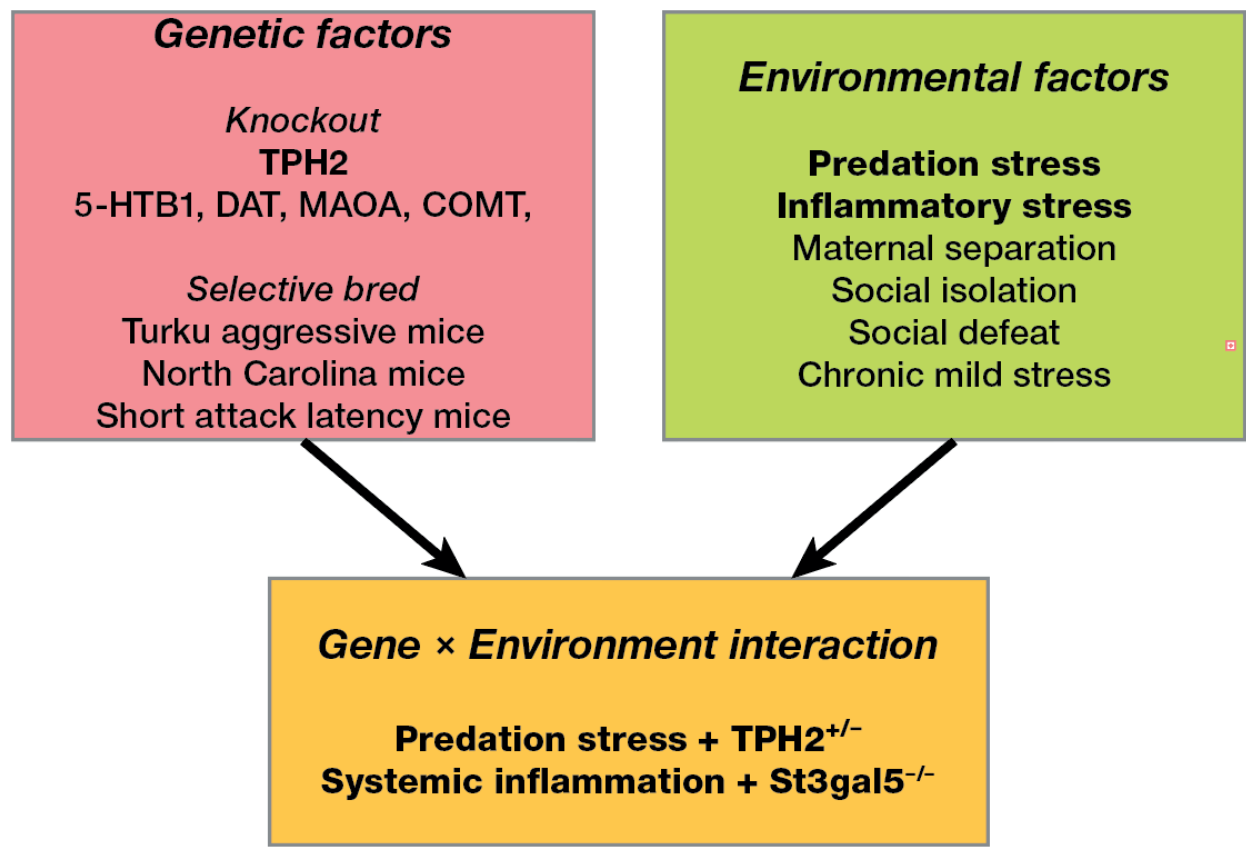

Figure 1.5. Animal models of excessive aggression. Models of animal aggression include genetic models, e.g., knockout of Tph2, Htr1b, Dat, Maoa, Comt; and mice selectively bred for excessive aggression. Induction of aggression is also reached by environmental stress factors. Gene $\times$ environment interaction models combine these factors, i.e., $T p h 2^{+/-}$animals subjected to predation stress or St3gal5 $5^{--}$mice with induced systemic inflammation (see the text).

cause opposing changes in intermale and maternal aggression: maternally separated females tended to be more aggressive towards male intruders than wt control females, while in males, maternal separation decreased intermale aggression (Veenema et al., 2007). Post-weaning social isolation or subjugation also caused elevated intermale aggression in mice and rats, as well as hamsters and guinea pigs (Veenema, 2009).

Other methods of modeling excessive aggression in rodents involve selective breeding and genetic manipulations. There are several mouse lines selectively bred for aggressive behavior, such as the North 
Carolina 900 and 100 mice, Turku aggressive mice, or short attack latency (SAL) mice (Natarajan et al., 2009). Genetic manipulations leading to abnormal aggression include those affecting DA or 5-HT systems of the brain. Excessive aggression is observed in mice with a genetic lack of 5$\mathrm{HT}_{1 \mathrm{~B}}$ receptor (Saudou et al., 1994), DAT (Rodriguiz et al., 2004), MAOA (Cases et al., 1995), TPH2 (Angoa-Pérez et al., 2012b), and COMT (Gogos et al., 1998).

Genetic manipulations may also have the opposite effect. Lowered aggression was found in mice with a lack of DBH (Marino et al., 2005) and the long form of DRD2 (Vukhac et al., 2001). Recently, Tph2 ${ }^{+/-}$mice were found to be a promising model of gene $\times$ environment $(\mathrm{G} \times \mathrm{E})$ interaction in excessive aggression, as they do not show behavioral abnormalities under normal conditions, but exhibit excessive aggression after stress (Gorlova et al., 2020). 
In the current study, we employed two mouse models of neurodevelopmental abnormalities: heterozygous Tph2-deficient mice and mice with a knockout of St3gal5 gene. Since Tph2 heterozygous mice display increased aggressiveness after being subjected to stress, we used rat exposure stress to investigate the possible role of alterations in brain catecholaminergic systems, neuroinflammation, and myelination abnormalities as mechanisms of neurodevelopmental pathology underlying excessive aggression and accompanying behavioral changes in these mice. We also aimed to study these putative non-specific pathogenetic mechanisms in another model of neurodevelopmental abnormalities, St3gal5 knockout mice, sharing common behavioral features with Tph2 heterozygous mice. Given possible converging pathways of environmental challenges contributing to neurodevelopmental diseases, we used LPS to induce systemic inflammation (inflammatory sress) to investigate whether St3gal5 knockout mouse behavior and inflammatory response will be altered compared to those of wild-type mice. 


\section{References}

Abad-Rodríguez, J., Bernabé, M., Romero-Ramírez, L., VallejoCremades, M., Fernández-Mayoralas, A., Nieto-Sampedro, M., 2002. Purification and Structure of Neurostatin, an Inhibitor of Astrocyte Division of Mammalian Brain. J. Neurochem. 74, 2547-2556. DOI:10.1046/j.1471-4159.2000.0742547.x

Abazyan, B., Nomura, J., Kannan, G., Ishizuka, K., Tamashiro, K.L., Nucifora, F., Pogorelov, V., Ladenheim, B., Yang, C., Krasnova, I.N., Cadet, J.L., Pardo, C., Mori, S., Kamiya, A., Vogel, M.W., Sawa, A., Ross, C.A., Pletnikov, M. V., 2010. Prenatal interaction of mutant DISC1 and immune activation produces adult psychopathology. Biol. Psychiatry 68, 1172-1181. DOI:10.1016/j.biopsych.2010.09.022

Ambroggi, F., Ishikawa, A., Fields, H.L., Nicola, S.M., 2008. Basolateral Amygdala Neurons Facilitate Reward-Seeking Behavior by Exciting Nucleus Accumbens Neurons. Neuron 59, 648-661. DOI:10.1016/j.neuron.2008.07.004

Angoa-Pérez, M., Kane, M.J., Briggs, D.I., Sykes, C.E., Shah, M.M., Francescutti, D.M., Rosenberg, D.R., Thomas, D.M., Kuhn, D.M., 2012a. Genetic depletion of brain 5HT reveals a common molecular pathway mediating compulsivity and impulsivity. J. Neurochem. 121, 974-984. DOI:10.1111/j.1471-4159.2012.07739.x

Angoa-Pérez, M., Kane, M.J., Briggs, D.I., Sykes, C.E., Shah, M.M., Francescutti, D.M., Rosenberg, D.R., Thomas, D.M., Kuhn, D.M., 2012b. Genetic depletion of brain 5HT reveals a common molecular pathway mediating compulsivity and impulsivity. J. Neurochem. 121, 974-84. DOI:10.1111/j.1471-4159.2012.07739.x

Apter, A., van Praag, H.M., Plutchik, R., Sevy, S., Korn, M., Brown, S.L., 1990. Interrelationships among anxiety, aggression, impulsivity, and mood: A serotonergically linked cluster? Psychiatry Res. 32, 191-199. DOI:10.1016/0165-1781(90)90086-K

Arancibia-Cárcamo, I.L., Ford, M.C., Cossell, L., Ishida, K., Tohyama, K., Attwell, D., 2017. Node of ranvier length as a potential regulator of myelinated axon conduction speed. Elife 6, 1-15. DOI:10.7554/eLife.23329 
Ariga, T., 2017. The Pathogenic Role of Ganglioside Metabolism in Alzheimer's Disease-Cholinergic Neuron-Specific Gangliosides and Neurogenesis. Mol. Neurobiol. 54, 623-638. DOI:10.1007/s12035-0159641-0

Arnsten, A.F.T., 2015. Stress weakens prefrontal networks: Molecular insults to higher cognition. Nat. Neurosci. 18, 1376-1385. DOI:10.1038/nn.4087

Ballester, J., Goldstein, B., Goldstein, T.R., Yu, H., Axelson, D., Monk, K., Hickey, M.B., Diler, R.S., Sakolsky, D.J., Sparks, G., Iyengar, S., Kupfer, D.J., Brent, D.A., Birmaher, B., 2014. Prospective longitudinal course of aggression among adults with bipolar disorder. Bipolar Disord. 16, 262-269. DOI:10.1111/bdi.12168

Banks, W.A., 2009. The Blood-Brain Barrier in Psychoneuroimmunology. Immunol. Allergy Clin. North Am. 29, 223228. DOI:10.1016/j.iac.2009.02.001

Barhwal, K., Das, S.K., Kumar, A., Hota, S.K., Srivastava, R.B., 2015. Insulin receptor $A$ and Sirtuin 1 synergistically improve learning and spatial memory following chronic salidroside treatment during hypoxia. J. Neurochem. 135, 332-346. DOI:10.1111/jnc. 13225

Barnow, S., Lucht, M., Freyberger, H.J., 2001. Influence of punishment, emotional rejection, child abuse, and broken home on aggression in adolescence: An examination of aggressive adolescents in Germany. Psychopathology 34, 167-173. DOI:10.1159/000049302

Bartzokis, G., 2011. Alzheimer's disease as homeostatic responses to age-related myelin breakdown. Neurobiol. Aging 32, 1341-1371. DOI:10.1016/j.neurobiolaging.2009.08.007

Been, L.E., Gibbons, A.B., Meisel, R.L., 2019. Towards a neurobiology of female aggression. Neuropharmacology 156, 107451. DOI:10.1016/j.neuropharm.2018.11.039

Bjork, J.M., Dougherty, D.M., Moeller, F.G., 1997. A positive correlation between self-ratings of depression and laboratory-measured aggression. Psychiatry Res. 69, 33-38. DOI:10.1016/S01651781(96)03025-9 
Björkqvist, K., 2018. Gender differences in aggression. Curr. Opin. Psychol. 19, 39-42. DOI:10.1016/j.copsyc.2017.03.030

Blair, R.J.R., 2016. The Neurobiology of Impulsive Aggression. J. Child Adolesc. Psychopharmacol. 26, 4-9. DOI:10.1089/cap.2015.0088

Bobes, M.A., Ostrosky, F., Diaz, K., Romero, C., Borja, K., Santos, Y., Valdés-Sosa, M., 2013. Linkage of functional and structural anomalies in the left amygdala of reactive-aggressive men. Soc. Cogn. Affect. Neurosci. 8, 928-936. DOI:10.1093/scan/nss101

Bondar, N.P., Boyarskikh, U.A., Kovalenko, I.L., Filipenko, M.L., Kudryavtseva, N.N., 2009. Molecular implications of repeated aggression: Th, Dat1, Snca and Bdnf gene expression in the VTA of victorious male mice. PLoS One 4. DOI:10.1371/journal.pone.0004190

Bortolato, M., Pivac, N., Muck Seler, D., Nikolac Perkovic, M., Pessia, M., Di Giovanni, G., 2013. The role of the serotonergic system at the interface of aggression and suicide. Neuroscience 236, 160-185. DOI:10.1016/j.neuroscience.2013.01.015

Bosch, O.J., 2013. Maternal aggression in rodents: Brain oxytocin and vasopressin mediate pup defence. Philos. Trans. R. Soc. B Biol. Sci. 368. DOI:10.1098/rstb.2013.0085

Bosch, O.J., Meddle, S.L., Beiderbeck, D.I., Douglas, A.J., Neumann, I.D., 2005. Brain oxytocin correlates with maternal aggression: Link to anxiety. J. Neurosci. 25, 6807-6815. DOI:10.1523/JNEUROSCI.134205.2005

Boukhris, A., Schule, R., Loureiro, J.L., Lourenço, C.M., Mundwiller, E., Gonzalez, M.A., Charles, P., Gauthier, J., Rekik, I., Acosta Lebrigio, R.F., Gaussen, M., Speziani, F., Ferbert, A., Feki, I., Caballero-Oteyza, A., Dionne-Laporte, A., Amri, M., Noreau, A., Forlani, S., Cruz, V.T., Mochel, F., Coutinho, P., Dion, P., Mhiri, C., Schols, L., Pouget, J., Darios, F., Rouleau, G.A., Marques, W., Brice, A., Durr, A., Zuchner, S., Stevanin, G., 2013. Alteration of ganglioside biosynthesis responsible for complex hereditary spastic paraplegia. Am. J. Hum. Genet. 93, 118-123. DOI:10.1016/j.ajhg.2013.05.006

Boulanger-Bertolus, J., Pancaro, C., Mashour, G.A., 2018. Increasing role of maternal immune activation in neurodevelopmental 
disorders. Front. Behav. Neurosci. 12, 1-6. DOI:10.3389/fnbeh.2018.00230

Bowser, L.E., Young, M., Wenger, O.K., Ammous, Z., Brigatti, K.W., Carson, V.J., Moser, T., Deline, J., Aoki, K., Morlet, T., Scott, E.M., Puffenberger, E.G., Robinson, D.L., Hendrickson, C., Salvin, J., Gottlieb, S., Heaps, A.D., Tiemeyer, M., Strauss, K.A., 2019. Recessive GM3 synthase deficiency: Natural history, biochemistry, and therapeutic frontier. Mol. Genet. Metab. 126, 475-488. DOI:10.1016/j.ymgme.2019.01.013

Brain, P.F., Nowell, N.W., Wouters, A., 1971. Some relationships between adrenal function and the effectiveness of a period of isolation in inducing intermale aggression in albino mice. Physiol. Behav. 6, 27-29. DOI:10.1016/0031-9384(71)90008-4

Brennan, P.A., Hammen, C., Sylvers, P., Bor, W., Najman, J., Lind, P., Montgomery, G., Smith, A.K., 2011. Interactions between the COMT Val108/158Met polymorphism and maternal prenatal smoking predict aggressive behavior outcomes. Biol. Psychol. 87, 99-105. DOI:10.1016/j.biopsycho.2011.02.013

Britton, K.T., S. Segal, D., Kuczenski, R., Hauger, R., 1992. Dissociation between in vivo hippocampal norepinephrine response and behavioral/neuroendocrine responses to noise stress in rats. Brain Res. 574, 125-130. DOI:10.1016/0006-8993(92)90808-M

Bucciantini, M., Leri, M., Stefani, M., Melki, R., Zecchi-Orlandini, S., Nosi, D., 2020. The Amphipathic GM1 Molecule Stabilizes Amyloid Aggregates, Preventing their Cytotoxicity. Biophys. J. 119, 326-336. DOI:10.1016/j.bpj.2020.06.005

Buckholtz, J.W., Treadway, M.T., Cowan, R.L., Woodward, N.D., Li, R., Ansari, M.S., Baldwin, R.M., Schwartzman, A.N., Shelby, E.S., Smith, C.E., Kessler, R.M., Zald, D.H., 2010. Dopaminergic network differences in human impulsivity. Science. 329, 532. DOI:10.1126/science.1185778

Budygin, E.A., Park, J., Bass, C.E., Grinevich, V.P., Bonin, K.D., Wightman, R.M., 2012. Aversive stimulus differentially triggers subsecond dopamine release in reward regions. Neuroscience 201, 331337. DOI:10.1016/j.neuroscience.2011.10.056 
Butovskaya, M.L., Vasilyev, V.A., Lazebny, O.E., Suchodolskaya, E.M., Shibalev, D. V., Kulikov, A.M., Karelin, D. V., Burkova, V.N., Mabulla, A., Ryskov, A.P., 2013. Aggression and polymorphisms in AR, DAT1, DRD2, and COMT genes in Datoga pastoralists of Tanzania. Sci. Rep. 3, 1-8. DOI:10.1038/srep03148

Cachon-Gonzalez, M.B., Zaccariotto, E., Cox, T.M., 2018. Genetics and Therapies for GM2 Gangliosidosis. Curr. Gene Ther. 18, 68-89. DOI:10.2174/1566523218666180404162622

Cardinal, R.N., Parkinson, J.A., Hall, J., Everitt, B.J., 2003. The contribution of the amygdala, nucleus accumbens, and prefrontal cortex to emotion and motivated behaviour. Int. Congr. Ser. 1250, 347-370. DOI:10.1016/S0531-5131(03)01013-6

Cardoso, F.L., Herz, J., Fernandes, A., Rocha, J., Sepodes, B., Brito, M.A., McGavern, D.B., Brites, D., 2015. Systemic inflammation in early neonatal mice induces transient and lasting neurodegenerative effects. J. Neuroinflammation 12, 1-18. DOI:10.1186/s12974-015-0299-3

Cases, O., Seif, I., Grimsby, J., Gaspar, P., Chen, K., Pournin, S., Muller, U., Aguet, M., Babinet, C., Shih, J., Et, A., 1995. Aggressive behavior and altered amounts of brain serotonin and norepinephrine in mice lacking MAOA. Science. 268, 1763-1766. DOI:10.1126/science.7792602

Chang, C.H., Gean, P.W., 2019. The Ventral Hippocampus Controls Stress-Provoked Impulsive Aggression through the Ventromedial Hypothalamus in Post-Weaning Social Isolation Mice. Cell Rep. 28, 1195 1205.e3. DOI:10.1016/j.celrep.2019.07.005

Chang, E.H., Argyelan, M., Aggarwal, M., Chandon, T.-S.S., Karlsgodt, K.H., Mori, S., Malhotra, A.K., 2017. The role of myelination in measures of white matter integrity: Combination of diffusion tensor imaging and two-photon microscopy of CLARITY intact brains. Neuroimage 147, 253-261. DOI:10.1016/j.neuroimage.2016.11.068

Chen, F., Zhou, C.C., Yang, Y., Liu, J.W., Yan, C.H., 2019. GM1 Ameliorates Lead-Induced Cognitive Deficits and Brain Damage Through Activating the SIRT1/CREB/BDNF Pathway in the Developing Male Rat Hippocampus. Biol. Trace Elem. Res. 190, 425-436. DOI:10.1007/s12011018-1569-6 
Chen, J., 2014. Heme oxygenase in neuroprotection: From mechanisms to therapeutic implications. Rev. Neurosci. 25, 269-280. DOI:10.1515/revneuro-2013-0046

Chen, T.J.H., Blum, K., Mathews, D., Fisher, L., Schnautz, N., Braverman, E.R., Schoolfield, J., Downs, B.W., Comings, D.E., 2005. Are dopaminergic genes involved in a predisposition to pathological aggression?: Hypothesizing the importance of "super normal controls" in psychiatricgenetic research of complex behavioral disorders. Med. Hypotheses 65, 703-707. DOI:10.1016/j.mehy.2005.04.037

Coccaro, E.F., McCloskey, M.S., Fitzgerald, D.A., Phan, K.L., 2007. Amygdala and Orbitofrontal Reactivity to Social Threat in Individuals with Impulsive Aggression. Biol. Psychiatry 62, 168-178. DOI:10.1016/j.biopsych.2006.08.024

Costa-Nunes, J., Zubareva, O., Araújo-Correia, M., Valença, A., Schroeter, C.A., Pawluski, J.L., Vignisse, J., Steinbusch, H., Hermes, D., Phillipines, M., Steinbusch, H.M.W., Strekalova, T., 2014. Altered emotionality, hippocampus-dependent performance and expression of NMDA receptor subunit mRNAs in chronically stressed mice. Stress 17, 108-116. DOI:10.3109/10253890.2013.872619

Costa-Nunes, J.P., Gorlova, A., Pavlov, D., Cespuglio, R., Gorovaya, A., Proshin, A., Umriukhin, A., Ponomarev, E.D., Kalueff, A. V., Strekalova, T., Schroeter, C.A., 2020. Ultrasound stress compromises the correlates of emotional-like states and brain AMPAR expression in mice: effects of antioxidant and anti-inflammatory herbal treatment. Stress 0, 000. DOI:10.1080/10253890.2019.1709435

Couch, Y., Anthony, D.C., Dolgov, O., Revischin, A., Festoff, B., Santos, A.I., Steinbusch, H.W., Strekalova, T., 2013. Microglial activation, increased TNF and SERT expression in the prefrontal cortex define stress-altered behaviour in mice susceptible to anhedonia. Brain. Behav. Immun. 29, 136-146. DOI:10.1016/j.bbi.2012.12.017

Covington, H.E., Newman, E.L., Leonard, M.Z., Miczek, K.A., 2019. Translational models of adaptive and excessive fighting: An emerging role for neural circuits in pathological aggression. F1000Research 8 . DOI:10.12688/f1000research.18883.1 
Cupaioli, F.A., Zucca, F.A., Caporale, C., Lesch, K.P., Passamonti, L., Zecca, L., 2021. The neurobiology of human aggressive behavior: Neuroimaging, genetic, and neurochemical aspects. Prog. NeuroPsychopharmacology Biol. Psychiatry 106, 110059. DOI:10.1016/j.pnpbp.2020.110059

Dantzer, R., O'Connor, J.C., Freund, G.G., Johnson, R.W., Kelley, K.W., 2008. From inflammation to sickness and depression: When the immune system subjugates the brain. Nat. Rev. Neurosci. 9, 46-56. DOI:10.1038/nrn2297

Deal, A.L., Park, J., Weiner, J.L., Budygin, E.A., 2021. Stress Alters the Effect of Alcohol on Catecholamine Dynamics in the Basolateral Amygdala. Front. Behav. Neurosci. 15. DOI:10.3389/fnbeh.2021.640651

Dean, D.C., Sojkova, J., Hurley, S., Kecskemeti, S., Okonkwo, O., Bendlin, B.B., Theisen, F., Johnson, S.C., Alexander, A.L., Gallagher, C.L., 2016. Alterations of myelin content in Parkinson's disease:a crosssectional neuroimaging study. PLoS One 11, 1-20. DOI:10.1371/journal.pone.0163774

Dodge, J.C., Treleaven, C.M., Pacheco, J., Cooper, S., Bao, C., Abraham, M., Cromwell, M., Sardi, S.P., Chuang, W.L., Sidman, R.L., Cheng, S.H., Shihabuddin, L.S., 2015. Glycosphingolipids are modulators of disease pathogenesis in amyotrophic lateral sclerosis. Proc. Natl. Acad. Sci. U. S. A. 112, 8100-8105. DOI:10.1073/pnas.1508767112

Dohare, P., Cheng, B., Ahmed, E., Yadala, V., Singla, P., Thomas, S., Kayton, R., Ungvari, Z., Ballabh, P., 2018. Glycogen synthase kinase-3 $\beta$ inhibition enhances myelination in preterm newborns with intraventricular hemorrhage, but not recombinant Wnt3A. Neurobiol. Dis. 118, 22-39. DOI:10.1016/j.nbd.2018.06.015

Ducharme, S., Hudziak, J.J., Botteron, K.N., Ganjavi, H., Lepage, C., Collins, D.L., Albaugh, M.D., Evans, A.C., Karama, S., 2011. Right anterior cingulate cortical thickness and bilateral striatal volume correlate with child behavior checklist aggressive behavior scores in healthy children. Biol. Psychiatry 70, 283-290. DOI:10.1016/j.biopsych.2011.03.015

Dukhinova, M., Kuznetsova, I., Kopeikina, E., Veniaminova, E., Yung, A.W.Y., Veremeyko, T., Levchuk, K., Barteneva, N.S., Wing-Ho, K.K., Yung, W.H., Liu, J.Y.H., Rudd, J., Yau, S.S.Y., Anthony, D.C., 
Strekalova, T., Ponomarev, E.D., 2018. Platelets mediate protective neuroinflammation and promote neuronal plasticity at the site of neuronal injury. Brain. Behav. Immun. 74, 7-27. DOI:10.1016/j.bbi.2018.09.009

Dunn, A.J., File, S.E., 1983. Cold restraint alters dopamine metabolism in frontal cortex, nucleus accumbens and neostriatum. Physiol. Behav. 31, 511-3. DOI:10.1016/0031-9384(83)90074-4

Fadok, J.P., Markovic, M., Tovote, P., Lüthi, A., 2018. New perspectives on central amygdala function. Curr. Opin. Neurobiol. 49, 141-147. DOI:10.1016/j.conb.2018.02.009

Fan, L.W., Bhatt, A., Tien, L.T., Zheng, B., Simpson, K.L., Lin, R.C.S., Cai, Z., Kumar, P., Pang, Y., 2015. Exposure to serotonin adversely affects oligodendrocyte development and myelination in vitro. J. Neurochem. 133, 532-543. DOI:10.1111/jnc.12988

Fanibunda, S.E., Deb, S., Maniyadath, B., Tiwari, P., Ghai, U., Gupta, S., Figueiredo, D., Weisstaub, N., Gingrich, J.A., Vaidya, A.D.B., KolthurSeetharam, U., Vaidya, V.A., 2019. Serotonin regulates mitochondrial biogenesis and function in rodent cortical neurons via the 5-HT2A receptor and SIRT1-PGC-1 $\alpha$ axis. Proc. Natl. Acad. Sci. U. S. A. 166, 11028-11037. DOI:10.1073/pnas.1821332116

Faraone, S. V., Rostain, A.L., Blader, J., Busch, B., Childress, A.C., Connor, D.F., Newcorn, J.H., 2019. Practitioner Review: Emotional dysregulation in attention-deficit/hyperactivity disorder - implications for clinical recognition and intervention. J. Child Psychol. Psychiatry Allied Discip. 60, 133-150. DOI:10.1111/jcpp.12899

Fazel, S., Danesh, J., 2002. Serious mental disorder in 23000 prisoners: A systematic review of 62 surveys. Lancet 359, 545-550. DOI:10.1016/S0140-6736(02)07740-1

Fazel, S., Wolf, A., Palm, C., Lichtenstein, P., 2014. Violent crime, suicide, and premature mortality in patients with schizophrenia and related disorders: A 38-year total population study in Sweden. The Lancet Psychiatry 1, 44-54. DOI:10.1016/S2215-0366(14)70223-8

Feenstra, M.G.P., 2000. Dopamine and noradrenaline release in the prefrontal cortex in relation to unconditioned and conditioned stress and 
reward. Prog. Brain Res. 126, 133-163. DOI:10.1016/S00796123(00)26012-3

Fernandes Filho, J.A., Shapiro, B.E., 2004. Tay-Sachs Disease. Arch. Neurol. 61, 1466. DOI:10.1001/archneur.61.9.1466

Fields, R.D., Bukalo, O., 2020. Myelin makes memories. Nat. Neurosci. 23, 469-470. DOI:10.1038/s41593-020-0606-X

Fontes, M.A.P., Xavier, C.H., Marins, F.R., Limborço-Filho, M., Vaz, G.C., Müller-Ribeiro, F.C., Nalivaiko, E., 2014. Emotional stress and sympathetic activity: Contribution of dorsomedial hypothalamus to cardiac arrhythmias. Brain Res. 1554, 49-58. DOI:10.1016/j.brainres.2014.01.043

Galleguillos, D., Wang, Q., Steinberg, N., Shrivastava, G., Dhami, K., Rubinstein, K., Giuliani, F., Churchward, M., Power, C., Todd, K., Sipione, S., 2020. Anti-inflammatory role of GM1 and modulatory effects of gangliosides on microglia functions. bioRxiv 3-36. DOI:10.1101/2020.03.04.975862

Gansler, D.A., McLaughlin, N.C.R., Iguchi, L., Jerram, M., Moore, D.W., Bhadelia, R., Fulwiler, C., 2009. A multivariate approach to aggression and the orbital frontal cortex in psychiatric patients. Psychiatry Res. - Neuroimaging 171, 145-154. DOI:10.1016/j.pscychresns.2008.03.007

Garbern, J.Y., Yool, D.A., Moore, G.J., Wilds, I.B., Faulk, M.W., Klugmann, M., Nave, K.A., Sistermans, E.A., Van Der Knaap, M.S., Bird, T.D., Shy, M.E., Kamholz, J.A., Griffiths, I.R., 2002. Patients lacking the major CNS myelin protein, proteolipid protein 1, develop lengthdependent axonal degeneration in the absence of demyelination and inflammation. Brain 125, 551-561. DOI:10.1093/brain/awf043

Gendreau, P.L., Petitto, J.M., Petrova, A., Gariépy, J.L., Lewis, M.H., 2000. D3 and D2 dopamine receptor agonists differentially modulate isolation-induced social-emotional reactivity in mice. Behav. Brain Res. 114, 107-117. DOI:10.1016/S0166-4328(00)00193-5

Gershon, M.D., 2012. Serotonin is a sword and a shield of the bowel: serotonin plays offense and defense. Trans. Am. Clin. Climatol. Assoc. 123, 268-280. 
Glebov, K., Löchner, M., Jabs, R., Lau, T., Merkel, O., Schloss, P., Steinhäuser, C., Walter, J., 2015. Serotonin stimulates secretion of exosomes from microglia cells. Glia 63, 626-634. DOI:10.1002/glia.22772

Glick, A.R., 2015. The role of serotonin in impulsive aggression, suicide, and homicide in adolescents and adults: A literature review. Int. J. Adolesc. Med. Health 27, 143-150. DOI:10.1515/ijamh-2015-5005

Gobrogge, K.L., 2013. Sex, Drugs, and Violence: Neuromodulation of Attachment and Conflict in Voles, in: Brain Imaging in Behavioral Neuroscience. pp. 229-264. DOI:10.1007/7854_2013_264

Godar, S.C., Fite, P.J., McFarlin, K.M., Bortolato, M., 2016. The role of monoamine oxidase $\mathrm{A}$ in aggression: Current translational developments and future challenges. Prog. Neuro-Psychopharmacology Biol. Psychiatry 69, 90-100. DOI:10.1016/j.pnpbp.2016.01.001

Gogos, J.A., Morgan, M., Luine, V., Santha, M., Ogawa, S., Pfaff, D., Karayiorgou, M., 1998. Catechol-O-methyltransferase-deficient mice exhibit sexually dimorphic changes in catecholamine levels and behavior. Proc. Natl. Acad. Sci. U.S.A. 95, 9991-9996. DOI:10.1073/pnas.95.17.9991

Gold, A.K., Otto, M.W., Deckersbach, T., Sylvia, L.G., Nierenberg, A.A., Kinrys, G., 2018. Substance use comorbidity in bipolar disorder: A qualitative review of treatment strategies and outcomes. Am. J. Addict. 27, 188-201. DOI:10.1111/ajad.12713

Golden, S.A., Jin, M., Heins, C., Venniro, M., Michaelides, M., Shaham, Y., 2019. Nucleus accumbens Drd1-expressing neurons control aggression self-administration and aggression seeking in mice. J. Neurosci. 39, 2482-2496. DOI:10.1523/JNEUROSCI.2409-18.2019

González, R.A., Kallis, C., Coid, J.W., 2013. Adult Attention Deficit Hyperactivity Disorder and Violence in the Population of England: Does Comorbidity Matter? PLoS One 8, 1-10.

DOI:10.1371/journal.pone.0075575

Gopal, A., Clark, E., Allgair, A., D’Amato, C., Furman, M., Gansler, D.A., Fulwiler, C., 2013. Dorsal/ventral parcellation of the amygdala: Relevance to impulsivity and aggression. Psychiatry Res. - Neuroimaging 211, 24-30. DOI:10.1016/j.pscychresns.2012.10.010 
Gorlova, A., Ortega, G., Waider, J., Bazhenova, N., Veniaminova, E., Proshin, A., Kalueff, A. V., Anthony, D.C., Lesch, K.P., Strekalova, T., 2020. Stress-induced aggression in heterozygous TPH2 mutant mice is associated with alterations in serotonin turnover and expression of 5HT6 and AMPA subunit 2A receptors. J. Affect. Disord. 272, 440-451. DOI:10.1016/j.jad.2020.04.014

Gorlova, A., Pavlov, D., Anthony, D.C., Ponomarev, E.D., Sambon, M., Proshin, A., Shafarevich, I., Babaevskaya, D., Lesch, K.P., Bettendorff, L., Strekalova, T., 2019. Thiamine and benfotiamine counteract ultrasound-induced aggression, normalize AMPA receptor expression and plasticity markers, and reduce oxidative stress in mice. Neuropharmacology 156, 107543.

DOI:10.1016/j.neuropharm.2019.02.025

Gozzi, M., Nielson, D.M., Lenroot, R.K., Ostuni, J.L., Luckenbaugh, D.A., Thurm, A.E., Giedd, J.N., Swedo, S.E., 2012. A magnetization transfer imaging study of corpus callosum myelination in young children with autism. Biol. Psychiatry 72, 215-220. DOI:10.1016/j.biopsych.2012.01.026

Grafman, J., Schwab, K., Warden, D., Pridgen, A., Brown, H.R., Salazar, A.M., 1996. Frontal lobe injuries, violence, and aggression: A report of the Vietnam head injury study. Neurology 46, 1231-1238. DOI:10.1212/wnl.46.5.1231

Grech, L.B., Butler, E., Stuckey, S., Hester, R., 2019. Neuroprotective benefits of antidepressants in multiple sclerosis: Are we missing the mark? J. Neuropsychiatry Clin. Neurosci. 31, 289-297. DOI:10.1176/appi.neuropsych.18070164

Gutknecht, L., Popp, S., Waider, J., Sommerlandt, F.M.J., Göppner, C., Post, A., Reif, A., Van Den Hove, D., Strekalova, T., Schmitt, A., Colaço, M.B.N., Sommer, C., Palme, R., Lesch, K.P., 2015. Interaction of brain 5-HT synthesis deficiency, chronic stress and sex differentially impact emotional behavior in Tph2 knockout mice. Psychopharmacology (Berl). 232, 2429-2441. DOI:10.1007/s00213-015-3879-0

Gutzler, S.J., Karom, M., Erwin, W.D., Albers, H.E., 2010. Argininevasopressin and the regulation of aggression in female Syrian hamsters 
(Mesocricetus auratus). Eur. J. Neurosci. 31, 1655-1663. DOI:10.1111/j.1460-9568.2010.07190.x

Haddad, F.L., Patel, S. V., Schmid, S., 2020. Maternal Immune Activation by Poly I:C as a preclinical Model for Neurodevelopmental Disorders: A focus on Autism and Schizophrenia. Neurosci. Biobehav. Rev. 113, 546-567. DOI:10.1016/j.neubiorev.2020.04.012

Hadjkacem, I., Ayadi, H., Turki, M., Yaich, S., Khemekhem, K., Walha, A., Cherif, L., Moalla, Y., Ghribi, F., 2016. Prenatal, perinatal and postnatal factors associated with autism spectrum disorder. J. Pediatr. (Rio. J). 92, 595-601. DOI:10.1016/j.jped.2016.01.012

Hall, L.S., Pain, O., O’Brien, H.E., Anney, R., Walters, J.T.R., Owen, M.J., O’Donovan, M.C., Bray, N.J., 2020. Cis-effects on gene expression in the human prenatal brain associated with genetic risk for neuropsychiatric disorders. Mol. Psychiatry. DOI:10.1038/s41380-0200743-3

Haller, J., 2017. The role of central and medial amygdala in normal and abnormal aggression: a review of classical approaches. Neurosci. Biobehav. Rev. DOI:10.1126/science.1071829

Han, F., Perrin, R.J., Wang, Q., Wang, Y., Perlmutter, J.S., Morris, J.C., Benzinger, T.L.S., Xu, J., 2019. Neuroinflammation and Myelin Status in Alzheimer's Disease, Parkinson's Disease, and Normal Aging Brains: A Small Sample Study. Parkinsons. Dis. 2019, 1-12. DOI:10.1155/2019/7975407

Harlalka, G. V., Lehman, A., Chioza, B., Baple, E.L., Maroofian, R., Cross, H., Sreekantan-Nair, A., Priestman, D.A., Al-Turki, S., McEntagart, M.E., Proukakis, C., Royle, L., Kozak, R.P., Bastaki, L., Patton, M., Wagner, K., Coblentz, R., Price, J., Mezei, M., Schlade-Bartusiak, K., Platt, F.M., Hurles, M.E., Crosby, A.H., 2013. Mutations in B4GALNT1 (GM2 synthase) underlie a new disorder of ganglioside biosynthesis. Brain 136, 3618-3624. DOI:10.1093/brain/awt270

Haroon, E., Raison, C.L., Miller, A.H., 2012. Psychoneuroimmunology meets neuropsychopharmacology: Translational implications of the impact of inflammation on behavior. Neuropsychopharmacology 37, 137-162. DOI:10.1038/npp.2011.205 
Heim, C., Nemeroff, C.B., 2001. The role of childhood trauma in the neurobiology of mood and anxiety disorders: Preclinical and clinical studies. Biol. Psychiatry 49, 1023-1039. DOI:10.1016/S00063223(01)01157-X

Heinsbroek, R.P.W., van Haaren, F., Feenstra, M.G.P., van Galen, H., Boer, G., van de Poll, N.E., 1990. Sex differences in the effects of inescapable footshock on central catecholaminergic and serotonergic activity. Pharmacol. Biochem. Behav. 37, 539-550. DOI:10.1016/00913057(90)90025-D

Herr, N., Bode, C., Duerschmied, D., 2017. The Effects of Serotonin in Immune Cells. Front. Cardiovasc. Med. 4, 1-11. DOI:10.3389/fcvm.2017.00048

Hess, C., Reif, A., Strobel, A., Boreatti-Hümmer, A., Heine, M., Lesch, K.P., Jacob, C.P., 2009. A functional dopamine- $\beta$-hydroxylase gene promoter polymorphism is associated with impulsive personality styles, but not with affective disorders. J. Neural Transm. 116, 121-130. DOI:10.1007/s00702-008-0138-0

Hofstetter, H.H., Mössner, R., Lesch, K.P., Linker, R.A., Toyka, K. V., Gold, R., 2005. Absence of reuptake of serotonin influences susceptibility to clinical autoimmune disease and neuroantigen-specific interferon-gamma production in mouse EAE. Clin. Exp. Immunol. 142, 39-44. DOI:10.1111/j.1365-2249.2005.02901.x

Holmes, A., Murphy, D.L., Crawley, J.N., 2002. Reduced aggression in mice lacking the serotonin transporter. Psychopharmacology (Berl). 161, 160-167. DOI:10.1007/s00213-002-1024-3

Hoptman, M.J., 2015. Impulsivity and aggression in schizophrenia: a neural circuitry perspective with implications for treatment. CNS Spectr. 20, 280-286. DOI:10.1017/S1092852915000206

Hornedo-Ortega, R., Da Costa, G., Cerezo, A.B., Troncoso, A.M., Richard, T., Garcia-Parrilla, M.C., 2018. In Vitro Effects of Serotonin, Melatonin, and Other Related Indole Compounds on Amyloid- $\beta$ Kinetics and Neuroprotection. Mol. Nutr. Food Res. 62, 1-12. DOI:10.1002/mnfr.201700383 
Hunt, G.E., Large, M.M., Cleary, M., Lai, H.M.X., Saunders, J.B., 2018. Prevalence of comorbid substance use in schizophrenia spectrum disorders in community and clinical settings, 1990-2017: Systematic review and meta-analysis. Drug Alcohol Depend. 191, 234-258. DOI:10.1016/j.drugalcdep.2018.07.011

Hunter, P., 2010. The psycho gene. EMBO Rep. 11, 667-669. DOI:10.1038/embor.2010.122

Huxley, A.F., Stämpeli, R., 1949. Evidence for saltatory conduction in peripheral myelinated nerve fibres. J. Physiol. 108, 315-339. DOI:10.1113/jphysiol.1949.sp004335

Ida, T., Hara, M., Nakamura, Y., Kozaki, S., Tsunoda, S., Ihara, H., 2008. Cytokine-induced enhancement of calcium-dependent glutamate release from astrocytes mediated by nitric oxide. Neurosci. Lett. 432, 232-6. DOI:10.1016/j.neulet.2007.12.047

Ieraci, A., Mallei, A., Popoli, M., 2016. Social Isolation Stress Induces Anxious-Depressive-Like Behavior and Alterations of Neuroplasticity-Related Genes in Adult Male Mice. Neural Plast. 2016. DOI:10.1155/2016/6212983

Indellicato, R., Parini, R., Domenighini, R., Malagolini, N., Iascone, M., Gasperini, S., Masera, N., Dall’Olio, F., Trinchera, M., 2019. Total loss of GM3 synthase activity by a normally processed enzyme in a novel variant and in all ST3GAL5 variants reported to cause a distinct congenital disorder of glycosylation. Glycobiology 29, 229-241. DOI:10.1093/glycob/cwy112

Ishii, A., Ohta, M., Watanabe, Y., Matsuda, K., Ishiyama, K., Sakoe, K., Nakamura, M., Inokuchi, J.I., Sanai, Y., Saito, M., 1999. Expression cloning and functional characterization of human cDNA for ganglioside G(M3) synthase. J. Biol. Chem. 273, 31652-31655. DOI:10.1074/jbc.273.48.31652

Israelyan, N., Del Colle, A., Li, Z., Park, Y., Xing, A., Jacobsen, J.P.R., Luna, R.A., Jensen, D.D., Madra, M., Saurman, V., Rahim, R., Latorre, R., Law, K., Carson, W., Bunnett, N.W., Caron, M.G., Margolis, K.G., 2019. Effects of Serotonin and Slow-Release 5-Hydroxytryptophan on Gastrointestinal Motility in a Mouse Model of Depression. Gastroenterology 157, 507-521.e4. DOI:10.1053/j.gastro.2019.04.022 
Jha, S.C., Meltzer-Brody, S., Steiner, R.J., Cornea, E., Woolson, S., Ahn, M., Verde, A.R., Hamer, R.M., Zhu, H., Styner, M., Gilmore, J.H., Knickmeyer, R.C., 2016. Antenatal depression, treatment with selective serotonin reuptake inhibitors, and neonatal brain structure: A propensity-matched cohort study. Psychiatry Res. - Neuroimaging 253, 43-53. DOI:10.1016/j.pscychresns.2016.05.004

Ji, S., Doucette, J.R., Nazarali, A.J., 2011. Sirt2 is a novel in vivo downstream target of $\mathrm{Nkx} 2.2$ and enhances oligodendroglial cell differentiation. J. Mol. Cell Biol. 3, 351-359. DOI:10.1093/jmcb/mjr009

Karlsson, H., Dalman, C., 2019. Epidemiological Studies of Prenatal and Childhood Infection and Schizophrenia, in: Brain Imaging in Behavioral Neuroscience. pp. 35-47. DOI:10.1007/7854_2018_87

Katzman, M.A., Bilkey, T.S., Chokka, P.R., Fallu, A., Klassen, L.J., 2017. Adult ADHD and comorbid disorders: Clinical implications of a dimensional approach. BMC Psychiatry 17, 1-15. DOI:10.1186/s12888017-1463-3

Kazumori, H., Ishihara, S., Rumi, M.A.K., Ortega-Cava, C.F., Kadowaki, Y., Kinoshita, Y., 2004. Transforming growth factor- $\alpha$ directly augments histidine decarboxylase and vesicular monoamine transporter 2 production in rat enterochromaffin-like cells. Am. J. Physiol. Gastrointest. Liver Physiol. 286, 508-515. DOI:10.1152/ajpgi.00269.2003

Keifer, O.P., Hurt, R.C., Ressler, K.J., Marvar, P.J., 2015. The physiology of fear: Reconceptualizing the role of the central amygdala in fear learning. Physiology 30, 389-401. DOI:10.1152/physiol.00058.2014

Kelly, S., Yenari, M.A., 2002. Neuroprotection: Heat shock proteins. Curr. Med. Res. Opin. 18, 55-60. DOI:10.1185/030079902125000732

Khan, A., Ali, T., Rehman, S.U., Khan, M.S., Alam, S.I., Ikram, M., Muhammad, T., Saeed, K., Badshah, H., Kim, M.O., 2018. Neuroprotective effect of quercetin against the detrimental effects of LPS in the adult mouse brain. Front. Pharmacol. 9, 1-16. DOI:10.3389/fphar.2018.01383

Kim, K.I., Chung, Y.C., Kwan Jin, B., 2018. Norfluoxetine prevents degeneration of dopamine neurons by inhibiting microglia-derived oxidative stress in an MPTP mouse model of Parkinson's disease. Mediators Inflamm. 2018. DOI:10.1155/2018/4591289 
Kim, M.J., Gee, D.G., Loucks, R.A., Davis, F.C., Whalen, P.J., 2011. Anxiety Dissociates dorsal and ventral medial prefrontal cortex functional connectivity with the amygdala at rest. Cereb. Cortex 21, 1667-1673. DOI:10.1093/cercor/bhq237

Kim, M.J., Whalen, P.J., 2009. The structural integrity of an amygdala-prefrontal pathway predicts trait anxiety. J. Neurosci. 29, 11614-11618. DOI:10.1523/JNEUROSCI.2335-09.2009

Kim, N., Kim, J.Y., Yenari, M.A., 2012. Anti-inflammatory properties and pharmacological induction of Hsp70 after brain injury. Inflammopharmacology 20, 177-185. DOI:10.1007/s10787-011-0115-3

Kim, Y.-K., Jeon, S.W., 2018. Neuroinflammation and the ImmuneKynurenine Pathway in Anxiety Disorders. Curr. Neuropharmacol. 16, 574-582. DOI:10.2174/1570159x15666170913110426

Klein, M., Singgih, E.L., van Rens, A., Demontis, D., Børglum, A.D., Mota, N.R., Castells-Nobau, A., Kiemeney, L.A., Brunner, H.G., AriasVasquez, A., Schenck, A., van der Voet, M., Franke, B., 2020. Contribution of intellectual disability-related genes to ADHD risk and to locomotor activity in Drosophila. Am. J. Psychiatry 177, 526-536. DOI:10.1176/appi.ajp.2019.18050599

Koenigs, M., Grafman, J., 2009. Posttraumatic stress disorder: The role of medial prefrontal cortex and amygdala. Neuroscientist 15, 540548. DOI:10.1177/1073858409333072

Kolind, S., Sharma, R., Knight, S., Johansen-Berg, H., Talbot, K., Turner, M.R., 2013. Myelin imaging in amyotrophic and primary lateral sclerosis. Amyotroph. Lateral Scler. Front. Degener. 14, 562-573. DOI:10.3109/21678421.2013.794843

Konsman, J.P., Vigues, S., Mackerlova, L., Bristow, A., Blomqvist, A., 2004. Rat Brain Vascular Distribution of Interleukin-1 Type-1 Receptor Immunoreactivity: Relationship to Patterns of Inducible Cyclooxygenase Expression by Peripheral Inflammatory Stimuli. J. Comp. Neurol. 472, 113-129. DOI:10.1002/cne.20052

Kopeikina, E., Dukhinova, M., Yung, A.W.Y., Veremeyko, T., Kuznetsova, I.S., Lau, T.Y.B., Levchuk, K., Ponomarev, E.D., 2020. Platelets promote epileptic seizures by modulating brain serotonin level, 
enhancing neuronal electric activity, and contributing to neuroinflammation and oxidative stress. Prog. Neurobiol. 188, 101783. DOI:10.1016/j.pneurobio.2020.101783

Kostowski, W., Cztonkowski, A., Markowska, L., Markiewicz, L., 1975. Intraspecific aggressiveness after lesions of midbrain raphe nuclei in rats. Pharmacology 13, 81-85. DOI:10.1159/000136887

Krabbe, G., Matyash, V., Pannasch, U., Mamer, L., Boddeke, H.W.G.M., Kettenmann, H., 2012. Activation of serotonin receptors promotes microglial injury-induced motility but attenuates phagocytic activity. Brain. Behav. Immun. 26, 419-428. DOI:10.1016/j.bbi.2011.12.002

Kroeze, Y., Peeters, D., Boulle, F., Van Den Hove, D.L.A., Van Bokhoven, H., Zhou, H., Homberg, J.R., 2015. Long-term consequences of chronic fluoxetine exposure on the expression of myelination-related genes in the rat hippocampus. Transl. Psychiatry 5. DOI:10.1038/tp.2015.145

Kulikova, M.A., Trushkin, E. V., Timofeeva, M.A., Shlepzova, V.A., Schegolkova, J. V., Maluchenko, N. V., Tonevitsky, A.G., 2008. Genetic markers of predisposition to increased anxiety. Bull. Exp. Biol. Med. 146, 774-778. DOI:10.1007/s10517-009-0373-x

Kulkarni, O.P., Lichtnekert, J., Anders, H.J., Mulay, S.R., 2016. The Immune System in Tissue Environments Regaining Homeostasis after Injury: Is "Inflammation" Always Inflammation? Mediators Inflamm. 2016. DOI:10.1155/2016/2856213

Kunik, M.E., Stanley, M.A., Shrestha, S., Ramsey, D., Richey, S., Snow, L., Freshour, J., Rn, T.E., Newmark, M., Williams, S., Msw, N.W., Amspoker, A.B., 2020. Aggression Prevention Training for Individuals with Dementia and their Caregivers: A Randomized Controlled Trial. Am. J. Geriatr. Psychiatry. DOI:10.1016/j.jagp.2020.01.190

Laine, M.A., Trontti, K., Misiewicz, Z., Sokolowska, E., Kulesskaya, N., Heikkinen, A., Saarnio, S., Balcells, I., Ameslon, P., Greco, D., Mattila, P., Ellonen, P., Paulin, L., Auvinen, P., Jokitalo, E., Hovatta, I., 2018. Genetic control of myelin plasticity after chronic psychosocial stress. eNeuro 5. DOI:10.1523/ENEURO.0166-18.2018 
Landrø, N.I., 2014. Towards personalized treatment of depression: a candidate gene approach. Scand. J. Psychol. 55, 219-24. DOI:10.1111/sjop.12124

Lane, S.D., Kjome, K.L., Moeller, F.G., 2011. Neuropsychiatry of Aggression. Neurol. Clin. 29, 49-64. DOI:10.1016/j.ncl.2010.10.006

Ledeen, R.W., Wu, G., 2018. Gangliosides, $\alpha$-Synuclein, and Parkinson's Disease. Prog. Mol. Biol. Transl. Sci. 156, 435-454. DOI:10.1016/bs.pmbts.2017.12.009

Lee, J.S., Yoo, Y., Lim, B.C., Kim, K.J., Song, J., Choi, M., Chae, J.H., 2016. GM3 synthase deficiency due to ST3GAL5 variants in two Korean female siblings: Masquerading as Rett syndrome-like phenotype. Am. J. Med. Genet. Part A 170, 2200-2205. DOI:10.1002/ajmg.a.37773

Lee, S.C., Ueki, S., 1986. Pharmacological studies on aggressive behavior induced by lesions of the nucleus accumbens septi in rats. Arch. Pharm. Res. 9, 169-174. DOI:10.1007/BF02900002

Leroy, F., Park, J., Asok, A., Brann, D.H., Meira, T., Boyle, L.M., Buss, E.W., Kandel, E.R., Siegelbaum, S.A., 2018. A circuit from hippocampal CA2 to lateral septum disinhibits social aggression. Nature 564, 213-218. DOI:10.1038/s41586-018-0772-0

Lesch, K.-P., Bengel, D., Heils, A., Sabol, S.Z., Greenberg, B.D., Petri, S., Benjamin, J., Muller, C.R., Hamer, D.H., Murphy, D.L., 1996. Association of Anxiety-Related Traits with a Polymorphism in the Serotonin Transporter Gene Regulatory Region. Science. 274, 1527-1531. DOI:10.1126/science.274.5292.1527

Lesch, K.P., 2019. Editorial: Can dysregulated myelination be linked to ADHD pathogenesis and persistence? J. Child Psychol. Psychiatry Allied Discip. 60, 229-231. DOI:10.1111/jcpp.13031

Lesch, K.P., 2005. Alcohol dependence and gene $\mathrm{x}$ environment interaction in emotion regulation: Is serotonin the link? Eur. J. Pharmacol. 526, 113-124. DOI:10.1016/j.ejphar.2005.09.027

Lesch, K.P., Araragi, N., Waider, J., van den Hove, D., Gutknecht, L., 2012. Targeting brain serotonin synthesis: insights into neurodevelopmental disorders with long-term outcomes related to 
negative emotionality, aggression and antisocial behaviour. Philos. Trans. R. Soc. B Biol. Sci. 367, 2426-2443. DOI:10.1098/rstb.2012.0039

Lesch, K.P., Merschdorf, U., 2000. Impulsivity, aggression, and serotonin: A molecular psychobiological perspective. Behav. Sci. Law 18, 581-604.

DOI:10.1002/1099-0798(200010)18:5<581::AID-

BSL411>3.0.CO;2-L

Lesch, K.P., Mössner, R., 2006. Inactivation of 5HT transport in mice: Modeling altered 5HT homeostasis implicated in emotional dysfunction, affective disorders, and somatic syndromes. Handb. Exp. Pharmacol. 175, 417-456. DOI:10.1007/3-540-29784-7-18

Li, W., Zhang, B., Tang, J., Cao, Q., Wu, Y., Wu, C., Guo, J., Ling, E.A., Liang, F., 2007. Sirtuin 2, a mammalian homolog of yeast silent information regulator-2 longevity regulator, is an oligodendroglial protein that decelerates cell differentiation through deacetylating $\alpha$ tubulin. J. Neurosci. 27, 2606-2616. DOI:10.1523/JNEUROSCI.418106.2007

Lindberg, N., Tani, P., Putkonen, H., Sailas, E., Takala, P., Eronen, M., Virkkunen, M., 2009. Female impulsive aggression: A sleep research perspective. Int. J. Law Psychiatry 32, 39-42. DOI:10.1016/j.ijlp.2008.11.009

Liu, F.Y., Cai, J., Wang, C., Ruan, W., Guan, G.P., Pan, H.Z., Li, J.R., Qian, C., Chen, J. Sen, Wang, L., Chen, G., 2018. Fluoxetine attenuates neuroinflammation in early brain injury after subarachnoid hemorrhage: A possible role for the regulation of TLR4/MyD88/NF- $\mathrm{BB}$ signaling pathway. J. Neuroinflammation 15, 1-14. DOI:10.1186/s12974-018-1388$\mathrm{x}$

Lovelace, M.D., Varney, B., Sundaram, G., Lennon, M.J., Lim, C.K., Jacobs, K., Guillemin, G.J., Brew, B.J., 2017. Recent evidence for an expanded role of the kynurenine pathway of tryptophan metabolism in neurological diseases. Neuropharmacology 112, 373-388. DOI:10.1016/j.neuropharm.2016.03.024

Lowery-Gionta, E.G., Crowley, N.A., Bukalo, O., Silverstein, S., Holmes, A., Kash, T.L., 2018. Chronic stress dysregulates amygdalar output to the prefrontal cortex. Neuropharmacology 139, 68-75. DOI:10.1016/j.neuropharm.2018.06.032 
Luthi-Carter, R., Taylor, D.M., Pallos, J., Lambert, E., Amore, A., Parker, A., Moffitt, H., Smith, D.L., Runne, H., Gokce, O., Kuhn, A., Xiang, Z., Maxwell, M.M., Reeves, S.A., Bates, G.P., Neri, C., Thompson, L.M., Marsh, J.L., Kazantsev, A.G., 2010. SIRT2 inhibition achieves neuroprotection by decreasing sterol biosynthesis. Proc. Natl. Acad. Sci. U. S. A. 107, 7927-7932. DOI:10.1073/pnas.1002924107

Maglione, V., Marchi, P., Di Pardo, A., Lingrell, S., Horkey, M., Tidmarsh, E., Sipione, S., 2010. Impaired ganglioside metabolism in Huntington's disease and neuroprotective role of GM1. J. Neurosci. 30, 4072-4080. DOI:10.1523/JNEUROSCI.6348-09.2010

Mahé, C., Loetscher, E., Dev, K.K., Bobirnac, I., Otten, U., Schoeffter, P., 2005. Serotonin 5-HT7 receptors coupled to induction of interleukin-6 in human microglial MC-3 cells. Neuropharmacology 49, 40-47. DOI:10.1016/j.neuropharm.2005.01.025

Makinodan, M., Ikawa, D., Miyamoto, Y., Yamauchi, J., Yamamuro, K., Yamashita, Y., Toritsuka, M., Kimoto, S., Okumura, K., Yamauchi, T., Fukami, S.I., Yoshino, H., Wanaka, A., Kishimoto, T., 2016. Social isolation impairs remyelination in mice through modulation of IL-6. FASEB J. 30, 4267-4274. DOI:10.1096/fj.201600537R

Makinodan, M., Ikawa, D., Yamamuro, K., Yamashita, Y., Toritsuka, M., Kimoto, S., Yamauchi, T., Okumura, K., Komori, T., Fukami, S.I., Yoshino, H., Kanba, S., Wanaka, A., Kishimoto, T., 2017. Effects of the mode of re-socialization after juvenile social isolation on medial prefrontal cortex myelination and function. Sci. Rep. 7, 1-9. DOI:10.1038/s41598-017-05632-2

Malki, K., Tosto, M.G., Pain, O., Sluyter, F., Mineur, Y.S., Crusio, W.E., de Boer, S., Sandnabba, K.N., Kesserwani, J., Robinson, E., Schalkwyk, L.C., Asherson, P., 2016. Comparative mRNA analysis of behavioral and genetic mouse models of aggression. Am. J. Med. Genet. Part B Neuropsychiatr. Genet. 171, 427-436. DOI:10.1016/j.brainres.2013.09.033.

Mann, J., 2001. The Neurobiology and Genetics of Suicide and Attempted Suicide: A Focus on the Serotonergic System. Neuropsychopharmacology 24, 467-477. DOI:10.1016/S0893133X(00)00228-1 
Manzari, N., Matvienko-Sikar, K., Baldoni, F., O’Keeffe, G.W., Khashan, A.S., 2019. Prenatal maternal stress and risk of neurodevelopmental disorders in the offspring: a systematic review and meta-analysis. Soc. Psychiatry Psychiatr. Epidemiol. 54, 1299-1309. DOI:10.1007/s00127-019-01745-3

Marino, M.D., Bourdélat-Parks, B.N., Cameron Liles, L., Weinshenker, D., 2005. Genetic reduction of noradrenergic function alters social memory and reduces aggression in mice. Behav. Brain Res. 161, 197-203. DOI:10.1016/j.bbr.2005.02.005

Matsumoto, K., Pinna, G., Puia, G., Guidotti, A., Costa, E., 2005. Social isolation stress-induced aggression in mice: A model to study the pharmacology of neurosteroidogenesis. Stress 8, 85-93. DOI:10.1080/10253890500159022

Matthies, S., Rsch, N., Weber, M., Lieb, K., Philipsen, A., Tuescher, O., Ebert, D., Hennig, J., Van Elst, L.T., 2012. Small amygdala high aggression? the role of the amygdala in modulating aggression in healthy subjects. World J. Biol. Psychiatry 13, 75-81. DOI:10.3109/15622975.2010.541282

Matute, C., Domercq, M., Sánchez-Gómez, M.-V., 2006. Glutamatemediated glial injury: mechanisms and clinical importance. Glia 53, 21224. DOI:10.1002/glia.20275

Mazurek, M.O., Kanne, S.M., Wodka, E.L., 2013. Physical aggression in children and adolescents with autism spectrum disorders. Res. Autism Spectr. Disord. 7, 455-465. DOI:10.1016/j.rasd.2012.11.004

Meesters, C., Muris, P., Van Rooijen, B., 2007. Relations of neuroticism and attentional control with symptoms of anxiety and aggression in non-clinical children. J. Psychopathol. Behav. Assess. 29, 149-158. DOI:10.1007/s10862-006-9037-6

Meng, H., Wang, L., He, J., Wang, Z., 2016. The protective effect of gangliosides on lead $(\mathrm{Pb})$-induced neurotoxicity is mediated by autophagic pathways. Int. J. Environ. Res. Public Health 13. DOI:10.3390/ijerph13040365 
Milad, M.R., Rauch, S.L., 2007. The role of the orbitofrontal cortex in anxiety disorders. Ann. N. Y. Acad. Sci. 1121, 546-561. DOI:10.1196/annals.1401.006

Minakova, E., Warner, B.B., 2018. Maternal immune activation, central nervous system development and behavioral phenotypes. Birth Defects Res. 110, 1539-1550. DOI:10.1002/bdr2.1416

Mineur, Y.S., Prasol, D.J., Belzung, C., Crusio, W.E., 2003. Agonistic behavior and unpredictable chronic mild stress in mice. Behav. Genet. 33, 513-519. DOI:10.1023/A:1025770616068

Misri, S., Reebye, P., Kendrick, K., Carter, D., Ryan, D., Grunau, R.E., Oberlander, T.F., 2006. Internalizing behaviors in 4-year-old children exposed in utero to psychotropic medications. Am. J. Psychiatry 163, 1026-1032. DOI:10.1176/appi.ajp.163.6.1026

Modabbernia, A., Velthorst, E., Reichenberg, A., 2017. Environmental risk factors for autism: an evidence-based review of systematic reviews and meta-analyses. Mol. Autism 8, 13. DOI:10.1186/s13229-017-0121-4

Mora, S., Martín-González, E., Prados-Pardo, Á., Moreno, J., López, M.J., Pilar-Cuellar, F., Castro, E., Díaz, Á., Flores, P., Moreno, M., 2020. Increased vulnerability to impulsive behavior after streptococcal antigen exposure and antibiotic treatment in rats. Brain. Behav. Immun. 89, 675688. DOI:10.1016/j.bbi.2020.08.010

Morón, J.A., Zakharova, I., Ferrer, J. V, Merrill, G.A., Hope, B., Lafer, E.M., Lin, Z.C., Wang, J.B., Javitch, J.A., Galli, A., Shippenberg, T.S., 2003. Mitogen-activated protein kinase regulates dopamine transporter surface expression and dopamine transport capacity. J. Neurosci. 23, 8480-8.

Mosienko, V., Bader, M., Alenina, N., 2020. The serotonin-free brain: behavioral consequences of Tph2 deficiency in animal models, in: Handbook of Behavioral Neuroscience. pp. 601-607. DOI:10.1016/B9780-444-64125-0.00035-9

Mutlu, O., Gumuslu, E., Ulak, G., Celikyurt, I.K., Kokturk, S., Kir, H.M., Akar, F., Erden, F., 2012. Effects of fluoxetine, tianeptine and olanzapine on unpredictable chronic mild stress-induced depression-like behavior in mice. Life Sci. 91, 1252-1262. DOI:10.1016/j.lfs.2012.09.023 
Najt, P., Perez, J., Sanches, M., Peluso, M.A.M., Glahn, D., Soares, J.C., 2007. Impulsivity and bipolar disorder. Eur. Neuropsychopharmacol. 17, 313-320. DOI:10.1016/j.euroneuro.2006.10.002

Nasrabady, S.E., Rizvi, B., Goldman, J.E., Brickman, A.M., 2018. White matter changes in Alzheimer's disease: a focus on myelin and oligodendrocytes. Acta Neuropathol. Commun. 6, 22. DOI:10.1186/s40478-018-0515-3

Natarajan, D., de Vries, H., de Boer, S.F., Koolhaas, J.M., 2009. Violent Phenotype in SAL Mice is inflexible and fixed in adulthood. Aggress. Behav. 35, 430-436. DOI:10.1002/ab.20312

Natarajan, R., Einarsdottir, E., Riutta, A., Hagman, S., Raunio, M., Mononen, N., Lehtimäki, T., Elovaara, I., 2012. Melatonin pathway genes are associated with progressive subtypes and disability status in multiple sclerosis among Finnish patients. J. Neuroimmunol. 250, 106-110. DOI:10.1016/j.jneuroim.2012.05.014

Niño, D.F., Zhou, Q., Yamaguchi, Y., Martin, L.Y., Wang, S., Fulton, W.B., Jia, H., Lu, P., Jr, T.P., Zhang, F., Crawford, J., Hou, Z., Mori, S., Chen, L.L., Guajardo, A., Fatemi, A., Pletnikov, M., Kannan, R.M., Kannan, S., Sodhi, C.P., Hackam, D.J., 2018. Cognitive impairments induced by necrotizing enterocolitis can be prevented by inhibiting microglial activation in mouse brain. Sci. Transl. Med. 10. DOI:10.1126/scitranslmed.aan0237

O’Connor, J.C., Lawson, M.A., André, C., Moreau, M., Lestage, J., Castanon, N., Kelley, K.W., Dantzer, R., 2009. Lipopolysaccharideinduced depressive-like behavior is mediated by indoleamine 2,3dioxygenase activation in mice. Mol. Psychiatry 14, 511-522. DOI:10.1038/sj.mp.4002148

Oberlander, T.F., 2012. Fetal Serotonin Signaling: Setting Pathways for Early Childhood Development and Behavior. J. Adolesc. Heal. 51, S9S16. DOI:10.1016/j.jadohealth.2012.04.009

Ofengeim, D., Yuan, J., 2013. Regulation of RIP1 kinase signalling at the crossroads of inflammation and cell death. Nat. Rev. Mol. Cell Biol. 14, 727-736. DOI:10.1038/nrm3683 
Ohmi, Y., Tajima, O., Ohkawa, Y., Yamauchi, Y., Sugiura, Y., Furukawa, Keiko, Furukawa, Koichi, 2011. Gangliosides are essential in the protection of inflammation and neurodegeneration via maintenance of lipid rafts: Elucidation by a series of ganglioside-deficient mutant mice. J. Neurochem. 116, 926-935. DOI:10.1111/j.14714159.2010.07067.x

Onnink, A.M.H., Zwiers, M.P., Hoogman, M., Mostert, J.C., Dammers, J., Kan, C.C., Vasquez, A.A., Schene, A.H., Buitelaar, J., Franke, B., 2015. Deviant white matter structure in adults with attentiondeficit/hyperactivity disorder points to aberrant myelination and affects neuropsychological performance. Prog. Neuro-Psychopharmacology Biol. Psychiatry 63, 14-22. DOI:10.1016/j.pnpbp.2015.04.008

Orlovska, S., Vestergaard, C.H., Bech, B.H., Nordentoft, M., Vestergaard, M., Benros, M.E., 2017. Association of streptococcal throat infection with mental disorders: Testing key aspects of the PANDAS hypothesis in a nationwide study. JAMA Psychiatry 74, 740-746. DOI:10.1001/jamapsychiatry.2017.0995

Outeiro, T.F., Kontopoulos, E., Altmann, S.M., Kufareva, I., Strathearn, K.E., Amore, A.M., Volk, C.B., Maxwell, M.M., Rochet, J.C., McLean, P.J., Young, A.B., Abagyan, R., Feany, M.B., Hyman, B.T., Kazantsev, A.G., 2007. Sirtuin 2 inhibitors rescue $\alpha$-synuclein-mediated toxicity in models of Parkinson's disease. Science. 317, 516-519. DOI:10.1126/science. 1143780

Palmer, A.M., DeKosky, S.T., 1993. Monoamine neurons in aging and Alzheimer's disease. J. Neural Transm. 91, 135-159. DOI:10.1007/BF01245229

Pan, B., Fromholt, S.E., Hess, E.J., Crawford, T.O., Griffin, J.W., Sheikh, K.A., Schnaar, R.L., 2005. Myelin-associated glycoprotein and complementary axonal ligands, gangliosides, mediate axon stability in the CNS and PNS: Neuropathology and behavioral deficits in single- and double-null mice. Exp. Neurol. 195, 208-217. DOI:10.1016/j.expneurol.2005.04.017

Pan, S., Mayoral, S.R., Choi, H.S., Chan, J.R., Kheirbek, M.A., 2020. Preservation of a remote fear memory requires new myelin formation. Nat. Neurosci. 23, 487-499. DOI:10.1038/s41593-019-0582-1 
Pardini, D.A., Raine, A., Erickson, K., Loeber, R., 2014. Lower amygdala volume in men is associated with childhood aggression, early psychopathic traits, and future violence. Biol. Psychiatry 75, 73-80. DOI:10.1016/j.biopsych.2013.04.003

Pavlov, D., Bettendorff, L., Gorlova, A., Olkhovik, A., Kalueff, A. V., Ponomarev, E.D., Inozemtsev, A., Chekhonin, V., Lesch, K.P., Anthony, D.C., Strekalova, T., 2019. Neuroinflammation and aberrant hippocampal plasticity in a mouse model of emotional stress evoked by exposure to ultrasound of alternating frequencies. Prog. Neuro-Psychopharmacology Biol. Psychiatry 90, 104-116. DOI:10.1016/j.pnpbp.2018.11.014

Pavlov, K.A., Chistiakov, D.A., Chekhonin, V.P., 2012. Genetic determinants of aggression and impulsivity in humans. J. Appl. Genet. 53, 61-82. DOI:10.1007/s13353-011-0069-6

Piggott, V.M., Bosse, K.E., Lisieski, M.J., Strader, J.A., Stanley, J.A., Conti, A.C., Ghoddoussi, F., Perrine, S.A., 2019. Single-prolonged stress impairs prefrontal cortex control of amygdala and striatum in rats. Front. Behav. Neurosci. 13, 1-9. DOI:10.3389/fnbeh.2019.00018

Ping, L., Xu, J., Zhou, C., Lu, J., Lu, Y., Shen, Z., Jiang, L., Dai, N., $\mathrm{Xu}$, X., Cheng, Y., 2019. Tryptophan hydroxylase-2 polymorphism is associated with white matter integrity in first-episode, medication-naïve major depressive disorder patients. Psychiatry Res. - Neuroimaging 286, 4-10. DOI:10.1016/j.pscychresns.2019.02.002

Pinna, G., 2010. In a mouse model relevant for post-traumatic stress disorder, selective brain steroidogenic stimulants (SBSS) improve behavioral deficits by normalizing allopregnanolone biosynthesis. Behav. Pharmacol. DOI:10.1097/FBP.0b013e32833d8ba0

Piontkewitz, Y., Arad, M., Weiner, I., 2012. Tracing the development of psychosis and its prevention: What can be learned from animal models. Neuropharmacology 62, 1273-1289. DOI:10.1016/j.neuropharm.2011.04.019

Polanska, K., Krol, A., Merecz-Kot, D., Jurewicz, J., MakowiecDabrowska, T., Chiarotti, F., Calamandrei, G., Hanke, W., 2017. Maternal stress during pregnancy and neurodevelopmental outcomes of children during the first 2 years of life. J. Paediatr. Child Health 53, 263-270. DOI:10.1111/jpc. 13422 
Prasanna, X., Jafurulla, M., Sengupta, D., Chattopadhyay, A., 2016. The ganglioside GM1 interacts with the serotonin1A receptor via the sphingolipid binding domain. Biochim. Biophys. Acta - Biomembr. 1858, 2818-2826. DOI:10.1016/j.bbamem.2016.08.009

Pucilowski, O., Valzelli, L., 1986. Chemical lesions of the nucleus accumbens septi in rats: Effects on muricide and apomorphine-induced aggression. Behav. Brain Res. 19, 171-178. DOI:10.1016/01664328(86)90015-X

Pulay, A.J., Dawson, D.A., Hasin, D.S., Goldstein, R.B., Ruan, W.J., Pickering, R.P., Huang, B., Chou, S.P., Grant, B.F., 2008. Violent behavior and DSM-IV psychiatric disorders: Results from the national epidemiologic survey on alcohol and related conditions. J. Clin. Psychiatry 69, 12-22. DOI:10.4088/JCP.v69n0103

Raine, A., Ishikawa, S.S., Arce, E., Lencz, T., Knuth, K.H., Bihrle, S., LaCasse, L., Colletti, P., 2004. Hippocampal structural asymmetry in unsuccessful psychopaths. Biol. Psychiatry 55, 185-191. DOI:10.1016/S0006-3223(03)00727-3

Rakofsky, J.J., Dunlop, B.W., 2011. Treating Nonspecific Anxiety and Anxiety Disorders in Patients With Bipolar Disorder. J. Clin. Psychiatry 72, 81-90. DOI:10.4088/JCP.09r05815gre

Rodriguiz, R.M., Chu, R., Caron, M.G., Wetsel, W.C., 2004. Aberrant responses in social interaction of dopamine transporter knockout mice. Behav. Brain Res. 148, 185-198. DOI:10.1016/S0166-4328(03)00187-6

Rosell, D.R., Siever, L.J., 2015. The neurobiology of aggression and violence. CNS Spectr. 20, 254-279. DOI:10.1017/S109285291500019X

Rudebeck, P.H., Murray, E.A., 2014. The orbitofrontal oracle: Cortical mechanisms for the prediction and evaluation of specific behavioral outcomes. Urology 84, 1143-1156. DOI:10.1016/j.neuron.2014.10.049

Rund, B.R., 2018. A review of factors associated with severe violence in schizophrenia. Nord. J. Psychiatry 72, 561-571. DOI:10.1080/08039488.2018.1497199 
Saab, A.S., Tzvetanova, I.D., Nave, K.A., 2013. The role of myelin and oligodendrocytes in axonal energy metabolism. Curr. Opin. Neurobiol. 23, 1065-1072. DOI:10.1016/j.conb.2013.09.008

Saddichha, S., Schuetz, C., 2014. Impulsivity in remitted depression: A meta-analytical review. Asian J. Psychiatr. 9, 13-16. DOI:10.1016/j.ajp.2014.02.003

Saddoris, M.P., Gallagher, M., Schoenbaum, G., 2005. Rapid associative encoding in basolateral amygdala depends on connections with orbitofrontal cortex. Neuron 46, 321-331. DOI:10.1016/j.neuron.2005.02.018

Sagar-Ouriaghli, I., Lievesley, K., Santosh, P.J., 2018. Propranolol for treating emotional, behavioural, autonomic dysregulation in children and adolescents with autism spectrum disorders. J. Psychopharmacol. 32, 641-653. DOI:10.1177/0269881118756245

Salzer, J.L., 2015. Schwann cell myelination. Cold Spring Harb. Perspect. Biol. 7, 1-26. DOI:10.1101/cshperspect.a020529

Sandhoff, K., 1969. Variation of $\beta$-N-acetylhexosaminidase-pattern in Tay-Sachs disease. FEBS Lett. 4, 351-354. DOI:10.1016/00145793(69)80274-7

Saudou, F., Amara, D.A., Dierich, A., LeMeur, M., Ramboz, S., Segu, L., Buhot, M.C., Hen, R., 1994. Enhanced aggressive behavior in mice lacking 5-HT1B receptor. Science. 265, 1875-1878. DOI:10.1126/science.8091214

Schatz, D.B., Rostain, A.L., 2006. ADHD with comorbid anxiety. A review of the current literature. J. Atten. Disord. 10, 141-149. DOI:10.1177/1087054706286698

Schnaar, R.L., 2016. Gangliosides of the Vertebrate Nervous System. J. Mol. Biol. 428, 3325-3336. DOI:10.1016/j.jmb.2016.05.020

Schnaar, R.L., 2010. Brain gangliosides in axon-myelin stability and axon regeneration. FEBS Lett. 584, 1741-1747. DOI:10.1016/j.febslet.2009.10.011

Schnaar, R.L., Gerardy-Schahn, R., Hildebrandt, H., 2014. Sialic acids in the brain: Gangliosides and polysialic acid in nervous system 
development, stability, disease, and regeneration. Physiol. Rev. 94, 461518. DOI:10.1152/physrev.00033.2013

Schnaar, R.L., Lopez, P.H.H., 2009. Myelin-associated glycoprotein and its axonal receptors. J. Neurosci. Res. 87, 3267-3276. DOI:10.1002/jnr.21992

Schoenbaum, G., Roesch, M.R., Stalnaker, T.A., 2006. Orbitofrontal cortex, decision-making and drug addiction. Trends Neurosci. 29, 116124. DOI:10.1016/j.tins.2005.12.006

Sharp, B.M., 2017. Basolateral amygdala and stress-induced hyperexcitability affect motivated behaviors and addiction. Transl. Psychiatry 7, e1194. DOI:10.1038/tp.2017.161

She, D.T., Wong, L.J., Baik, S.H., Arumugam, T. V., 2018. SIRT2 Inhibition Confers Neuroprotection by Downregulation of FOXO3a and MAPK Signaling Pathways in Ischemic Stroke. Mol. Neurobiol. 55, 91889203. DOI:10.1007/s12035-018-1058-0

Sjögren, B., Svenningsson, P., 2007. Depletion of the lipid raft constituents, sphingomyelin and ganglioside, decreases serotonin binding at human 5-HT7(a) receptors in HeLa cells. Acta Physiol. 190, 47-53. DOI:10.1111/j.1365-201X.2007.01687.x

Slaughter, K.E., Leaberry, K.D., Fogleman, N.D., Rosen, P.J., 2020. Reactive and proactive aggression in children with and without ADHD and negative emotional lability. Soc. Dev. 29, 320-338. DOI:10.1111/sode. 12402

Soyka, M., 2011. Neurobiology of aggression and violence in schizophrenia. Schizophr. Bull. 37, 913-920. DOI:10.1093/schbul/sbr103

Stadelmann, C., Timmler, S., Barrantes-Freer, A., Simons, M., 2019. Myelin in the central nervous system: Structure, function, and pathology. Physiol. Rev. 99, 1381-1431. DOI:10.1152/physrev.00031.2018

Strekalova, T., Couch, Y., Kholod, N., Boyks, M., Malin, D., Leprince, P., Steinbusch, H.M.W., 2011. Update in the methodology of the chronic stress paradigm: Internal control matters. Behav. Brain Funct. 7, 9. https://doi.org/10.1186/1744-9081-7-9

Sturm, V., Lenartz, D., Koulousakis, A., Treuer, H., Herholz, K., Klein, J.C., Klosterkötter, J., 2003. The nucleus accumbens: A target for 
deep brain stimulation in obsessive-compulsive- and anxiety-disorders. J. Chem. Neuroanat. 26, 293-299. DOI:10.1016/j.jchemneu.2003.09.003

Sysoeva, O. V., Maluchenko, N. V., Timofeeva, M.A., Portnova, G. V., Kulikova, M.A., Tonevitsky, A.G., Ivanitsky, A.M., 2009. Aggression and 5HTT polymorphism in females: Study of synchronized swimming and control groups. Int. J. Psychophysiol. 72, 173-178. DOI:10.1016/j.ijpsycho.2008.12.005

Takahashi, J.L., Giuliani, F., Power, C., Imai, Y., Yong, V.W., 2003. Interleukin- $1 \beta$ promotes oligodendrocyte death through glutamate excitotoxicity. Ann. Neurol. 53, 588-595. DOI:10.1002/ana.10519

Takahashi, N., Sakurai, T., Davis, K.L., Buxbaum, J.D., 2011. Linking oligodendrocyte and myelin dysfunction to neurocircuitry abnormalities in schizophrenia. Prog. Neurobiol. 93, 13-24. DOI:10.1016/j.pneurobio.2010.09.004

Takeda, A., Iwaki, H., Ide, K., Tamano, H., Oku, N., 2012. Therapeutic effect of Yokukansan on social isolation-induced aggressive behavior of zinc-deficient and pair-fed mice. Brain Res. Bull. 87, 551555. DOI:10.1016/j.brainresbull.2012.02.003

Tanaka, M., Yoshida, M., Emoto, H., Ishii, H., 2000. Noradrenaline systems in the hypothalamus, amygdala and locus coeruleus are involved in the provocation of anxiety: Basic studies. Eur. J. Pharmacol. 405, 397406. DOI:10.1016/S0014-2999(00)00569-0

Tawfik, M.K., Helmy, S.A., Badran, D.I., Zaitone, S.A., 2018. Neuroprotective effect of duloxetine in a mouse model of diabetic neuropathy: Role of glia suppressing mechanisms. Life Sci. 205, 113-124. DOI:10.1016/j.lfs.2018.05.025

Temmingh, H., Stein, D.J., 2015. Anxiety in Patients with Schizophrenia: Epidemiology and Management. CNS Drugs 29, 819-832. DOI:10.1007/s40263-015-0282-7

Thapar, A., Harold, G., Rice, F., Langley, K., O’donovan, M., 2007. The contribution of gene-environment interaction to psychopathology. Dev. Psychopathol. 19, 989-1004. DOI:10.1017/S0954579407000491

Tien, L.-T., Kaizaki, A., Pang, Y., Cai, Z., Bhatt, A.J., Fan, L.-W., 2013. Neonatal exposure to lipopolysaccharide enhances accumulation of 
$\alpha$-synuclein aggregation and dopamine transporter protein expression in the substantia nigra in responses to rotenone challenge in later life. Toxicology 308, 96-103. DOI:10.1016/j.tox.2013.03.014

Tottenham, N., Galván, A., 2016. Stress and the adolescent brain: Amygdala-prefrontal cortex circuitry and ventral striatum as developmental targets. Neurosci. Biobehav. Rev. 70, 217-227. DOI:10.1016/j.neubiorev.2016.07.030

Trinchera, M., Parini, R., Indellicato, R., Domenighini, R., dall'Olio, F., 2018. Diseases of ganglioside biosynthesis: An expanding group of congenital disorders of glycosylation. Mol. Genet. Metab. 124, 230-237. DOI:10.1016/j.ymgme.2018.06.014

Tsiouris, J.A., Kim, S.Y., Brown, W.T., Cohen, I.L., 2011. Association of aggressive behaviours with psychiatric disorders, age, sex and degree of intellectual disability: A large-scale survey. J. Intellect. Disabil. Res. 55, 636-649. DOI:10.1111/j.1365-2788.2011.01418.x

Tuvblad, C., Baker, L.A., 2011. Human aggression across the lifespan. Genetic propensities and environmental moderators, 1st ed, Advances in Genetics. Elsevier Inc. DOI:10.1016/B978-0-12-3808585.00007-1

Tzeng, S.F., Deibler, G.E., DeVries, G.H., 1999. Myelin basic protein and myelin basic protein peptides induce the proliferation of Schwann cells via ganglioside GM1 and the FGF receptor. Neurochem. Res. 24, 255-260. DOI:10.1023/A:1022514105129

Van Bockstaele, E.J., Colago, E.E.O., Valentino, R.J., 1998. Amygdaloid corticotropin-releasing factor targets locus coeruleus dendrites: Substrate for the co-ordination of emotional and cognitive limbs of the stress response. J. Neuroendocrinol. 10, 743-758. DOI:10.1046/j.1365-2826.1998.00254.x

Van Voorhees, E.E., Dennis, P.A., Elbogen, E.B., Clancy, C.P., Hertzberg, M.A., Beckham, J.C., Calhoun, P.S., 2014. Personality assessment inventory internalizing and externalizing structure in veterans with posttraumatic stress disorder: Associations with aggression. Aggress. Behav. 40, 582-592. DOI:10.1002/ab.21554 
Vasa, R.A., Mazurek, M.O., Mahajan, R., Bennett, A.E., Bernal, M.P., Nozzolillo, A.A., Arnold, L.E., Coury, D.L., 2016. Assessment and treatment of anxiety in youth with Autism spectrum disorders. Pediatrics 137, S115-S123. DOI:10.1542/peds.2015-2851J

Veenema, A.H., 2009. Early life stress, the development of aggression and neuroendocrine and neurobiological correlates: What can we learn from animal models? Front. Neuroendocrinol. 30, 497-518. DOI:10.1016/j.yfrne.2009.03.003

Veenema, A.H., Blume, A., Niederle, D., Buwalda, B., Neumann, I.D., 2006. Effects of early life stress on adult male aggression and hypothalamic vasopressin and serotonin. Eur. J. Neurosci. 24, 1711-1720. DOI:10.1111/j.1460-9568.2006.05045.x

Veenema, A.H., Bredewold, R., Neumann, I.D., 2007. Opposite effects of maternal separation on intermale and maternal aggression in C57BL/6 mice: Link to hypothalamic vasopressin and oxytocin immunoreactivity. Psychoneuroendocrinology 32, 437-450. DOI:10.1016/j.psyneuen.2007.02.008

Vignisse, J., Sambon, M., Gorlova, A., Pavlov, D., Caron, N., Malgrange, B., Shevtsova, E., Svistunov, A., Anthony, D.C., Markova, N., Bazhenova, N., Coumans, B., Lakaye, B., Wins, P., Strekalova, T., Bettendorff, L., 2017. Thiamine and benfotiamine prevent stress-induced suppression of hippocampal neurogenesis in mice exposed to predation without affecting brain thiamine diphosphate levels. Mol. Cell. Neurosci. 82, 126-136. DOI:10.1016/j.mcn.2017.05.005

Vinson, M., Strijbos, P.J.L.M., Rowles, A., Facci, L., Moore, S.E., Simmons, D.L., Walsh, F.S., 2001. Myelin-associated glycoprotein interacts with ganglioside GT1b. A mechanism for neurite outgrowth inhibition. J. Biol. Chem. 276, 20280-20285. DOI:10.1074/jbc.M100345200

Virkkunen, M., Goldman, D., Nielsen, D.A., Linnoila, M., 1995. Low brain serotonin turnover rate (low CSF 5-HIAA) and impulsive violence. J. Psychiatry Neurosci. 20, 271-275.

Virkkunen, M., Nuutila, A., Goodwin, F.K., Linnoila, M., 1987. Cerebrospinal Fluid Monoamine Metabolite Levels in Male Arsonists. 
Arch.

Gen. Psychiatry

44 ,

$241-247$.

DOI:10.1001/archpsyc.1987.01800150053007

Vukhac, K.L., Sankoorikal, E.B., Wang, Y., 2001. Dopamine D2L receptor- and age-related reduction in offensive aggression. Neuroreport 12, 1035-1038. DOI:10.1097/00001756-200104170-00034

Walton, M.E., Croxson, P.L., Behrens, T.E.J., Kennerley, S.W., Rushworth, M.F.S., 2007. Adaptive decision making and value in the anterior cingulate cortex. Neuroimage 36, 142-154. DOI:10.1016/j.neuroimage.2007.03.029

Weinshenker, D., 2008. Functional Consequences of Locus Coeruleus Degeneration in Alzheimers Disease. Curr. Alzheimer Res. 5, 342-345. DOI:10.2174/156720508784533286

Weissenberger, S., Ptacek, R., Klicperova-Baker, M., Erman, A., Schonova, K., Raboch, J., Goetz, M., 2017. ADHD, lifestyles and comorbidities: A call for an holistic perspective - From medical to societal intervening factors. Front. Psychol. 8, 1-13. DOI:10.3389/fpsyg.2017.00454

Winstanley, C.A., 2007. The orbitofrontal cortex, impulsivity, and addiction. Ann. N. Y. Acad. Sci. 1121, 639-655. DOI:10.1196/annals.1401.024

Wirleitner, B., Neurauter, G., Schrocksnadel, K., Frick, B., Fuchs, D., 2005. Interferon-\&\#947;-Induced Conversion of Tryptophan: Immunologic and Neuropsychiatric Aspects. Curr. Med. Chem. 10, 15811591. DOI:10.2174/0929867033457179

Witt, S.N., 2010. Hsp70 molecular chaperons and Parkinson's disease. Biopolymers 93, 218-228. DOI:10.1002/bip.21302

Yamamoto, T., Ueki, S., 1977. Characteristics in aggressive behavior induced by midbrain raphe lesions in rats. Physiol. Behav. 19, 105-110. DOI:10.1016/0031-9384(77)90166-4

Yang, Y., Boza-Serrano, A., Dunning, C.J.R., Clausen, B.H., Lambertsen, K.L., Deierborg, T., 2018. Inflammation leads to distinct populations of extracellular vesicles from microglia. J. Neuroinflammation 15, 1-19. DOI:10.1186/s12974-018-1204-7 
Yanguas-casás, N., Ojalvo-sanz, A.C., Martínez-vázquez, A., Goneau, M., Gilbert, M., Nieto-sampedro, M., Romero-ramírez, L., 2019. Neurostatin and other $\mathrm{O}$-acetylated gangliosides show anti- neuroin $\mathrm{fl}$ ammatory activity involving the NF $\kappa$ B pathway. Toxicol. Appl. Pharmacol. 377, 114627. DOI:10.1016/j.taap.2019.114627

Ye, P., Carson, J., D’Ercole, A.J., 1995. Insulin-like growth factor-I influences the initiation of myelination: studies of the anterior commissure of transgenic mice. Neurosci. Lett. 201, 235-238. DOI:10.1016/0304-3940(95)12194-3

Yu, R., Topiwala, A., Jacoby, R., Fazel, S., 2019. Aggressive Behaviors in Alzheimer Disease and Mild Cognitive Impairment: Systematic Review and Meta-Analysis. Am. J. Geriatr. Psychiatry 27, 290300. DOI:10.1016/j.jagp.2018.10.008

Yuan, J., Amin, P., Ofengeim, D., 2019. Necroptosis and RIPK1mediated neuroinflammation in CNS diseases. Nat. Rev. Neurosci. 20, 19-33. DOI:10.1038/s41583-018-0093-1

Zhang, F., Wang, S., Gan, L., Vosler, P.S., Gao, Y., Zigmond, M.J., Chen, J., 2011. Protective effects and mechanisms of sirtuins in the nervous system. Prog. Neurobiol. 95, 373-395. DOI:10.1016/j.pneurobio.2011.09.001

Zhang, Y., Anoopkumar-Dukie, S., Arora, D., Davey, A.K., 2020. Review of the anti-inflammatory effect of SIRT1 and SIRT2 modulators on neurodegenerative diseases. Eur. J. Pharmacol. 867. DOI:10.1016/j.ejphar.2019.172847

Zhao, Y., Liang, X., Zhu, F., Wen, Y., Xu, J., Yang, J., Ding, M., Cheng, B., Ma, M., Zhang, L., Cheng, S., Wu, C., Wang, S., Wang, X., Ning, Y., Guo, X., Zhang, F., 2018. A large-scale integrative analysis of GWAS and common meQTLs across whole life course identifies genes, pathways and tissue/cell types for three major psychiatric disorders. Neurosci. Biobehav. Rev. 95, 347-352. DOI:10.1016/j.neubiorev.2018.10.005 


\section{CHAPTER}

\section{Altered behaviour, dopamine and norepinephrine regulation in stressed mice heterozygous in Tph2 gene}

Evgeniy Svirin ${ }^{a, b, c, 1}$, Tatyana Strekalova $a^{a, b, c, 1,2}$, Jonas Waider ${ }^{c}$, Anna Gorlova ${ }^{\mathrm{a}, \mathrm{b}}$, Raymond Cespuglio ${ }^{\mathrm{b}, \mathrm{d}}$, Allan Kalueffe, ${ }^{\mathrm{e}, \mathrm{g}}$, Igor Pomytkin ${ }^{\mathrm{h}}$, Angelika G. Schmitt-Boehrer ${ }^{c}$, Klaus-Peter Lesch ${ }^{\mathrm{a}, \mathrm{b}, \mathrm{c}}$, Daniel C. Anthony ${ }^{\mathrm{b}, \mathrm{i}, 2}$

Prog. Neuro-Psychopharmacology Biol. Psychiatry, 2020 DOI: 10.1016/j.pnpbp.2020.110155

a Department of Psychiatry and Neuropsychology, Maastricht University, Maastricht, the Netherlands

${ }^{b}$ Laboratory of Psychiatric Neurobiology, Institute of Molecular Medicine, I.M. Sechenov First Moscow State Medical University, Moscow, Russia

${ }^{c}$ Division of Molecular Psychiatry, Centre of Mental Health, University of Würzburg, Würzburg, Germany

${ }^{\mathrm{d}}$ Neurocampus Michel Jouvet, VELIB Plateau, Claude-Bernard Lyon-1 University, Lyon, France

${ }^{\mathrm{e}}$ Laboratory of Cell and Molecular Biology and Neurobiology, Moscow Institute of Physics and Technology, Dolgoprudny, Russia

${ }^{f}$ Institute of Translational Biomedicine, St. Petersburg State, University, St. Petersburg, Russia

${ }^{9}$ Ural Federal University, Ekaterinburg, Russia

${ }^{\mathrm{h}}$ Center for Advanced Cell Technologies, Institute of Regenerative Medicine, I.M. Sechenov First Moscow State Medical University, Moscow, Russia i Department of Pharmacology, Oxford University, Oxford, United Kingdom

${ }^{1}$ Joint first authorship ${ }^{2}$ Joint corresponding authors 


\title{
Chapter 2. Altered behaviour, dopamine and norepinephrine regulation in stressed mice heterozygous in Tph2 gene
}

\begin{abstract}
Gene-environment interaction $(\mathrm{G} \times \mathrm{E})$ determines the vulnerability of an individual to a spectrum of stress-related neuropsychiatric disorders. Increased impulsivity, excessive aggression, and other behavioural characteristics are associated with variants within the tryptophan hydroxylase-2 (Tph2) gene, a key enzyme in brain serotonin synthesis. This phenotype is recapitulated in naïve mice with complete, but not with partial Tph2 inactivation. Tph2 haploinsufficiency in animals reflects allelic variation of Tph2 facilitating the elucidation of respective $\mathrm{G} \times \mathrm{E}$ mechanisms. Recently, we showed excessive aggression and altered serotonin brain metabolism in heterozygous Tph2-deficient male mice $\left(T p h 2^{+/}\right)$after predator stress exposure. Here, we sought to extend these studies by investigating aggressive and anxiety-like behaviours, sociability, and brain metabolism of dopamine and noradrenaline. Separately, $T p h 2^{+/-}$mice were examined for exploration activity in a novel environment and for the potentiation of helplessness in the modified swim test (ModFST). Predation stress procedure increased measures of aggression, dominancy, and suppressed sociability in $T p h 2^{+/-}$mice, which was the opposite of that observed in control mice. Anxiety-like behaviour was unaltered in the mutants and elevated in controls. Tph $2^{+/-}$mice exposed to environmental novelty or to the ModFST exhibited increased novelty exploration and no increase in


floating behaviour compared to controls, which is suggestive of resilience to stress and despair. High-performance liquid chromatography (HPLC) revealed significant genotype-dependent differences in the metabolism of dopamine and norepinephrine within the brain tissue. In conclusion, environmentally challenged $\mathrm{Tph}^{+/-}$mice exhibit behaviours that resemble the behaviour of non-stressed null mutants, which reveals how GxE interaction studies can unmask latent genetically determined predispositions.

Keywords: Tryptophan hydroxylase-2 (TPH2), Aggression, Dopamine, Noradrenaline, Stress, Mouse

\section{Introduction}

Pathological aggression is a common feature of many neuropsychiatric diseases (Van Voorhees et al., 2014; Yu et al., 2019; Kunik et al., 2020; Slaughter et al., 2020). Aggression is also associated with a higher incidence of suicide attempts (Dumais et al., 2005; Conejero et al., 2019; Reich et al., 2019). Moreover, as a consequence of the ongoing COVID-19 pandemic, the incidence of mental disorders is expected to rise, as levels of stress, anxiety, aggression and depression increase, both through direct cases of viral illness and through negative social and economic consequences (Chaturvedi, 2020; Wind et al., 2020). Yet, excessive aggression is currently treated in conjunction with other psychiatric disorders using non-specific drugs with serious side effects, such general sedation, dizziness and rebound effect (Lane et al., 2011; Zaman et al., 2018). 
The unmet medical need for therapy for aggression requires the development of improved animal models of excessive aggression. Recent genome-wide association studies suggest that there is greater variability in the genetic mechanisms thought to underpin neuropsychiatric disorders in comparison to neurological diseases (Lee et al., 2019), which further support the need to better understand the role of gene $\mathrm{x}$ environment interaction in psychiatric pathologies (Lesch, 2005; Lesch and Mössner, 2006). The majority of the translational studies performed to date have employed either conventional laboratory animals that have been exposed to a stressor, e.g., predation (Costa-Nunes et al., 2014; Strekalova et al., 2015), social defeat (Patki et al., 2013), maternal separation (Auth et al., 2018; Kiser et al., 2018; Veenema et al., 2007; Weidner et al., 2019), ultrasound (Gorlova et al., 2019; Pavlov et al., 2019) and others (Mineur et al., 2003; Malki et al., 2016), or they have used naïve genetically manipulated mice and rats (Nelson and Chiavegatto, 2001; Manchia et al., 2017).

Recently, we proposed a new aggression paradigm in which the contribution of gene $x$ environment interaction in the mechanisms of pathological aggression is modelled in heterozygous $\left(T p h 2^{+/}\right)$mice by a five-day rat exposure (Gorlova et al., 2020). The interaction of the Tph2 $2^{+-}$ genotype and stress had also been explored in earlier studies of Gutknecht et al. (2012) and Weidner et al. (2019). Behavioural trends seemed to be present, but they were not significant, which was felt likely to be a consequence of the mild chronic stress paradigm and maternal separation that were employed. Conceptually, the stress studies with the 
$\mathrm{Tph}^{+/-}$mutants were based on the reported relationships between single nucleotide polymorphisms (SNPs) in the TPH2 gene e.g., rs1843809, rs4570625, and rs6582071 and psychiatric symptoms of excessive aggression (Oades et al., 2008; Perez-Rodriguez et al., 2010; Plemenita`s et al., 2015; Laas et al., 2017), personality disorder (Perez- Rodriguez et al., 2010), negative emotionality (Lesch et al., 2012), depression (Wigner et al., 2018), mood disorder and suicidality (Ottenhof et al., 2018). Importantly, the incidence of these associations can be increased by a history of life stressors (Forssman et al., 2014; Xu et al., 2016).

While naive mice with a complete inactivation of Tph2 gene $\left(T p h 2^{-/-}\right)$recapitulate many symptoms related to SNPs of the Tph2 gene, showing increased aggression, decreased sociability (Angoa-Perez et al., 2012; Weidner et al., 2019; Lieb et al., 2019), hyperactivity, impulsive and compulsive behaviours (Jia et al., 2014; Angoa-Perez et al., 2012; Waider et al., 2017) and enhanced fear learning (Lesch et al., 2012; Gutknecht et al., 2015; Waider et al., 2019), but also signs of stress resilience, altered depressive-like behaviour, decreased anxiety and increased neurogenesis (Savelieva et al., 2008; Jia et al., 2014; Gutknecht et al., 2012, 2015; Zhang et al., 2018; Weidner et al., 2019); these changes were not found in unchallenged $\mathrm{Tph}^{+/-}$mice. However, in $\mathrm{Tph} 2^{+/-}$mice, predation stress elicits excessive aggressiveness with pathological behavioural patterns of impulsive aggression, as well as changes of the brain concentrations of serotonin, its precursor hydroxytryptophan, and its metabolite 5hydroxyindoleacetic acid, which were studied in different regions of the brain (Gorlova et al., 2020). Remarkably, behavioural changes in mutants 
were found to be the opposite to those found in $T p h 2^{+/+}$mice exposed to the predation, i.e., males and females on a C57BL/6 J background display a decrease in aggressive and dominant behaviours in response to predation (Gorlova et al., 2020). As such, the use of predation stress model in $\mathrm{Tph}^{+/-}$mice offers a promising model to explore the neurobiology of pathological aggression. In this paradigm, the stressed mutants have been shown to have altered measures of plasticity compared to the controls (Gorlova et al., 2020). These results are in keeping with other molecular abnormalities found in the $T p h 2^{+/-}$mice subjected to a maternal separation, where the stressed mutants exhibited altered brain expression of the sodium-dependent serotonin transporter (Lieb et al., 2019) and changes in the DNA methylation of cholecystokinin receptor (Weidner et al., 2019).

Here, we sought to extend our studies with the $T p h 2^{+/-}$mice exposed to stress in order to examine how other endpoints are altered following environmental challenges. In particular, we were keen to understand how the gene $\mathrm{x}$ environment interactions affect the levels of the monoamines dopamine (DA) and norepinephrine (NE), whose role in aggression is well established in a clinical context (Comai et al., 2012) and in animal studies (Hutchins and Pearson, 1975; Lewis et al., 1994; Adamczyk et al., 2012). We also sought to discover what other behaviours would be affected by the $T p h 2^{+/-}$genotype in response to predation stress or to other environmental challenges including exposure to a novel environment and to a modified forced swim test (modFST), which is known to induce helplessness in mice (Strekalova et al., 2016). 
Here, we found increased aggression and dominancy, and suppressed sociability in the $T p h 2^{+/-}$mice that were exposed to a predation stress procedure. In response to stress, anxiety-like behaviours were only observed in the WT mice, but not in the $T p h 2^{+/-}$. These behaviours were associated with significant genotype-dependent differences in the concentrations of DA and NE and of their metabolites 3,4-dihydroxyphenylacetic acid (DOPAC) and 3-methoxy-4hydroxyphenylglycol (MHPG), respectively, as well as DA and NE turnover rates. Tph2 $2^{+-}$mice challenged with a novel environment exhibited increased vertical exploratory activity, and, in the ModFST, they exhibited no floating behaviour potentiation, suggesting the presence of a behavioural resilience to stress. Thus, stressed $T p h 2^{+/-}$ mutants display a behavioural profile that resembles that of unstressed

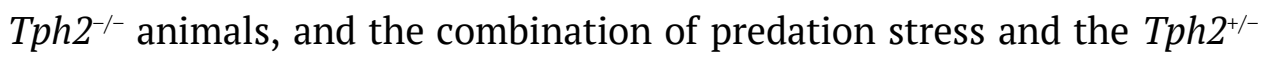
genotype presents itself as a promising model of excessive human aggression induced by changing environmental conditions.

\section{Materials and methods}

\subsection{Animals}

We used 10-12-week-old male $T p h 2^{+/-}$mice, and their wild-type littermates $\left(T p h 2^{+/+}\right)$as controls, which were bred and genotyped in the facilities of the University of Würzburg (Gutknecht et al., 2015). 12week-old male CD1 mice were used as intruders for a resident-intruder test and 2-to-5-month-old male Wistar rats (Charles River, Janvier, France) were used for the predator stress. $T p h 2^{+/-}$and $T p h 2^{+/+}$littermates 
were housed individually, while CD1 mice and rats were housed in groups of five. Animals were kept under controlled laboratory conditions $(22 \pm 1$ -C, 55\% humidity, food and water ad libitum, lights on: 21:00 h). Studies were carried out in accordance with the European Communities Council Directive for the care and use of laboratory animals (permission issued by Ethical Committee of C. Bernard University of Lyon).

\subsection{Study outline}

Two cohorts of animals (Fig. 1A\&B) were exposed predation stress in which $\mathrm{Tph}^{+/-}$mutants, and littermate controls, were subjected to a daily rat-exposure stress for 5 days (Costa-Nunes et al., 2014, Vignisse et al., 2017; see below). The groups of mice were balanced according to their body weight, and for latency to attack in a baseline resident-intruder test (Couch et al., 2016; Strekalova et al., 2018). Beginning $24 \mathrm{~h}$ after the end of the predation stress procedure, the first set of animals were tested in the elevated O-maze (day 6), dark/light box (day 6), and, on days 6-10, in a resident-intruder test, with $3 \mathrm{~h}$ inter-test intervals (see below, Fig. 1A). In the second cohort, $24 \mathrm{~h}$ after the end of the last predator stress session, the mice were killed and their brains were isolated and dissected (seebelow) for subsequent HPLC tissue assay (see below, Fig. 1B). An additional cohort of $T p h 2^{+/-}$mutants and their littermate $T p h 2^{+/+}$control mice were subjected to a novel cage testand to the modified swim test (Fig. 1C). In each part of the experiment, an average of seven to ten mice per group were used (group sizes are indicated in Figure legends). 


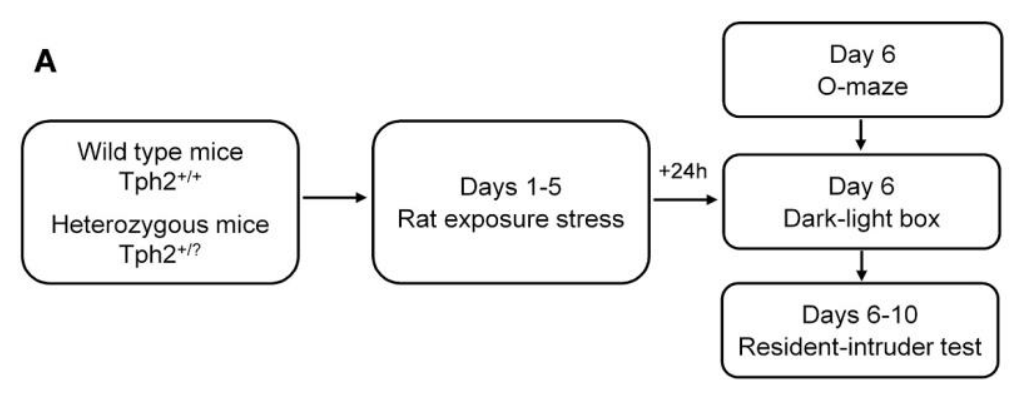

B
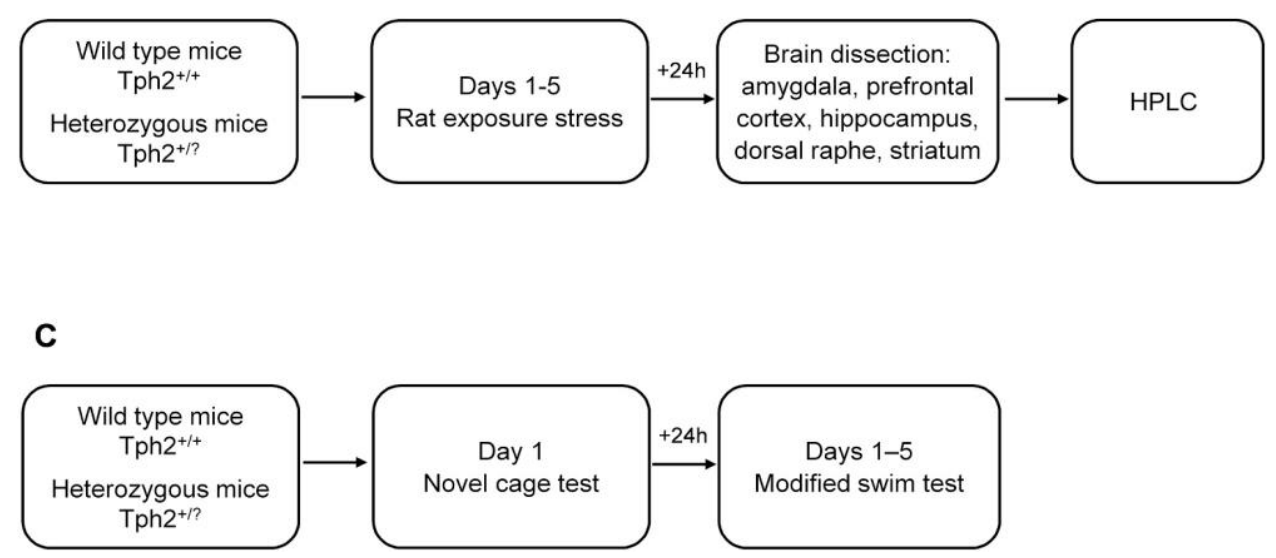

Fig. 1. Experiment design. $T p h 2^{+/+}$and $T p h 2^{+/-}$mice were subjected to rat exposure stress for 5 consecutive nights, and $24 \mathrm{~h}$ after last stress session both groups were (A) studied in a battery of behavioural tests or (B) killed and brains were dissected for HPLC study. (C) Naïve $T p h 2^{+/+}$and $T p h 2^{+/-}$mice were studied for 5 consecutive days in novel cage test and modified swim test.

\subsection{Predation stress}

Mice were introduced into a spacious transparent glass cylinder (15 cm high x $8 \mathrm{~cm}$ diameter) and placed into the rat cage as described elsewhere (Costa-Nunes et al., 2014; Vignisse et al., 2017; Gorlova et al., 2020). A 15-h long exposure was performed between 18:00 and 9:00 for five consecutive nights. Mice had free access to food and water in their home cages between the stress sessions. The timing of the rat exposure 
model was designed to minimize the impact of food and water deprivation, as the predation period overlaps with the light (inactive) phase of activity of the mice when food and water consumption is minimal. While there is no doubt that food and water deprivation during this period might add to the stress, our earlier studies, with another version of this stress model, revealed that if food and water is made available during the predation stress the $\mathrm{C} 57 / \mathrm{Bl} 6$ mice do not consume it (Strekalova et al., 2004; Strekalova and Steinbusch, 2009, 2010). Thus, while the environment undoubtedly results in a mixture of stresses, the principal stress is based on the fear of predation. 2.4. O-maze test The Omaze apparatus (Technoplast, Rome, Italy) consisted of a circular path (runway width $5.5 \mathrm{~cm}$, diameter $46 \mathrm{~cm}$ ) placed $50 \mathrm{~cm}$ above the floor. Two opposing arms were protected by walls (height $10 \mathrm{~cm}$ ), and the illumination strength was 25 Lux. Anxiety-like behaviour was assessed using previously validated parameters as described elsewhere (Couch et al., 2016; Costa-Nunes et al., 2020). Mice were placed in one of the closed arm compartments of the maze. Total duration of time spent in the open arms of the maze and the number of visits to the open arms were scored as established measures of anxiety-like behaviour during the first $5 \mathrm{~min}$ period.

\subsection{Dark/light box test}

At the start, mice were placed into the dark compartment $(15 \mathrm{~cm} \mathrm{x}$ $20 \mathrm{~cm} \times 25 \mathrm{~cm}$ ) of the box from where they could visit the lit box $(30 \mathrm{~cm} \mathrm{x}$ $20 \mathrm{~cm}$ x $25 \mathrm{~cm}$, Technoplast, Rome, Italy). The time spent by the mice in the lit part of the box, which was set to 25 Lux on the floor of the 
apparatus, was recorded overt a 5-min period, as described elsewhere (Costa-Nunes et al., 2014; Strekalova et al., 2018).

\subsection{Resident-intruder test}

The resident-intruder test procedure was carried out on five consecutive days (Strekalova et al., 2004, 2018; Costa-Nunes et al., 2014; Gorlova et al., 2020). Mice were placed individually in an observation cage $(30 \mathrm{~cm} \times 60 \mathrm{~cm} \times 30 \mathrm{~cm})$ for $30 \mathrm{~min}$, after which a CD1 mouse was introduced. During the next $4 \mathrm{~min}$, mice were separated by a transparent wall with holes it is, which was removed for the following 4-min-long period. Latency to attack and the duration of attacks were recorded. In addition, measures of neutral social exploration were evaluated; the latency to contact and the number of nose/anal and nose/nose contacts were recorded as described elsewhere (Couch et al., 2016; Veniaminova et al., 2017).

\subsection{Novel cage test}

A 5-min long novel cage test was carried out to assess exploration in a new environment as described elsewhere (Strekalova et al., 2004; Couch et al., 2016; Veniaminova et al., 2020). Mice were introduced into a standard plastic cage $(21 \mathrm{~cm} \times 21 \mathrm{~cm} \times 15 \mathrm{~cm})$ filled with fresh sawdust. The number of exploratory rears was counted in white light for $5 \mathrm{~min}$; the strength of illumination was set to $25 \mathrm{Lux}$. 
2.8. The modified swim test to assess helplessness

Mice were subjected to two swimming sessions with an interval of $24 \mathrm{~h}$. After the first two swim session a third swim session was carried out on day 5 as previously described (Strekalova et al., 2016; Pavlov et al., 2017, 2020). All sessions were 6-min long and were performed by placing a mouse in a transparent cylinder $(\emptyset 17 \mathrm{~cm})$ filled with water $\left(+23^{\circ} \mathrm{C}\right.$, water height $13 \mathrm{~cm}$, height of cylinder $20 \mathrm{~cm}$ ). The duration of floating behaviour that was defined as the absence of any directed movements of the head or body, which was scored by an observer unaware of the identity of the animal with Noldus EthoVision XT 8.5 (Noldus Information Technology, Wageningen, The Netherlands) as described elsewhere (Malatynska et al., 2012). It is of note that the increase in floating behaviour, which is observed on day 5 compared to day 2, is reversible by pre-treatment common antidepressant compounds (Markova et al., 2017). For this reason, the increase in day 5 floating is regarded as a measure of learning in an adverse context and helplessness (Pavlov et al., 2017, 2020).

\subsection{Tissue collection}

Mice were terminally anaesthetized with an intraperitoneal injection of sodium pentobarbitone. The left ventricle was perfused with $10 \mathrm{ml}$ of ice-cold saline and the brains were removed an dissected (Couch et al., 2013). The prefrontal cortex, striatum, amygdala, hippocampus and dorsal raphe were isolated and stored at $-80^{\circ} \mathrm{C}$ as described elsewhere (Gorlova et al., 2020). Selected brain structures were 
microdissected using Paxinos atlas as a guide (Paxinos and Franklin, 2001). As the HPLC method requires a substantial amount of tissue, all brain structures were analysed as a whole.

2.10. High-performance liquid chromatography (HPLC) tissue assay

The concentrations of dopamine, norepinephrine, and their metabolites 3,4-dihydroxyphenylacetic acid (DOPAC) and 3-methoxy-4hydroxyphenylglycol (MHPG), respectively, were measured in the parts of the brain mentioned above using HPLC with electrochemical detection using the method of Waider et al. (2017). Dopamine turnover was calculated as a ratio of DOPAC/DA, and norepinephrine turnover was calculated as MHPG/NE. 2.11. Statistical analysis Data were analysed using GraphPad Prism v.8.3.0 for Windows (San Diego, CA). Three-way, or two-way, or repeated measures ANOVA were employed followed by post-hoc testing were appropriate. For the two-group comparisons in the novel cage test and modFST, unpaired $t$-test were used. The level of confidence was set at 95\% $(p<0.05)$. For non-parametric data $(\mathrm{O}$-maze exits) a Kruskal-Wallis rank sum test was performed with post-hoc pairwise comparisons using Wilcoxon rank sum test.

\section{Results}

\subsection{Increased aggressive behaviour in stressed $T p h 2^{+/-}$mice}

A three-way ANOVA revealed that there was no interaction between predator stress, genotype, and the day of testing for the latency to attack in the resident-intruder test $(\mathrm{F} 1,21=0.095 ; p=0.76)$, There was 
also no significant interaction between stress and the day was present independent of genotype (F1,46 $<0.01, p=0.89$, two-way ANOVA). However, a significant interaction, independent of day, was found between predator stress and genotype (F1, $46=17.44, p<0.01$, two-way ANOVA). Post hoc analysis revealed that there was a significantly shorter latency to attack in the stressed $T p h 2^{+/-}$group than in either the nonstressed $T p h 2^{+/-}$or the stressed $T p h 2^{+/+}$mice (both $\mathrm{p}<0.01$, Sidak's test). A significant day $\times$ genotype interaction, independent of predator stress, was also present ( $\mathrm{F} 1,23=6.215, p=0.02$, two-way ANOVA). Sidak's posthoc testing revealed that significant decrease in the latency to attack on the day 5 in $T p h 2^{+/-}$group compared to day 1 (p $<0.01$; Fig. $\left.2 \mathrm{~A}\right)$.

Total duration of attacks was found to be dependent on an interaction between predator stress, genotype, and the day of testing as revealed by a three-way ANOVA $(\mathrm{F} 1,21=5.046, p=0.04)$. Post hoc analysis showed that stress increased the duration of attacks in the $\mathrm{Tph}^{+/-}$animals on days 1 and 5 compared to non-stressed $\mathrm{Tph}^{+/-}$animals or the stressed $\mathrm{Tph}^{+/+}$animals (all $\mathrm{p}<0.01$, Bonferroni test). In the mutant mice the duration of attacks was higher on day 5 than on day 1 ( $p$ $=0.01$; Fig. $2 \mathrm{~B}$ ). Thus, predator stress appears to have the opposite effect on the duration of attacks in the Tph2 $2^{++}$animals subjected to.

\subsection{Stressed $\mathrm{Tph}^{+/-}$mice display a decrease of neutral social exploration}

Both latency and number of nose/anal contacts were dependent on a stress, genotype and the day of testing (F1,21 $=7.06, p=0.015$ and $\mathrm{F} 1,20=12.13, \mathrm{p}<0.01$, respectively, three-way ANOVA). Post hoc testing revealed a significant increase in the latency to nose/anal contact on day 
5 in stressed $\mathrm{Tph}^{+/-}$animals in comparison to stressed $T p h 2^{+/+}$animals and to the non-stressed Tph2 $2^{+-}$animals on the same day $(p=0.03$ and $\mathrm{p}=$ 0.04, respectively, Bonferroni test) and in comparison to stressed $T p h 2^{+/}$ on day 1 ( $p=0.02$; Fig. $2 \mathrm{C}$ ). On day 5 , stress significantly reduced the number of nose/anal contacts in the stressed $T p h 2^{+/-}$compared to the stressed $T p h 2^{+/+}$animals $(p<0.01)$, while in $T p h 2^{+/+}$mice stress increased the number of contacts $(\mathrm{p}=0.04)$.

Three-way ANOVA also showed the presence of an interaction between stress, genotype, and the day for both latency to nose/nose contact and the total number of nose/nose contacts $(\mathrm{F} 1,20=6.23, p=$ 0.02 and $\mathrm{F} 1,21=13.46, p<0.01$, respectively). On day 5 , the latency to a nose/nose contact was significantly longer in the predator stressed

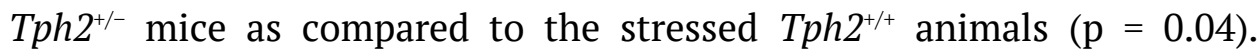
Number of nose/nose contacts was significantly elevated in the stressed Tph $2^{+/+}$animals from day 1 to day $5(p<0.01)$, which was not observed in the $T p h 2^{+/-}$animals. 


\section{Resident-intruder test}
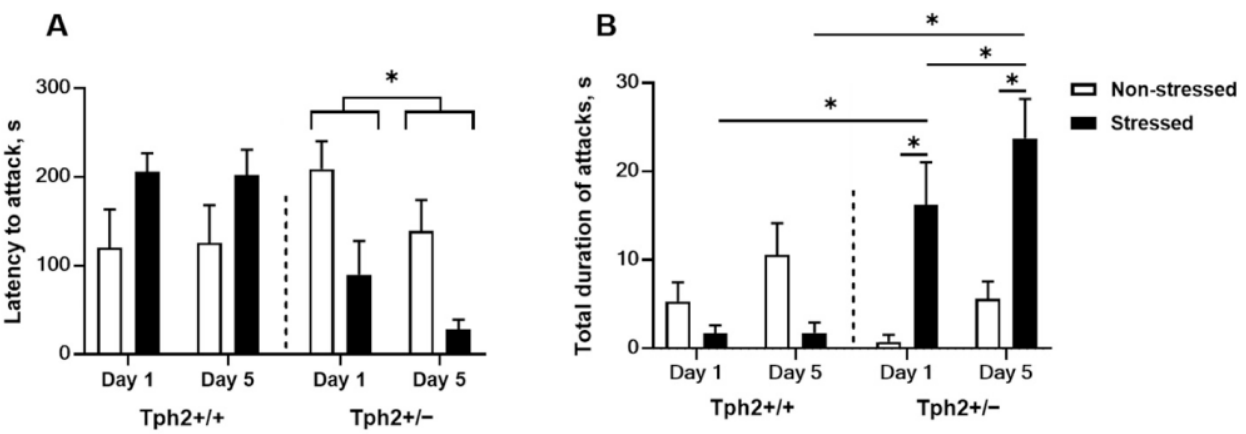

Neutral social exploration
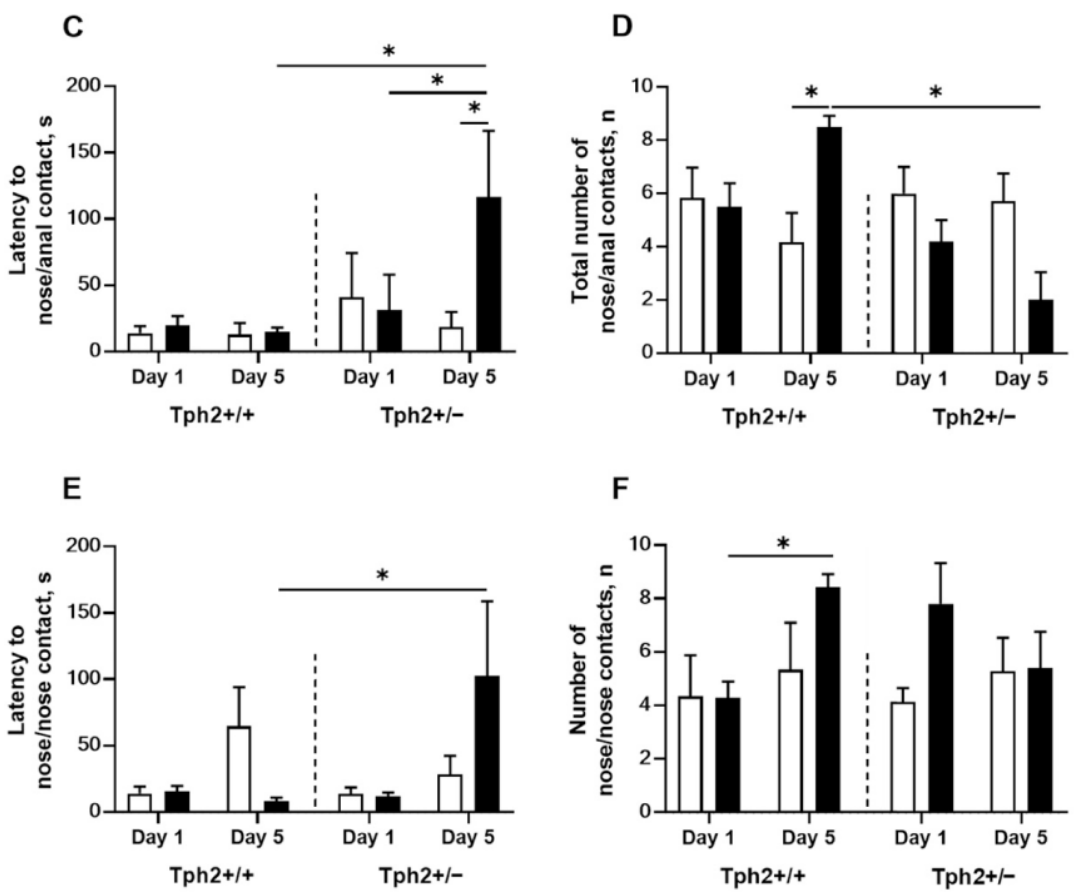

Fig. 2. Opposing effects of predator stress on aggressive behaviour on $\mathrm{Tph2}^{+++}$and $\mathrm{Tph2}^{+/-}$mice. (A) In the resident-intruder test, $\mathrm{Tph2}^{+/-}$showed significant decrease in latency to attack on day 5 compared to day 1. (B) On both day 1 and day 5 stressed $T p h 2^{+/-}$mice displayed a significant increase in duration of attacks in comparison to non-stressed $T p h 2^{+-}$and stressed $\mathrm{Tph}^{+/+}$groups on corresponding days. Total duration of attacks was longer on day 5 than on day 1 in Tph2 ${ }^{+/-}$animals. (C) Latency to nose/anal contact was significantly elevated in stressed $\mathrm{Tph}^{++-}$on day 5 in comparison to nonstressed $\mathrm{Tph2}^{+/-}$and stressed $\mathrm{Tph2}^{+++}$animals on the same day, and to 
stressed $\mathrm{Tph}^{+/-}$on day 1. (D) Number of nose/anal contacts was significantly increased on day 5 in stressed $T p h 2^{+/+}$mice compare to stressed $\mathrm{Tph}^{+/-}$mice on the same day and to stressed $\mathrm{Tph}^{+/+}$mice on day 1 . (E) Latency to nose/ nose contact was significantly higher in stressed $T p h 2^{+/-}$ mice on day 5 than in stressed $T p h 2^{+/+}$group on the same day. (F) In stressed $\mathrm{Tph}^{+/+}$number of nose/nose contacts was significantly higher on day 5 than on day 1. ${ }^{*} p<0.05$, repeated measures three-way ANOVA and post hoc Bonferroni's test or Sidak's tests (see the text). 5-7 animals per group were used. Bars represent Mean \pm SEM.

3.3. Anxiety-like behaviour after stress exposure does not alter in Tph2 $2^{+/-}$ mice

In the elevated O-maze, using Kruskal-Wallis rank sum test it was found that there was an interaction between the genotype and stress (chi-squared $=11.932, \mathrm{df}=3, p$-value $=0.0076)$. Subsequent pairwise comparisons using Wilcoxon rank sum test revealed that there were significant differences between the stressed $T p h 2^{+/+}$group and both the Tph2 $2^{+-}$stressed $(p=0.030)$ and non-stressed animals $(p=0.026)$. Stressed $\mathrm{Tph}^{+/-}$mice displayed shorter latency to exit to an open arm than nonstressed $\operatorname{Tph}^{+/-}(\mathrm{p}=0.03$, Tukey's test, data not shown $)$. In stressed $\mathrm{Tph}^{+/+}$animals the number of exits was significantly lower in comparison to non-stressed controls ( $p=0.03$; Fig. 3A). The main effect of genotype, but not main stress effect or stress $\mathrm{x}$ genotype interaction was significant for the time spent the open arms of the $\mathrm{O}$-maze $(\mathrm{F} 1,20=6.12, \mathrm{p}=0.02$; $\mathrm{F} 1,20=1.55, p=0.23$ and F1.20 $=4.087, p=0.06$, respectively; Fig. 3B). Thus, in essence, $T p h 2^{+/-}$mice do not exhibit the anxiety-like behaviours that are observed in $\mathrm{Tph}^{+/+}$group in the elevated O-maze. 


\section{O-maze}

A

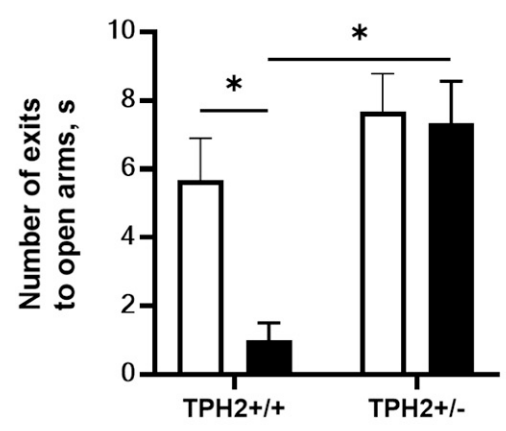

B

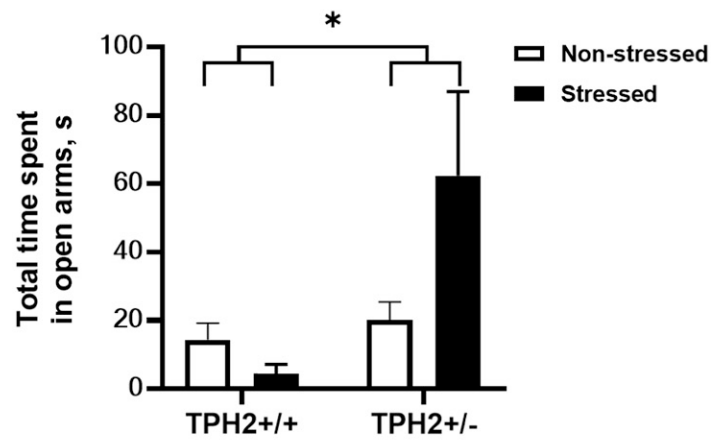

\section{Dark-light box}

C

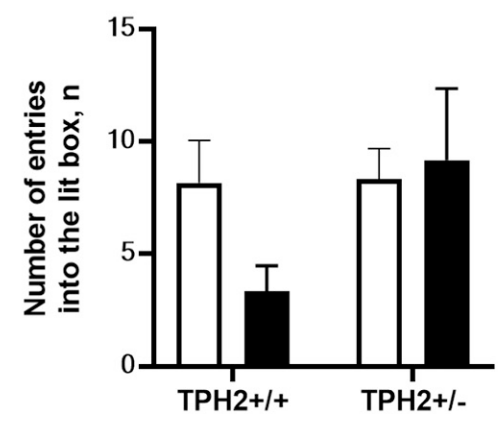

D

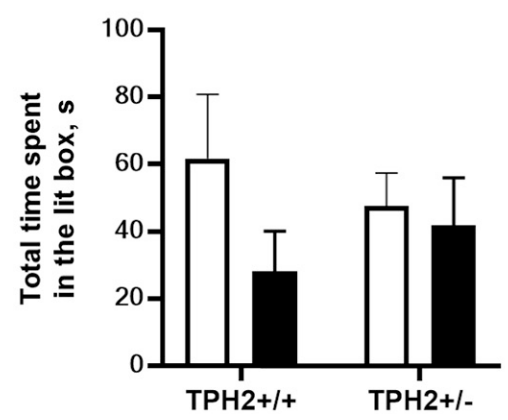

Fig. 3. Stress-induced increase in anxiety-like behaviour in $\mathrm{Tph} 2^{+/+}$, but not in $\mathrm{Tph}^{+/-}$mice. (A) In comparison to non-stressed $\mathrm{Tph}^{+/-}$, stressed $\mathrm{Tph}^{+/-}$ mice demonstrated significantly increased latency to exit to open arms of the O-maze, while (B) $\mathrm{Tph}^{+/-}$and $\mathrm{Tph}^{+/+}$mice differed significantly in time spent therein. No significant differences were found in (C) number of entries into the lit box in the dark-light box test and (D) time spent in the lit box. ${ }^{*} p$ $<0.05$, Kruskal- Wallis rank sum test and two-way ANOVA and post hoc Tukey's test (see the text). 7-9 animals per group were used. Bars represent Mean \pm SEM.

In the dark-light box test, no significant stress $\mathrm{x}$ genotype interaction was found for latency to entry into the lit box, number of entries and time spent in the lit box $(\mathrm{F} 1,20=0.027, p=0.87 ; \mathrm{F} 1,20=$ 
1.903, $p=0.18$ and F1,20 = 0.95, $p=0.34$, respectively; Fig. 3C,D), as well as no significant stress effects $(\mathrm{F} 1,20=1.56, \mathrm{p}=0.23 ; \mathrm{F} 1,20=0.95, \mathrm{p}=$ 0.34 and $\mathrm{F} 1,20=1.9, \mathrm{p}=0.18$, respectively; Fig. 3C,D) and no genotype effects $(\mathrm{F} 1,20=0.48, p=0.49 ; \mathrm{F} 1,20=2.13, p=0.16$ and $\mathrm{F} 1,20<0.01, p\rangle$ 0.99, respectively; Fig. 3C,D).

3.4. Stress-induced changes in dopamine metabolism in the brain of Tph2 $2^{+-}$ mice

The was a significant interaction between stress and genotype for the concentration of dopamine in the amygdala and prefrontal cortex, but not in hippocampus, dorsal raphe or striatum $(F 1,27=5.75, p=0.02$; $\mathrm{F} 1,28=8.41, \mathrm{p}<0.01 ; \mathrm{F} 1,28<0.01, \mathrm{p}=0.98 ; \mathrm{F} 1,27=0.04, \mathrm{p}=0.84$ and $\mathrm{F} 1,26=0.05, \mathrm{p}=0.82$, respectively, two-way ANOVA). In the hippocampus, dorsal raphe, and striatum the concentration of dopamine was significantly affected by stress $(F 1,28=28.58, \mathrm{p}<0.01 ; \mathrm{F} 1,27=5.08$, $\mathrm{p}=0.03$ and $\mathrm{F} 1,26=47.73, \mathrm{p}<0.01$, respectively). A post-hoc analysis revealed significantly lower concentrations of dopamine in the amygdala of the stressed $\mathrm{Tph}^{+/-}$mice in comparison to both the non-stressed $\mathrm{Tph}^{+/-}$and the stressed $\mathrm{Tph}^{+/+}$animals $(\mathrm{p}<0.01$ and $\mathrm{p}=0.02$, respectively Tukey's test. Fig. 4A). The concentration of dopamine in the prefrontal cortex was decreased in stressed $\mathrm{Tph} 2^{+/-}$mice compared to the non-stressed mutants ( $<<0.01$; Fig. 4D). Finally, the concentration of dopamine was lower in the stressed controls and mutants in comparison with non-stressed groups in the hippocampus (both $\mathrm{p}<0.01$, Tukey's test; Fig. 4G) and striatum (both $\mathrm{p}<0.01$; Fig. 4M). 
Amygdala
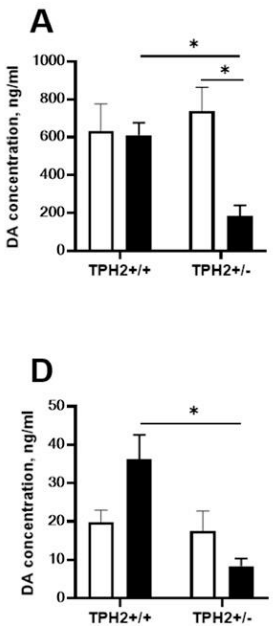

G

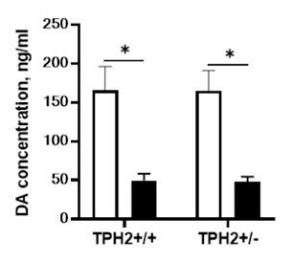

J

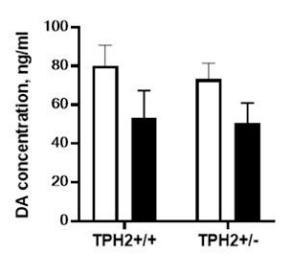

M

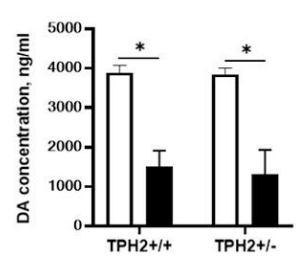

B

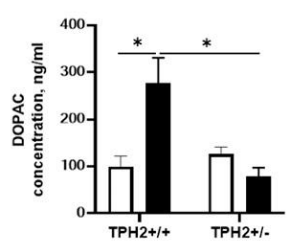

Prefrontal cortex

E

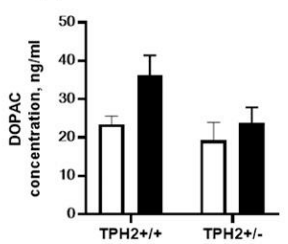

Hippocampus

$\mathrm{H}$

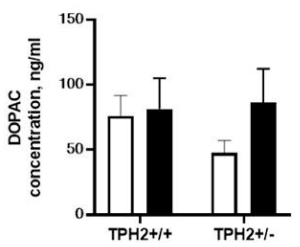

Dorsal raphe

K

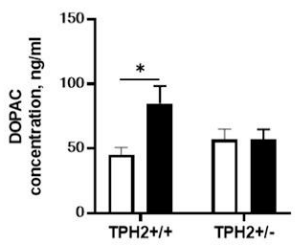

Striatum

N

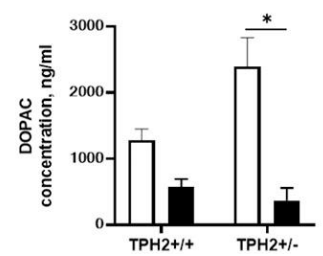

C

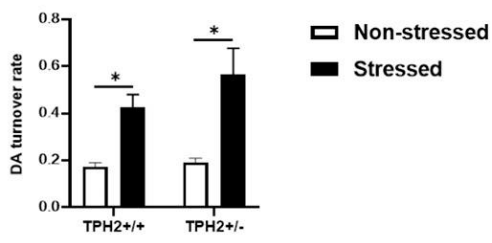

$F$

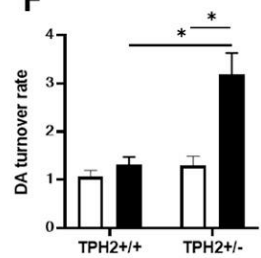

I

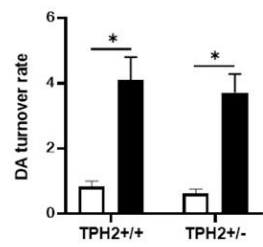

L

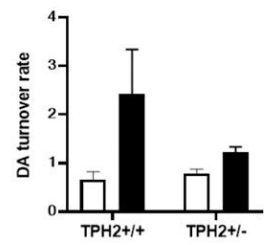

O

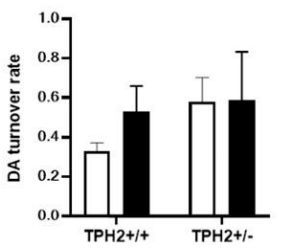

Fig. 4. Stress-induced alterations in concentrations of dopamine, its metabolite DOPAC, and dopamine turnover rate in $\mathrm{Tph}^{+/+}$and $\mathrm{Tph}^{+/-}$mice. (A) Dopamine concentration in the amygdala was significantly lower in 
stressed $\mathrm{Tph2}^{+/-}$mice in comparison to both stressed $\mathrm{Tph}^{+/+}$and nonstressed $\mathrm{Tph}^{+/-}$mice. (B) DOPAC concentration in the amygdala showed a significant increase in stressed $\mathrm{Tph}^{+/+}$mice compared to non-stressed $\mathrm{Tph2}^{+/+}$group and stressed $\mathrm{Tph2}^{+/-}$mice. (C) The dopamine turnover rate in the amygdala was significantly increased in stressed groups compared to non-stressed animals of the same genotype. (D) In the prefrontal cortex, dopamine concentration was significantly lower in stressed $\mathrm{Tph}^{+{ }^{+-}}$in comparison to stressed $\mathrm{Tph}^{+/+}$group. (E) No differences in the DOPAC concentration between groups were observed. (F) The dopamine turnover was significantly higher in stressed $T p h 2^{+/-}$mice compared to both nonstressed $\mathrm{Tph}^{+/-}$and stressed $T p h 2^{+/+}$animals. (G) In the hippocampus in both $\mathrm{Tph}^{+/+}$and $\mathrm{Tph}^{+/-}$significant decrease in dopamine concentration under stress condition was observed in comparison to non-stressed animals of the same genotype. (H) No significant differences between the groups were found in the DOPAC concentrations in the hippocampus. (I) Dopamine turnover rate in the hippocampus was higher in both stressed groups in comparison to non-stressed group of the same genotype. (J) Dopamine concentration in the dorsal raphe was not changed significantly between the groups. $(K)$ There was a significant increase in the DOPAC concentration in stressed compared to non-stressed $\mathrm{Tph}^{++/}$mice in the dorsal raphe, while $(L)$ no alterations were found in the dopamine turnover ratio. (M) In the striatum, dopamine concentration showed a significant decrease in stressed mice compared to non-stressed groups. (N) DOPAC concentration was significantly elevated in the striatum of non-stressed $\mathrm{Tph}^{\mathrm{H}^{+-}}$compared to stressed $\mathrm{Tph}^{+/-}$group. (0) No significant group differences were found in the dopamine turnover ratio in the striatum. ${ }^{*} p<0.05$, two-way ANOVA and post hoc Tukey's test. 7-9 animals per group were used. Bars represent Mean \pm SEM. DA = dopamine, DOPAC = 3,4-Dihydroxyphenylacetic acid.

In contrast to the levels of dopamine, there was found to be an interaction between stress and genotype for DOPAC in the amygdala and in the dorsal raphe, but not in prefrontal cortex, hippocampus, or striatum $(F 1,28=12.86, \mathrm{p}<0.01 ; \mathrm{F} 1,27=4.25, \mathrm{p}<0.05 ; \mathrm{F} 1,28=1.09, \mathrm{p}=$ $0.31 ; \mathrm{F} 1,28=0.76, \mathrm{p}=0.39$ and $\mathrm{F} 1,26=3.87, \mathrm{p}=0.06$, respectively). Stress alone significantly affected DOPAC concentrations in the prefrontal cortex and striatum $(\mathrm{F} 1,28=4.42, \mathrm{p}=0.04$ and $\mathrm{F} 1,26=21.49, \mathrm{p}<0.01$, 
respectively) and post hoc analysis revealed that in the amygdala of stressed $\mathrm{Tph}^{+/+}$mice the DOPAC concentration was elevated compared to non-stressed $\mathrm{Tph}^{+/+}$animals or predator stressed $\mathrm{Tph} 2^{+/-}$mice (both $\mathrm{p}$ $<0.01$, Tukey's test; Fig. 4B). The concentration of DOPAC was increased in stressed $\mathrm{Tph}^{+/+}$mice in comparison with non-stressed controls in dorsal raphe $(p=0.06$; Fig. $4 \mathrm{~K})$. It was also elevated in striatum of stressed $\mathrm{Tph}^{+/+}$compared to the non-stressed mutants $(p<0.01$; Fig. $4 N)$.

A significant interaction between stress and genotype on the dopamine turnover rate was found in the prefrontal cortex $(F 1,28=11.30$, $\mathrm{p}<0.01$, two-way ANOVA), but not in amygdala, hippocampus, dorsal raphe, or striatum $(\mathrm{F} 1,27=1.13, p=0.30 ; \mathrm{F} 1,28<0.05, p=0.86 ; \mathrm{F} 1,27=$ $1.77, p=0.19$ and F1,26 $=0.46, p=0.5$, respectively). However, stress had significant main effect on dopamine turnover in amygdala, hippocampus, and dorsal raphe $(\mathrm{F} 1,27=30.07, p<0.01 ; \mathrm{F} 1,28=51.13, \mathrm{p}<0.01$ and F1,27 $=5.03, p=0.03$, respectively). Post hoc analysis revealed an increase in turnover rate in the stressed controls and mutants in comparison with non-stressed groups in the amygdala $(p=0.02$ and $\mathrm{p}<$ 0.01, Tukey's test, respectively; Fig. 4C) and hippocampus (both $\mathrm{p}<0.01$; Fig. 4I), while in the prefrontal cortex of stressed $T p h 2^{+/-}$mice it was increased compared to both non-stressed $T p h 2^{+/-}$or $T p h 2^{+/+}$animals (both $p<0.01$; Fig. 4F). 
3.5. Altered brain metabolism of norepinephrine in stressed Tph2 $2^{+/-}$mice

There was no significant interaction between stress and genotype for norepinephrine concentrations in amygdala, prefrontal cortex, hippocampus, dorsal raphe and striatum $(\mathrm{F} 1,28<0.01, p=0.89 ; \mathrm{F} 1,28=$ $0.11, p=0.75 ; \mathrm{F} 1,28=1.77, \mathrm{p}=0.19 ; \mathrm{F} 1,27=1.21, p=0.28$ and $\mathrm{F} 1,28=$ $0.78, \mathrm{p}=0.39$, respectively, two-way ANOVA). Stress significantly affected concentrations of norepinephrine in prefrontal cortex, hippocampus, and striatum $(\mathrm{F} 1,28=7.96, \mathrm{p}<0.01 ; \mathrm{F} 1,28=6.00, \mathrm{p}=0.02$ and F1,28 $=50.82, \mathrm{p}<0.01$, respectively). Post hoc analysis revealed that there was a significant increase in norepinephrine levels in the stressed $\mathrm{Tph}^{+/-}$and $\mathrm{Tph}^{+++}$mice compared to non-stressed animals of respective genotype (both $\mathrm{p}<0.01$, Tukey's test; Fig. $5 \mathrm{M}$ ).

MHPG concentrations exhibited a stress x genotype interaction in the amygdala, but not in the prefrontal cortex, hippocampus, dorsal raphe, or striatum $(\mathrm{F} 1,28=13.45, \mathrm{p}<0.01 ; \mathrm{F} 1,28=0.86, p=0.36 ; \mathrm{F} 1,28=$ $1.7, \mathrm{p}=0.2 ; \mathrm{F} 1,27=0.42, p=0.52$ and $\mathrm{F} 1,28<0.01, p=0.78$, respectively). Main effects for stress and genotype were observed in the hippocampus $(\mathrm{F} 1,28=28.75, \mathrm{p}<0.01$ and $\mathrm{F} 1,28=6.34, \mathrm{p}=0.02$, respectively; Fig. $5 \mathrm{H})$. In the stressed $\mathrm{Tph}^{+/-}$group, the MHPG level in the amygdala was significantly lower than in both the non-stressed $\mathrm{Tph}^{+/-}$mutants and stressed Tph2 $2^{+-}$mice (both $p=0.01$, Tukey's test; Fig. 5B). 


\section{Amygdala}

A

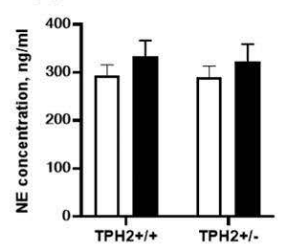

D

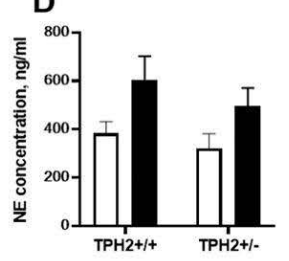

G

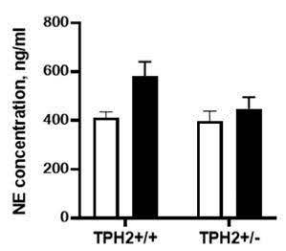

J

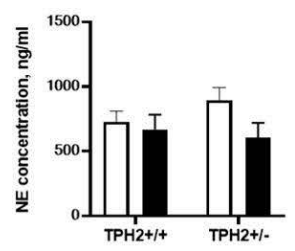

M

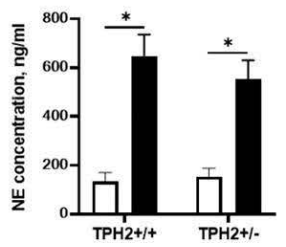

B

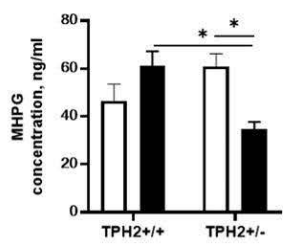

Prefrontal cortex

E

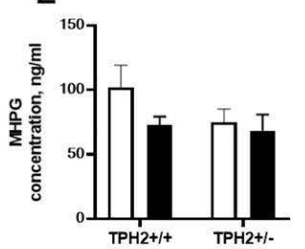

Hippocampus

H

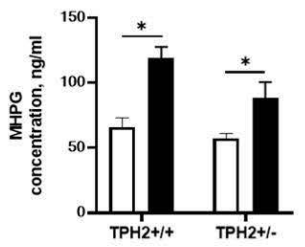

Dorsal raphe

$$
\text { K }
$$

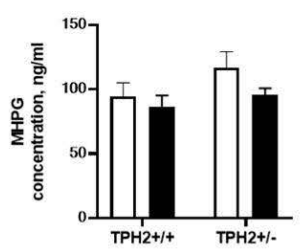

Striatum

N

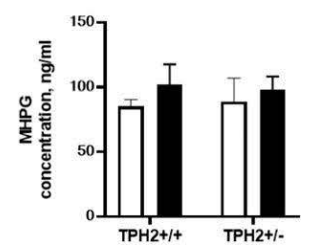

C

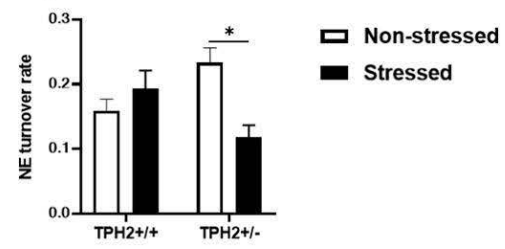

F

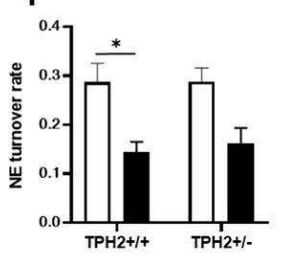

I

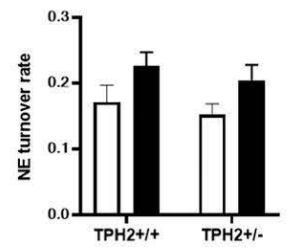

L

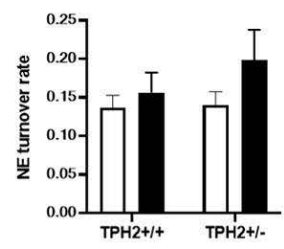

O

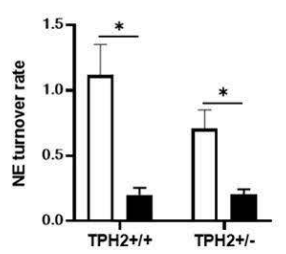

Fig. 5. Stress-induced alterations in concentrations of norepinephrine, its metabolite MHPG, and norepinephrine turnover rate in $\mathrm{Tph2}^{+/+}$and $\mathrm{Tph2}^{+/-}$mice. (A) In the amygdala, no significant group 
differences were observed in the norepinephrine concentration. (B) MHPG concentration was significantly lower in the stressed $\mathrm{Tph}^{+/-}$compared to both stressed $\mathrm{Tph}^{+/+}$and non-stressed $\mathrm{Tph}^{+/-}$mice. (C) Norepinephrine turnover rate was significantly lower in stressed $\mathrm{Tph}^{+/-}$in comparison to non-stressed $\mathrm{Tph}^{+/-}$mice. No significant changes between the groups were found in (D) norepinephrine concentration and (E) MHPG concentration in the prefrontal cortex. (F) However, norepinephrine turnover rate in the prefrontal cortex was significantly lower in stressed $T p h 2^{+/+}$compared to non-stressed $\mathrm{Tph}^{+/+}$mice. (G) No significant group changes in the norepinephrine concentration were observed in the hippocampus. $(H)$ In the hippocampus, MHPG concentration was elevated significantly in both genotypes in stressed groups compared to non-stressed animals, but (I) no significant changes between the groups were found in the norepinephrine turnover rate. $(J-L)$ No significant group changes in the norepinephrine metabolism were found in the dorsal raphe. (M) In the striatum, in both genotypes, there were significant increases in the norepinephrine concentrations in stressed groups compared to non-stressed animals of the same genotype. (N) MHPG concentration in the striatum did not show any significant changes between the groups. (0) Norepinephrine turnover ratio was significantly lowered in both genotypes in stressed groups in comparison to non-stressed animals. ${ }^{*} p<0.05$, two-way ANOVA and post hoc Tukey's test. 7-9 animals per group were used. Bars represent Mean \pm SEM. NE = norepinephrine, MHPG = 3-Methoxy-4-hydroxyphenylglycol.

There was a significant interaction between genotype and stress for norepinephrine turnover rate in the amygdala, but not in prefrontal cortex, hippocampus, dorsal raphe, or striatum $(\mathrm{F} 1,28=11.31, \mathrm{p}<0.01$; $\mathrm{F} 1,28=0.25, \mathrm{p}=0.62 ; \mathrm{F} 1,28<0.01, \mathrm{p}=0.95 ; \mathrm{F} 1,27=0.59, \mathrm{p}=0.45$ and $\mathrm{F} 1,28=2.35, \mathrm{p}=0.14$, respectively). Norepinephrine turnover rate was significantly lower in the stressed $\mathrm{Tph}^{+/-}$compared to the non-stressed $\mathrm{Tph}^{+/-}$in the amygdala ( $\mathrm{p}<0.01$, Tukey's test; Fig. $5 \mathrm{C}$ ). Stress alone significantly changed norepinephrine turnover rate in prefrontal cortex, hippocampus, and striatum $(\mathrm{F} 1,28=18.32, \mathrm{p}<0.01 ; \mathrm{F} 1,28=6.17, \mathrm{p}=0.02$ and $\mathrm{F} 1,28=27.84, \mathrm{p}<0.01$, respectively). Norepinephrine turnover rate 
was decreased in the prefrontal cortex of stressed $\mathrm{Tph} 2^{+/+}$in comparison to controls $(p=0.01$; Fig. $5 F)$. It also was decreased in the striatum of stressed $\mathrm{Tph}^{+/-}$and $\mathrm{Tph} 2^{+/+}$mice compared to the non-stressed groups of same genotypes ( $p<0.01$ and $p<0.05$, respectively; Fig. 50).

3.6. Tph2 $2^{+-}$mice display increased novelty exploration and reduced helplessness in the modified swim test

In the modFST test, there was an interaction between day and genotype in the duration of floating, but not in the latency to float or the number of floating episodes $(\mathrm{F} 2,22=3.73, p=0.04 ; \mathrm{F} 2,22=3.06, p=0.07$ and F2,22 $=0.69, p=0.51$, respectively, two-way ANOVA). A main effect of the day was observed for the latency to float and number of floating episodes $(F 1.134,12.47=9.80, \mathrm{p}<0.01$ and F1.901,20.91 $=6.44, \mathrm{p}<0.01$, respectively). No significant group differences in latency to float were found on day 1 ( $p=0.14$, Bonferroni test; Fig. 6A). Latency to float was shortened in $\mathrm{Tph}^{+/-}$mice on day 5 compared to day $1(\mathrm{p}=0.02$, Bonferroni test; Fig. 6A), the number of floating episodes was increased in $T p h 2^{+/+}$on day 5 compared to day $1(\mathrm{p}=0.04$; Fig. $6 \mathrm{~B})$. On day 5 , the duration of floating was significantly shorter in $T p h 2^{+/-}$than in the $T p h 2^{+/+}$ animals ( $\mathrm{p}<0.01$; Fig. 6C).

In the novel cage test, $T p h 2^{+/-}$mice showed significantly higher number of exploratory rears than their $T p h 2^{+/+}$littermates $(p=0.04$, unpaired $t$-test; Fig. 6D). Together, observations in these two behavioural tests suggest that there is a lower propensity to float and increased exploratory activity in the naïve $T p h 2^{+/-}$mice when they are exposed to 
environmental challenges, which may reflect increased stress-resilience in these animals.

\section{Modified swim test in naïve mice}
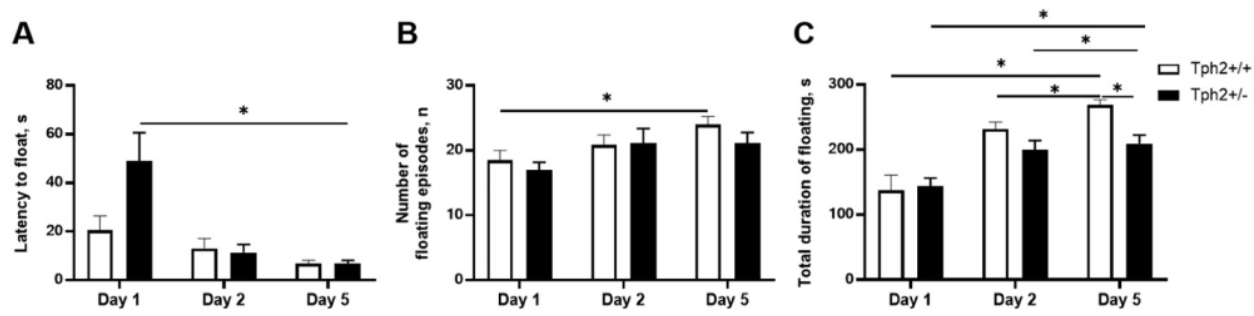

Novel cage test in naïve mice

D

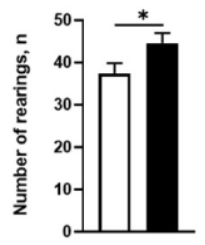

Fig. 6. Reduced propensity to float and increased vertical exploratory activity in naïve $\mathrm{Tph}^{+/-}$mice. In the modified swim test, (A) naive $\mathrm{Tph}^{+/-}$ showed significant decrease in the latency to the first immobility episode between days 1 and 5 of the test. (B) Total number of immobility episodes significantly increased from day 1 to day 5 in naïve $T p h 2^{+++}$mice. (C) Total duration of floating was significantly lower in naïve $\mathrm{Tph}^{+/-}$mice compared to naïve $\mathrm{Tph}^{+/+}$mice on day 5 of the test. Both in $\mathrm{Tph}^{+/+}$and $\mathrm{Tph}^{+{ }^{+-}}$mice total immobility time was significantly lower on day 1 in comparison with day 2 and day 5. (D) In the novel cage test, naïve $T p h 2^{+-}$mice showed significantly higher number of rearings in comparison to naïve $\mathrm{Tph}^{+/+}$mice. ${ }^{*} \mathrm{p}<0.05$; in A-C repeated measures two-way ANOVA and post hoc Tukey's test; in D unpaired t-test. 5-8 animals per group were used. Bars represent Mean \pm SEM. 


\section{Discussion}

$T p h 2^{+/-}$mice subjected to the predation stress paradigm displayed a marked increase of aggression, dominancy and a suppression of neutral sociability, whereas the stressed $T p h 2^{++\mid}$group showed opposing changes in social behaviour. Rat exposure paradigm increased anxiety-like behaviour in $T p h 2^{++}$control mice but did not alter it in the $T p h 2^{+/-}$ mutants. The separate cohort of $T p h 2^{+/-}$mice exhibited increased exploration in a novel environment and a lack of potentiation of floating behaviour over the course of repeated sessions of the ModFST. The HPLC tissue assays revealed profound changes in the content and metabolism of brain DA and NE in the stressed and in the non-stressed $T p h 2^{+/}$mice, suggesting that this monoamine dysregulation might contribute to the altered behaviours that are observed in the mutants.

In accordance with previous results, we found that $T p h 2^{+/}$mice subjected to a five-day predation stress paradigm displayed excessive aggression, which was the opposite of the changes found in the littermate controls (Gorlova et al., 2020) and reminiscent to aggressive behaviour typical of non-stressed Tph2/- mice (Gutknecht et al., 2012, 2015). Additional analysis of the social behaviour showed that the stressed $T p h 2^{+/-}$mice also displayed increased measures of dominancy and decreased scores of neutral social exploration, which are known to correlate with the appearance of aggressive traits in small laboratory

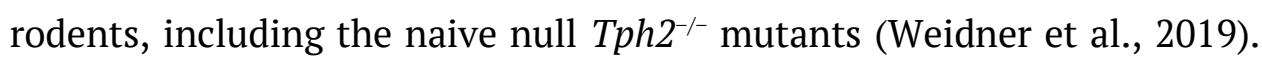
Again, control mice exposed to predation stress model exhibited the opposite response in these forms of social behaviour. In particular, in the 
$\mathrm{Tph}^{-/-}$group, rat exposure stress did not elicit anxiogenic-like behaviour in the elevated $\mathrm{O}$-maze test, in contrast to the $\mathrm{Tph} 2^{+/+}$controls. Changes in the dark-light box test did not reach statistical significance, but numerically the data suggest their similar changes in direction to abovementioned group differences in anxiety. Lowered anxiety levels have been reported in naïve and stressed Tph2 $2^{-/-}$mice (Mosienko et al., 2012; Gutknecht et al., 2012, 2015; Jia et al., 2014; Weidner et al., 2019), and the present findings further supports the view of phenotypical resemblance between naïve $T p h 2^{-/-}$and stressed $T p h 2^{+/-}$mice (Gorlova et al., 2020).

Previous work with stress paradigm that was employed here demonstrated altered brain concentrations and metabolism of serotonin, a major regulator of aggression and anxiety (Nelson and Chiavegatto, 2001; Abela et al., 2020; Quah et al., 2020), in the stressed Tph2 $2^{+-}$mice (Gorlova et al., 2020). The serotonergic system closely interacts with brain dopaminergic system of the brain, reciprocally modulating dopaminergic activity (Millan et al., 1998; De Deurwaerd`ere et al., 2005; Seo et al., 2008; Rosell and Siever, 2015). Lower levels of dopamine were previously measured in the brains of naïve $T p h 2^{-/-}$mice in the hippocampus and in the frontal cortex (Gutknecht et al., 2012). Similarly, in the present study, stress resulted in diminished DA concentrations in the amygdala and in the prefrontal cortex of $\mathrm{Tph}^{+/-}$mice that was not found in $T p h 2^{+/+}$animals. In the stressed $T p h 2^{+/-}$mice, DA concentrations were also lower in the hippocampus and striatum in comparison with naïve mutants. Thus, changes in the dopaminergic system of the stressed 
$\mathrm{Tph}^{+/-}$mice are strikingly different from those found in the $T p h 2^{+/+}$ animals and overly resemble those observed in $T p h 2^{-/-}$mice; they can underpin stress-induced excessive aggression and other behavioural changes reported in this study.

Changes to the serotonergic system are often associated with changes to NE neurotransmission, particularly, in amygdala (Pucilowski et al., 1987; Millan et al., 1998). Here, stress exposure resulted in similar genotype-related increases of NE concentration and NE turnover in the striatum, elevated concentrations of NE metabolite MHPG in the hippocampus and decreased NE turnover in the prefrontal cortex. However, genotype differences between stressed groups were shown for MHPG concentrations in the amygdala, whose values in the $T p h 2^{+/-}$group were lower than in stressed $T p h 2^{+/+}$mice. Stress significantly decreased this measure, as well as NE turnover in the amygdala of $T p h 2^{+/-}$mice, but not in the littermate $T p h 2^{+/+}$controls. These data further show the contribution of amygdala and suggest the role of NE in described here stress-induced behavioural abnormalities of $T p h 2^{+/-}$mice.

Together, the HPLC data presented here provides evidence for genotype-governed differences in the stress-induced changes of DA and NE regulation in the amygdala and prefrontal cortex. These are brain areas in which genotype changes in the TPH2-deficient mice were also shown for serotonin precursor 5-hydroxytrypthophan (5-HTP). This led to the suggestion that these inter-related changes in the three monoamines in the amygdala might underlie excessive aggression and altered social behaviour in general of stressed $\mathrm{Tph}^{+/-}$mutants. This 
suggestion is keeping with previously reported monoamine changes in the amygdala of stressed $\mathrm{Tph}^{+/-}$mice in relation to GABA metabolism (Waider et al., 2017), as well as the altered methylation profile of CCK in this brain structure (Weidner et al., 2019). These findings are in line with the well-documented primary role of the amygdala in the regulation of aggression (Haller et al., 2017) and stress response (Tottenham and Galvan, 2016). Moreover, they are also in agreement with clinical data showing that the amygdala has a key function in the response to emotional stimuli of valence in carriers of SNPs of the TPH2 gene G-844T and G-703T (Brown et al., 2005; Canli et al., 2005).

Regarding other brain structures that could be potentially involved in behavioural changes reported here in the $T p h 2^{+/-}$mice, it should be noted that prefrontal cortex was shown to regulate amygdaladependent processing of social cues in fMRI studies in humans with acute tryptophan depletion (Passamonti et al., 2012). Reduced inhibitory control of the amygdala by the prefrontal cortex is considered to result in impulsive aggression (Jackson and Moghaddam, 2001; Haller, 2017). Here, we found diminished DA levels in the prefrontal cortex in stressed $\mathrm{Tph}^{+/-}$group. These changes might lead to a decrease in the top-down control of the amygdala (Rosenkranz and Grace, 2001) resulting in excessive aggression that is in keeping with earlier studies. For example, the hypoactivation of the prefrontal cortex in rats was associated with elevated activation of the amygdala in a single-prolonged stress paradigm (Piggott et al., 2019). Chronic restraint stress in C57BL/6 mice was shown to enhance amygdala-prefrontal cortex interactions, and 
optogenetic activation of these circuits elicited anxiety-like and hyperactivity in naïve mice (Lowery-Gionta et al., 2018). The changes of NE regulation observed here after stress in the prefrontal cortex may alter the function of the amygdala that is keeping with previous findings (Van Bockstaele et al., 1998).

Our previous study showed a decrease of 5-HTP and the serotonin metabolite 5-Hydroxyindoleacetic acid (5-HIAA) in the striatum of stressed $\mathrm{Tph}^{+/-}$mice, but not in other experimental groups (Gorlova et al., 2020). Together with the findings of a decreased DOPAC concentration in the striatum in stressed $T p h 2^{+/-}$mice, this suggests a role for this brain area in differential effects of stress in these mutants compared to the $T p h 2^{+/+}$controls. The striatum, and, particularly, the nucleus accumbens, is essential in the so called 'limbic-motor' interface, which is functionally connected to the amygdala (Cardinal et al., 2003; Ambroggi et al., 2008) and to the prefrontal cortex (Del Arco and Mora, 2008; Janak and Tye, 2015). In rats, lesions of the nucleus accumbens provoked excessive aggression and muricide behaviour (Lee and Ueki, 1986; Pucilowski and Valzelli, 1986). Whereas social defeat stimulated dopamine signalling by increasing both DA release and uptake (Anstrom et al., 2009; Deal et al., 2018), isolation stress supressed baseline DA levels, but increased the DA-mediated response to various stimuli (Yorgason et al., 2016; Karkhanis et al., 2016). While nucleus accumbens is distinct from dorsal region of striatum functionally, many data suggest unidirectional stress-induced changes in DA metabolism in these areas (Abercrombie et al., 1989; Porcelli et al., 2012). A decrease of DA 
concentrations in the striatum of stressed mice in our study may resemble previously reported effects of chronic isolation stress on basal DA levels in rats (Yorgason et al., 2016; Karkhanis et al., 2016). Thus, in addition to the changes reported here in the whole striatum, the studies highlighted above argue for the importance of the striatal DA system in the mechanisms of stress associated with social determinants.

The stress model employed here is based largely on social stress. The model was designed to minimize the impact of physical stressors such as food and water deprivation, and the loss of consummatory behaviour in mice during the rat exposure was shown to be secondary to the fear of predation (Strekalova and Steinbusch, 2009, 2010). Yet, the role of these stressors, as well as other potential factors cannot be completely ruled out (Nakamura et al., 1990; Bekkevold et al., 2013), thus, the nature of the applied stress model should be considered in the broader context.

Separate experiments on $T p h 2^{+/-}$mice revealed elevated vertical exploratory activity in a situation of novelty and a lack of increase in floating behaviour between days 2 and 5 , which is a marker of enhanced acquisition of despair behaviour (Strekalova et al., 2016; Pavlov et al., 2020). Both features can be interpreted in a light of increased resilience to environmental challenges and stressors, as diminished rearing activity in the novel cage and increased floating behaviour were associated with a susceptibility of mice to chronic stress (Strekalova et al., 2004; Cline et al., 2012, 2015). Elevated locomotor activity in home cage conditions was reported in naïve $T p h 2^{-/-}$mice (Zhang et al., 2018), which is reminiscent 
of the finding reported here. Notably, increased aggression scores were found to inversely correlate with the stress response and the development of depressive behaviour in mice (Strekalova et al., 2004; Comai et al., 2012). Together, these findings suggest the presence of similar behavioural patterns in $T p h 2^{+/-}$mice and the null mutants, which were also described to show decreased signs of stress resilience (Savelieva et al., 2008; Jia et al., 2014; Weidner et al., 2019).

\section{Conclusions}

Thus, the present findings suggest that $T p h 2^{+/-}$mutants exposed to the predation stress model display changes in social behaviour that are the opposite of those observed in control mice. In summary, these results, along with data on anxiety-like behaviour and the outcome from studies on mutants challenged with novelty and repeated swimming, suggest that under stress conditions, $T p h 2^{+/-}$demonstrate behavioural profile that is reminiscent of naïve $T p h 2^{-/-}$animals. This behavioural repertoire is associated with increased aggressive behaviour, decreased stress-induced anxiety and other signs of stress resilience, such as reduced floating and elevated exploratory activity. In addition to previously demonstrated changes in serotonin metabolism in the amygdala, altered dopamine concentration and turnover in this brain structure are likely to mediate excessive aggression and reduced sociability of stressed $T p h 2^{+/-}$mice. These neurochemical changes, along with genotype differences in monoamine regulation the prefrontal cortex and striatum and a lack of changes in DOPAC levels in the dorsal raphe in stressed mutants are likely to contribute to the behavioural phenotype of 
these mice. In conclusion, present paradigm can be considered as a promising model of gene $\mathrm{x}$ environment interactions underlying excessive human aggression.

\section{Author statement}

All authors confirm that they have contributed to the manuscript “Altered behavior, dopamine and norepinephrine regulation in stressed mice heterozygous in TPH2 gene”, have read and approved its final form and Response to reviewers.

\section{Ethical statement}

All experiments described in the manuscript "Altered behavior, dopamine and norepinephrine regulation in stressed mice heterozygous in TPH2 gene” by Tatyana Strekalova, Evgeniy Svirin, Jonas Waider, Anna Gorlova, Raymond Cespuglio, Allan Kalueff, Igor Pomytkin, Angelika G. Schmitt-Boehrer, Klaus-Peter Lesch, and Daniel Anthony were carried out in accordance with the European Communities Council Directive for the care and use of laboratory animals upon approval by the local governmental body of animal care and welfare.

\section{Declaration of Competing Interest}

All authors express a lack of any conflict of interests in connection with the manuscript "Altered behavior, dopamine and norepinephrine regulation in stressed mice heterozygous in TPH2 gene”. 


\section{Acknowledgments}

The authors' work reported here was supported by Deutsche Forschungsgemeinschaft (DFG:CRC TRR58A1/A5), DAAD (to ES), the European Union's Seventh Framework Programme (FP7/2007-2013) under Grant No.602805 (Aggressotype) and the Horizon 2020 Research and Innovation Programme under Grant No.728018 (Eat2beNICE) (to KPL and TS) and the President's program of PhD Exchange of RF-2017 (to TS and DA). We appreciate the valuable technical help of Natalia Bazhenova, Drs. Alexander Trofimov and Natalia Markova with this project. 


\section{References}

Abela, A.R., Browne, C.J., Sargin, D., Prevot, T.D., Ji, X.D., Li, Z., Lambe, E.K., Fletcher, P.J., 2020. Median raphe serotonin neurons promote anxiety-like behavior via inputs to the dorsal hippocampus. Neuropharmacology 168, 107985.

DOI:10.1016/j.neuropharm.2020.107985.

Abercrombie, E.D., Keefe, K.A., DiFrischia, D.S., Zigmond, M.J., 1989. Differential effect of stress on in vivo dopamine release in striatum, nucleus accumbens, and medial frontal cortex. J. Neurochem. 52, 16551658. DOI:10.1111/j.1471-4159.1989.tb09224.x.

Adamczyk, A., Mejias, R., Takamiya, K., Yocum, J., Krasnova, I.N., Calderon, J., Cadet, J. L., Huganir, R.L., Pletnikov, M.V., Wang, T., 2012. GluA3-deficiency in mice is associated with increased social and aggressive behavior and elevated dopamine in striatum. Behav. Brain Res. 229, 265-272. DOI:10.1016/j. bbr.2012.01.007.

Ambroggi, F., Ishikawa, A., Fields, H.L., Nicola, S.M., 2008. Basolateral amygdala neurons facilitate reward-seeking behavior by exciting nucleus accumbens neurons. Neuron 59, 648-661. DOI:10.1016/j.neuron.2008.07.004.

Angoa-Perez, M., Kane, M.J., Briggs, D.I., Sykes, C.E., Shah, M.M., Francescutti, D.M., Rosenberg, D.R., Thomas, D.M., Kuhn, D.M., 2012. Genetic depletion of brain 5HT reveals a common molecular pathway mediating compulsivity and impulsivity. J. Neurochem. 121, 974-984. DOI:10.1111/j.1471-4159.2012.07739.x.

Anstrom, K.K., Miczek, K.A., Budygin, E.A., 2009. Increased phasic dopamine signaling in the mesolimbic pathway during social defeat in rats. Neuroscience 161, 3-12. DOI:10.1016/j.neuroscience.2009.03.023.

Auth, C.S., Weidner, M.T., Popp, S., Strekalova, T., Schmitt-bohrer, A.G., La, D., Den Hove, V., Lesch, K., Waider, J., 2018. Differential anxiety-related behaviours and brain activation in Tph2-deficient female mice exposed to adverse early environment. Eur. Neuropsychopharmacol. 1-14. DOI:10.1016/j. euroneuro.2018.07.103. 
Bekkevold, C.M., Robertson, K.L., Reinhard, M.K., Battles, A.H., Rowland, N.E., 2013. Dehydration parameters and standards for laboratory mice. J. Am. Assoc. Lab. Anim. Sci. 52, 233-239.

Brown, S.M., Peet, E., Manuck, S.B., Williamson, D.E., Dahl, R.E., Ferrell, R.E., Hariri, A. R., 2005. A regulatory variant of the human tryptophan hydroxylase-2 gene biases amygdala reactivity. Mol. Psychiatry 10, 884-888. DOI:10.1038/sj. mp.4001716.

Canli, T., Congdon, E., Gutknecht, L., Constable, R.T., Lesch, K.P., 2005. Amygdala responsiveness is modulated by tryptophan hydroxylase2 gene variation. J. Neural Transm. 112, 1479-1485. DOI:10.1007/s00702005-0391-4.

Cardinal, R.N., Parkinson, J.A., Hall, J., Everitt, B.J., 2003. The contribution of the amygdala, nucleus accumbens, and prefrontal cortex to emotion and motivated behaviour. Int. Congr. Ser. 1250, 347-370. DOI:10.1016/S0531-5131 (03)01013-6.

Chaturvedi, S.K., 2020. Covid-19, coronavirus and mental health rehabilitation at times of crisis. J. Psychosoc. Rehabil. Ment. Heal. 7, 1-2. DOI:10.1007/s40737- 020-00162-z.

Cline, B.H., Steinbusch, H.W.M., Malin, D., Revishchin, A.V., Pavlova, G.V., Cespuglio, R., Strekalova, T., 2012. The neuronal insulin sensitizer dicholine succinate reduces stress-induced depressive traits and memory deficit: possible role of insulin-like growth factor 2. BMC Neurosci. 13, 1. DOI:10.1186/1471- 2202-13-110.

Cline, B.H., Anthony, D.C., Lysko, A., Dolgov, O., Anokhin, K., Schroeter, C., Malin, D., Kubatiev, A., Steinbusch, H.W., Lesch, K.P., Strekalova, T., 2015. Lasting downregulation of the lipid peroxidation enzymes in the prefrontal cortex of mice susceptible to stress-induced anhedonia. Behav. Brain Res. 276, 118-129.

DOI:10.1016/j.bbr.2014.04.037.

Comai, S., Tau, M., Gobbi, G., 2012. The psychopharmacology of aggressive behavior: a translational approach: part 1: neurobiology. J. Clin. Psychopharmacol. 32, 83-94. DOI:10.1097/JCP.0b013e31823f8770.

Conejero, I., Jaussent, I., Lopez, R., Guillaume, S., Olié, E., Hebbache, C., Cohen, R.F., Kahn, J.P., Leboyer, M., Courtet, P., Lopez- 
Castroman, J., 2019. Association of symptoms of attention deficithyperactivity disorder and impulsive-aggression with severity of suicidal behavior in adult attempters. Sci. Rep. 9, 1-8. DOI: 10.1038/s41598-01941046-y.

Costa-Nunes, J., Zubareva, O., Araújo-Correia, M., Valença, A., Schroeter, C.A., Pawluski, J.L., Vignisse, J., Steinbusch, H., Hermes, D., Phillipines, M., Steinbusch, H.M.W., Strekalova, T., 2014. Altered emotionality, hippocampus-dependent performance and expression of NMDA receptor subunit mRNAs in chronically stressed mice. Stress 17, 108-116. DOI:10.3109/ 10253890.2013.872619.

Costa-Nunes, J.P., Gorlova, A., Pavlov, D., Cespuglio, R., Gorovaya, A., Proshin, A., Umriukhin, A., Ponomarev, E.D., Kalueff, A. V., Strekalova, T., Schroeter, C.A., 2020. Ultrasound stress compromises the correlates of emotional-like states and brain AMPAR expression in mice: effects of antioxidant and anti-inflammatory herbal treatment. Stress 0, 000. doi:DOI:10.1080/10253890.2019.1709435.

Couch, Y., Anthony, D.C., Dolgov, O., Revischin, A., Festoff, B., Santos, A.I., Steinbusch, H.W., Strekalova, T., 2013. Microglial activation, increased TNF and SERT expression in the prefrontal cortex define stress-altered behaviour in mice susceptible to anhedonia. Brain Behav. Immun. 29, 136-146. DOI: 10.1016/j.bbi.2012.12.017.

Couch, Y., Trofimov, A., Markova, N., Nikolenko, V., Steinbusch, H.W., Chekhonin, V., Schroeter, C., Lesch, K.P., Anthony, D.C., Strekalova, T., 2016. Low-dose lipopolysaccharide (LPS) inhibits aggressive and augments depressive behaviours in a chronic mild stress model in mice. J. Neuroinflammation 13, 1-17. DOI:10.1186/s12974-0160572-0.

De Deurwaerdere, P., Moison, D., Navailles, S., Porras, G., Spampinato, U., 2005. Regionally and functionally distinct serotonin3 receptors control in vivo dopamine outflow in the rat nucleus accumbens. J. Neurochem. 94, 140-149. DOI:10.1111/j.1471-4159.2005.03174.x.

Deal, A.L., Konstantopoulos, J.K., Weiner, J.L., Budygin, E.A., 2018. Exploring the consequences of social defeat stress and intermittent ethanol drinking on dopamine dynamics in the rat nucleus accumbens. Sci. Rep. 8, 1-9. DOI:10.1038/ s41598-017-18706-y. 
Del Arco, A., Mora, F., 2008. Prefrontal cortex-nucleus accumbens interaction: in vivo modulation by dopamine and glutamate in the prefrontal cortex. Pharmacol. Biochem. Behav. 90, 226-235. DOI:10.1016/j.pbb.2008.04.011.

Dumais, A., Sc, B., Lesage, A.D., Phil, M., Alda, M., Rouleau, G., Ph, D., Dumont, M., Chawky, N., Ps, M., Roy, M., Mann, J.J., Benkelfat, C., Turecki, G., Ph, D., 2005. Risk Factors for Suicide Completion in Major Depression: A Case-Control Study of Impulsive and Aggressive Behaviors in Men, pp. 2116-2124.

Forssman, L., Peltola, M.J., Yrttiaho, S., Puura, K., Mononen, N., Lehtimäki, T., Leppänen, J.M., 2014. Regulatory variant of the TPH2 gene and early life stress are associated with heightened attention to social signals of fear in infants. J. Child Psychol. Psychiatry 55, 793-801. DOI:10.1111/jcpp.12181.

Gorlova, A., Pavlov, D., Anthony, D.C., Ponomarev, E.D., Sambon, M., Proshin, A., Shafarevich, I., Babaevskaya, D., Lesch, K.P., Bettendorff, L., Strekalova, T., 2019. Thiamine and benfotiamine counteract ultrasound-induced aggression, normalize AMPA receptor expression and plasticity markers, and reduce oxidative stress in mice. Neuropharmacology 156, 107543.

DOI:10.1016/j. neuropharm.2019.02.025.

Gorlova, A., Ortega, G., Waider, J., Bazhenova, N., Veniaminova, E., Proshin, A., Kalueff, A.V., Anthony, D.C., Lesch, K.P., Strekalova, T., 2020. Stress-induced aggression in heterozygous TPH2 mutant mice is associated with alterations in serotonin turnover and expression of 5HT6 and AMPA subunit 2A receptors. J. Affect. Disord. 272, 440-451. DOI:10.1016/j.jad.2020.04.014.

Gutknecht, L., Araragi, N., Merker, S., Waider, J., Sommerlandt, F.M.J., Mlinar, B., Baccini, G., Mayer, U., Proft, F., Hamon, M., Schmitt, A.G., Corradetti, R., Lanfumey, L., Lesch, K.P., 2012. Impacts of brain serotonin deficiency following Tph2 inactivation on development and raphe neuron serotonergic specification. PLoS One 7. DOI:10.1371/journal.pone.0043157.

Gutknecht, L., Popp, S., Waider, J., Sommerlandt, F.M.J., Göppner, C., Post, A., Reif, A., Van Den Hove, D., Strekalova, T., Schmitt, A., 
Colaço, M.B.N., Sommer, C., Palme, R., Lesch, K.P., 2015. Interaction of brain 5-HT synthesis deficiency, chronic stress and sex differentially impact emotional behavior in Tph2 knockout mice. Psychopharmacology 232, 2429-2441. DOI:10.1007/s00213-015-3879- 0.

Haller, J., 2017. The role of central and medial amygdala in normal and abnormal aggression: a review of classical approaches. Neurosci. Biobehav. Rev. DOI:10.1126/science.1071829.

Hutchins, D.A., Pearson, J.D.M., 1975. Striatal metabolism of dopamine in mice, p. 24. Jackson, M.E., Moghaddam, B., 2001. Amygdala regulation of nucleus accumbens dopamine output is governed by the prefrontal cortex. J. Neurosci. 21, 676-681. DOI:10.1523/jneurosci.21-0200676.2001.

Janak, P.H., Tye, K.M., 2015. From circuits to behaviour in the amygdala. Nature 517, 284-292. DOI:10.1038/nature14188.

Jia, Y.F., Song, N.N., Mao, R.R., Li, J.N., Zhang, Q., Huang, Y., Zhang, L., Han, H.L., Ding, Y.Q., Xu, L., 2014. Abnormal anxiety-and depression-like behaviors in mice lacking both central serotonergic neurons and pancreatic islet cells. Front. Behav. Neurosci. 8, 1-11. DOI:10.3389/fnbeh.2014.00325.

Karkhanis, A.N., Rose, J.H., Weiner, J.L., Jones, S.R., 2016. Early-life social isolation stress increases kappa opioid receptor responsiveness and downregulates the dopamine system. Neuropsychopharmacology 41, 2263-2274. DOI: 10.1038/npp.2016.21.

Kiser, D.P., Popp, S., Schmitt-böhrer, A.G., Strekalova, T., Van Den Hove, D.L., Lesch, K., Rivero, O., 2018. Early-life stress impairs developmental programming in Cadherin 13 (CDH13)-deficient mice. Prog. Neuro-Psychopharmacol. Biol. Psychiatry 13. DOI:10.1016/j.pnpbp.2018.08.010.

Kunik, M.E., Stanley, M.A., Shrestha, S., Ramsey, D., Richey, S., Snow, L., Freshour, J., Rn, T.E., Newmark, M., Williams, S., Msw, N.W., Amspoker, A.B., 2020. Aggression prevention training for individuals with dementia and their caregivers: a randomized controlled trial. Am. J. Geriatr. Psychiatry. DOI:10.1016/j. jagp.2020.01.190. 
Laas, K., Kiive, E., Mäestu, J., Vaht, M., Veidebaum, T., Harro, J., 2017. Nice guys: homozygocity for the TPH2 -703G/T (rs4570625) minor allele promotes low aggressiveness and low anxiety. J. Affect. Disord. 215, 230-236. DOI: 10.1016/j.jad.2017.03.045.

Lane, S.D., Kjome, K.L., Moeller, F.G., 2011. Neuropsychiatry of aggression. Neurol. Clin. 29, 49-64. DOI:10.1016/j.ncl.2010.10.006.

Lee, S.C., Ueki, S., 1986. Pharmacological studies on aggressive behavior induced by lesions of the nucleus accumbens septi in rats. Arch. Pharm. Res. 9, 169-174. DOI:10.1007/BF02900002.

Lee, Y.C., Chao, Y.L., Chang, C.E., Hsieh, M.H., Liu, K.T., Chen, H.C., Lu, M.L., Chen, W. Y., Chen, C.H., Tsai, M.H., Lu, T.P., Huang, M.C., Kuo, P.H., 2019. Transcriptome changes in relation to manic episode. Front. Psychiatry 10, 1-12. DOI: 10.3389/fpsyt.2019.00280.

Lesch, K.P., 2005. Alcohol dependence and gene x environment interaction in emotion regulation: is serotonin the link? Eur. J. Pharmacol. 526, 113-124. DOI: 10.1016/j.ejphar.2005.09.027.

Lesch, K.P., Mössner, R., 2006. Inactivation of 5HT transport in mice: modeling altered 5HT homeostasis implicated in emotional dysfunction, affective disorders, and somatic syndromes. Handb. Exp. Pharmacol. 175, 417-456. DOI: 10.1007/3-540-29784-7-18.

Lesch, K.P., Araragi, N., Waider, J., van den Hove, D., Gutknecht, L., 2012. Targeting brain serotonin synthesis: insights into neurodevelopmental disorders with long-term outcomes related to negative emotionality, aggression and antisocial behaviour. Philos. Trans. R. Soc. B Biol. Sci. 367, 2426-2443. DOI: 10.1098/rstb.2012.0039.

Lewis, M.H., Gáriepy, J.L., Gendreau, P., Nichols, D.E., Mailman, R.B., 1994. Social reactivity and D1 dopamine receptors: studies in mice selectively bred for high and low levels of aggression. Neuropsychopharmacology 10, 115-122. DOI: 10.1038/npp.1994.13.

Lieb, M.W., Weidner, M., Arnold, M.R., Loupy, K.M., Nguyen, K.T., Hassell, J.E., Schnabel, K.S., Kern, R., Day, H.E.W., Lesch, K.P., Waider, J., Lowry, C.A., 2019. Effects of maternal separation on serotonergic systems in the dorsal and median raphe nuclei of adult male Tph2-deficient mice. Behav. Brain Res. 373, 112086. DOI:10.1016/j.bbr.2019.112086. 
Lowery-Gionta, E.G., Crowley, N.A., Bukalo, O., Silverstein, S., Holmes, A., Kash, T.L., 2018. Chronic stress dysregulates amygdalar output to the prefrontal cortex. Neuropharmacology 139, 68-75. DOI:10.1016/j.neuropharm.2018.06.032.

Malatynska, E., Steinbusch, H.W.M., Redkozubova, O., Bolkunov, A., Kubatiev, A., Yeritsyan, N.B., Vignisse, J., Bachurin, S., Strekalova, T., 2012. Anhedonic-like traits and lack of affective deficits in 18-month-old C57BL/6 mice: implications for modeling elderly depression. Exp. Gerontol. 47, 552-564. DOI:10.1016/j.exger.2012.04.010.

Malki, K., Tosto, M.G., Pain, O., Sluyter, F., Mineur, Y.S., Crusio, W.E., de Boer, S., Sandnabba, K.N., Kesserwani, J., Robinson, E., Schalkwyk, L.C., Asherson, P., 2016. Comparative mRNA analysis of behavioral and genetic mouse models of aggression. Am. J. Med. Genet. Part B Neuropsychiatr. Genet. 171, 427-436.

DOI:10.1016/j.brainres.2013.09.033.

Manchia, M., Carpiniello, B., Valtorta, F., Comai, S., 2017. Serotonin dysfunction, aggressive behavior, and mental illness: exploring the link using a dimensional approach. ACS Chem. Neurosci. 8, 961-972. DOI:10.1021/ acschemneuro.6b00427.

Markova, N., Bazhenova, N., Anthony, D.C., Vignisse, J., Svistunov, A., Lesch, K.P., Bettendorff, L., Strekalova, T., 2017. Thiamine and benfotiamine improve cognition and ameliorate GSK-3 $\beta$-associated stress-induced behaviours in mice. Prog. Neuro- Psychopharmacology Biol. Psychiatry 75, 148-156. DOI:10.1016/j.pnp bp.2016.11.001.

Millan, M.J., Dekeyne, A., Gobert, A., 1998. Serotonin (5-HT)(2C) receptors tonically inhibit dopamine (DA) and noradrenaline (NA), but not 5-HT, release in the frontal cortex in vivo. Neuropharmacology 37, 953-955. DOI:10.1016/S0028- 3908(98)00078-1.

Mineur, Y.S., Prasol, D.J., Belzung, C., Crusio, W.E., 2003. Agonistic behavior and unpredictable chronic mild stress in mice. Behav. Genet. 33, 513-519. DOI:10.1023/A:1025770616068.

Mosienko, V., Bert, B., Beis, D., Matthes, S., Fink, H., Bader, M., Alenina, N., 2012. Exaggerated aggression and decreased anxiety in mice deficient in brain serotonin. Transl. Psychiatry 2, e122-e129. DOI:10.1038/tp.2012.44. 
Nakamura, K., Aoike, A., Hosokawa, T., Rokutan, K.K.K., Nishi, Y., Yoshida, A., 1990. Effect of food-restriction stress on immune response in mice. J. Neuroimmunol. 30, 23-29. DOI:10.1016/0165-5728(90)90049s.

Nelson, R.J., Chiavegatto, S., 2001. Molecular basis of aggression. Trends Neurosci. 24, 713-719. DOI:10.1016/S0166-2236(00)01996-2.

Oades, R.D., Lasky-Su, J., Christiansen, H., Faraone, S.V., SonugaBarke, E.J.S., Banaschewski, T., Chen, W., Anney, R.J.L., Buitelaar, J.K., Ebstein, R.P., Franke, B., Gill, M., Miranda, A., Roeyers, H., Rothenberger, A., Sergeant, J.A., Steinhausen, H. C., Taylor, E.A., Thompson, M., Asherson, P., 2008. The influence of serotonin- and other genes on impulsive behavioral aggression and cognitive impulsivity in children with attention-deficit hyperactivity disorder (ADHD): findings from a family-based association test (FBAT) analysis. Behav. Brain Funct. 4, 114. DOI: $10.1186 / 1744-9081-4-48$.

Ottenhof, K.W., Sild, M., Lévesque, M.L., Ruhé, H.G., Booij, L., 2018. TPH2 polymorphisms across the spectrum of psychiatric morbidity: a systematic review and meta-analysis. Neurosci. Biobehav. Rev. 92, 2942. DOI:10.1016/j. neubiorev.2018.05.018.

Passamonti, L., Crockett, M.J., Apergis-Schoute, A.M., Clark, L., Rowe, J.B., Calder, A.J., Robbins, T.W., 2012. Effects of acute tryptophan depletion on prefrontal-amygdala connectivity while viewing facial signals of aggression. Biol. Psychiatry 71, 36-43. DOI:10.1016/j.biopsych.2011.07.033.

Patki, G., Solanki, N., Atrooz, F., Allam, F., Salim, S., 2013. Depression, anxiety-like behavior and memory impairment are associated with increased oxidative stress and inflammation in a rat model of social stress. Brain Res. 1539, 73-86. DOI: 10.1016/j.brainres.2013.09.033.

Pavlov, D., Markova, N., Bettendorff, L., Chekhonin, V., Pomytkin, I., Lioudyno, V., Svistunov, A., Ponomarev, E., Lesch, K.P., Strekalova, T., 2017. Elucidating the functions of brain GSK3 $\alpha$ : possible synergy with GSK3 $\beta$ upregulation and reversal by antidepressant treatment in a mouse model of depressive-like behaviour. Behav. Brain Res. 335, 122-127. DOI:10.1016/j.bbr.2017.08.018. 
Pavlov, D., Bettendorff, L., Gorlova, A., Olkhovik, A., Kalueff, A.V., Ponomarev, E.D., Inozemtsev, A., Chekhonin, V., Lesch, K.P., Anthony, D.C., Strekalova, T., 2019. Neuroinflammation and aberrant hippocampal plasticity in a mouse model of emotional stress evoked by exposure to ultrasound of alternating frequencies. Prog. Neuro Psychopharmacology Biol. Psychiatry 90, 104-116. DOI:10.1016/ j.pnpbp.2018.11.014.

Pavlov, D., Gorlova, A., Bettendorff, L., Kalueff, A.A., Umriukhin, A., Proshin, A., Lysko, A., Landgraf, R., Anthony, D.C., Strekalova, T., 2020. Enhanced conditioning of adverse memories in the mouse modified swim test is associated with neuroinflammatory changes - effects that are susceptible to antidepressants. Neurobiol. Learn. Mem. 172, 107227. DOI:10.1016/j.nlm.2020.107227.

Paxinos, G., Franklin, K.B.J., 2001. Paxinos and Franklin's the Mouse Brain in Stereotaxic Coordinates, 2nd edition. Academic Press, San Diego, p. 246.

Perez-Rodriguez, M.M., Weinstein, S., New, A.S., Bevilacqua, L., Yuan, Q., Zhou, Z., Hodgkinson, C., Goodman, M., Koenigsberg, H.W., Goldman, D., Siever, L.J., 2010. Tryptophan-hydroxylase 2 haplotype association with borderline personality disorder and aggression in a sample of patients with personality disorders and healthy controls. J. Psychiatr. Res. 44, 1075-1081. DOI:10.1016/j.jpsychires.2010.03.014.

Piggott, V.M., Bosse, K.E., Lisieski, M.J., Strader, J.A., Stanley, J.A., Conti, A.C., Ghoddoussi, F., Perrine, S.A., 2019. Single-prolonged stress impairs prefrontal cortex control of amygdala and striatum in rats. Front. Behav. Neurosci. 13, 1-9. DOI:10.3389/fnbeh.2019.00018.

Plemenita`s, A., Kores Plesni`car, B., Kastelic, M., Porcelli, S., Serretti, A., Dol`zan, V., 2015. Genetic variability in tryptophan hydroxylase 2 gene in alcohol dependence and alcohol-related psychopathological symptoms. Neurosci. Lett. 604, 86-90. DOI:10.1016/j.neulet.2015.07.037.

Porcelli, A.J., Lewis, A.H., Delgado, M.R., 2012. Acute stress influences neural circuits of reward processing. Front. Neurosci. 6, 1-9. DOI:10.3389/fnins.2012.00157.

Pucilowski, O., Valzelli, L., 1986. Chemical lesions of the nucleus accumbens septi in rats: effects on muricide and apomorphine-induced 
aggression. Behav. Brain Res. 19, 171-178. DOI:10.1016/01664328(86)90015-X.

Pucilowski, O., Trzaskowska, E., Kostowski, W., Valzelli, L., 1987. Norepinephrine-mediated suppression of apomorphine-induced aggression and locomotor activity in the rat amygdala. Pharmacol. Biochem. Behav. 26, 217-222. DOI: 10.1016/0091-3057(87)90108-0.

Quah, S.K., McIver, L., Roberts, A.C., Santangelo, A.M., 2020. Trait anxiety mediated by amygdala serotonin transporter in the common marmoset. J. Neurosci. DOI:10.1523/JNEUROSCI.2930-19.2020. JN-RM2930-19.

Reich, R., Gilbert, A., Clari, R., Burdick, K.E., Szeszko, P.R., 2019. A preliminary investigation of impulsivity, aggression and white matter in patients with bipolar disorder and a suicide attempt history. J. Affect. Disord. 247, 88-96. DOI:10.1016/j.jad.2019.01.001.

Rosell, D.R., Siever, L.J., 2015. The neurobiology of aggression and violence. CNS Spectr. 20, 254-279. DOI:10.1017/S109285291500019X.

Rosenkranz, J.A., Grace, A.A., 2001. Dopamine attenuates prefrontal cortical suppression of sensory inputs to the basolateral amygdala of rats. J. Neurosci. 21, 4090-4103. DOI:10.1523/jneurosci.2111-04090.2001.

Savelieva, K.V., Zhao, S., Pogorelov, V.M., Rajan, I., Yang, Q., Cullinan, E., Lanthorn, T. H., 2008. Genetic disruption of both tryptophan hydroxylase genes dramatically reduces serotonin and affects behavior in models sensitive to antidepressants. PLoS One 3. DOI:10.1371/journal.pone.0003301.

Seo, D., Patrick, C.J., Kennealy, P.J., 2008. Role of serotonin and dopamine system interactions in the neurobiology of impulsive aggression and its comorbidity with other clinical disorders. Aggress. Violent Behav. 13, 383-395. DOI: 10.1016/j.avb.2008.06.003.

Slaughter, K.E., Leaberry, K.D., Fogleman, N.D., Rosen, P.J., 2020. Reactive and proactive aggression in children with and without ADHD and negative emotional lability. Soc. Dev. 29, 320-338. DOI:10.1111/sode.12402. 
Strekalova, T., Steinbusch, H., 2009. Factors of reproducibility of anhedonia induction in a chronic stress depression model in mice. In: Gould, T.D. (Ed.), Mood and Anxiety Related Phenotypes in Mice: Characterization Using Behavioral Tests, Neuromethods. Humana Press, Totowa, NJ, pp. 153-176. DOI:10.1007/978-1-60761-303-9_9.

Strekalova, T., Steinbusch, H.W.M., 2010. Measuring behavior in mice with chronic stress depression paradigm. Prog. Neuro Psychopharmacology Biol. Psychiatry 34, 348-361.

DOI:10.1016/j.pnpbp.2009.12.014.

Strekalova, T., Spanagel, R., Bartsch, D., Henn, F.A., Gass, P., 2004. Stress-induced anhedonia in mice is associated with deficits in forced swimming and exploration. Neuropsychopharmacology 29, 2007-2017. DOI:10.1038/sj.npp.1300532.

Strekalova, T., Evans, M., Chernopiatko, A., Couch, Y., CostaNunes, J., Cespuglio, R., Chesson, L., Vignisse, J., Steinbusch, H.W., Anthony, D.C., Pomytkin, I., Lesch, K.P., 2015. Deuterium content of water increases depression susceptibility: the potential role of a serotonin-related mechanism. Behav. Brain Res. 277, 237-244. DOI:10.1016/j.bbr.2014.07.039.

Strekalova, T., Markova, N., Shevtsova, E., Zubareva, O., Bakhmet, A., Steinbusch, H.M., Bachurin, S., Lesch, K.-P., 2016. Individual differences in Behavioural despair predict brain GSK-3beta expression in mice: the power of a modified swim test. Neural Plast. 2016, 5098591. DOI:10.1155/2016/5098591.

Strekalova, T., Bahzenova, N., Trofimov, A., Schmitt-Böhrer, A.G., Markova, N., Grigoriev, V., Zamoyski, V., Serkova, T., Redkozubova, O., Vinogradova, D., Umriukhin, A., Fisenko, V., Lillesaar, C., Shevtsova, E., Sokolov, V., Aksinenko, A., Lesch, K.P., Bachurin, S., 2018. Proneurogenic, memory-enhancing and anti-stress effects of DF302, a novel fluorine gamma-carboline derivative with multi-target mechanism of action. Mol. Neurobiol. 55, 335-349. DOI:10.1007/ s12035-017-0745-6.

Tottenham, N., Galván, A., 2016. Stress and the adolescent brain: amygdala-prefrontal cortex circuitry and ventral striatum as developmental targets. Neurosci. Biobehav. Rev. 70, 217-227. DOI:10.1016/j.neubiorev.2016.07.030. 
Van Bockstaele, E.J., Colago, E.E.O., Valentino, R.J., 1998. Amygdaloid corticotropin-releasing factor targets locus coeruleus dendrites: substrate for the co-ordination of emotional and cognitive limbs of the stress response. J. Neuroendocrinol. 10, 743-758. DOI:10.1046/j.1365-2826.1998.00254.x.

Van Voorhees, E.E., Dennis, P.A., Elbogen, E.B., Clancy, C.P., Hertzberg, M.A., Beckham, J.C., Calhoun, P.S., 2014. Personality assessment inventory internalizing and externalizing structure in veterans with posttraumatic stress disorder: associations with aggression. Aggress. Behav. 40, 582-592. DOI: 10.1002/ab.21554.

Veenema, A.H., Bredewold, R., Neumann, I.D., 2007. Opposite effects of maternal separation on intermale and maternal aggression in C57BL/6 mice: link to hypothalamic vasopressin and oxytocin immunoreactivity. Psychoneuroendocrinology 32, 437-450. DOI:10.1016/j. psyneuen.2007.02.008.

Veniaminova, E., Cespuglio, R., Cheung, C.W., Umriukhin, A., Markova, N., Shevtsova, E., Lesch, K.P., Anthony, D.C., Strekalova, T., 2017. Autism-like Behaviours and memory deficits result from a Western diet in mice. Neural Plast. 2017 DOI:10.1155/2017/9498247.

Veniaminova, E., Oplatchikova, M., Bettendorff, L., Kotenkova, E., Lysko, A., Vasilevskaya, E., Kalueff, A.V., Fedulova, L., Umriukhin, A., Lesch, K.-P., Anthony, D. C., Strekalova, T., 2020. Prefrontal cortex inflammation and liver pathologies accompany cognitive and motor deficits following Western diet consumption in non-obese female mice. Life Sci. 241, 117163. DOI:10.1016/j. lfs.2019.117163.

Vignisse, J., Sambon, M., Gorlova, A., Pavlov, D., Caron, N., Malgrange, B., Shevtsova, E., Svistunov, A., Anthony, D.C., Markova, N., Bazhenova, N., Coumans, B., Lakaye, B., Wins, P., Strekalova, T., Bettendorff, L., 2017. Thiamine and benfotiamine prevent stress-induced suppression of hippocampal neurogenesis in mice exposed to predation without affecting brain thiamine diphosphate levels. Mol. Cell. Neurosci. 82, 126-136. DOI:10.1016/j.mcn.2017.05.005.

Waider, J., Popp, S., Lange, M.D., Kern, R., Kolter, J.F., Kobler, J., Donner, N.C., Lowe, K. R., Malzbender, J.H., Brazell, C.J., Arnold, M.R., Aboagye, B., Schmitt-Böhrer, A., Lowry, C.A., Pape, H.C., Lesch, K.P., 
2017. Genetically driven brain serotonin deficiency facilitates panic-like escape behavior in mice. Transl. Psychiatry 7, e1246. DOI:10.1038/tp.2017.209.

Waider, J., Popp, S., Mlinar, B., Montalbano, A., Bonfiglio, F., Aboagye, B., Thuy, E., Kern, R., Thiel, C., Araragi, N., Svirin, E., SchmittBöhrer, A.G., Corradetti, R., Lowry, C.A., Lesch, K.-P., 2019. Serotonin deficiency increases context-dependent fear learning through modulation of hippocampal activity. Front. Neurosci. 13, 245 DOI:10.3389/fnins.2019.00245.

Weidner, M.T., Lardenoije, R., Eijssen, L., Mogavero, F., De Groodt, L.P.M.T., Popp, S., Palme, R., Förstner, K.U., Reese, B.E., Kippin, T.E., 2019. Identification of Cholecystokinin by Genome-Wide Profiling as Potential Mediator of Serotonin- Dependent Behavioral Effects of Maternal Separation in the Amygdala, p. 13. DOI:10.3389/fnins.2019.00460.

Wigner, P., Czarny, P., Synowiec, E., Bijak, M., Białek, K., Talarowska, M., Galecki, P., Szemraj, J., Sliwinski, T., 2018. Association between single nucleotide polymorphisms of TPH1 and TPH2 genes, and depressive disorders. J. Cell. Mol. Med. 22, 1778-1791. DOI:10.1111/jcmm.13459.

Wind, T.R., Rijkeboer, M., Andersson, G., Riper, H., 2020. The COVID-19 pandemic: the 'black swan' for mental health care and a turning point for e-health. Internet Interv. 20, 100317. DOI:10.1016/j.invent.2020.100317.

Xu, Z., Reynolds, G.P., Yuan, Y., Shi, Y., Pu, M., Zhang, Z., 2016. TPH-2 polymorphisms interact with early life stress to influence response to treatment with antidepressant drugs. Int. J. Neuropsychopharmacol. 19, pyw070. DOI:10.1093/ijnp/pyw070.

Yorgason, J.T., Calipari, E.S., Ferris, M.J., Karkhanis, A.N., Fordahl, S.C., Weiner, J.L., Jones, S.R., 2016. Social isolation rearing increases dopamine uptake and psychostimulant potency in the striatum. Neuropharmacology 101, 471-479.

DOI:10.1016/j.neuropharm.2015.10.025.

Yu, R., Topiwala, A., Jacoby, R., Fazel, S., 2019. Aggressive behaviors in Alzheimer disease and mild cognitive impairment: 
systematic review and meta-analysis. Am. J. Geriatr. Psychiatry 27, 290300. DOI:10.1016/j.jagp.2018.10.008.

Zaman, H., Sampson, S., Beck, A., Sharma, T., Clay, F., Spyridi, S., Zhao, S., Gillies, D., 2018. Benzodiazepines for psychosis-induced aggression or agitation. Schizophr. Bull. 44, 966-969. DOI:10.1093/schbul/sby056.

Zhang, X., Yan, H., Luo, Y., Huang, Z., Rao, Y., 2018. Thermoregulation-independent regulation of sleep by serotonin revealed in mice defective in serotonin synthesis S. Mol. Pharmacol. 93, 657-664. DOI:10.1124/mol.117.111229. 


\section{CHAPTER}

Predation stress causes excessive aggression in female mice with partial genetic inactivation of tryptophan hydroxylase-2: evidence for altered myelination-related processes

Evgeniy Svirin ${ }^{1,2,3, \dagger}$, Ekaterina Veniaminova ${ }^{4 \dagger}$, João Costa-Nunes ${ }^{4,5 \dagger}$, Anna Gorlova ${ }^{4 \dagger}$, Aleksei Umriukhin ${ }^{4}$, Allan V. Kalueff ${ }^{6,7}$, Andrey Proshin ${ }^{8}$, Daniel C. Anthony ${ }^{4,9}$, Andrey Nedorubov ${ }^{10}$, Anna C. K. Tse ${ }^{11}$, Susanne Walitza ${ }^{12}$, Lee Wei Lim ${ }^{9 \#}$, Klaus-Peter Lesch ${ }^{1,2,4, \#}$, Tatyana Strekalova ${ }^{1,3,4, \#^{*}}$ Cells, under revision

${ }^{1}$ Department of Psychiatry and Neuropsychology, School for Mental Health and Neuroscience, Maastricht University, The Netherlands.

${ }^{2}$ Division of Molecular Psychiatry, Center of Mental Health, University of Würzburg, Würzburg, Germany.

${ }^{3}$ Institute of General Pathology and Pathophysiology, Russian Academy of Medical Sciences, Moscow, Russia.

${ }^{4}$ Laboratory of Psychiatric Neurobiology, Institute of Molecular Medicine and Department of Normal Physiology, Sechenov Moscow State Medical University, Moscow, Russia.

${ }^{5}$ Institute of Molecular Medicine, New University of Lisbon, Portugal.

${ }^{6}$ Neuroscience Program, Sirius University, Sochi, Russia

${ }^{7}$ School of Biological and Medical Physics, Moscow Institute of Physics and Technology, Moscow, Russia

${ }^{8}$ P.K. Anokhin Research Institute of Normal Physiology, Moscow, Russia ${ }^{9}$ Department of Pharmacology, Oxford University, Oxford, UK

10 Institute of Translational Medicine and Biotechnology, Sechenov University, Moscow, Russia

${ }^{11}$ School of Biomedical Sciences, Faculty of Medicine, the Chinese University of Hong Kong, Shatin, Hong Kong

12 Department for Child and Adolescent Psychiatry and Psychotherapy of the University of Zurich and the University Hospital of Psychiatry Zurich,

Switzerland †Joint first authorship, \#Joint senior authorship 


\section{Chapter 3. Predation stress causes excessive aggression in female mice with partial genetic inactivation of tryptophan hydroxylase-2: evidence for altered myelination-related processes}

\section{Abstract}

The interaction between brain serotonin $(5-\mathrm{HT})$ deficiency and environmental adversity may predispose females to aggravated aggression. Specifically, complete inactivation of the gene encoding tryptophan hydroxylase-2 (TPH2) results in the absence of neuronal 5HT synthesis and excessive aggressiveness both in male and female null mutant $\left(T p h 2^{---}\right)$mice. Heterozygous male mice $\left(T p h 2^{+/-}\right)$have a moderate reduction in 5-HT, and when exposed to stress also display increased aggression. Here, we subjected female $T p h 2^{+/-}$mice to a five-day predation stress comprising rat exposure and assessed their emotionality and social interaction/aggression-like behaviors. Tph2 $2^{+-}$females exhibited excessive aggression and increased dominant behavior. Stressed mutants displayed altered gene expression of 5-HT receptors Htr1a and Htr2a, glycogen synthase kinase-3 $\beta$ (GSK-3 $\beta$ ), and c-fos as well as several myelination-related markers in the prefrontal cortex: myelin basic protein $(M b p)$, proteolipid protein 1 (Plp1), myelinassociated glycoprotein ( $\mathrm{Mag}$ ) and myelin oligodendrocyte glycoprotein (Mog). The expression of the plasticity markers synaptophysin (Syn) and 
AMPA receptor subunit GluA2 were not affected by genotype. Moreover, in a separate experiment, naïve female $T p h 2^{+/-}$mice showed signs of enhanced stress resilience in the modified swim test with repeated swimming sessions. Taken together, an interaction of a moderate reduction in brain 5-HT with environmental challenges results in behavioral changes in female mice that resemble aggression-related behavior and resilience of stressed male mutants that altogether is comparable to a phenotype of null mutants lacking neuronal 5-HT. Alteration in myelination-associated processes may point to a molecular mechanism in the manifestation of aggressive behavior.

\section{Introduction}

Aggression is a behavior that is frequently accompanied by violence, and as such, results in numerous social and health adverse effects. World Health Organization categorizes violent behavior, the incidence of which continues to increase, among the top 20 causes of disability worldwide [1]. Although women are less aggressive than men, and female aggression is often expressed in more indirect forms, it is important to note of women are just as likely to aggress against a partner as men, but men cause more serious physical and psychological harm [2]. Recently, an increased incidence of female aggressive behavior in individuals with neuropsychiatric disorders [3] and more frequent crime statistics involving women have been reported [4]. This rise demands a better understanding of the molecular mechanisms that underpin female aggression, but the neurobiology of female aggression is largely unstudied. The use of experimental animal models to investigate the 
neurobiology of female aggression is limited, as this behavior is outside of the normal repertoire of mouse and rat behavioral assessments that commonly focus on male aggression $[5,6]$.

Female aggression can result from decreased synthesis of neuronal serotonin (5-HT); studies employing complete inactivation of the gene encoding tryptophan hydroxylase-2 (TPH2), a key enzyme of 5HT synthesis in the brain, have revealed a higher scores of aggression in female $T p h 2^{--}$mice [7-10]. In humans, the Tph2 gene polymorphism G$703 \mathrm{~T}$ was found to contribute to anger-related traits and the expression of anger in women [11]. Variations in the TPH2 gene were also associated with higher incidences of anxiety disorder in women and peripartum major depression $[12,13]$.

Accumulating evidence highlights the importance of gene $\times$ environment interaction in neuropsychiatric conditions [2,14-17]. This implicates both genetic factors and stressful experience interacting at the molecular level in the neurobiology of aggression. Mechanistic studies addressing this interaction in the context of female aggression are scarce. Nevertheless, female aggression was demonstrated to be influenced by environmental adversities including stress both in animal experiments $[2,6,18]$ and in clinical studies, where verbal and physical aggression was associated with traumatic stress experience [19].

he relevance of gene $x$ environment interaction in the manifestation of pathological aggression is further supported by studies in male mice heterozygous for Tph2 gene inactivation, which exhibit a moderate brain $5-\mathrm{HT}$ reduction of $15-20 \%[7,8]$. Tph $2^{+/-}$mice showed 
unaltered social behavior at baseline, but after subchronic rat exposure stress demonstrated markedly increased levels of aggression and dominancy, and reduced sociability compared to wild type controls $[20,21]$. These changes were accompanied by profound alterations in the brain metabolism of 5-HT, dopamine, and norepinephrine. Altogether, this suggested a phenotype of stressed $T p h 2^{+/-}$male mice reminiscent of naïve Tph2 null mutants.

The effects of environmental challenges and stress on aggression are gender-specific [6]. In rodents, a decrease in aggressive and dominant behaviors was reported in females subjected to a maternal separation paradigm in C57BL6 mice [22], and following social isolation stress in Wistar rats [23], while males showed increased aggression in these studies. Here, we aimed to clarify how gene $x$ environment interaction affects aggressive behavior in female $\mathrm{Tph}^{+/-}$mice and whether aggression in stressed female $T p h 2^{+/-}$mice displays similarities to male mutants. Owing to sex differences in the neurobiology of aggression under stressful conditions, we hypothesized that female $\mathrm{Tph}^{+/-}$mice would not demonstrate the abnormally elevated aggressive behavior found in male mutants. We adopted a previously validated fiveday rat exposure paradigm with includes an element of restraint, by virtue of limiting the extent free movement available to the $T p h 2^{+/-}$ female mice. This approach has been shown to induce changes in monoamine transmitters, neurogenesis, oxidative stress [24,25], as well as aggressive behavior in male $T p h 2^{+/-}$mice [20,21]. The rat exposure 
procedure applied here has been shown to result in increases in blood levels of CORT in C57BL/6 mice at 6 and 24 h post-stress [25].

In the current study, social interaction/aggression-like behaviors of stressed female mice were scored using tests of home cage social interaction and food competition [26-28]. Potential molecular changes were investigated in the prefrontal cortex, a brain area implicated in the mechanisms of both aggression and responses to stress. Based on previous findings in $T p h 2^{-/-}$males $[7,29,30]$, we studied gene expression of 5-HT receptors Htr1a and Htr2a. We also examined gene expression of

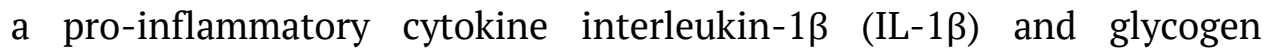

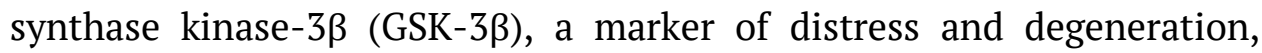
whose changes can accompany aberrant serotoninergic processes [31] and regulate aggression and stress responses [32]. Expression of plasticity markers AMPA receptor subunit GluA2, synaptophysin (Syp), and a marker of neuronal activation c-fos were also measured [24,33,34]. Gene expression relating to brain myelination was also explored based on our previous findings in stressed male $\mathrm{Tph}^{+/-}$mice [35] and established relationships between myelination and the 5-HT system [36] and stress [37]. Gene expression of myelin basic protein (Mbp), proteolipid protein 1 (Plp1), myelin-associated glycoprotein (Mag) and myelin oligodendrocyte glycoprotein (Mog), was measured.

Finally, we sought to determine whether female $T p h 2^{+/-}$mice resemble features of $\mathrm{Tph}^{+/-}$males in the broader context of emotional resilience to environmental challenges found in the modified swim test (modFST) and 
in tests for anxiety-like behavior [20,38] in naïve and stressed female Tph2 $2^{+/-}$mutants.

\section{Results}

2.1 Predation stress induces aggressive and dominant behavior in Tph2 ${ }^{+/-}$ females

In the novel cage test, the number of exploratory rears did not differ significantly between $T p h 2^{+/+}$and $T p h 2^{+/-}$mice $(\mathrm{t}=0.6140, \mathrm{df}=22$, $\mathrm{p}=0.55$, unpaired t-test. Figure 1A). Time spent in the lit box of the darklight box test also was not significantly different between these groups $(t=1.378, d f=18, p=0.19$, unpaired t-test. Figure $1 B)$.

The latency to crawl-over, number of crawl-overs, and total duration of this behavior, as a measure of home cage dominance, were significantly different between the groups as studied in the home cage $(\mathrm{H}=15.14, \mathrm{p}<0.01, \mathrm{H}=17.73, \mathrm{p}<0.01$ and $\mathrm{H}=17.39, \mathrm{p}<0.01$, respectively; Kruskal-Wallis test. Figure 1C-E). The latency to crawl-over in the stressed $\mathrm{Tph}^{+/-}$group was significantly shorter in comparison to both non-stressed $T p h 2^{+/-}$and stressed $T p h 2^{+/+}$(wild type) animals (both $\mathrm{p}<0.01$, Dunn's test). The number of episodes and the duration of crawlover behavior were significantly higher in the stressed mutant mice in comparison to non-stressed $\mathrm{Tph}^{+/-}$animals and stressed controls (all $\mathrm{p}<0.01$ ). While there was no significant group difference in number of animals displaying following behavior (all $\mathrm{p}=0.07$, Fisher's exact test. Figure $1 \mathrm{~F}$ ), in comparison to both non-stressed $\mathrm{Tph}^{+/-}$and stressed $\mathrm{Tph}^{+/+}$mice, the number of animals displaying agonistic (attacking) 
behavior was significantly higher in the stressed $T p h 2^{+/-}$group (both $\mathrm{p}=0.02$, Figure $1 \mathrm{G}$ ). None of the non-stressed mice exhibited following or attacking behaviors, regardless the genotype (Figure 1F,G).

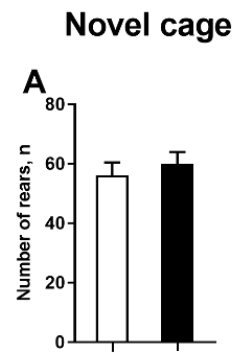

\section{Dark-light box}

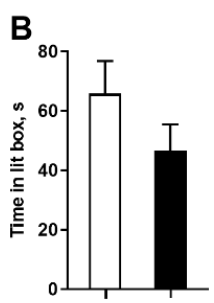

Crawl-over behavior in home cage
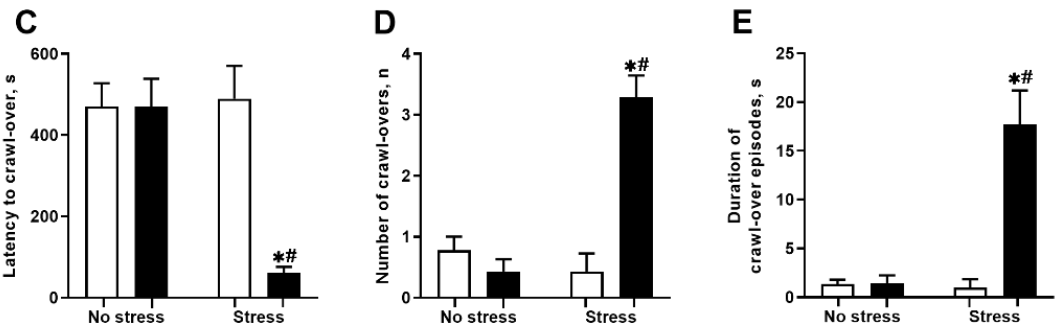

Following and attacking behavior in a home cage
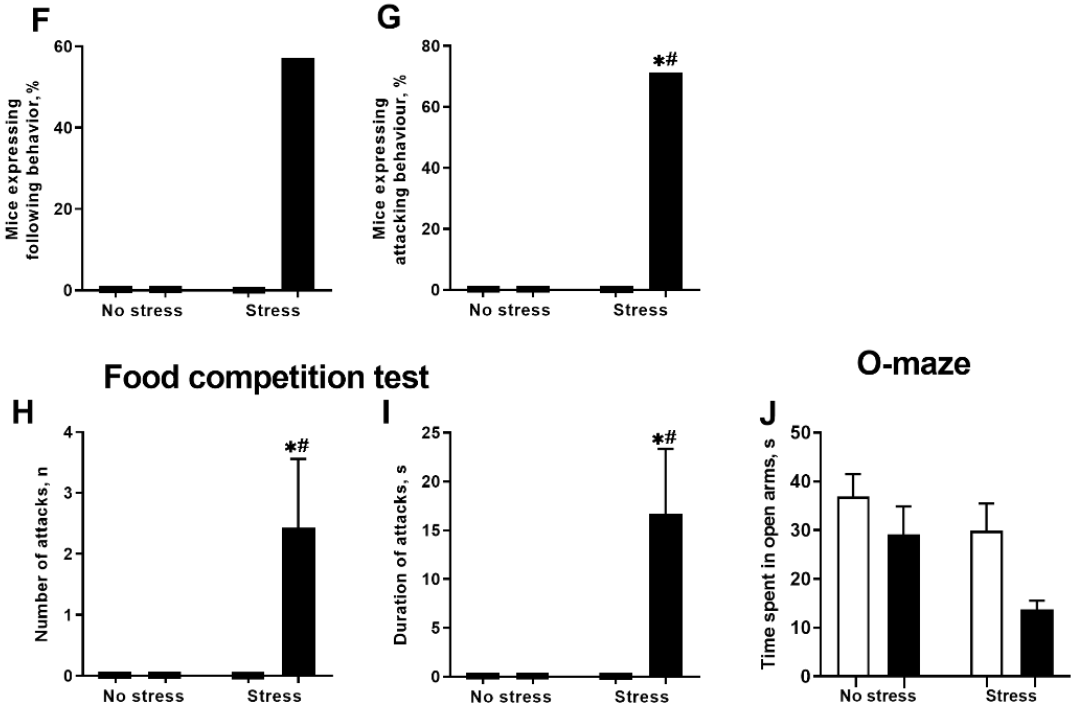

Figure 1. Behavioral features of naïve and stressed $\mathrm{Tph2}^{+/-}$female mice. (A) No alterations in the exploratory behavior of naïve $\mathrm{Tph}^{+/-}$mice were found 
in the novel cage test and in (B) the time spent in the lit box (controls: $n=14$, mutants: $n=10$ ). (C) Significantly lowered latency to crawl-over, and significantly elevated number of crawl-overs (D) and duration of crawl-over behavior $(E)$ in the social interaction in the home cage were found in stressed $\mathrm{Tph}^{+/-}$group. (F) There was no significant group difference in the percentage of the animals exhibiting following behavior in the social interaction in the home cage. $(\mathbf{G})$ In the social interaction in the home cage, agonistic behavior was displayed by a significantly higher percentage of animals in the stressed $\mathrm{Tph}^{+/-}$group, in comparison with non-stressed $\mathrm{Tph}^{+/-}$mice or stressed wild type animals. $(\mathbf{H})$ In the food competition test, a significantly higher number and (I) duration of attacks in stressed Tph2 $2^{+-}$ group was observed. (J) No significant group differences in the time spent in the open arms were found in the 0-maze (C-J: no stress: $n=9$; stress, $n=7$.). WT - Tph $2^{+/+},{ }^{*}-p<0.05$ vs same-genotype non-stressed group, \# $-p<0.05$ vs stress-matched WT group.

In the food competition test, significant differences were found between the groups in both the number and the duration of attacks $(\mathrm{H}=14.57, \mathrm{p}<0.01$, and $\mathrm{H}=14.57, \mathrm{p}<0.01$, respectively. Figure $1 \mathrm{H}, \mathrm{I})$. Posthoc analysis revealed that, in comparison to both non-stressed $T p h 2^{+/-}$ group and stressed $T p h 2^{+/+}$mice, the number and duration of attacks were significantly elevated in the stressed $T p h 2^{+/-}$group (both $\mathrm{p}=0.01$, Dunn's test). In a similar manner to the home cage assay, none of the nonstressed mice exhibited following or attacking behaviors in the food competition test, regardless the genotype (Figure 1H, I). In the O-maze, Kruskal-Wallis testing showed significant group difference in the time spent in the open arms $(\mathrm{H}=14.19, \mathrm{p}<0.01$. Figure $1 \mathrm{~J})$. The only significant difference was found between non-stressed wild type mice and stressed mutants $(\mathrm{p}<0.01)$; post-hoc analysis did not show significant differences between genotype-matched or stress-matched groups. Kruskal-Wallis 
test did not demonstrate any significant group differences in the food intake $(\mathrm{H}=0.17, \mathrm{p}=0.99$, Kruskal-Wallis test. Figure A1).

2.2 Altered gene expression of selected molecular markers in the prefrontal cortex of stressed $\mathrm{Tph}^{+/-}$mice

Two-way ANOVA revealed a significant main effect of genotype $(\mathrm{F} 1,21=21.40, \mathrm{p}<0.01)$ and no significant stress $\times$ genotype interaction $(\mathrm{F} 1,21=0.93, \mathrm{p}=0.35)$ in Htr1a expression. Irrespectively of the stress factor, a significant decrease in the expression of the Htr1a was found in $\mathrm{Tph}^{+/-}$animals (Figure 2A). No significant stress $\times$genotype interaction was shown in the expression of Htr2a (F1,20=1.240, p=0.28, two-way ANOVA. Figure 2B), though both main effects of stress and genotype significant altered expression $(F 1,20=26.58, p<0.01$, and $F 1,20=10.59$, $\mathrm{p}<0.01$, respectively, two-way ANOVA). Htr2a expression was significantly higher in the stressed animals independently of the genotype, and significantly lower in the mutant groups irrespective of the stress factor. These data suggest differential regulation of expression of 5-HT receptor subtypes by stress and partial Tph2 inactivation.

For Gsk-3 $\beta$ expression, a significant stress $\times$ genotype interaction was observed $(\mathrm{F} 1,16=16.47, \mathrm{p}<0.01$, two-way ANOVA. Figure $2 \mathrm{C})$. In comparison to non-stressed $\mathrm{Tph}^{+/-}$animals, post-hoc analysis revealed significantly higher Gsk-3 $\beta$ expression in both the stressed $T p h 2^{+/-}$group, and the non-stressed $T p h 2^{+/+}$mice (both $\mathrm{p}<0.01$, Tukey's test). GluA2 expression was not significantly affected by stress $\times$ genotype interaction $(\mathrm{F} 1,22=0.248, \mathrm{p}=0.62$. Figure $2 \mathrm{D})$, and only a significant main effect of stress was observed $(\mathrm{F} 1,22=4.331, \mathrm{p}=0.05)$. Specifically, stress elevated 
GluA2 expression compared to non-stressed animals irrespectively of their genotype.

No stress $\times$ genotype interaction was found for both $c$-fos and Syp expression $(\mathrm{F} 1,22=0.437, \mathrm{p}=0.52$, and $\mathrm{F} 1,22=1.149, \mathrm{p}=0.30$, respectively, two-way ANOVA), though main effects of genotype or stress on gene expression were observed. The expression of $c$-fos was significantly higher in $\mathrm{Tph}^{+/-}$mice in comparison with control animals, irrespectively of stress $(\mathrm{F} 1,22=6.63, \mathrm{p}=0.02$, two-way ANOVA. Figure $2 \mathrm{E})$. Irrespectively of the genotype, the expression of Syp was significantly higher in stressed animals than in controls $(F 1,22=5.24, p=0.03$. Figure $2 F)$.

Stress $\times$ genotype interaction significantly affected Plp1 expression ( $\mathrm{F} 1,19=4.949, \mathrm{p}=0.04$, two-way ANOVA). Post-hoc analysis revealed significantly lower expression of $P l p 1$ in stressed $T p h 2^{+/-}$mice in comparison to non-stressed $T p h 2^{+/-}$mice $(\mathrm{p}=0.02$, Tukey's test, Figure 3A). No significant differences were observed between $T p h 2^{+/+}$stressed and naïve mice ( $\mathrm{p}=0.07)$. For $M b p$ and Mag expression, ANOVA revealed significant stress $\times$ genotype interaction $(\mathrm{F} 1,16=16.68, \mathrm{p}<0.01$ and $\mathrm{F} 1,18=7.610, \mathrm{p}=0.01$ respectively, Figure $3 \mathrm{~B}, \mathrm{C})$. Compared to the nonstressed $\mathrm{Tph}^{+/-}$group, the expression of $\mathrm{Mbp}$ and $\mathrm{Mag}$ was significantly lower in both stressed $T p h 2^{+/-}(\mathrm{p}=0.01$ and $\mathrm{p}=0.02$, respectively, Tukey's test) and non-stressed Tph $2^{+/+}$mice $(\mathrm{p}<0.01$ and $\mathrm{p}=0.03$, respectively). ANOVA revealed no sig-nificant interaction for $M o g$ expression (F1,19=4.098, p=0.06, two-way ANOVA. Figure 3D), though a significant main effect of stress was observed $(F 1,19=10.08, p<0.01)$. In comparison 
to non-stressed mice, stressed animals had a significantly lower expression level of $M o g$ irrespective of their genotype.

A

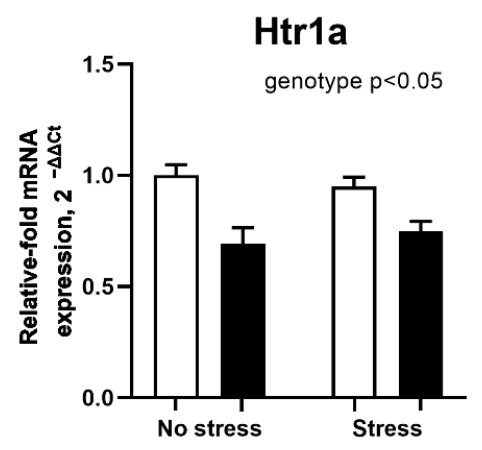

C

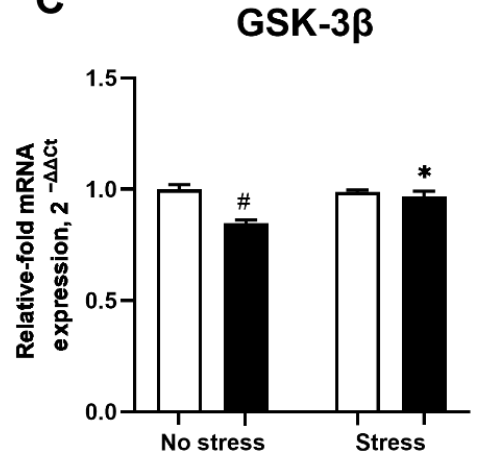

E

c-fos

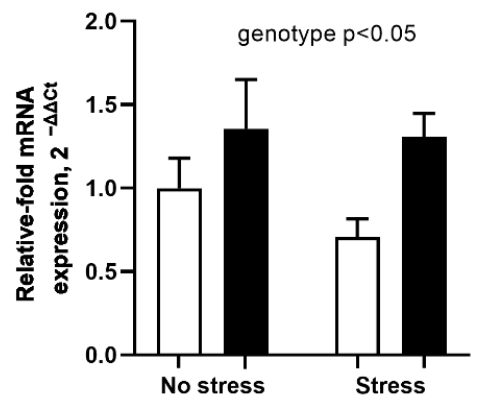

B

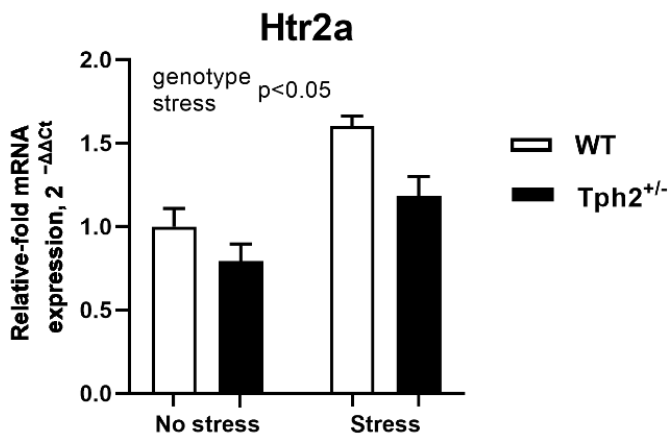

D

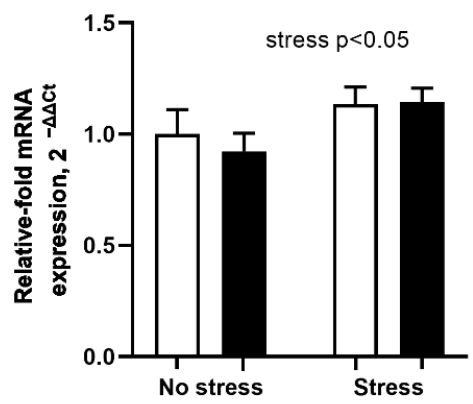

$\mathbf{F}$

Syp

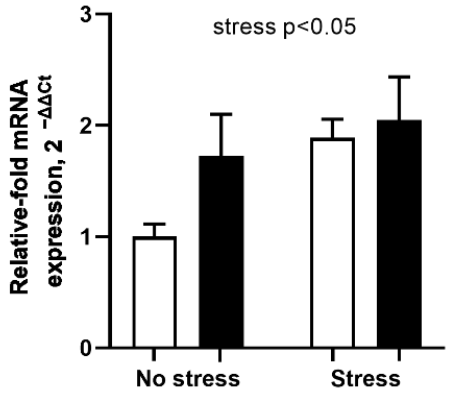


Figure 2. Expression of 5-HT receptors, Gsk-36, GluA2, c-fos and Syp in the brain of stressed $\mathrm{Tph}^{+/-}$mice. (A) Compared to control groups, Htr1a expression was significantly lowered in $\mathrm{Tph}^{+/-}$animals. (B) In comparison to non-stressed animals, in stressed groups Htr2a expression was significantly higher. Irrespectively of stress, Htr2a expression was higher in wild type groups. (C) Significantly higher Gsk-36 expression in both stressed $\mathrm{Tph}^{+/-}$group, and non-stressed $\mathrm{Tph}^{+/+}$mice was observed in comparison to non-stressed $\mathrm{Tph}^{+/-}$animals. (D) A significant main effect of stress was observed for the GluA2 subunit, whereby expression was elevated irrespectively of the genotype in stressed groups. (E) Expression of the c-fos was higher in $T p h 2^{+/-}$mice than in wild-type mice irrespectively of stress. (F) In stressed animals, expression of Syp was higher than in non-stressed animals, irrespectively of the genotype. WT - wild type, ${ }^{*}-p<0.05$ vs same-genotype non-stressed group, \# - p<0.05 vs stress-matched WT group. 6-9 mice per group were used.

Two-way ANOVA did not reveal any significant interaction between stress and genotype for the expression of the IL-1 $\beta$ $(\mathrm{F} 1,22=0.226, \mathrm{p}=0.64)$, and no post-hoc group differences were observed (Figure A2).

2.3 Naïve female Tph2 ${ }^{+-}$mice show signs of decreased learning of adverse memories and helplessness as a manifestation of stress resilience

In the modFST, in comparison to wild type mice, Tph2 $2^{+-}$mice demonstrated a significantly smaller increase in floating duration in first two minutes of the test session between days 2 and $5(\mathrm{U}=15, \mathrm{p}<0.01$, Mann-Whitney test; Figure A3 A). In the latency to float and the duration of floating, there was no significant interaction between day and genotype, though a main effect of the test day was found $(\mathrm{F} 1,14=91.79$ and $\mathrm{F} 1,12=89.22$, respectively, both $\mathrm{p}<0.01$, repeated measures two-way ANOVA; Figure A3 B,C). No significant group differences in the latency and duration of floating were found on either day of the test. 
A

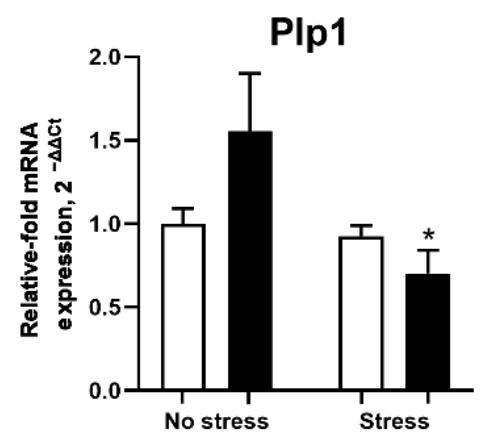

C

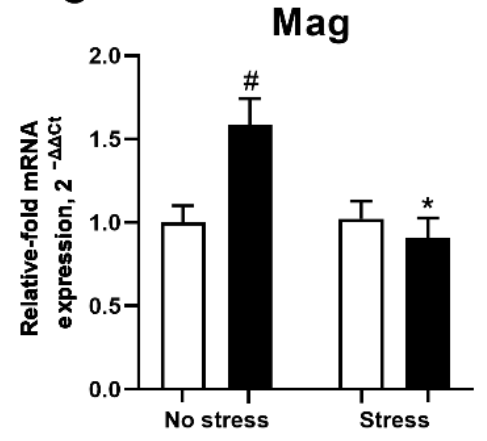

B

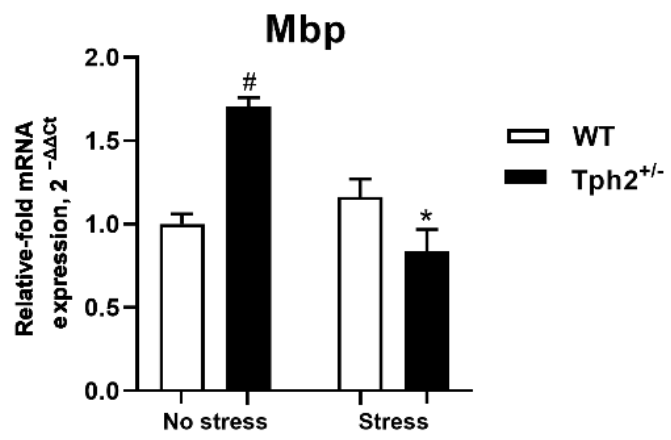

D

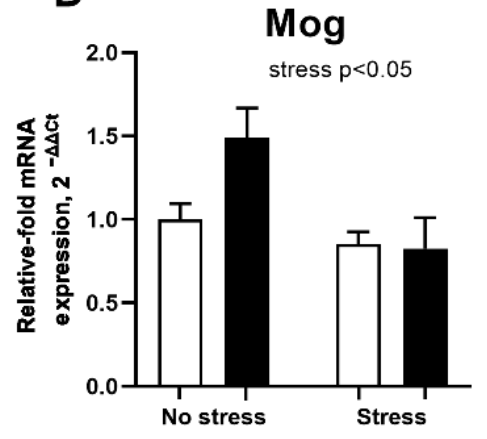

Figure 3. Elevated expression of myelination-related genes in the prefrontal cortex of non-stressed $\mathrm{Tph2}^{+/-}$mice. (A) Significantly lower expression of Plp1 was observed in stressed $\mathrm{Tph}^{+--}$mice in comparison to the nonstressed $\mathrm{Tph}^{+/-}$group (B, C) Compared to non-stressed $\mathrm{Tph}^{+{ }^{+-}}$group, expression of $\mathrm{Mbp}$ and Mag was significantly lower in both stressed $\mathrm{Tph}^{+{ }^{+-}}$ and non-stressed $\mathrm{Tph}^{+/+}$mice. (D) In comparison to non-stressed mice, stressed animals had a significantly lower expression level of Mog irrespective of the genotype. WT - wild type, ${ }^{*}-p<0.05$ vs same-genotype non-stressed group, \# $-p<0.05$ vs stress-matched WT group. 6-9 mice per group were used. 


\section{Discussion}

Our study revealed aggressive and dominant behaviors in female $\mathrm{Tph}^{+/-}$mice subjected to predation stress, resembling a behavioral profile reported for stressed male $T p h 2^{+/-}$mutants and mice with a complete inactivation of Tph2. Wild type stressed controls did not show any of these changes. We also found a decrease in gene expression of Plp1, Mbp, and Mag in the prefrontal cortex of stressed mutants, which may reflect aberrant myelination processes that might underlie their stress-induced aggression and dominance behavior. Baseline expression of Gsk-3 $\beta$ was lower in the non-stressed $T p h 2^{+/-}$mice than in wild type animals. Unlike wild type mice, mutants showed relatively increased Gsk$3 \beta$ expression under stress conditions. The lowered basal expression of Gsk-3 $\beta$ in female $T p h 2^{+/-}$mutants may also explain a diminished increase in behavioral despair during repeated swimming in the modFST, a sign of stress resilience.

The increased aggression and dominance in stressed mutants were accompanied by genotype effects on the prefrontal cortex expression of Htr1a and Htr2a. Both receptors are known to modulate aggressive behavior [39-41]. The expression of Htr1a and Htr2a were decreased in $\mathrm{Tph}^{+/-}$females regardless of stress, which is also a feature of $T p h 2^{-/-}$mutants; it was explained by potentially higher sensitivity of this receptor on a protein level resulting from the central 5-HT deficiency [42]. However, the $T p h 2^{+/-}$males subjected to predation stress did not affect Htr1a and Htr2a expression. Thus, for Htr1a, the sex-dependent behavioral effects that has been reported after the pharmacological 
targeting of Htr1a in rodents [43] suggests that there is likely to be a differential role for this receptor in abnormal aggression in males and females. Moreover, lowered gene expression of Htr6 reported in stressed male $T p h 2^{+/-}$mice [21] was also found in stressed female mutants in the present study.

The predation stress used in this work was previously shown to increase 5-HT turnover in the prefrontal cortex of stressed male Tph2 $2^{+-}$ mice [21] and significantly correlate with measures of aggressiveness (Bazhenova and Lesch, unpublished results). Surprisingly, stressed $\mathrm{Tph}^{+/-}$males exhibited unaltered 5-HT levels in the prefrontal cortex, while wildtype mice showed significant increases in 5-HT levels under these conditions. These abnormalities might arise from compromised 5HT metabolism in the prefrontal cortex of stressed mutants that result in disrupted cortical top-down control of limbic structures regulating aggression, including the amygdala, and is thus could underpin the social abnormalities of the stressed female $T p h 2^{+/-}$mice.

As compromised serotonin metabolism in the $\mathrm{Tph}^{+/-}$mutants can independently result in altered regulation of appetite, satiety, and metabolic processes, in which changes in monoamine levels and changes in the expression of their receptors can play a major role [44], excessive aggression in stressed mutants in our study might be food deprivation state-dependent. Preliminary studies on $\mathrm{Tph}^{+/-}$stressed mice housed under normal conditions did not reveal any changes in social behavior in the food competition test (Strekalova and Costa-Nunes, unpublished results). In the present study, we used a food deprivation challenge, a 
well-established inducer of aggression in male mice $[45,46]$ and hierarchical dominance behaviors in female mice [47]. Further studies are warranted to address the issue as to how the changes in serotonin receptor expression, the effects of food deprivation and aggression in stressed $\mathrm{Tph}^{+/-}$mice are related.

Genetic deficits in 5-HT function are well-established to result in developmental abnormalities of brain connectivity [36,48-50]. Compromised frontostriatal white matter integrity and connectivity is believed to underlie increased impulsivity and aggression [51-53]. Here, for the first time we report increased expression of genes encoding myelination-related proteins in the prefrontal cortex of naïve $T p h 2^{+/}$ female mice, and its significant decrease following predation stress. Previously work showed a decreased expression of $M b p$ and $M a g$ in naïve $\mathrm{Tph}^{+/-}$males [35]. Thus, the present findings in naïve $T p h 2^{+--}$females may mirror compensatory effects of the overexpression of myelination factors that is neutralized by stress, leading to impaired connectivity and maladaptive aggression in these animals. The stress-induced decrease of myelination-related marker expression was previously reported in numerous rodent models of stress, such as chronic unpredictable stress, social defeat and social isolation, immobilization stress and early-life stress $[54,55]$.

Moreover, others have previously demonstrated a relationship between the myelination in the prefrontal cortex and aggression and emotional dysregulation. Reduced thickness of the myelin sheath in the prefrontal cortex was reported to correlate with increased aggression 
caused by juvenile isolation [56]. Group housing was shown to ameliorate both aggressive behaviors and the myelination deficit in another study of social isolation in mice $[37,57]$. In rats, overexpression of the myelin transcription factor 1 (MyT1) promoting differentiation of oligodendrocytes, which is also regulated by PLP1 and MBP [58], ameliorates anxiety-like and compulsive behaviors [59]. Aberrant myelination is believed to underlie impaired brain connectivity and be associated with impulsive and aggressive behaviors, contributing to neurodevelopmental disorders, such as attention deficit hyperactivity disorder (ADHD), autism spectrum disorders (ASD), and schizophrenia $[60,61]$. We speculate that the observed changes in the expression of myelination proteins in stressed $T p h 2^{+-}$mice may mirror deficient development of white matter and brain connectivity and underpin the excessive aggression observed here.

Other molecular processes can potentially contribute to abnormal social behavior of stressed $\mathrm{Tph}^{+/-}$mice. Genotype differences in the expression of brain $c$-fos argues for a role for this factor in the aggressive behavior of stressed female $T p h 2^{+/-}$mice. In males, by comparison, $c$-fos expression was increased in the amygdala and prefrontal cortex of stressed mice of both genotypes [21]. Overexpression of $c$-fos in the hippocampus of $\mathrm{Tph}^{-/-}$mice is accompanied by increased freezing in the fear conditioning paradigm; a trend both towards molecular and behavioral changes was reported in the $T p h 2^{+--}$mutants $[8,62]$. It can be speculated that the over-expression of this immediately early gene as found in the stressed $T p h 2^{+/-}$groups twenty-four hours after the last 
manipulation might be owing to increased conditioning after the handling procedure. While chronic stress has been reported to suppress expression of Syp, a marker of neuronal plasticity [63,64], here Syp expression was elevated in $T p h 2^{+/-}$mice regardless of stress exposure. Elevated expression of Syp in $T p h 2^{+--}$females may indicate compensatory plasticity processes related to the upregulation of myelination in naïve mutants and may further contribute to their stress resilience shown in the modFST. Upregulated myelination markers may also relate to the decreased baseline expression of $G s k-3 \beta$, a key indicator of helplessness behavior, in naïve mutants [38]. Previous studies point to a reciprocal relationship between GSK-3 $\beta$ and myelination-related factors, e.g., Mbp $[65,66]$ that is in keeping with our findings of increased gene expression of the latter molecules found in naïve mutants.

In the present study, stress-induced overexpression of $G s k-3 \beta$ and GluA2 was not affected by the mutation. Similar results were found in the brain of stressed $T p h 2^{+-}$in males for Gsk-3 $\beta$, but GluA2 was upregulated selectively in the male mutants [21]. This challenges the view that these transcripts play a pivotal role in the aggression elicited in stressed $T p h 2^{+/-}$ females $[25,33]$ and further suggests that differences sex difference result in the differential regulation of aggression in the $T p h 2^{+/-}$mice. For GSK$3 \beta$, given that the level of the phosphorylated form of this kinase is the principal determinant of its activity, activity has been shown to correlate with Gsk-3 $\beta$ gene expression changes [67]. However, the further assessment of the level of GSK-3 $\beta$ phosphorylation might be useful to 
confirm this association and its role in the behavioral abnormalities of $\mathrm{Tph}^{+/-}$females reported here.

While molecular changes reported here are based on gene expression data, they are likely to also result in the changes in the level of protein expression. Similar studies reporting stress-induced increases of aggressive behavior in mice killed on the next day after the last manipulation showed congruent changes on gene and protein levels for the markers investigated here [32], and for myelin proteins [68].

\section{Materials and Methods}

\subsection{The animals and housing conditions}

We used 12-week-old $T p h 2^{+/-}$female mice, and their wild type littermates as controls, which were bred and genotyped in the facilities at the Institute of Molecular Medicine, New University of Lisbon, Portugal as previously described [8]. Mice of the same genotype were housed in standard cages in groups of 5 under controlled laboratory conditions $\left(22 \pm 1^{\circ} \mathrm{C}, 55 \%\right.$ humidity) and maintained on a reversed 12 -hour light/dark cycle (lights on at 19:00), with food and water provided ad libitum. All mice were tested during the dark phase of light/dark cycle. Laboratory housing conditions and experimental procedures were set up and maintained in accordance with Directive 2010/63/EU of 22 September 2010 and had been approved by the Ethics Committee of the New University of Lisbon (No. 0421/000/000/2013). All efforts were undertaken to minimize the potential discomfort of experimental animals. Experimental protocols conformed to directive 2010/63/EU and 
were compliant with ARRIVE guidelines (http://www.nc3rs.org.uk/arriveguidelines).

\subsection{Study design}

Female $\mathrm{Tph}^{+/-}$mice and their wild type littermates $\left(\mathrm{Tph} 2^{+/+}\right.$ controls) were studied for baseline behavior in novel cage and dark-light box paradigms (Figure 4, Experiment 1). Mice from four cages per genotype were studied: two cages per genotype per stress condition. Thereafter, they were subjected to a five-day rat exposure stress and investigated for social behaviors in their home cage, and in food competition tests and the elevated O-maze. The sequence of the behavioral tests was designed in a manner to minimize any potential effects of the testing procedure on the experimental animals and on the outcome of the subsequent tests $[69,70]$. In total, mice from four cages per genotype were studied: two cages per genotype per stress condition. Mice were sacrificed $24 \mathrm{~h}$ after the last behavioral test, and their brains were dissected for qRT-PCR assay. During this study, daily food intake was monitored (see below). A separate cohort of mice was studied in the modFST, in which the animals were exposed to three 6-min swim sessions on days 1,2 , and 5 . The learning of adverse context is defined by an increase in floating behavior from day 2 to day 5 (Figure 4, Experiment 2) [38]. On average, 7-10 animals per group were used in molecular and behavioral assays, group sizes are indicated in figure legends. 


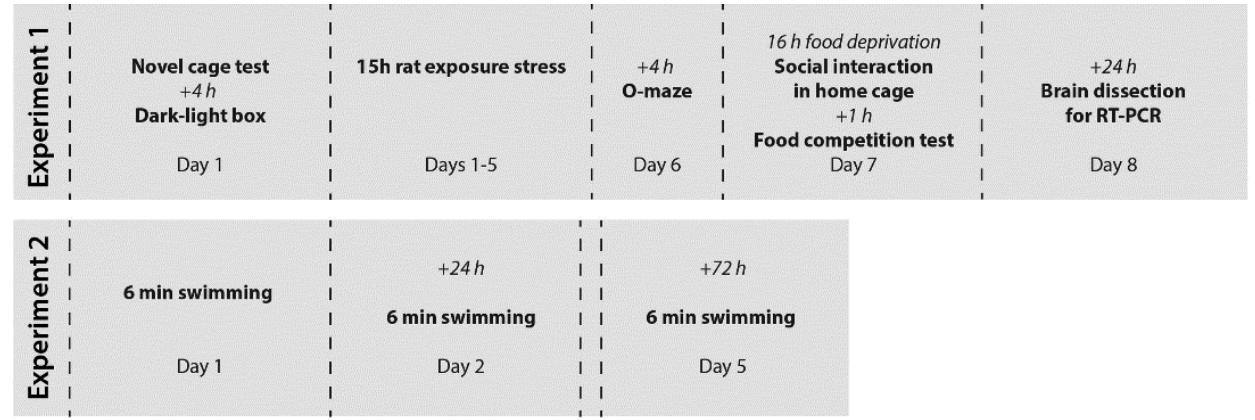

Figure 4. Experiment design. (Experiment 1). Female $T p h 2^{+/-}$mice and their wild type littermates were studied for baseline behavior. Thereafter, they were subjected to a 5-day rat exposure predation stress. Mice were studied in a battery of behavioral tests for aggression and anxiety-like behavior, then their brains were dissected for qRT-PCR assay. (Experiment 2) Separate cohort of mice was used for modFST. qRT-PCR - quantitative reverse transcription polymerase chain reaction assay.

\section{$4.3 \quad$ Novel cage}

Vertical exploratory activity of mice was studied in the novel cage test under red light as described elsewhere [34,70,71]. Briefly, mice were placed into a plastic cage and the number of exploratory rears was counted during a five-minute period under red light.

\subsection{Dark-light box}

The dark-light box consisted of two plexiglass compartments, dark box $(15 \times 20 \times 25 \mathrm{~cm})$ and light box $(30 \times 20 \times 25 \mathrm{~cm})$, connected by a tunnel. Mice were placed into the dark compartment, from where they could visit the light compartment, illuminated by bright light (300 lx intensity). Total duration of time spent in the light compartment was scored over $5 \min [72]$. 


\subsection{Rat exposure stress}

Mice were introduced into a spacious transparent glass cylinder $(15 \mathrm{~cm}$ high $\times 8 \mathrm{~cm}$ diameter) and placed into the rat cage between 18:00 and 9:00 for five consecutive nights as described elsewhere [20,25]. Mice had free access to food and water in their home cages between the stress sessions. The timing of the rat exposure model was designed to minimize the impact of food and water deprivation, as the predation period overlaps with the light (inactive) phase of activity of the mice when food and water consumption is minimal [73,74]. As the analysis of aggressive behavior in $\mathrm{Tph}^{+/-}$male mice that were exposed to a five-day predation stress only exhibited a significant increase of aggressiveness on day 5 [75], we used the same five-day stress procedure as minimally sufficient for the induction of aggression in the current study.

\subsection{Home cage interaction}

In all experimental groups, dominant, aggressive, and other social behaviors in a home cage were assessed during a ten-minute period under low lighting ( 5 lux) after a $16 \mathrm{~h}$ food deprivation. In this study, daily food intake was measured three days prior and one day after the behavioral test. The top of a home cage was replaced by a transparent cover, and mice were scored for the latency, total duration and number of episodes of crawl-over, following and agonistic (attacking) behaviors, and the number of mice expressing these behaviors [26,27]. The social interaction behavioral parameters employed here were validated in previous studies on female mice [27]. 
The crawl-over behavior, considered as a manifestation of hierarchical dominance [76-78], was defined as the movement of a mouse over the body of the partner; predominantly head first crossing transversely from one side to the other [77,79]. Following behavior, another sign of hierarchical dominance in female mice [47] was defined as the aggressive and rapid chasing of a fleeing counter-partner where the maximum distance between the animals was one body length (adapted from [78]). Agonistic (attacking) behavior was defined by the occurrence of physical attack of one mouse against another, which involved kicking, wrestling, biting, and rolling over the body of the counter-partner (adapted from [80,81]).

\subsection{Food competition test}

The food competition test was carried out immediately after the recording of the home cage behavior (see 2.6). Pairs of $16 \mathrm{~h}$ fooddeprived mice from different cages and the same experimental group were placed in a plastic observation cage $(21 \times 27 \times 14 \mathrm{~cm})$ and allowed to compete for a piece of beef meat ( $2 \mathrm{~g}$ ) for $10 \mathrm{~min}$ under low lighting (5 lux). The number and duration of attacks were scored [26,27]. Same definitions of social behavior as in a home cage interaction situation were used; these parameters were validated in previous studies on female mice [26].

\subsection{Elevated O-maze}

The apparatus consisted of a circular path (runway width $5.5 \mathrm{~cm}$, diameter $46 \mathrm{~cm}$ ) that was placed $45 \mathrm{~cm}$ above the floor. Two opposing 
arms were protected by walls (closed area, height $10 \mathrm{~cm}$ ). The apparatus was placed on a dark surface to maintain control over lighting conditions during testing, which were kept constant at 25 lux. Mice were placed in one of the closed-arm areas of the apparatus. Behavior was assessed using previously validated parameters during a 5-min observation period. The latency of the first exit to the open arms of the maze, the number of exits to the open arms and time spent in open arms were recorded [82].

\section{9 $\quad$ Modified forced swim test}

The modified forced swim test (modFST) was used here as a model that seeks to mimic the neurobiological changes that involve the enhanced learning of adversities and result in a helplessness in a particular context [38]. Mice were subjected to two swimming sessions with an interval of $24 \mathrm{~h}$. After the first two swim sessions, a third swim session was carried out on day 5 as previously described $[38,83,84]$. All sessions were 6-min long and were performed by placing a mouse in a transparent cylinder $(\varnothing 17 \mathrm{~cm})$ filled with water $\left(23^{\circ} \mathrm{C}\right.$, water height 13 $\mathrm{cm}$, height of cylinder $20 \mathrm{~cm}$ ). The floating behavior was defined as the absence of any directed movements of the head or body, and was scored by an observer unaware of the identity of the animal with Noldus EthoVision XT 8.5 (Noldus Information Technology, Wageningen, The Netherlands) as described elsewhere [85]. The duration of floating behavior was assessed in 2-minute intervals; the latency to float was measured. It is of note that in this model, the increase in floating behaviour, which is observed on day 5 compared to day 2 , is reversible by pre-treatment with antidepressant compounds [86-88]. For this reason, 
the increase in day 5 floating is regarded as a measure of excessive conditional learning and helplessness in an adverse context [83,84]. The increase in floating behavior during the first observation interval from day 2 to day 5 was expressed in percent and interpreted as a measure of learning in an adverse context, and helplessness $[83,84,86]$.

\subsection{Brain dissection and tissue collection}

Mice were terminally anaesthetized with an intraperitoneal injection of sodium pentobarbitone, the left ventricle was perfused with $10 \mathrm{ml}$ of ice-cold saline [71]. The brains were removed and the prefrontal cortex was isolated and stored at $-80^{\circ} \mathrm{C}$ as described elsewhere $[75,89]$.

\subsection{Quantitative real-time PCR (qRT-PCR)}

RNA extraction and cDNA synthesis were performed as described elsewhere [88]. Total mRNA was isolated from each sample with TRI Reagent (Invitrogen, Carlsbad, CA, USA). During first-strand cDNA synthesis $1 \mu \mathrm{g}$ total RNA was converted into cDNA using random primers and Superscript III transcriptase (Invitrogen, Carlsbad, CA, USA). qRTPCR was performed using the SYBR Green master mix (Bio-Rad Laboratories, Phila-delphia, PA, USA) qRT-PCR was performed using the SYBR Green master mix (Bio-Rad Laboratories, Philadelphia, PA, USA). qRT-PCR was performed in a $10 \mu$ reaction volume containing a SYBR Green master mix $(5 \mu \mathrm{l})$, RNase-free water $(3 \mu \mathrm{l})$, specific forward and reverse primers used at the concentration $20 \mathrm{pmol} / \mu \mathrm{l}(1 \mu \mathrm{l})$ and cDNA (1 $\mu \mathrm{l})$. The initial denaturation step for $\mathrm{qRT}-\mathrm{PCR}$ was at $95^{\circ} \mathrm{C}$ for $5 \mathrm{~min}$ followed by 40 cycles of denaturation at $95^{\circ} \mathrm{C}$ for $30 \mathrm{~s}$ and annealing at 
$60^{\circ} \mathrm{C}$ for $30 \mathrm{~s}$. The sequences of primers used are listed in Supplementary Table A1; all primers were purchased from Life Technologies (Carlsbad, CA, USA). All samples were run in triplicate. Relative gene expression was calculated using the $\Delta \Delta \mathrm{Ct}$ method and normalized to the expression of glyceraldehyde 3-phosphate dehydrogenase (GAPDH) housekeeping gene and to the expression of the control sample as described elsewhere $[34,90]$.

\subsection{Statistical analysis}

Data analysis was performed using GraphPad Prism software version 8.3 (San Diego CA, USA). Normally distributed data were analyzed using an unpaired t-test or a two-way ANOVA test followed by the Tukey's correction for the pairwise comparisons of the group means of behavioral and molecular data. Specifically, the Tukey's test was used for the post-hoc analysis of gene expression results, as each RT PCR assay in this study, was carried out separately for each transcript and because the confidence intervals obtained for the values of the mRNA concentrations and the fold changes of all investigated transcripts do not include zero values. Further corrections for multiple comparisons, or the use of a three-way ANOVA, for distinct transcripts was not considered appropriate owing to altered variances, the method of normalization, and because corrections across multiple independent experiments would be expected to give rise to an increase in false negatives. Nonparametric data were analyzed by Kruskal-Wallis test and Dunn's post-hoc test. Fisher's exact test was performed for analysis of contingency tables. Statistical significance was set at $p<0.05$. Data are shown as mean \pm SEM. 


\section{Conclusions}

Taken together, our findings show that an interaction between partial genetic inactivation of neuronal $\mathrm{Tph} 2$ expression and environmental adversity results in aggressive and dominant behaviors in female $T p h 2^{+/-}$mice. Naïve female $T p h 2^{+/-}$mice show decreased learning of adverse memories and helplessness, a sign of stress resilience. These behaviors are reminiscent to changes in $T p h 2^{+/}$males and null mutants of both sexes lacking Tph2. For the first time, we report altered expression of myelination markers in naïve and stressed female $T p h 2^{+/-}$ mice. These data encourage speculation regarding impaired brain connectivity in these mice, which likely contributes to the increased aggression and dominance observed in the stressed $T p h 2^{+/}$mice. Further studies are required to shed light on the detailed mechanisms of the relationships between serotonin deficiency, stress, and myelination in the context of gene $\times$ environment interaction and female aggression.

Author Contributions: Conceptualization: LWL, KPL, SW, TS; Data curation: AU, AK, DA,; Formal analysis: AN, AK, DA; Funding acquisition: LW, KPL, TS; Investigation: ES, EV, AG, JN, ACKT; Methodology: EV, AP, ACKT, LWL, TS; Project administration: AP, SW, TS; Resources: AN, LWL, KPL, SW, TS; Software: AU, AN; Supervision: AP, AU, TS; Visualization: ES, KV, AG; Roles/Writing -original draft ES, AG, KPL, TS; Writing - review \& editing: AK, EV, AP, LWL, KPL, DA, SW.

Funding: The authors' animal work reported here was supported by Deutsche Forschungsgemeinschaft (DFG:CRC TRR58A1/A5), the 
European Union's Seventh Framework Programme (FP7/2007-2013) under Grant No.602805 (Aggressotype), the Horizon 2020 Research and Innovation Programme under Grant No.728018 (Eat2beNICE) (to KPL and TS) and Swiss-Russian Cooperation grant RPG Russia 2020 (to SW and KPL). Molecular data analysis was supported by RAS №0520-2019-0031 (to ES and TS). The sponsors had no role in study design, in the collection, analysis and interpretation of data; in the writing of the report and in the decision to submit the article for publication.

Institutional Review Board Statement: The study was conducted according to the guidelines of the Directive 2010/63/EU of 22 September 2010 and had been approved by the Ethics Committee of the New University of Lisbon (No. 0421/000/000/2013). Experimental protocols conformed to directive 2010/63/EU and were compliant with ARRIVE guidelines (http://www.nc3rs.org.uk/arrive-guidelines).

Data Availability Statement: In this section, please provide details regarding where data supporting reported results can be found, including links to publicly archived datasets analyzed or generated during the study. Please refer to suggested Data Availability Statements in section “MDPI Research Data Policies” at https://www.mdpi.com/ethics. You might choose to exclude this statement if the study did not report any data.

Acknowledgments: We appreciate the valuable help of Dr. Dolores Bonopartos with this project and kind help of Mr. Daniel Radford-Smith with editing the language. We also thank Dr. Alexander Silchenko from 
the Institute of Neuroscience and Medicine (INM-7: Brain and Behavior), Jülich Research Center, Jülich, Germany for their kind help with the statistical analysis of the data.

Conflicts of Interest: Declare conflicts of interest or state "The authors declare no conflict of interest." Authors must identify and declare any personal circumstances or interest that may be perceived as inappropriately influencing the representation or interpretation of reported research results. Any role of the funders in the design of the study; in the collection, analyses or interpretation of data; in the writing of the manuscript, or in the decision to publish the results must be declared in this section. If there is no role, please state "The funders had no role in the design of the study; in the collection, analyses, or interpretation of data; in the writing of the manuscript, or in the decision to publish the results". 


\section{Appendix A}

Supplementary methods

Table A1. Primer sequences for mRNA expression analysis

\begin{tabular}{|c|c|c|}
\hline Gene & Primer & Sequence \\
\hline \multirow[t]{2}{*}{ Htr1a } & Forward & 5'-GACAGGCGGCAACGATACT-3' \\
\hline & Reverse & 5'-CCAAGGAGCCGATGAGATAGTT-3' \\
\hline \multirow[t]{2}{*}{ Htr2a } & Forward & 5'-TAATGCAATTAGGTGACGACTCG-3' \\
\hline & Reverse & 5'-GCAGGAGAGGTTGGTTCTGTTT-3' \\
\hline \multirow[t]{2}{*}{ GSK-3 $\beta$} & Forward & 5'-GCACTCTTCAACTTTACCACTCA-3' \\
\hline & Reverse & 5'-CGAGCATGTGGAGGGATAAG-3' \\
\hline \multirow[t]{2}{*}{ GluA2 } & Forward & 5'-GCGTGGAAATAGAAAGGGCC-3' \\
\hline & Reverse & 5'-ACTCCAGTACCCAATCTTCCG-3' \\
\hline \multirow[t]{2}{*}{ c-fos } & Forward & 5'-CGGGTTTCAACGCCGACTA-3' \\
\hline & Reverse & 5'-TTGGCACTAGAGACGGACAGA-3' \\
\hline \multirow[t]{2}{*}{ Syp } & Forward & 5'- TGTGTTTGCCTTCCTCTACTC-3' \\
\hline & Reverse & 5'- TCAGTGGCCATCTTCACATC-3' \\
\hline \multirow[t]{2}{*}{ Plp1 } & Forward & 5'-CCAGAATGTATGGTGTTCTCCC-3' \\
\hline & Reverse & 5'-GGCCCATGAGTTTAAGGACG-3' \\
\hline \multirow[t]{2}{*}{ Mbp } & Forward & 5'- TCACAGCGATCCAAGTACCTG-3' \\
\hline & Reverse & 5'-CCCCTGTCACCGCTAAAGAA-3' \\
\hline \multirow[t]{2}{*}{ Mag } & Forward & 5'-GGTACATGGCGTCTGGTATTTC-3' \\
\hline & Reverse & 5'-ACTTGTGTGCGGGACTTGAAG-3' \\
\hline \multirow[t]{2}{*}{ Mog } & Forward & 5'-TCATGCAGCTATGCAGGACAA-3' \\
\hline & Reverse & 5'-TTTCGGTAGAGGTGAACCACT-3' \\
\hline \multirow[t]{2}{*}{ IL-1 $\beta$} & Forward & 5'- CTTCCAGGATGAGGACATGAGCAC -3' \\
\hline & Reverse & 5'-TCATCATCCCATGAGTCACAGAGG -3' \\
\hline \multirow[t]{2}{*}{ GAPDH } & Forward & 5'-ATGACCACAGTCCATGCCATC -3' \\
\hline & Reverse & 5'-GAGCTTCCCGTTCAGCTCTG -3' \\
\hline
\end{tabular}


Supplementary results

Daily food intake of $\mathrm{Tph}^{++-}$mice

The Kruskal-Wallis test did not reveal significant differences in the average daily food intake measured during the observation period $(\mathrm{H}=0.17, \mathrm{p}=0.99$, Kruskal-Wallis test. Figure A1).

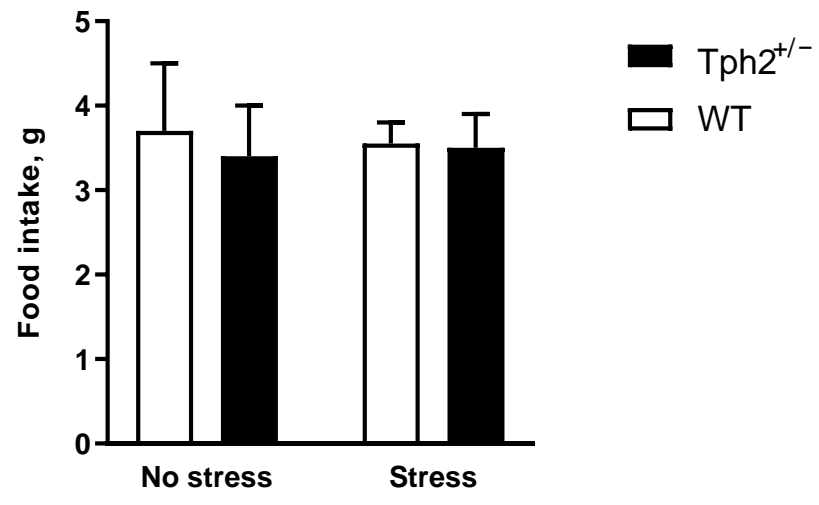

Figure A1. Daily food intake of $T p h 2^{+/-}$mice. No significant group difference in the average daily food intake during the observation period was found. WT - wild type.

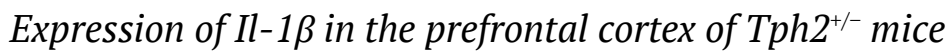

No significant differences were found by two-way ANOVA in the expression of $I l-1 \beta$ in the prefrontal cortex (interaction: $F 1,22=0.226$, $\mathrm{p}=0.64$; stress: $\mathrm{F} 1,22=0.062, \mathrm{p}=0.81$ : genotype: $\mathrm{F} 1,22=2.635, \mathrm{p}=0.12$. Figure A2). 


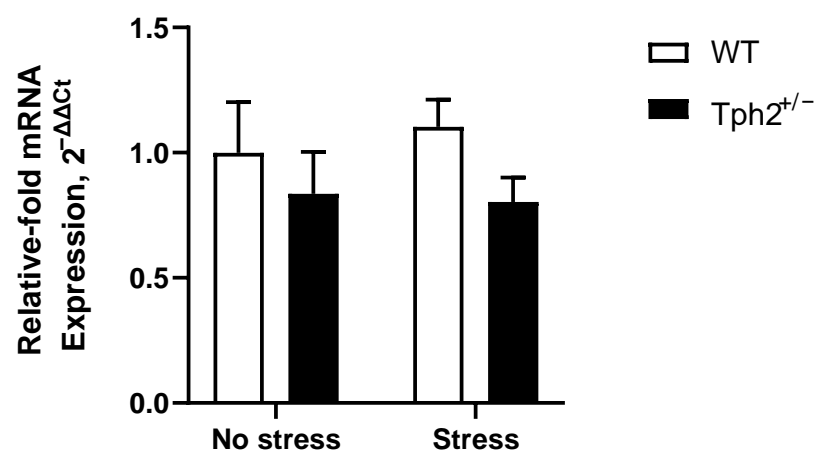

Figure A2. Expression of $I l-16$ in the prefrontal cortex of $T p h 2^{+/-}$mice. No significant group differences were found in the expression of $1 /-16$. WT wild type, 6-9 mice per group were used.

$\mathrm{Tph}^{+/-}$mice display reduced potentiation of floating in the modFST paradigm

The change in floating duration in the first two minutes of the test session between days 2 and 5 in $T p h 2^{+-}$animals was significantly smaller than in wild type mice (see ms text, Figure A3 A). In the latency to float and the duration of floating, only the main effect of the test day was found (see ms text, Figure A3 B,C). Post-hoc analysis revealed significant decrease in latency to float and significant increase in the duration of floating on days 2 and 5 compared to day 1 irrespective of the genotype (both p<0.01, Šídák's multiple comparisons test). 
A

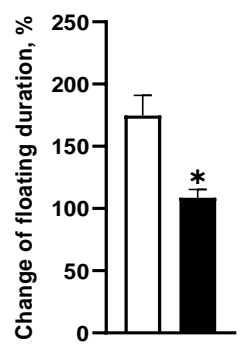

B

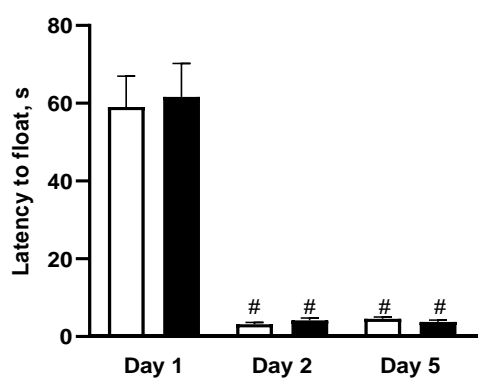

C

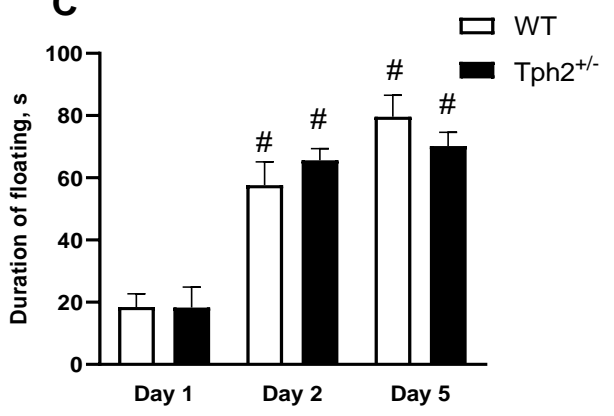

Figure A3. Floating behavior in the modified swim test. (A) Significantly lower increase of floating duration from day 2 to day 5 in $\mathrm{Tph}^{+/-}$mice. (B) Significant decrease in latency to float on days 2 and 5 compared to day 1 was observed irrespectively of the genotype. (C) There was significant increase in the duration of floating on days 2 and 5 compared to day 1 irrespective of the genotype. WT - wild type, ${ }^{*} p<0.01$ vs. wild type, $\# p<0.01$ vs same genotype on day 1.11-13 animals per group were used. 


\section{References}

1. Vakili, V.; Ziaee, M.; Zarifian, A. Aggression: Is that an issue for worrying? Iran. J. Public Health 2015, 44, 1561-1562.

2. Xiang, C.; Liu, S.; Fan, Y.; Wang, X.; Jia, Y.; Li, L.; Cong, S.; Han, F. Single nucleotide polymorphisms, variable number tandem repeats and allele influence on serotonergic enzyme modulators for aggressive and suicidal behaviors: A review. Pharmacol. Biochem. Behav. 2019, 180, 74-82, doi:10.1016/j.pbb.2019.03.008.

3. Freitag, C.M.; Konrad, K.; Stadler, C.; De Brito, S.A.; Popma, A.; Herpertz, S.C.; Herpertz-Dahlmann, B.; Neumann, I.; Kieser, M.; Chiocchetti, A.G.; et al. Conduct disorder in adolescent females: current state of research and study design of the FemNAT-CD consortium. Eur. Child Adolesc. Psychiatry 2018, 27, 1077-1093, doi:10.1007/s00787-0181172-6.

4. Denson, T.F.; O’Dean, S.M.; Blake, K.R.; Beames, J.R. Aggression in women: Behavior, brain and hormones. Front. Behav. Neurosci. 2018, 12, 1-20, doi:10.3389/fnbeh.2018.00081.

5. Neumann, I.D.; Veenema, A.H.; Beiderbeck, D.I. Aggression and anxiety: Social context and neurobiological links. Front. Behav. Neurosci. 2010, 4, 1-16, doi:10.3389/fnbeh.2010.00012.

6. Takahashi, A.; Miczek, K.A. Neurogenetics of aggressive behavior: studies in rodents. Curr. Top. Behav. Neurosci. 2014, 17, 3-44, doi:10.1007/7854_2013_263.

7. Gutknecht, L.; Araragi, N.; Merker, S.; Waider, J.; Sommerlandt, F.M.J.; Mlinar, B.; Baccini, G.; Mayer, U.; Proft, F.; Hamon, M.; et al. Impacts of brain serotonin deficiency following Tph2 inactivation on development and Raphe neuron serotonergic specification. PLoS One 2012, 7, doi:10.1371/journal.pone.0043157.

8. Gutknecht, L.; Popp, S.; Waider, J.; Sommerlandt, F.M.J.; Göppner, C.; Post, A.; Reif, A.; Van Den Hove, D.; Strekalova, T.; Schmitt, A.; et al. Interaction of brain 5-HT synthesis deficiency, chronic stress and sex differentially impact emotional behavior in Tph2 knockout mice. Psychopharmacology (Berl). 2015, 232, 2429-2441, doi:10.1007/s00213015-3879-0. 
9. Angoa-Pérez, M.; Kane, M.J.; Briggs, D.I.; Sykes, C.E.; Shah, M.M.; Francescutti, D.M.; Rosenberg, D.R.; Thomas, D.M.; Kuhn, D.M. Genetic depletion of brain 5HT reveals a common molecular pathway mediating compulsivity and impulsivity. J. Neurochem. 2012, 121, 974-984, doi:10.1111/j.1471-4159.2012.07739.x.

10. Weidner, M.T.; Lardenoije, R.; Eijssen, L.; Mogavero, F.; Groodt, L.P.M.T. De; Popp, S.; Palme, R.; Förstner, K.U.; Reese, B.E.; Kippin, T.E. Identification of Cholecystokinin by Genome-Wide Profiling as Potential Mediator of Serotonin-Dependent Behavioral Effects of Maternal Separation in the Amygdala. 2019, 13, doi:10.3389/fnins.2019.00460.

11. Yang, J.; Lee, M.S.; Lee, S.H.; Lee, B.C.; Kim, S.H.; Joe, S.H.; Jung, I.K.; Choi, I.G.; Ham, B.J. Association between tryptophan hydroxylase 2 polymorphism and anger-related personality traits among young Korean women. Neuropsychobiology 2010, 62, 158-163, doi:10.1159/000318572.

12. Lin, Y.M.J.; Ko, H.C.; Chang, F.M.; Yeh, T.L.; Sun, H.S. Population-specific functional variant of the TPH2 gene $2755 \mathrm{C}>\mathrm{A}$ polymorphism contributes risk association to major depression and anxiety in Chinese peripartum women. Arch. Womens. Ment. Health 2009, 12, 401-408, doi:10.1007/s00737-009-0088-z.

13. Fasching, P.A.; Faschingbauer, F.; Goecke, T.W.; Engel, A.; Häberle, L.; Seifert, A.; Voigt, F.; Amann, M.; Rebhan, D.; Burger, P.; et al. Genetic variants in the tryptophan hydroxylase 2 gene (TPH2) and depression during and after pregnancy. J. Psychiatr. Res. 2012, 46, 11091117, doi:10.1016/j.jpsychires.2012.05.011.

14. Anstrom, K.K.; Miczek, K.A.; Budygin, E.A. Increased phasic dopamine signaling in the mesolimbic pathway during social defeat in rats. Neuroscience 2009, 161, 3-12, doi:10.1016/j.neuroscience.2009.03.023.

15. Deal, A.L.; Park, J.; Weiner, J.L.; Budygin, E.A. Stress Alters the Effect of Alcohol on Catecholamine Dynamics in the Basolateral Amygdala. Front. Behav. Neurosci. 2021, 15, doi:10.3389/fnbeh.2021.640651.

16. Lee, Y.C.; Chao, Y.L.; Chang, C.E.; Hsieh, M.H.; Liu, K.T.; Chen, H.C.; Lu, M.L.; Chen, W.Y.; Chen, C.H.; Tsai, M.H.; et al. Transcriptome 
changes in relation to manic episode. Front. Psychiatry 2019, 10, 1-12, doi:10.3389/fpsyt.2019.00280.

17. Lesch, K.P. Alcohol dependence and gene $\mathrm{x}$ environment interaction in emotion regulation: Is serotonin the link? Eur. J. Pharmacol. 2005, 526, 113-124, doi:10.1016/j.ejphar.2005.09.027.

18. Haller, J.; Harold, G.; Sandi, C.; Neumann, I.D. Effects of adverse early-life events on aggression and anti-social behaviours in animals and humans. J. Neuroendocrinol. 2014, 26, 724-738, doi:10.1111/jne.12182.

19. Augsburger, M.; Maercker, A. Associations between trauma exposure, posttraumatic stress disorder, and aggression perpetrated by women. A meta-analysis. Clin. Psychol. Sci. Pract. 2020, 27, 1-13, doi:10.1111/cpsp.12322.

20. Strekalova, T.; Svirin, E.; Waider, J.; Gorlova, A.; Cespuglio, R.; Kalueff, A.; Pomytkin, I.; Schmitt-Boehrer, A.G.; Lesch, K.-P.; Anthony, D.C. Altered behaviour, dopamine and norepinephrine regulation in stressed mice heterozygous in TPH2 gene. Prog. NeuroPsychopharmacology Biol. Psychiatry 2021, 108, 110155, doi:10.1016/j.pnpbp.2020.110155.

21. Gorlova, A.; Ortega, G.; Waider, J.; Bazhenova, N.; Veniaminova, E.; Proshin, A.; Kalueff, A. V.; Anthony, D.C.; Lesch, K.P.; Strekalova, T. Stress-induced aggression in heterozygous TPH2 mutant mice is associated with alterations in serotonin turnover and expression of 5HT6 and AMPA subunit 2A receptors. J. Affect. Disord. 2020, 272, 440451, doi:10.1016/j.jad.2020.04.014.

22. Veenema, A.H.; Bredewold, R.; Neumann, I.D. Opposite effects of maternal separation on intermale and maternal aggression in C57BL/6 mice: Link to hypothalamic vasopressin and oxytocin immunoreactivity. Psychoneuroendocrinology 2007, 32, 437-450, doi:10.1016/j.psyneuen.2007.02.008.

23. Oliveira, V.E. de M.; Neumann, I.D.; de Jong, T.R. Post-weaning social isolation exacerbates aggression in both sexes and affects the vasopressin and oxytocin system in a sex-specific manner. Neuropharmacology 2019, 156, 107504, doi:10.1016/j.neuropharm.2019.01.019. 
24. Costa-Nunes, J.; Zubareva, O.; Araújo-Correia, M.; Valença, A.; Schroeter, C.A.; Pawluski, J.L.; Vignisse, J.; Steinbusch, H.; Hermes, D.; Phillipines, M.; et al. Altered emotionality, hippocampus-dependent performance and expression of NMDA receptor subunit mRNAs in chronically stressed mice. Stress 2014, 17, 108-116, doi:10.3109/10253890.2013.872619.

25. Vignisse, J.; Sambon, M.; Gorlova, A.; Pavlov, D.; Caron, N.; Malgrange, B.; Shevtsova, E.; Svistunov, A.; Anthony, D.C.; Markova, N.; et al. Thiamine and benfotiamine prevent stress-induced suppression of hippocampal neurogenesis in mice exposed to predation without affecting brain thiamine diphosphate levels. Mol. Cell. Neurosci. 2017, 82, 126-136, doi:10.1016/j.mcn.2017.05.005.

26. Veniaminova, E.; Cespuglio, R.; Markova, N.; Mortimer, N.; Wai Cheung, C.; Steinbusch, H.W.; Lesch, K.-P.; Strekalova, T. Behavioral features of mice fed with a cholesterol-enriched diet:Deficient novelty exploration and unaltered aggressive behavior. Transl. Neurosci. Clin. 2016, 2, 87, doi:10.18679/CN11-6030/R.2016.014.

27. Veniaminova, E.; Cespuglio, R.; Cheung, C.W.; Umriukhin, A.; Markova, N.; Shevtsova, E.; Lesch, K.P.; Anthony, D.C.; Strekalova, T. Autism-Like Behaviours and Memory Deficits Result from a Western Diet in Mice. Neural Plast. 2017, 2017, doi:10.1155/2017/9498247.

28. Veniaminova, E.; Cespuglio, R.; Chernukha, I.; Schmitt-Boehrer, A.G.; Morozov, S.; Kalueff, A. V.; Kuznetsova, O.; Anthony, D.C.; Lesch, K.-P.; Strekalova, T. Metabolic, Molecular, and Behavioral Effects of Western Diet in Serotonin Transporter-Deficient Mice: Rescue by Heterozygosity? Front. Neurosci. 2020, 14, doi:10.3389/fnins.2020.00024.

29. Kim, J.Y.; Kim, A.; Zhao, Z.Q.; Liu, X.Y.; Chen, Z.F. Postnatal maintenance of the 5-Ht1a-Pet1 autoregulatory loop by serotonin in the raphe nuclei of the brainstem. Mol. Brain 2014, 7, 1-11, doi:10.1186/1756-6606-7-48.

30. Mlinar, B.; Montalbano, A.; Waider, J.; Lesch, K.P.; Corradetti, R. Increased functional coupling of 5-HT1A autoreceptors to GIRK channels in Tph2 ${ }^{-/-}$mice. Eur. Neuropsychopharmacol. 2017, 27, 1258-1267, doi:10.1016/j.euroneuro.2017.10.033. 
31. Wang, L.R.; Kim, S.H.; Baek, S.S. Effects of treadmill exercise on the anxiety-like behavior through modulation of GSK3 $\beta / \beta$-catenin signaling in the maternal separation rat pup. J. Exerc. Rehabil. 2019, 15, 206-212, doi:10.12965/jer.1938094.047.

32. Pavlov, D.; Bettendorff, L.; Gorlova, A.; Olkhovik, A.; Kalueff, A. V.; Ponomarev, E.D.; Inozemtsev, A.; Chekhonin, V.; Lesch, K.P.; Anthony, D.C.; et al. Neuroinflammation and aberrant hippocampal plasticity in a mouse model of emotional stress evoked by exposure to ultrasound of alternating frequencies. Prog. Neuro-Psychopharmacology Biol. Psychiatry 2019, 90, 104-116, doi:10.1016/j.pnpbp.2018.11.014.

33. Costa-Nunes, J.P.; Gorlova, A.; Pavlov, D.; Cespuglio, R.; Gorovaya, A.; Proshin, A.; Umriukhin, A.; Ponomarev, E.D.; Kalueff, A. V.; Strekalova, T.; et al. Ultrasound stress compromises the correlates of emotional-like states and brain AMPAR expression in mice: effects of antioxidant and anti-inflammatory herbal treatment. Stress 2020, 0, 000, doi:10.1080/10253890.2019.1709435.

34. Gorlova, A.; Pavlov, D.; Anthony, D.C.; Ponomarev, E.D.; Sambon, M.; Proshin, A.; Shafarevich, I.; Babaevskaya, D.; Lesch, K.P.; Bettendorff, L.; et al. Thiamine and benfotiamine counteract ultrasoundinduced aggression, normalize AMPA receptor expression and plasticity markers, and reduce oxidative stress in mice. Neuropharmacology 2019, 156, 107543, doi:10.1016/j.neuropharm.2019.02.025.

35. Svirin, E.; Gorlova, A.; Lim, L.W.; Veniaminova, E.; Costa-Nunes, J.; Anthony, D.; Lesch, K.-P.; Strekalova, T. Sexual bias in the altered expression of myelination factors in mice with partial genetic deficiency of tryptophan hydroxylase 2 and pro-aggressive effects of predation stress. In Proceedings of the IBNS 30th Annual Meeting; 2021.

36. Jha, S.C.; Meltzer-Brody, S.; Steiner, R.J.; Cornea, E.; Woolson, S.; Ahn, M.; Verde, A.R.; Hamer, R.M.; Zhu, H.; Styner, M.; et al. Antenatal depression, treatment with selective serotonin reuptake inhibitors, and neonatal brain structure: A propensity-matched cohort study. Psychiatry Res. - Neuroimaging 2016, 253, 43-53, doi:10.1016/j.pscychresns.2016.05.004.

37. Makinodan, M.; Ikawa, D.; Miyamoto, Y.; Yamauchi, J.; Yamamuro, K.; Yamashita, Y.; Toritsuka, M.; Kimoto, S.; Okumura, K.; 
Yamauchi, T.; et al. Social isolation impairs remyelination in mice through modulation of IL-6. FASEB J. 2016, 30, 4267-4274, doi:10.1096/fj.201600537R.

38. Strekalova, T.; Markova, N.; Shevtsova, E.; Zubareva, O.; Bakhmet, A.; Steinbusch, H.M.; Bachurin, S.; Lesch, K.-P. Individual Differences in Behavioural Despair Predict Brain GSK-3beta Expression in Mice: The Power of a Modified Swim Test. Neural Plast. 2016, 2016, 5098591, doi:10.1155/2016/5098591.

39. Audero, E.; Mlinar, B.; Baccini, G.; Skachokova, Z.K.; Corradetti, R.; Gross, C. Suppression of Serotonin Neuron Firing Increases Aggression in Mice. J. Neurosci. 2013, 33, 8678-8688, doi:10.1523/JNEUROSCI.2067-12.2013.

40. Juárez, P.; Valdovinos, M.G.; May, M.E.; Lloyd, B.P.; Couppis, M.H.; Kennedy, C.H. Serotonin2A/C receptors mediate the aggressive phenotype of TLX gene knockout mice. Behav. Brain Res. 2013, 256, 354361, doi:10.1016/j.bbr.2013.07.044.

41. Godar, S.C.; Mosher, L.J.; Scheggi, S.; Devoto, P.; Moench, K.M.; Strathman, H.J.; Jones, C.M.; Frau, R.; Melis, M.; Gambarana, C.; et al. Gene-environment interactions in antisocial behavior are mediated by early-life 5-HT2A receptor activation. Neuropharmacology 2019, 159, doi:10.1016/j.neuropharm.2019.01.028.

42. Araragi, N.; Mlinar, B.; Baccini, G.; Gutknecht, L.; Lesch, K.P.; Corradetti, R. Conservation of 5 -HT1A receptor-mediated autoinhibition of serotonin (5-HT) neurons in mice with altered 5-HT homeostasis. Front. Pharmacol. 2013, 4 AUG, 1-11, doi:10.3389/fphar.2013.00097.

43. Terranova, J.I.; Song, Z.; Larkin, T.E.; Hardcastle, N.; Norvelle, A.; Riaz, A.; Albers, H.E. Serotonin and arginine-vasopressin mediate sex differences in the regulation of dominance and aggression by the social brain. Proc. Natl. Acad. Sci. U. S. A. 2016, 113, 13233-13238, doi:10.1073/pnas.1610446113.

44. Voigt, J.P.; Fink, H. Serotonin controlling feeding and satiety. Behav. Brain Res. 2015, 277, 14-31, doi:10.1016/j.bbr.2014.08.065.

45. Ragnauth, A.K.; Devidze, N.; Moy, V.; Finley, K.; Goodwill, A.; Kow, L.M.; Muglia, L.J.; Pfaff, D.W. Female oxytocin gene-knockout mice, 
in a seminatural environment, display exaggerated aggressive behavior. Genes, Brain Behav. 2005, 4, 229-239, doi:10.1111/j.1601183X.2005.00118.x.

46. Wersinger, S.R.; Caldwell, H.K.; Christiansen, M.; Young, W.S. Disruption of the vasopressin $1 \mathrm{~b}$ receptor gene impairs the attack component of aggressive behavior in mice. Genes, Brain Behav. 2007, 6, 653-660, doi:10.1111/j.1601-183X.2006.00294.X.

47. Alleva, E. Assessment of Aggressive Behavior in Rodents. In MRS Bulletin; 1993; Vol. 58, pp. 111-137 ISBN 0385-5600 (Print) 0385-5600 (Linking).

48. Misri, S.; Reebye, P.; Kendrick, K.; Carter, D.; Ryan, D.; Grunau, R.E.; Oberlander, T.F. Internalizing behaviors in 4-year-old children exposed in utero to psychotropic medications. Am. J. Psychiatry 2006, 163, 1026-1032, doi:10.1176/appi.ajp.163.6.1026.

49. Oberlander, T.F.; Papsdorf, M.; Brain, U.M.; Misri, S.; Ross, C.; Grunau, R.E. Prenatal Effects of Selective Serotonin Reuptake Inhibitor Antidepressants, Serotonin Transporter Promoter Genotype (SLC6A4), and Maternal Mood on Child Behavior at 3 Years of Age. Arch. Pediatr. Adolesc. Med. 2010, 164, 444-451, doi:10.1001/archpediatrics.2010.51.

50. Oberlander, T.F.; Reebye, P.; Misri, S.; Papsdorf, M.; Kim, J.; Grunau, R.E. Externalizing and attentional behaviors in children of depressed mothers treated with a selective serotonin reuptake inhibitor antidepressant during pregnancy. Arch. Pediatr. Adolesc. Med. 2007, 161, 22-29, doi:10.1001/archpedi.161.1.22.

51. Blair, R.J.R. The Neurobiology of Impulsive Aggression. J. Child Adolesc. Psychopharmacol. 2016, 26, 4-9, doi:10.1089/cap.2015.0088.

52. Ziegler, G.; Hauser, T.U.; Moutoussis, M.; Bullmore, E.T.; Goodyer, I.M.; Fonagy, P.; Jones, P.B.; Lindenberger, U.; Dolan, R.J. Compulsivity and impulsivity traits linked to attenuated developmental frontostriatal myelination trajectories. Nat. Neurosci. 2019, 22, 992-999, doi:10.1038/s41593-019-0394-3.

53. Ikuta, T.; del Arco, A.; Karlsgodt, K.H. White matter integrity in the fronto-striatal accumbofrontal tract predicts impulsivity. Brain Imaging Behav. 2018, 12, 1524-1528, doi:10.1007/s11682-017-9820-X. 
54. Antontseva, E.; Bondar, N.; Reshetnikov, V.; Merkulova, T. The Effects of Chronic Stress on Brain Myelination in Humans and in Various Rodent Models. Neuroscience 2020, 441, 226-238, doi:10.1016/j.neuroscience.2020.06.013.

55. Chu, X.; Zhou, Y.; Hu, Z.; Lou, J.; Song, W.; Li, J.; Liang, X.; Chen, C.; Wang, S.; Yang, B.; et al. 24-Hour-Restraint Stress Induces LongTerm Depressive-Like Phenotypes in Mice. Sci. Rep. 2016, 6, 1-12, doi:10.1038/srep32935.

56. Ibi, D.; Takuma, K.; Koike, H.; Mizoguchi, H.; Tsuritani, K.; Kuwahara, Y.; Kamei, H.; Nagai, T.; Yoneda, Y.; Nabeshima, T.; et al. Social isolation rearing-induced impairment of the hippocampal neurogenesis is associated with deficits in spatial memory and emotionrelated behaviors in juvenile mice. J. Neurochem. 2008, 105, 921-932, doi:10.1111/j.1471-4159.2007.05207.x.

57. Makinodan, M.; Ikawa, D.; Yamamuro, K.; Yamashita, Y.; Toritsuka, M.; Kimoto, S.; Yamauchi, T.; Okumura, K.; Komori, T.; Fukami, S.I.; et al. Effects of the mode of re-socialization after juvenile social isolation on medial prefrontal cortex myelination and function. Sci. Rep. 2017, 7, 1-9, doi:10.1038/s41598-017-05632-2.

58. Nielsen, J.A.; Berndt, J.A.; Hudson, L.D.; Armstrong, R.C. Myelin transcription factor 1 (Myt1) modulates the proliferation and differentiation of oligodendrocyte lineage cells. Mol. Cell. Neurosci. 2004, 25, 111-123, doi:10.1016/j.mcn.2003.10.001.

59. Bahi, A.; Dreyer, J.L. Viral-mediated overexpression of the Myelin Transcription Factor 1 (MyT1) in the dentate gyrus attenuates anxietyand ethanol-related behaviors in rats. Psychopharmacology (Berl). 2017, 234, 1829-1840, doi:10.1007/s00213-017-4588-7.

60. Takahashi, N.; Sakurai, T.; Davis, K.L.; Buxbaum, J.D. Linking oligodendrocyte and myelin dysfunction to neurocircuitry abnormalities in schizophrenia. Prog. Neurobiol. 2011, 93, 13-24, doi:10.1016/j.pneurobio.2010.09.004.

61. Lesch, K.P. Editorial: Can dysregulated myelination be linked to ADHD pathogenesis and persistence? J. Child Psychol. Psychiatry Allied Discip. 2019, 60, 229-231, doi:10.1111/jcpp.13031. 
62. Waider, J.; Popp, S.; Mlinar, B.; Montalbano, A.; Bonfiglio, F.; Aboagye, B.; Thuy, E.; Kern, R.; Thiel, C.; Araragi, N.; et al. Serotonin Deficiency Increases Context-Dependent Fear Learning Through Modulation of Hippocampal Activity. Front. Neurosci. 2019, 13, 1-12, doi:10.3389/fnins.2019.00245.

63. Thome, J.; Pesold, B.; Baader, M.; Hu, M.; Gewirtz, J.C.; Duman, R.S.; Henn, F.A. Stress differentially regulates synaptophysin and synaptotagmin expression in hippocampus. Biol. Psychiatry 2001, 50, 809-812, doi:10.1016/S0006-3223(01)01229-X.

64. Xu, H.; He, J.; Richardson, J.S.; Li, X.M. The response of synaptophysin and microtubule-associated protein 1 to restraint stress in rat hippocampus and its modulation by venlafaxine. J. Neurochem. 2004, 91, 1380-1388, doi:10.1111/j.1471-4159.2004.02827.x.

65. Dohare, P.; Cheng, B.; Ahmed, E.; Yadala, V.; Singla, P.; Thomas, S.; Kayton, R.; Ungvari, Z.; Ballabh, P. Glycogen synthase kinase-3 $\beta$ inhibition enhances myelination in preterm newborns with intraventricular hemorrhage, but not recombinant Wnt3A. Neurobiol. Dis. 2018, 118, 22-39, doi:10.1016/j.nbd.2018.06.015.

66. Azim, K.; Butt, A.M. GSK3 $\beta$ negatively regulates oligodendrocyte differentiation and myelination in vivo. Glia 2011, 59, 540-553, doi:10.1002/glia.21122.

67. He, R.; Du, S.; Lei, T.; Xie, X.; Wang, Y. Glycogen synthase kinase $3 \beta$ in tumorigenesis and oncotherapy (Review). Oncol. Rep. 2020, 44, 2373-2385, doi:10.3892/or.2020.7817.

68. Strekalova, T.; Svirin, E.; Veniaminova, E.; Kopeikina, E.; Veremeyko, T.; Yung, A.W.Y.; Proshin, A.; Walitza, S.; Anthony, D.C.; Lim, L.W.; et al. ASD-like behaviors, a dysregulated inflammatory response and decreased expression of PLP1 characterize mice deficient for sialyltransferase ST3GAL5. Brain, Behav. Immun. - Heal. 2021, 16, 100306, doi:10.1016/j.bbih.2021.100306.

69. Strekalova, T. Optimization of the chronic stress depression model in C57 BL/6 mice: evidences for improved validity. In Behavioral models in stress research. Volume I; J, L., Ed.; Nova Science Publishers: NY, USA, 2008; pp. 95-139. 
70. Strekalova, T.; Steinbusch, H.W.M. Measuring behavior in mice with chronic stress depression paradigm. Prog. NeuroPsychopharmacology Biol. Psychiatry 2010, 34, 348-361, doi:10.1016/j.pnpbp.2009.12.014.

71. Couch, Y.; Anthony, D.C.; Dolgov, O.; Revischin, A.; Festoff, B.; Santos, A.I.; Steinbusch, H.W.; Strekalova, T. Microglial activation, increased TNF and SERT expression in the prefrontal cortex define stress-altered behaviour in mice susceptible to anhedonia. Brain. Behav. Immun. 2013, 29, 136-146, doi:10.1016/j.bbi.2012.12.017.

72. Costa-Nunes, J.P.; Cline, B.H.; Araújo-Correia, M.; Valença, A.; Markova, N.; Dolgov, O.; Kubatiev, A.; Yeritsyan, N.; Steinbusch, H.W.M.; Strekalova, T. Animal Models of Depression and Drug Delivery with Food as an Effective Dosing Method: Evidences from Studies with Celecoxib and Dicholine Succinate. Biomed Res. Int. 2015, 2015, 596126, doi:10.1155/2015/596126.

73. Strekalova, T.; Spanagel, R.; Bartsch, D.; Henn, F.A.; Gass, P. Stress-induced anhedonia in mice is associated with deficits in forced swimming and exploration. Neuropsychopharmacology 2004, 29, 20072017, doi:10.1038/sj.npp.1300532.

74. Strekalova, T.; Gorenkova, N.; Schunk, E.; Dolgov, O.; Bartsch, D. Selective effects of citalopram in a mouse model of stress-induced anhedonia with a control for chronic stress. Behav. Pharmacol. 2006, 17, 271-287, doi:10.1097/00008877-200605000-00008.

75. Gorlova, A.; Ortega, G.; Waider, J.; Bazhenova, N.; Veniaminova, E.; Proshin, A.; Kalueff, A. V.; Anthony, D.C.; Lesch, K.P.; Strekalova, T. Stress-induced aggression in heterozygous TPH2 mutant mice is associated with alterations in serotonin turnover and expression of 5HT6 and AMPA subunit 2A receptors. J. Affect. Disord. 2020, 272, 440451, doi:10.1016/j.jad.2020.04.014.

76. Clipperton Allen, A.E.; Cragg, C.L.; Wood, A.J.; Pfaff, D.W.; Choleris, E. Agonistic behavior in males and females: Effects of an estrogen receptor beta agonist in gonadectomized and gonadally intact mice. Psychoneuroendocrinology 2010, 35, 1008-1022, doi:10.1016/j.psyneuen.2010.01.002. 
77. Terranova, M.L.; Laviola, G.; Alleva, E. Ontogeny of amicable social behavior in the mouse: Gender differences and ongoing isolation outcomes. Dev. Psychobiol. 1993, 26, 467-481, doi:10.1002/dev.420260805.

78. Williamson, C.M.; Lee, W.; DeCasien, A.R.; Lanham, A.; Romeo, R.D.; Curley, J.P. Social hierarchy position in female mice is associated with plasma corticosterone levels and hypothalamic gene expression. Sci. Rep. 2019, 9, 1-14, doi:10.1038/s41598-019-43747-w.

79. Mackintosh, J.H.; Grant, E.C. A Comparison of the Social Postures of Some Common Laboratory Rodents. Behaviour 1963, 21, 246-259, doi:10.1163/156853963X00185.

80. Kästner, N.; Richter, S.H.; Urbanik, S.; Kunert, J.; Waider, J.; Lesch, K.P.; Kaiser, S.; Sachser, N. Brain serotonin deficiency affects female aggression. Sci. Rep. 2019, 9, 1-9, doi:10.1038/s41598-018-376134.

81. Kloke, V.; Jansen, F.; Heiming, R.S.; Palme, R.; Lesch, K.P.; Sachser, N. The winner and loser effect, serotonin transporter genotype, and the display of offensive aggression. Physiol. Behav. 2011, 103, 565574, doi:10.1016/j.physbeh.2011.04.021.

82. Couch, Y.; Trofimov, A.; Markova, N.; Nikolenko, V.; Steinbusch, H.W.; Chekhonin, V.; Schroeter, C.; Lesch, K.P.; Anthony, D.C.; Strekalova, T. Low-dose lipopolysaccharide (LPS) inhibits aggressive and augments depressive behaviours in a chronic mild stress model in mice. J. Neuroinflammation 2016, 13, 1-17, doi:10.1186/s12974-016-0572-0.

83. Pavlov, D.; Markova, N.; Bettendorff, L.; Chekhonin, V.; Pomytkin, I.; Lioudyno, V.; Svistunov, A.; Ponomarev, E.; Lesch, K.P.; Strekalova, T. Elucidating the functions of brain GSK3 $\alpha$ : Possible synergy with GSK3 $\beta$ upregulation and reversal by antidepressant treatment in a mouse model of depressive-like behaviour. Behav. Brain Res. 2017, 335, 122-127, doi:10.1016/j.bbr.2017.08.018.

84. Pavlov, D.; Gorlova, A.; Bettendorff, L.; Kalueff, A.A.; Umriukhin, A.; Proshin, A.; Lysko, A.; Landgraf, R.; Anthony, D.C.; Strekalova, T. Enhanced conditioning of adverse memories in the mouse modified swim test is associated with neuroinflammatory changes - Effects that are 
susceptible to antidepressants. Neurobiol. Learn. Mem. 2020, 172, 107227, doi:10.1016/j.nlm.2020.107227.

85. Malatynska, E.; Steinbusch, H.W.M.; Redkozubova, O.; Bolkunov, A.; Kubatiev, A.; Yeritsyan, N.B.; Vignisse, J.; Bachurin, S.; Strekalova, T. Anhedonic-like traits and lack of affective deficits in 18-month-old C57BL/6 mice: Implications for modeling elderly depression. Exp. Gerontol. 2012, 47, 552-64, doi:10.1016/j.exger.2012.04.010.

86. Markova, N.; Bazhenova, N.; Anthony, D.C.; Vignisse, J.; Svistunov, A.; Lesch, K.P.; Bettendorff, L.; Strekalova, T. Thiamine and benfotiamine improve cognition and ameliorate GSK-3 $\beta$-associated stress-induced behaviours in mice. Prog. Neuro-Psychopharmacology Biol. Psychiatry 2017, 75, 148-156, doi:10.1016/j.pnpbp.2016.11.001.

87. Strekalova, T.; Bahzenova, N.; Trofimov, A.; Schmitt-Böhrer, A.G.; Markova, N.; Grigoriev, V.; Zamoyski, V.; Serkova, T.; Redkozubova, O.; Vinogradova, D.; et al. Pro-neurogenic, memoryenhancing and anti-stress effects of DF302, a novel fluorine gammacarboline derivative with multi-target mechanism of action. Mol. Neurobiol. 2018, 55, 335-349, doi:10.1007/s12035-017-0745-6.

88. de Munter, J.; Pavlov, D.; Gorlova, A.; Sicker, M.; Proshin, A.; Kalueff, A. V.; Svistunov, A.; Kiselev, D.; Nedorubov, A.; Morozov, S.; et al. Increased Oxidative Stress in the Prefrontal Cortex as a Shared Feature of Depressive- and PTSD-Like Syndromes: Effects of a Standardized Herbal Antioxidant. Front. Nutr. 2021, 8, doi:10.3389/fnut.2021.661455.

89. de Munter, J.; Schafarevich, I.; Liundup, A.; Pavlov, D.; Wolters, E.; Gorlova, A.; Veniaminova, E.; Umriukhin, A.; Kalueff, A.; Svistunov, A.; et al. Neuro-Cell therapy improves motor outcomes and suppresses inflammation during experimental syndrome of amyotrophic lateral sclerosis in mice. CNS Neurosci. Ther. 2020.

90. Veniaminova, E.; Oplatchikova, M.; Bettendorff, L.; Kotenkova, E.; Lysko, A.; Vasilevskaya, E.; Kalueff, A. V.; Fedulova, L.; Umriukhin, A.; Lesch, K.P.; et al. Prefrontal cortex inflammation and liver pathologies accompany cognitive and motor deficits following Western diet consumption in non-obese female mice. Life Sci. 2020, 241, doi:10.1016/j.lfs.2019.117163. 


\section{CHAPTER}

\section{ASD-like behaviours, a dysregulated inflammatory response and decreased expression of PLP1 characterize mice deficient for sialyltransferase ST3GAL5}

Evgeniy Svirin ${ }^{1,2,3^{*}}$, Tatyana Strekalova $a^{1,2,3^{*}}$, Ekaterina Veniaminova ${ }^{1,2^{*}}$,

Ekaterina Kopeikina ${ }^{4}$, Tatyana Veremeyko ${ }^{4}$, Amanda W.Y. Yung ${ }^{4}$, Andrey Proshin ${ }^{5}$, Susanne Walitza ${ }^{6}$, Daniel C. Anthony ${ }^{7}$, Lee Wei Lim ${ }^{8}$,

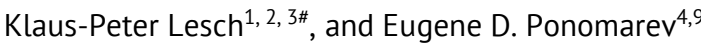

Brain Behav. Immun. Health, 2021, 2021 DOI: 10.1016/j.bbih.2021.100306

${ }^{1}$ Department of Psychiatry and Neuropsychology, School for Mental Health and Neuroscience (MHeNS), Maastricht University, Maastricht, Netherlands

${ }^{2}$ Laboratory of Psychiatric Neurobiology, Institute of Molecular Medicine and Department of Normal Physiology, Sechenov First Moscow State Medical University, Moscow, Russia

${ }^{3}$ Division of Molecular Psychiatry, Center of Mental Health, University of Würzburg, Würzburg, Germany

${ }^{4}$ School of Biomedical Sciences, Faculty of Medicine, the Chinese University of Hong Kong, Shatin, Hong Kong

${ }^{5}$ P.K. Anokhin Research Institute of Normal Physiology, Moscow, Russia

${ }^{6}$ Department for Child and Adolescent Psychiatry and Psychotherapy of the University of Zurich and the University Hospital of Psychiatry Zurich,

Switzerland

${ }^{7}$ Department of Pharmacology, Oxford University, Oxford, United Kingdom

${ }^{8}$ Neuromodulation Laboratory, School of Biomedical Sciences, Li Ka Shing Faculty of Medicine, The University of Hong Kong, Hong Kong

${ }^{9}$ Kunmin Institute of Zoology, Chinese University of Hong Kong Joint Laboratory of Bioresources and Molecular Research of Common Diseases, Kunmin-Hong Kong, China *Joint first authorship, \#Joint senior authorship 


\title{
Chapter 4. ASD-like behaviours, a dysregulated inflammatory response and decreased expression of PLP1 characterise mice deficient for sialyltransferase ST3GAL5
}

\begin{abstract}
Gangliosides are glycosphingolipids, which are abundant in brain, are known to modulate ion channels and cell-to-cell communication. Deficiencies can result in aberrant myelination and altered immune responses, which can give rise to neurodevelopmental psychiatric disorders. However, to date, little mechanistic data is available on how ganglioside deficiencies contribute to the behavioural disorders. In humans, the loss of lactosylceramide-alpha-2,3-sialyltransferase (ST3GAL5) leads to a severe neuropathology, but in St3gal5 knock-out $\left(\right.$ St3gal5 $\left.{ }^{--}\right)$mice the absence of GM3 and associated a-, b- and c-series gangliosides is partially compensated by 0 -series gangliosides and there is no overt behavioural phenotype. Here, we sought to examine the behavioural and molecular consequences of GM3 loss more closely. Mutants of both sexes exhibited impaired conditioned taste aversion in an inhibitory learning task and anxiety-like behaviours in the open field, moderate motor deficits, abnormal social interactions, excessive grooming and rearing behaviours. Taken together, the aberrant behaviours are suggestive of an autism spectrum disorder (ASD)-like syndrome. Molecular analysis showed decreased gene and protein expression of proteolipid protein-1 (Plp1) and over expression of proinflammatory cytokines, which has been associated with ASD-like


syndromes. The inflammatory and behavioural responses to lipopolysaccharide (LPS) were also altered in the St3gal5 $5^{-1-}$ mice compared to wild-type, which is indicative of the importance of GM3 gangliosides in regulating immune responses. Together, the St3gal5 ${ }^{-1-}$ mice display ASD- like behavioural features, altered response to systemic inflammation, signs of hypomyelination and neuroinflammation, which suggests that deficiency in a- and b-series gangliosides could contribute to the development of an ASD-like pathology in humans.

Keywords: lactosylceramide alpha-2,3-sialyltransferase (ST3GAL5), major brain gangliosides, putism spectrum disorder (ASD), aggression, proteolipid protein 1 (PLP1), neuroinflammation, mice.

\section{Introduction}

Gangliosides are glycosphingolipids that facilitate neuronal membrane protein organization, signalling and adhesion (Lopez and Baez, 2018; Schnaar et al., 2014). Brain gangliosides also regulate microgliaand cytokine-mediated immune responses, including microglial activation, myelination, CNS development, and platelet activation (Bowser et al., 2019; Dukhinova et al., 2018; Kim et al., 2002). The ganglioside GM3, is generated by alpha-2,3-sialyltransferase 5 (ST3GAL5) or GM3-synthase (Ishii et al., 1999), which is the precursor of the principal brain gangliosides including GM1, GD1a, GD1b, GD3, GT1b and GQ1b. Abnormalities in the ST3GAL5 gene disrupt GM3 synthesis, leading to intellectual disability, microcephaly, epilepsy, blindness and 
deafness, somatic growth failure and metabolic syndrome (GordonLipkin et al., 2018; Trinchera et al., 2018).

Emerging evidence suggests that ganglioside deficiency may have other effects in addition to severe neuropathologies observed in individuals with ST3GAL5 deficiency. Recent GWAS studies have reported an association between SNPs encoding alpha-2,3sialyltransferase 3 and factors regulating GM function, and the incidence of schizophrenia, attention-deficit/hyperactivity disorder (ADHD) or autism spectrum disorders (ASD). In particular, in a large-scale integrative analysis of genome-wide association studies (GWAS), comprising of 20,183 ADHD cases and 35,191 controls, using DEPICT analysis of gene prioritization, pathway and tissue/cell type enrichment analysis, ST3GAL3 was the top gene associated wirth ADHD $\left(\mathrm{P}=1.19 \times 10^{-2}\right)$ (Zhao et al., 2018). Furthermore, the homozygous loss-of-function mutation of SLC39A8, a well-established schizophrenia biomarker, was shown to result in serum manganese (Mn) abnormalities, a causal factor of glycosyltransferases dysfunction. This mechanism was suggested to underlie the pathophysiology of schizophrenia (Mealer et al., 2020). A more recent GWAS also revealed a relationship between increased expression of a ST3GAL3 transcript in the human fetal brain and a risk for ADHD and schizophrenia (Hall et al., 2020). Moreover, children with ASD often displayed increased anti-ganglioside antibody levels (Mostafa and Al-Ayadhi, 2011; Yang et al., 2018) and changes in the ganglioside expression has also been proposed as a biomarker for schizophrenia (Sarbu et al., 2018). 
The mechanisms underlying a link between the path physiology of neurodevelopmental disorders and dysregulated brain gangliosides implicate neuroinflammation as a risk factor of these pathologies (Dunn et al., 2019; Matta et al., 2019; Meyer, 2013), as gangliosides are known to regulate immune responses in which they have an anti-inflammatory role (Galleguillos et al., 2020; Sipione et al., 2020). Specifically, gangliosides have been shown to regulate the effects of tumour necrosis factor (TNF) (Tagami et al., 2002), microglial and platelet activation (Dukhinova et al., 2018; Sotnikov et al., 2013), nitric oxide synthase (NOS2), and ICAM-1 and MCP-1-mediated signalling (Kim et al., 2002; Ryu et al., 2002). For microglia treated with lipopolysaccharide (LPS),

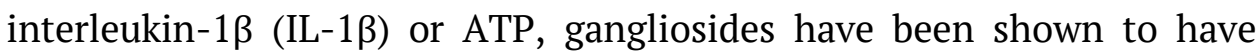
anti-inflammatory effects (Galleguillos et al., 2020). Moreover, neuroinflammation and neuro-immune system dysregulation are particularly well established as clinical features of ASD (Gevezova et al., 2020; Siniscalco et al., 2018). However, mechanistic studies of the role of the principal CNS gangliosides in neurodevelopmental psychiatric syndromes are still lacking.

ST3GAL5 dysfunction in humans has been modelled in St3gal5 mice (Yamashita et al., 2003), but these mutants only partly re-capitulate clinical abnormalities, which may be attributable to the compensatory synthesis of 0-series gangliosides GD1 $\alpha$ and GM1b. However, St3gal5 ${ }^{-1-}$ mice do lack the major CNS gangliosides GM3, GM1, GD1a, GD3, GT1b, GQ1b and display alterations in activity, insulin receptor sensitivity, platelet activation and neuronal damage following brain trauma 
(Dukhinova et al., 2018; Kopeikina et al., 2020; Niimi et al., 2011; Trinchera et al., 2018). While St3gal5-/- mice appear to only to display selective neurodegeneration in the Organ of Corti, they do afford the opportunity to explore the consequences of the brain ganglioside deficiency rather than complete absence (Niimi et al., 2011).

Here, we hypothesized that St3gal5 ${ }^{--}$mice would display features of neuropsychiatric developmental pathologies and that these changes, given the anti-inflammatory actions of brain gangliosides, would be exacerbated by an inflammatory challenge with LPS. Therefore, we studied male and female St3gal5 ${ }^{-/-}$mice for social, restricted-repetitive behaviours to determine whether the animals would display ASD-like features (Haratizadeh et al., 2021), as well as evaluation of inhibitory learning and the expression of myelination and inflammation markers in brain cortex and spleen.

\section{Methods}

\subsection{Animals}

Eight twelve-week-old St3gal5-/- and C57BL/6 mice were bred as described elsewhere (Dukhinova et al., 2018); six-week-old C57BL/6 mice were used in social interaction test. Mice were housed under standard conditions; all protocols complied 2010/63/EU and ARRIVE guidelines (see Supplementary file, SF).

\subsection{Study design}

Mice were examined for social interaction, rearing and conditioned taste aversion (Fig. S1A); in the separate groups, open field 
grooming, motor performance, the mRNA levels of myelination factors and protein concentrations of Plp1 in the brain cortex were studied. A cohort of mice was investigated for social behavior or mRNA expression of proinflammatory cytokines in the cortex and spleen $6 \mathrm{~h}$ following the i.p. administration of LPS $(0.1 \mathrm{mg} / \mathrm{kg})$ or PBS (Fig. S1B). For protocols used and group sizes, see SF and Figure legends; on average, 9 mice per group were used for the behavioural studies and 5 mice per group were used in molecular assays.

\subsection{Behavioural tests}

Experiments were performed during the dark period of light cycle, followed by offline analysis (Anymaze, Stoelting, Dublin, Ireland); customized equipment was used. Briefly, in the social interaction test, unfamiliar naïve juvenile mouse of the same sex was exposed to adult mice after its habituation to the apparatus, for $10 \mathrm{~min}$ (Couch et al., 2016; Veniaminova et al., 2017). The number of rears, latency, total duration, and number of episodes of attacking behavior and dominantlike behaviours: following and mounting, and neutral social exploration: nose-nose and nose-anal contacts were recorded. The number of mice displaying following and mounting were scored in the study with LPS. Inhibitory learning was studied in the conditioned taste aversion model, where mice were injected with $\mathrm{LiCl}$, causing nausea, after their exposure to a sucrose solution. A loss of sucrose preference thereafter was taken as a memory measure. Grooming scores in the open field center and time spent therein were investigated. To assess motor functions, latencies to fall or to descend and the incidence of falling or sliding were studied in 
the Pole and Wire tests, respectively (de Munter et al., 2020; Veniaminova et al., 2020).

\subsection{Induction of systemic inflammation}

Mice were injected with LPS dissolved in PBS (Sigma, St.Louis, MO, USA) at the dose $0.1 \mathrm{mg} / \mathrm{kg}$, i.p., or PBS (Couch et al, 2013, 2016). Previous studies reported a marked pro-inflammatory response both in the brain and peripheral tissue $6 \mathrm{~h}$ after the administration of LPS (Couch et al., 2013). At this time point, significant changes in floating behavior, novelty exploration and social interaction were observed in the mice (Couch et al., 2013; Strekalova and Anthony, unpublished results).

\subsection{Real-time polymerase chain reaction (RT-PCR) and Western Blot}

Mice were terminally anaesthetized with isoflurane inhalation and perfused intracardially with $20 \mathrm{ml}$ of PBS, brain cortex and spleen were dissected, homogenized, and stored until use under $-80 \mathrm{C}^{\circ}$ (Dukhinova et al., 2018; for details on brain cortex disection, see $S F$, Fig. S2). RT-PCR of samples of brain cortex and spleen were examined for the expression of $I l-1 \beta, I l-6$ and TNF and Western blot analysis of Plp1 expression in the brain cortex were performed (Ponomarev et al., 2011; Veremeyko et al., 2018). The pro-inflammatory cytokines were selected for gene expression analysis based on their pivotal roles in local and systemic immune processes (Kany et al., 2019) and for their established association with neuropsychiatric disorders (Dunn et al., 2019; Matta et al., 2019). Furthermore, previous studies in our laboratories have revealed the presence of altered gene expression of $I l-1 \beta, I l-6$ and TNF in mice with exhibiting aberrant social, emotional and cognitive features 
following exposure to stress, LPS challenge, or other adverse conditions (Couch et al, 2013, 2016; Gorlova et al., 2019; Pavlov et al, 2017, 2019). Relative gene expression was calculated using the $\Delta \Delta \mathrm{CT}$ method and normalized to the expression of glyceraldehyde 3-phosphate dehydrogenase (GAPDH) housekeeping gene and to the expression of the control sample, see Table S1. The choice of the reference gene was based on our previous experiments, in which, in comparison with other houskeeping genes, GAPDH demonstrated relatively stable expression in the tissue obtained in mouse models of systemic inflammation and stress (Couch et al, 2013, 2016; Pavlov et al., 2017). Relative expression of Plp1 protein was calculated as fold change relative to $\beta$-actin.

\subsection{Statistics}

Data were analyzed using GraphPad Prism v.8.01 (San Diego, CA, USA). Two- or three-way ANOVA was employed for multiple group comparisons, followed by Tukey's or Sidak's tests, respectively. Data were checked for normality using Shapiro-Wilk test. Data from LPS-treated groups were additionally normalized to PBS-treated groups of the respective genotypes. The level of significance was $\mathrm{p}<0.05$.

\section{Results}

3.1. St3gal5 ${ }^{-/}$mice display anxiety-like behavior, stereotypy and abnormalities in learning and social interaction

A two-way ANOVA revealed a significant sex $\times$ genotype interaction for the number of following events $(\mathrm{p}<0.05)$, but no group differences ( $p>0.05$, Tukey's test; Fig. 1A). There was a significant sex $\times$ 
genotype interaction in the duration of following behavior $(\mathrm{p}<0.05)$, which was longer in male St3gal5 $5^{-/-}$mice than in controls $(\mathrm{p}<0.05)$ and unaltered in females ( $p<0.05$; Fig. 1B). There was a main effect of genotype on the latency to follow ( $\mathrm{p}<0.05$; Fig. 3A); mounting and attacking behaviors did not exhibit a sex $\times$ genotype interaction (Figs. $S 2 B-G)$.

The number of nose-anal contacts exhibited a sex $\times$ genotype interaction ( $\mathrm{p}<0.05$, two-way ANOVA), this measure was higher in St3gal5 $5^{-1-}$ male mice than in wild type group $(\mathrm{p}<0.05$, Tukey's test; Fig. $1 C)$ that was not shown for females $(p<0.05)$. Congruent changes were found in the duration of this behavior as suggested by a significant effect of genotype (Fig. S4A). There were no significant effects of sex, genotype, or their interaction on the latency to nose-anal contact (all p >0.05). Genotype significantly affected the duration of this behavior $(p<0.05)$, which was increased in St3gal5 ${ }^{-/}$animals in comparison with controls irrespective of sex (both $\mathrm{p}<0.05$, unpaired t-test, Fig. S4B). (All statistical values of behavioural analysis are presented in Table S2).

Only main effects of sex and genotype were significant for the number of nose-nose contacts $(\mathrm{p}<0.05$, respectively, two-way ANOVA), where this measure was lower in mutants than in controls $(p<0.05)$ and lower in females $(p<0.05$, Fig. 1D). Changes in the latency to nose-nose contacts, as well as other measures of social interaction were unchanged, except for the main effect of genotype on the duration of nose-nose contacts $(p<0.05$; Figs. 4 C and D). 
Two-way ANOVA showed significant effect of genotype, but not sex $\times$ genotype interaction for the time mice spent in the center of the open field $(\mathrm{p}<0.05$ and $\mathrm{p}>0.05$, respectively). This behavior was shorter in $S t 3 \mathrm{gal5}^{-/}$groups than in controls ( $\mathrm{p}<0.05$; Fig. 1E). center was significantly affected by genotype where it was increased in the mutants $(\mathrm{p}<0.05$; Fig. 1F), but here there was no sex $\times$ genotype interaction $(\mathrm{p}<$ 0.05 and $\mathrm{p}>0.05$, respectively). While there was no sex $\times$ genotype interaction in the number of rears $(p>0.05)$, there was a significant main effect of genotype and sex on this measure (both $\mathrm{p}<0.05$ ), which was higher in female mutants than in controls and male mutants (both $\mathrm{p}<$ 0.05; Fig. 1G).

During recall session of the conditioned taste aversion test, all PBS-treated groups and LiCl-treated mutants exhibited no significant difference in sucrose preference from the 50\%-chance level (all p>0.05, one-sample t-test; Fig. $1 \mathrm{H})$, while the $\mathrm{LiCl}$-treated wild-type groups exhibited a decrease ( $\mathrm{p}<0.05$ for both males and females).

3.2. Motor deficits and lowered brain expression of myelin marker Plp1 in St3gal5 ${ }^{-/-}$mice

Genotype significantly affected the latency to fall in the Wire test $(p<0.05)$, which was shorter in St3gal5 $5^{-/-}$mice than in controls $(p<0.05$; Fig. 1I). No group differences in the incidence of falling were observed (both $\mathrm{p}>0.05$, Fisher's test; Fig. 1J). In the Pole test, we found increased incidence of sliding in male mutants $(\mathrm{p}<0.05)$ and no changes in the latency to descend ( $>0.05$;Fig. $1 \mathrm{~K}, \mathrm{~L})$. (Statistical values for the behavioral analysis and gene expression data are presented in Tables S2- 
S3).

Dominant behaviour

A

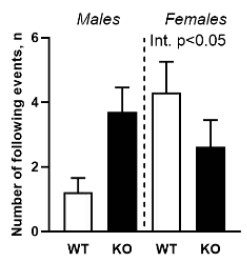

Open Field

E

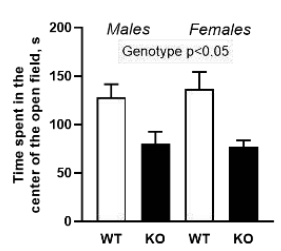

B

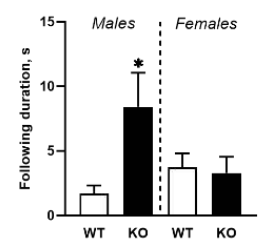

Social exploration

C

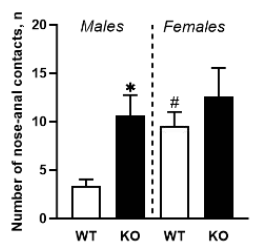

Rearing and Grooming

G

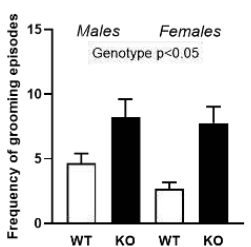

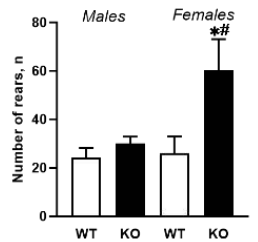

D

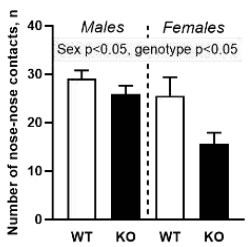

Inhibitory learning

H

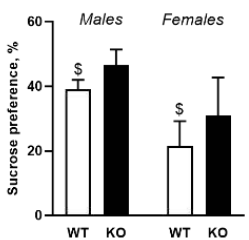

Motor functions

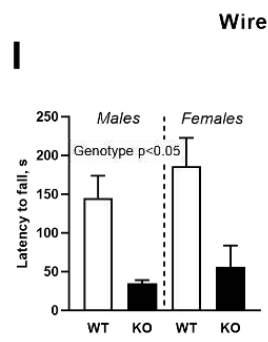

Wire test

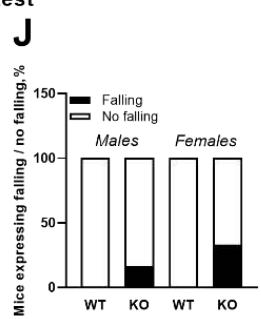

Pole test

K

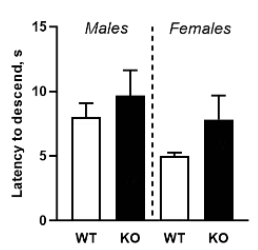

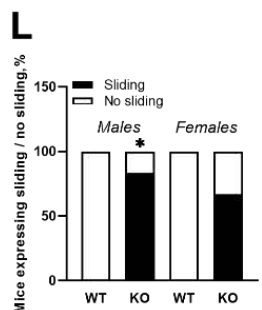

\section{Expression of myelination factors}
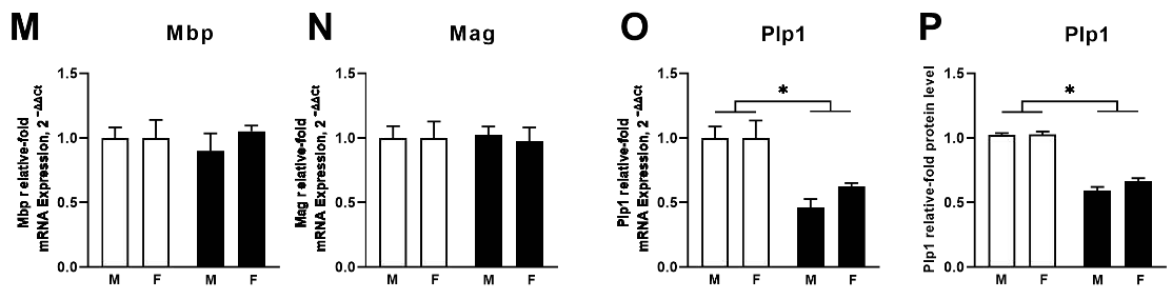

Figure 1. St3gal5 ${ }^{-/-}$mice display behavioral and molecular abnormalities. (AD) Social behavior ( $\mathrm{n}=14$ in each group). (E-G) Anxiety-like and stereotypic behavior ( $n=10$ per group for males, $n=8$ per group for females). (H) 
Associative inhibitory learning ( $n=6$ in each group). (I-L) Motor functions ( $n=6$ in each group). (M-0) Expression of mRNA of myelination transcripts and Plp1 protein ( $n=6$ in each group). ${ }^{*} p<0.05$ vs. wild-type group, $\# p<0.05$ vs. male group, $\$ p<0.05$ vs. $50 \%$-chance level. 'Genotype' - significant effect of genotype. Two-way ANOVA and Tukey's test; one-sample t-test; Chisquare and Fisher's exact test; data present as Mean \pm SEM except $\mathrm{J}$ and $\mathrm{L}$ (see the text).

Two-way ANOVA revealed a significant genotype effect on the concentration of Plp1 mRNA ( $\mathrm{p}<0.05$ ), but for the other myelin transcripts (all p > 0.05; Fig. 1M,N, Fig. 5). In St3gal5 $5^{-1-}$ mice, the level of Plp1 mRNA and relative fold protein expression of Plp1 were lower than in controls ( $\mathrm{p}<0.05$; Fig. 1O,P); the latter measure was significantly affected by genotype only $(\mathrm{p}<0.05)$.

3.3. Altered behavioral and molecular response of St3gal5 ${ }^{-1-}$ mice to LPS

A Chi-square test revealed a significantly higher incidence of following in males St3gal5 $5^{-1}$-LPS-treated animals compared to the St3gal5 ${ }^{-1-}$-PBS-treated and control-LPS-treated groups (both $\mathrm{p}<0.01$, Fisher's test; Fig. 2A); no such differences were found in females (p > 0.05). The duration of following was significantly affected by a sex $\times$ genotype interaction ( $\mathrm{p}<0.05$, two-way ANOVA). In comparison with the LPS-treated wild type groups, normalized to PBS-groups, the duration of following was unchanged in male LPS-treated mutants and decreased in the LPS-treated female mutants $(\mathrm{p}<0.05$, Tukey's test; Fig.2B, Fig. $\mathrm{S} 6 \mathrm{~A}, \mathrm{~B})$. However, no difference in the number of following episodes or the latency to follow was observed (Fig. S6A,B). (For statistical values of behavioural analysis, see Table S4). 

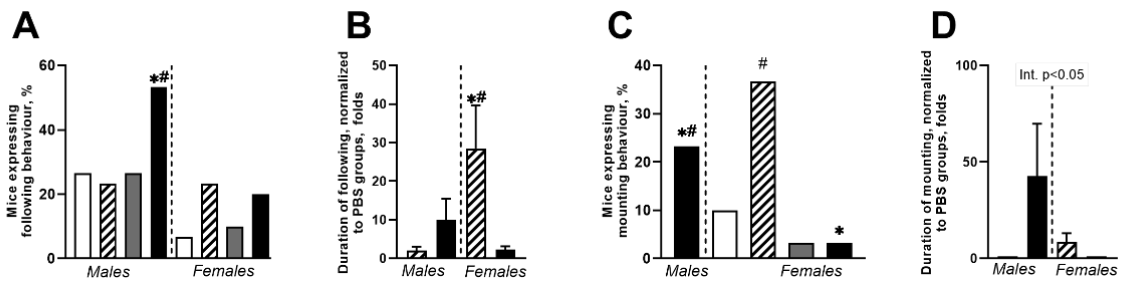

Attacking behaviour in males
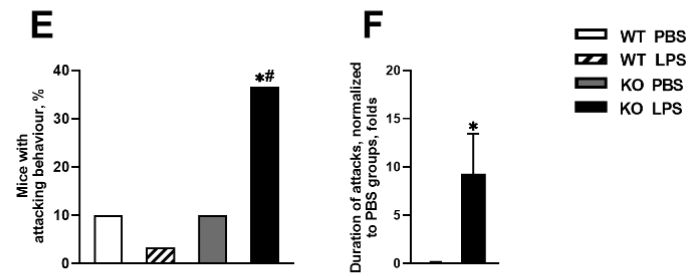

\section{Brain cytokine expression}
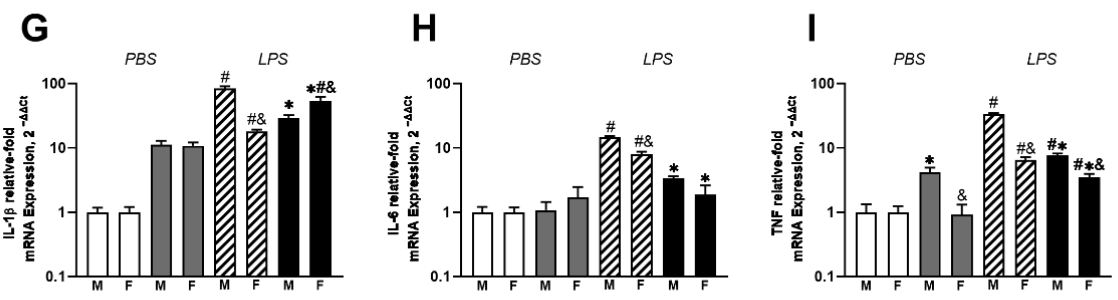

\section{Spleen cytokine expression}
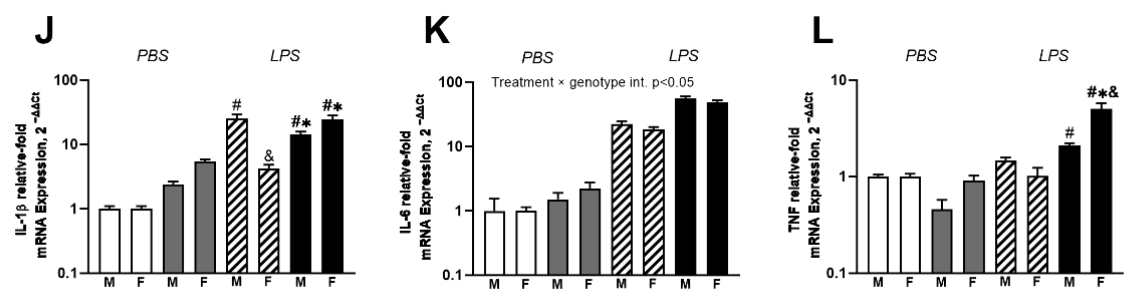

Figure. 2. Altered behavioural and molecular response of St3gal5 $5^{-1-}$ mice to LPS challenge. (A-F) Dominant and aggressive behavior $(n=6$ in each group). (G-I) Expression of pro-inflammatory cytokines in the brain and (J$L)$ in the spleen, ( $n=4-6$ in each group). ${ }^{*} p<0.05$ vs. wild-type group, \#p < 0.05 vs. PBS group. \&p $<0.05$ vs male group. Int. - significant interaction. $M$ - males, F - females. Two-way and three-way ANOVA, Tukey's and Sidak's post -hoc tests; Chi-square and Fisher's exact test; data present as Mean \pm SEM except $A$ and $C$ (see the text). 
There was a significant difference in the incidence of mounting in males and females (both $\mathrm{p}<0.01$, Chi-square test). This behavior was not displayed by the PBS-treated male mutants. Among LPS-treated St3gal5 $5^{--}$groups, the incidence was higher in males and lower in females compared to controls (both $\mathrm{p}<0.05$; Fig. 2C). Normalized to the PBSgroups, the duration of mounting was unaltered in the LPS-treated mice (all $\mathrm{p}>0.05$, two-way ANOVA; Fig. 2D). There was significant interaction, but no significant group differences in the number of mounting episodes or latency to mounting (Fig. S6 C,D).

There was a significant difference in the incidence of attacks in the males $\left(\mathrm{p}<0.01\right.$, Chi-square test), which was $\mathrm{s}$ higher in the St3gal5 ${ }^{-/}$ -LPS-treated group than in the St3gal5 ${ }^{-1-}$-PBS treated group or the wild type LPS-treated mice (both $\mathrm{p}<0.05$, Fisher's test; Fig. 2E). LPS-treated mutants exhibited an increased duration, normalized to PBS- t-test; Fig. $2 F)$. No differences in the number of attacks or latency to groups, of attacks in comparison to St3gal5 ${ }^{-1-}$-PBS group $(\mathrm{p}<0.05$, attack were observed (Fig. S6E,F).

For brain expression of mRNA for cytokines IL-1 $\beta$, IL-6 and TNF, significant sex $\times$ genotype $\times$ treatment interactions were observed following LPS administration (all p $<0.01$, three-way ANOVA). Il-16 mRNA and TNF mRNA concentrations were higher in LPS-treated animals than in PBS-treated groups (all p < 0.05, Sidak's test; Fig. $2 \mathrm{G}$ ). In the LPS-treated groups, Il-16 mRNA and TNF mRNA was lower in the St3gal5 $5^{--}$males than in wild-type mice and higher in St3gal5 $5^{-/-}$females than in controls and male mutants (all $\mathrm{p}<0.01$ ). Wild-type mice, but not 
St3gal5 $^{-/-}$groups showed significant increases in Il-6 mRNA after LPS administration in comparison with PBS-treated groups $(\mathrm{p}<0.01$ and $p>0.05$, for both males and females, respectively). LPS-treated mutants of both sexes had lower concentrations of Il-6 mRNA and TNF mRNA than LPS-treated wild-type mice (both $\mathrm{p}<0.01$; Fig. $2 \mathrm{H}$ and I). In males, $T N F$ mRNA levels were higher than in females among PBS-treated mutants and LPS-treated wild type and mutant mice (all $\mathrm{p}<0.01$ ). (Statistical values for the gene expression data are presented in Supplementary Tables S5-7). Spleen levels of Il-16 mRNA and TNF mRNA, but not of Il-6 mRNA were significantly affected by sex $\times$ genotype $\times$ treatment interaction ( $\mathrm{p}<0.01$, three-way ANOVA). LPS-treated groups, except in wild-type females, showed higher Il-16 mRNA concentrations (all $\mathrm{p}<$ 0.01, Sidak's test; Fig. $2 \mathrm{~J}$ ). In the LPS-treated groups of mutants, Il-16 mRNA concentrations were lower in males and higher in females than in the wild type groups (both $\mathrm{p}<0.01$ ). There was a significant interaction between treatment and genotype for spleen Il-6 mRNA concentrations ( $p$ $<0.01$ ). This measure was increased in all LPS-treated groups in comparison to the PBS-treated animals and was higher in St3gal5-1groups than in the wild-type mice (all $\mathrm{p}<0.01$, Tukey's test; Fig. 2K). Only mutants, both males and females, displayed a significant LPSinduced increase of TNF mRNA concentrations in comparison with PBStreated groups; this increase was significantly higher in females (all p < 0.01 , Fig. 2 L). (Statistical values for the gene expression data are presented in Supplementary Tables S5-7). 


\section{Discussion}

We observed substantial abnormalities in dominant behavior and neutral sociability in the St3gal5 ${ }^{-1-}$ mice. The St3gal5 ${ }^{-1-}$ mutants also ate motor deficits, systemic inflammation, and signs of hypomyelination. In addition, St3gal5 ${ }^{-1-}$ mutants exhibited aberrant behavioural and molecular responses to LPS. Naïve mutants showed decreased gene and protein expression of the major myelin component Plp1, and overexpression of pro-inflammatory cytokines in the brain and spleen. LPS administration to St3gal5 ${ }^{-/}$mice elicited increased dominant/attacking behaviours in males and decreased dominancy in females. Relative to the changes in wild-type mice, the expression of cytokines in the LPS-challenged St3gal5 $5^{--}$mice was reduced in the brain and exacerbated in the spleen.

These abnormalities are reminiscent of the established phenotypes of ASD in clinic (Thapar et al., 2017) and in animal models (Haratizadeh et al., 2021). The Diagnostic and Treatment Manual for Mental Disorders, Fifth Edition (DSM-5) defines ASD by the expression of deficient social communication and interaction, restricted-repetitive behaviours and developmental impairments (DSM-5R, 2013). The core ASD-like characteristics in rodents can be recapitulated by the expression of aberrant reciprocal social behavior, stereotypy and cognitive deficits (Haratizadeh et al., 2021; Veniaminova et al., 2017, 2020).

For example, in mice, abnormal interactions with counter partners, excessive following, dominancy, increased grooming and 
rearing, impaired inhibitory learning, are all signs of ASD-like behavior (Das et al., 2019; Lewis et al., 2007; Onore et al., 2013; Tatsukawa et al., 2019). We observed increased following behavior in male mutants, decreased social exploration in female mice, and aberrant nose-anal interaction in both sexes which are suggestive of social dysfunction. Social behaviours were also abnormally altered by the administration of LPS which is in keeping with findings that LPS exacerbates ASD-like behaviours in other mouse models including BTBR mice, a genetic model of ASD (Das et al., 2019; McFarlane et al., 2008; Onore et al., 2013). The impaired conditioned taste conditioning suggests cognitive rigidity in St3gal5 ${ }^{--}$animals, an important element of ASD-like phenotype (Haratizadeh et al., 2021). The presence of motor deficits in the St3gal5 mice also agrees with other studies in which an association between ASD syndrome and motor dyscoordination has been described (Das et al., 2019; Lewis et al., 2007; Thapar et al., 2017).

Clinical studies suggest a pivotal role of altered immunity and response to systemic inflammation in the behavioural/cognitive signs of ASD (Ashwood et al., 2011; Jyonouchi et al., 2012; Napolioni et al., 2013). In comparison to controls displaying developmental disabilities other than autism, plasma levels of cytokines IL-1 $\beta$, IL-6, IL-8 and IL-12p40 were increased in children with ASD, which correlated with the severity of the disease (Ashwood et al., 2011). The over-production of proinflammatory cytokines was also demonstrated by utilizing cultured and stimulated peripheral blood monocytes from children with ASD (Enstrom et al., 2010; Jyonouchi et al., 2012). Over-expression of IL-1 $\beta$, IL-6, IL-17 
and TNF has also been reported in the adult autistic brain (Napolioni et al., 2013; Theoharides et al., 2016; Wei et al., 2013).

Our data showing central and peripheral over-production of IL$1 \beta$, IL-6, and TNF are in keeping with these findings, as well as with previous demonstrations of systemic inflammation and up-regulated brain expression of IL-1 $\beta$, IL-6, IL-17, IL-18, IL-33, TNF and astrocyte/microglia activation in animal models of ASD (Das et al., 2019; Prata et al., 2017; Wei et al, 2012, 2016). We also found the upregulation of IL-1 $\beta$ in the double transgenic St3gal5-deficient 5xFAD female mice (Dukhinova et al., 2019). The synergistic interaction of abnormal baseline production of IL-1 $\beta$, IL- 6 and TNF in mutants and LPS-induced systemic inflammation is reminiscent of a 'double hit' phenomenon (Carlezon et al., 2019; Couch et al, 2013, 2016; Onore et al., 2013; Yasumatsu et al., 2020) and could explain the exacerbation ofthe changes in social behavior observed in the St3gal5 $5^{-/-}$mice. At the same time, no differences were fund in counts for mononuclear and polymorphonuclear white blood cells between controls and mutants (Ponomarev, unpublished results). The current study also revealed the presence of muted responses in cytokine expression following LPS in the mutants. This is in keeping with observations that cytokine production is reduced in the monocytes of children with ASD after TLR-targeted stimulation (Jyonouchi et al., 2012) and with decreased brain expression of IL-6 and TNF in St3gal5 ${ }^{-1-}$ mice after brain injury (Dukhinova et al., 2018).

Sex-specific expression profiles of TNF, TGF- $\beta$, IFN- $\gamma$, IL-17 and IL-6 were recently reported in ASD patients (Eftekharian et al., 2018). 
St3gal5 $5^{--}$mice display a sex bias in cytokine expression and this bias may underlie the sex-dependent behavioural changes reported here and elsewhere (Niimi et al., 2011). Similarly, LPS-induced social and repetitive behaviours in C57BL6 mice were sex-dependent (Carlezon et al., 2019).

Pro-inflammatory changes in mutants are likely to be owing to the lack of gangliosides of the a-, b- and c-series, which exert antiinflammatory functions (Schnaar, 2016). This imbalance is, seemingly, not compensated by expression in the St3gal5 $5^{-/-}$mice of GD1 $\alpha$ and GM1b, whose role in inflammation has been not shown (Trinchera et al., 2018). Congruently, signs of deficit in myelination, which is regulated by a- and b-series gangliosides, is unlikely to be compensated by the 0gangliosides in the St3gal5 $5^{--}$mutants. The decreased Plp1 expression in the St3gal5 $5^{--}$mice is in keeping with the myelin changes observed in carriers of St3gal5 gene variants that are associated with ganglioside deficiency (Bowser et al., 2019). Decreased Plp1 expression may also result from a bi-directional relationship with neuroinflammatory processes (Groh et al., 2018), that can compromise synaptic plasticity, brain connectivity, and motor function (Thapar et al., 2017), as well as give rise to aberrant social behavior. For example, studies have linked hypomyelination in the medial prefrontal cortex with behavioural abnormalities in a mouse ASD model (Makinodan et al., 2017).

Thus, genetic deficiency in a-, b- and c-series of ganglioside in the brain, due to the genetic lack of ST3GAL5 enzyme, leads to the abnormalities that are reminiscent to the ASD-like syndrome. We would 
not argue that gangliosides deficiency is likely to be a causal element of ASD pathology, but it could be a contributing factor in some cases. Our work warrants future investigation into the potential link between ASD and deficits in brain glycoprotein sialylation and a- and b-series ganglioside synthesis. In particular, further studies are needed to examine the correlation between the molecular and behavioural changes, whether the ASD-like phenotype can be recovered with a therapeutic intervention, and to better understand the impact of the myelin associated changes. Yet, given ASD is a disorder of highly variable genetics with as-yet-unknown pathophysiology, the St3gal5 ${ }^{-/-}$mice provide a useful animal model to explore ASD-like features associated with ganglioside deficiency.

\section{Declaration of competing interest}

On behalf of all authors, I would like to state that none of the authorsinvolved in the work have any competing interest.

\section{Acknowledgements}

We thank the Research Grant Council, the Area of Excellence scheme from Hong Kong Government and SBS Incentive Scheme (20192020) - Bridging Fund (AoE/M-604/16 and SBS-BF(2019-2020)-01 to EP), Eu- ropean Union's Horizon 2020 PhytoAPP to SW and KPL, No 10100764 to TS, RAS-0520-2019-0029 to TS and ES and Swiss-RF program-2020.

\section{Appendix A. Supplementary data}

Supplementary data to this article can be found online at https://do i.org/10.1016/j.bbih.2021.100306. 


\section{References}

Ashwood, P., Krakowiak, P., Hertz-Picciotto, I., Hansen, R., Pessah, I., Van de Water, J., 2011. Elevated plasma cytokines in autism spectrum disorders provide evidence of immune dysfunction and are associated with impaired behavioral outcome. Brain Behav. Immun. 25, 40-45. https://doi.org/10.1016/j.bbi.2010.08.003.

Bowser, L.E., Young, M., Wenger, O.K., Ammous, Z., Brigatti, K.W., Carson, V.J., Moser, T., Deline, J., Aoki, K., Morlet, T., Scott, E.M., Puffenberger, E.G., Robinson, D.L., Hendrickson, C., Salvin, J., Gottlieb, S., Heaps, A.D., Tiemeyer, M., Strauss, K.A., 2019. Recessive GM3 synthase deficiency: natural history, biochemistry, and therapeutic frontier. Mol. Genet. Metabol. 126, 475-488. https:// doi.org/10.1016/j.ymgme.2019.01.013.

Carlezon, W.A., Kim, W., Missig, G., Finger, B.C., Landino, S.M., Alexander, A.J., Mokler, E.L., Robbins, J.O., Li, Y., Bolshakov, V.Y., McDougle, C.J., Kim, K.-S., 2019. Maternal and early postnatal immune activation produce sex-specific effects on autism-like behaviors and neuroimmune function in mice. Sci. Rep. 9, 16928. https://doi.org/10.1038/s41598-019-53294-z.

Couch, Y., Anthony, D.C., Dolgov, O., Revischin, A., Festoff, B., Santos, A.I., Steinbusch, H.W., Strekalova, T., 2013. Microglial activation, increased TNF and SERT expression in the prefrontal cortex define stress-altered behaviour in mice susceptible to anhedonia. Brain Behav. Immun. 29, 136-146. https://doi.org/ 10.1016/j.bbi.2012.12.017.

Couch, Y., Trofimov, A., Markova, N., Nikolenko, V., Steinbusch, H.W., Chekhonin, V., Schroeter, C., Lesch, K.P., Anthony, D.C., Strekalova, T., 2016. Low-dose lipopolysaccharide (LPS) inhibits aggressive and augments depressive behaviours in a chronic mild stress model in mice. J. Neuroinflammation 13, 1-17. https://doi.org/ 10.1186/s12974-016-0572-0.

Das, I., Estevez, M.A., Sarkar, A.A., Banerjee-Basu, S., 2019. A multifaceted approach for analyzing complex phenotypic data in rodent models of autism. Mol. Autism. 10, 1-15. https://doi.org/10.1186/s13229019-0263-7. 
de Munter, J., Schafarevich, I., Liundup, A., Pavlov, D., Wolters, E., Gorlova, A., Veniaminova, E., Umriukhin, A., Kalueff, A., Svistunov, A., Kramer, B.W., Lesch, K.- P., Strekalova, T., 2020. Neuro-Cell therapy improves motor outcomes and suppresses inflammation during experimental syndrome of amyotrophic lateral sclerosis in mice. CNS Neurosci. Ther. 26, 504-517. https://doi.org/10.1111/cns.13280. Epub 2019 Dec 23.

Dukhinova, M., Kuznetsova, I., Kopeikina, E., Veniaminova, E., Yung, A.W.Y., Veremeyko, T., Levchuk, K., Barteneva, N.S., Wing-Ho, K.K., Yung, W.H., Liu, J.Y.H., Rudd, J., Yau, S.S.Y., Anthony, D.C., Strekalova, T., Ponomarev, E.D., 2018. Platelets mediate protective neuroinflammation and promote neuronal plasticity at the site of neuronal injury. Brain Behav. Immun. 74, 7-27. https://doi.org/10.1016/ j.bbi.2018.09.009.

Dukhinova, M., Veremeyko, T., Yung, A.W.Y., Kuznetsova, I.S., Lau, T.Y.B., Kopeikina, E., Chan, A.M.L., Ponomarev, E.D., 2019. Fresh evidence for major brain gangliosides as a target for the treatment of Alzheimer's disease. Neurobiol. Aging 77, 128-143. https://doi.org/10.1016/j.neurobiolaging.2019.01.020.

Dunn, G.A., Nigg, J.T., Sullivan, E.L., 2019. Neuroinflammation as a risk factor for attention deficit hyperactivity disorder. Pharmacol. Biochem. Behav. 182, 22-34. https://doi.org/10.1016/j.pbb.2019.05.005.

Eftekharian, M.M., Ghafouri-Fard, S., Noroozi, R., Omrani, M.D., Arsang-Jang, S., Ganji, M., Gharzi, V., Noroozi, H., Komaki, A., Mazdeh, M., Taheri, M., 2018. Cytokine profile in autistic patients. Cytokine 108, 120-126. https://doi.org/ 10.1016/j.cyto.2018.03.034.

Enstrom, A.M., Onore, C.E., Van de Water, J.A., Ashwood, P., 2010. Differential monocyte responses to TLR ligands in children with autism spectrum disorders. Brain Behav. Immun. 24, 64-71. https://doi.org/10.1016/j.bbi.2009.08.001.

Galleguillos, D., Wang, Q., Steinberg, N., Shrivastava, G., Dhami, K., Rubinstein, K., Giuliani, F., Churchward, M., Power, C., Todd, K., Sipione, S., 2020. Anti- inflammatory Role of GM1 and Modulatory Effects of Gangliosides on Microglia Functions. bioRxiv, pp. 3-36. https://doi.org/10.1101/2020.03.04.975862. 
Gevezova, M., Sarafian, V., Anderson, G., Maes, M., 2020. Inflammation and mitochondrial dysfunction in autism spectrum disorder. CNS neurol. Disord. Drug Targets 19, 320-333. https://doi.org/10.2174/1871527319666200628015039. Gordon-Lipkin, E., Cohen, J.S., Srivastava, S., Soares, B.P., Levey, E., Fatemi, A., 2018. ST3GAL5-Related disorders: a deficiency in ganglioside metabolism and a genetic cause of intellectual disability and choreoathetosis. J. Child Neurol 33, 825-831. https://doi.org/10.1177/0883073818791099.

Gorlova, A., Pavlov, D., Anthony, D.C., Ponomarev, E.D., Sambon, M., Proshin, A., Shafarevich, I., Babaevskaya, D., Lesch, K.P., Bettendorff, L., Strekalova, T., 2019. Thiamine and benfotiamine counteract ultrasound-induced aggression, normalize AMPA receptor expression and plasticity markers, and reduce oxidative stress in mice. Neuropharmacology 156, 107543. https://doi.org/10.1016/ j.neuropharm.2019.02.025.

Groh, J., H€orner, M., Martini, R., 2018. Teriflunomide attenuates neuroinflammation- related neural damage in mice carrying human PLP1 mutations. J. Neuroinflammation 15, 1-16. https://doi.org/10.1186/s12974-018-1228-z.

Hall, L.S., Pain, O., O'Brien, H.E., Anney, R., Walters, J.T.R., Owen, M.J., O'Donovan, M.C., Bray, N.J., 2020. Cis-effects on gene expression in the human prenatal brain associated with genetic risk for neuropsychiatric disorders. Mol. Psychiatr. https://doi.org/10.1038/s41380-020-0743-3.

Haratizadeh, S., Parvan, M., Mohammadi, S., Shabani, M., Nozari, M., 2021. An overview of modeling and behavioral assessment of autism in the rodent. Int. J. Dev. Neurosci. https://doi.org/10.1002/jdn.10096.

Ishii, A., Ohta, M., Watanabe, Y., Matsuda, K., Ishiyama, K., Sakoe, K., Nakamura, M., Inokuchi, J.I., Sanai, Y., Saito, M., 1999. Expression cloning and functional characterization of human cDNA for ganglioside G(M3) synthase. J. Biol. Chem. 273, 31652-31655. https://doi.org/10.1074/jbc.273.48.31652.

Jyonouchi, H., Geng, L., Streck, D.L., Toruner, G.A., 2012. Immunological characterization and transcription profiling of peripheral blood (PB) monocytes in children with autism spectrum disorders (ASD) 
and specific polysaccharide antibody deficiency (SPAD): case study. J. Neuroinflammation 9 (4). https://doi.org/10.1186/ 1742-2094-9-4.

Kany, S., Vollrath, J.T., Relja, B., 2019. Cytokines in inflammatory disease. Int. J. Mol. Sci. 20, 1-31. https://doi.org/10.3390/ijms20236008.

Kim, O.S., Park, E.J., Joe, E., Jou, I., 2002. JAK-STAT signaling mediates gangliosides- induced inflammatory responses in brain microglial cells. J. Biol. Chem. 277, 40594-40601. https://doi.org/10.1074/jbc.M203885200.

Kopeikina, E., Dukhinova, M., Yung, A.W.Y., Veremeyko, T., Kuznetsova, I.S., Lau, T.Y.B., Levchuk, K., Ponomarev, E.D., 2020. Platelets promote epileptic seizures by modulating brain serotonin level, enhancing neuronal electric activity, and contributing to neuroinflammation and oxidative stress. Prog. Neurobiol. 188, 101783. https://doi.org/10.1016/j.pneurobio.2020.101783.

Lewis, M.H., Tanimura, Y., Lee, L.W., Bodfish, J.W., 2007. Animal models of restricted repetitive behavior in autism. Behav. Brain Res. 176, 66-74. https://doi.org/ 10.1016/j.bbr.2006.08.023.

Lopez, P.H.H., Baez, B.B., 2018. Gangliosides in axon stability and regeneration. Prog. Mol. Biol. Transl. Sci. 156, 383-412. https://doi.org/10.1016/ bs.pmbts.2018.03.001.

Makinodan, M., Ikawa, D., Yamamuro, K., Yamashita, Y., Toritsuka, M., Kimoto, S., Yamauchi, T., Okumura, K., Komori, T., Fukami, S.I., Yoshino, H., Kanba, S., Wanaka, A., Kishimoto, T., 2017. Effects of the mode of re-socialization after juvenile social isolation on medial prefrontal cortex myelination and function. Sci. Rep. 7, 1-9. https://doi.org/10.1038/s41598-017-05632-2.

Matta, S.M., Hill-Yardin, E.L., Crack, P.J., 2019. The influence of neuroinflammation in autism spectrum disorder. Brain. Behav. Immun 79, 75-90. https://doi.org/10.1016/ j.bbi.2019.04.037.

McFarlane, H.G., Kusek, G.K., Yang, M., Phoenix, J.L., Bolivar, V.J., Crawley, J.N., 2008. Autism-like behavioral phenotypes in BTBR Tbtf/J mice. Gene Brain Behav. 7, 152-163. https://doi.org/10.1111/j.1601183X.2007.00330.x. 
Mealer, R.G., Jenkins, B.G., Chen, C.Y., Daly, M.J., Ge, T., Lehoux, S., Marquardt, T., Palmer, C.D., Park, J.H., Parsons, P.J., Sackstein, R., Williams, S.E., Cummings, R.D., Scolnick, E.M., Smoller, J.W., 2020. The schizophrenia risk locus in SLC39A8 alters brain metal transport and plasma glycosylation. Sci. Rep. 10, 1-15. https://doi.org/ 10.1038/s41598020-70108-9.

Meyer, U., 2013. Developmental neuroinflammation and schizophrenia. Prog. Neuro- Psychopharmacol. Biol. Psychiatry 42, 2034. https://doi.org/10.1016/j.pnpbp.2011.11.003.

Mostafa, G.A., Al-Ayadhi, L.Y., 2011. Increased serum levels of anti-ganglioside M1 auto- antibodies in autistic children: relation to the

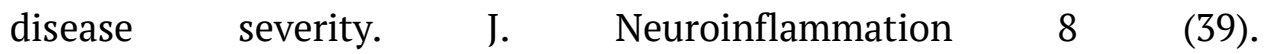
https://doi.org/10.1186/1742-2094-8-39.

Napolioni, V., Ober-Reynolds, B., Szelinger, S., Corneveaux, J.J., Pawlowski, T., Ober- Reynolds, S., Kirwan, J., Persico, A.M., Melmed, R.D., Craig, D.W., Smith, C.J., Huentelman, M.J., 2013. Plasma cytokine profiling in sibling pairs discordant for autism spectrum disorder. J. Neuroinflammation 10 (813). https://doi.org/10.1186/ 1742-2094-10-38.

Niimi, K., Nishioka, C., Miyamoto, T., Takahashi, E., Miyoshi, I., Itakura, C., Yamashita, T., 2011. Impairment of neuropsychological behaviors in ganglioside GM3-knockout mice. Biochem. Biophys. Res. Commun. 406, 524-528. https:// doi.org/10.1016/j.bbrc.2011.02.071.

Onore, C.E., Careaga, M., Babineau, B.A., Schwartzer, J.J., Berman, R.F., Ashwood, P., 2013. Inflammatory macrophage phenotype in BTBR Tptf/J mice. Front. Neurosci. 7 https://doi.org/10.3389/fnins.2013.00158.

Pavlov, D., Bettendorff, L., Gorlova, A., Olkhovik, A., Kalueff, A.V., Ponomarev, E.D., Inozemtsev, A., Chekhonin, V., Lesch, K.P., Anthony, D.C., Strekalova, T., 2019. Neuroinflammation and aberrant hippocampal plasticity in a mouse model of emotional stress evoked by exposure to ultrasound of alternating frequencies. Prog. Neuro-Psychopharmacol. Biol. Psychiatry 90, 104-116. https://doi.org/10.1016/ j.pnpbp.2018.11.014.

Pavlov, D., Markova, N., Bettendorff, L., Chekhonin, V., Pomytkin, I., Lioudyno, V., Svistunov, A., Ponomarev, E., Lesch, K.P., Strekalova, T., 
2017. Elucidating the functions of brain GSK3 $\alpha$ : possible synergy with GSK3 $\beta$ upregulation and reversal by antidepressant treatment in a mouse model of depressive-like behaviour. Behav. Brain Res. 335, 122-127. https://doi.org/10.1016/j.bbr.2017.08.018.

Ponomarev, E.D., Veremeyko, T., Barteneva, N., Krichevsky, A.M., Weiner, H.L., 2011. MicroRNA-124 promotes microglia quiescence and suppresses EAE by deactivating macrophages via the C/EBP- $\alpha-P U .1$ pathway. Nat. Med. 17, 64-70. https://doi.org/ 10.1038/nm.2266.

Prata, J., Santos, S.G., Almeida, M.I., Coelho, R., Barbosa, M.A., 2017. Bridging Autism Spectrum Disorders and Schizophrenia through inflammation and biomarkers - pre- clinical and clinical investigations. J. Neuroinflammation 14 (179). https://doi.org/ 10.1186/s12974-017-0938$\mathrm{y}$.

Ryu, J.K., Shin, W.H., Kim, J., Joe, E.H., Lee, Y.B., Cho, K.G., Oh, Y.J., Kim, S.U., Jin, B.K., 2002. Trisialoganglioside GT1b induces in vivo degeneration of nigral dopaminergic neurons: role of microglia. Glia 38, 15-23. https://doi.org/10.1002/glia.10047.

Sarbu, M., Vukelic, Z., Clemmer, D.E., Zamfir, A.D., 2018. Ion mobility mass spectrometry provides novel insights into the expression and structure of gangliosides in the normal adult human hippocampus. Analyst 143, 5234-5246. https://doi.org/ 10.1039/c8an01118d.

Schnaar, R.L., 2016. Gangliosides of the vertebrate nervous $\begin{array}{lllll}\text { system. } & \text { J. Mol. } & \text { Biol. 4325-3336. }\end{array}$ https://doi.org/10.1016/j.jmb.2016.05.020.

Schnaar, R.L., Gerardy-Schahn, R., Hildebrandt, H., 2014. Sialic acids in the brain: gangliosides and polysialic acid in nervous system development, stability, disease, and regeneration. Physiol. Rev. 94, 461518. https://doi.org/10.1152/ physrev.00033.2013.

Siniscalco, D., Schultz, S., Brigida, A., Antonucci, N., 2018. Inflammation and neuro- immune dysregulations in autism spectrum disorders. Pharmaceuticals 11 (56). https://doi.org/10.3390/ph11020056.

Sipione, S., Monyror, J., Galleguillos, D., Steinberg, N., Kadam, V., 2020. Gangliosides in the brain: physiology, pathophysiology and 
therapeutic

applications.

Front.

Neurosci

14.

https://doi.org/10.3389/fnins.2020.572965.

Sotnikov, I., Veremeyko, T., Starossom, S.C., Barteneva, N., Weiner, H.L., Ponomarev, E.D., 2013. Platelets recognize brain-specific glycolipid structures, respond to neurovascular damage and promote neuroinflammation.

PLoS

One

8. https://doi.org/10.1371/journal.pone.0058979.

Tagami, S., Inokuchi, J.I., Kabayama, K., Yoshimura, H., Kitamura, F., Uemura, S., Ogawa, C., Ishii, A., Saito, M., Ohtsuka, Y., Sakaue, S., Igarashi, Y., 2002. Ganglioside GM3 participates in the pathological conditions of insulin resistance. J. Biol. Chem. 277, 3085-3092. https://doi.org/10.1074/jbc.M103705200.

Tatsukawa, T., Raveau, M., Ogiwara, I., Hattori, S., Miyamoto, H., Mazaki, E., Itohara, S., Miyakawa, T., Montal, M., Yamakawa, K., 2019. Scn2a haploinsufficient mice display a spectrum of phenotypes affecting anxiety, sociability, memory flexibility and ampakine CX516 rescues their hyperactivity. Mol. Autism. 10 (15). https://doi.org/ 10.1186/s13229-0190265-5.

Thapar, A., Cooper, M., Rutter, M., 2017. Neurodevelopmental disorders. Lancet Psychiatr. 4, 339-346. https://doi.org/10.1016/S22150366(16)30376-5.

Theoharides, T.C., Tsilioni, I., Patel, A.B., Doyle, R., 2016. Atopic diseases and inflammation of the brain in the pathogenesis of autism spectrum disorders. Transl. Psychiatry 6, e844. https://doi.org/10.1038/tp.2016.77.

Trinchera, M., Parini, R., Indellicato, R., Domenighini, R., dall'Olio, F., 2018. Diseases of ganglioside biosynthesis: an expanding group of congenital disorders of glycosylation. Mol. Genet. Metabol. 124, 230-237. https://doi.org/10.1016/ j.ymgme.2018.06.014.

Veniaminova, E., Oplatchikova, M., Bettendorff, L., Kotenkova, E., Lysko, A., Vasilevskaya, E., Kalueff, A.V., Fedulova, L., Umriukhin, A., Lesch, K.P., Anthony, D.C., Strekalova, T., 2020. Prefrontal cortex inflammation and liver pathologies accompany cognitive and motor deficits following Western diet consumption in non-obese female mice. 
Life Sci. 241, 117163. https://doi.org/ 10.1016/j.lfs.2019.117163. Epub 2019 Dec 13.

Veniaminova, E., Cespuglio, R., Cheung, C.W., Umriukhin, A., Markova, N., Shevtsova, E., Lesch, K.P., Anthony, D.C., Strekalova, T., 2017. Autism-like behaviours and memory deficits result from a Western diet in mice. Neural Plast. https://doi.org/10.1155/ 2017/9498247, 2017.

Veremeyko, T., Yung, A.W.Y., Dukhinova, M., Kuznetsova, I.S., Pomytkin, I., Lyundup, A., Strekalova, T., Barteneva, N.S., Ponomarev, E.D., 2018. Cyclic AMP pathway suppress autoimmune neuroinflammation by inhibiting functions of encephalitogenic CD4 T cells and enhancing M2 macrophage polarization at the site of inflammation. Front. Immunol.

9

(50). https://doi.org/10.3389/fimmu.2018.00050.

Wei, H., Alberts, I., Li, X., 2013. Brain IL-6 and autism. Neuroscience 252 ,

$320-325$. https://doi.org/10.1016/j.neuroscience.2013.08.025.

Wei, H., Chadman, K.K., McCloskey, D.P., Sheikh, A.M., Malik, M., Brown, W.T., Li, X., 2012. Brain IL-6 elevation causes neuronal circuitry imbalances and mediates autism- like behaviors. Biochim. Biophys. Acta (BBA) Mol. Basis

Dis.

1822 ,

831-842. https://doi.org/10.1016/j.bbadis.2012.01.011.

Wei, H., Ma, Y., Liu, J., Ding, C., Jin, G., Wang, Y., Hu, F., Yu, L., 2016. Inhibition of IL-6 trans-signaling in the brain increases sociability in the BTBR mouse model of autism. Biochim. Biophys. Acta (BBA) - Mol. Basis Dis. 1862, 1918-1925. https://doi.org/ 10.1016/j.bbadis.2016.07.013.

Yamashita, T., Hashiramoto, A., Haluzik, M., Mizukami, H., Beck, S., Norton, A., Kono, M., Tsuji, S., Daniotti, J.L., Werth, N., Sandhoff, R., Sandhoff, K., Proia, R.L., 2003. Enhanced insulin sensitivity in mice lacking ganglioside GM3. Proc. Natl. Acad. Sci. U. S. A 100, 3445-3449. https://doi.org/10.1073/pnas.0635898100.

Yang, X., Liang, S., Wang, L., Han, P., Jiang, X., Wang, J., Hao, Y., $\mathrm{Wu}, \mathrm{L} ., 2$ 2018. Sialic acid and anti-ganglioside antibody levels in children with autism spectrum disorders. Brain Res. 1678, 273-277. https://doi.org/10.1016/j.brainres.2017.10.027. 
Yasumatsu, K., Nagao, J.-I., Arita-Morioka, K.-I., Narita, Y., Tasaki, S., Toyoda, K., Ito, S., Kido, H., Tanaka, Y., 2020. Bacterialinduced maternal interleukin-17A pathway promotes autistic-like behaviors in mouse offspring. Exp. Anim. 69, 250-260. https://doi.org/10.1538/expanim.19-0156.

Zhao, Y., Liang, X., Zhu, F., Wen, Y., Xu, J., Yang, J., Ding, M., Cheng, B., Ma, M., Zhang, L., Cheng, S., Wu, C., Wang, S., Wang, X., Ning, Y., Guo, X., Zhang, F., 2018. A large-scale integrative analysis of GWAS and common meQTLs across whole life course identifies genes, pathways and tissue/cell types for three major psychiatric disorders. Neurosci. BioBehav. Rev. 95, 347-352. https://doi.org/10.1016/ j.neubiorev.2018.10.005. 


\section{Supplementary File}

\section{Methods}

\section{Animals}

Eight to twelve-week-old male and female St3gal5 ${ }^{-/}$mice and C57BL/6 mice used as wild-type controls and six-week-old counter partners in the social interaction test were bred as described elsewhere (Dukhinova et al., 2019, 2018; Sotnikov et al., 2013). Male mice were housed individually in standard plastic cages $(27 \times 22 \times 15 \mathrm{~cm})$, female mice were housed in groups of three-five per cage. Mice were maintained on reversed 12-h light/dark cycle, under controllable laboratory conditions $\left(22 \pm 1^{\circ} \mathrm{C}, 55 \%\right.$ humidity, room temperature $22^{\circ} \mathrm{C}$, lights were on at 19:00), food and water were available ad libitum. All efforts were undertaken to minimize the potential discomfort of experimental animals. Experimental protocols conformed to directive 2010/63/EU and were compliant with ARRIVE guidelines (http://www.nc3rs.org.uk/arriveguidelines) and were approved by local veterinarian committee of School of Biomedical Sciences, Faculty of Medicine, the Chinese University of Hong Kong, Shatin, Hong Kong.

\section{Study design}

The social behaviour of the St3gal5 $5^{--}$mice was studied in two sets of experiments (Fig S1A\&B). In cohort A, mice were first employed to examine social interaction and rearing behaviours $(n=14$ in each group and then they were used to detect the ability to induce conditioned taste aversion ( $\mathrm{n}=6$ in each group; Fig.S1A). In cohort $\mathrm{B}$, the mice were used to investigate social behaviour or cytokine expression in following the i.p. administration of LPS $(0.1 \mathrm{mg} / \mathrm{kg}$ ) or PBS ( $\mathrm{n}=6$ per group). Additional groups of mice were used to study behaviour in the open field and grooming ( $n=10$ per group for males, $n=8$ per group for females). The motor function of St3gal5 $5^{--}$mice and wild-type animals was evaluated in the Pole test and Wire test ( $\mathrm{n}=6$ in each group). The mRNA levels for myelin proteins and protein concentrations of PLP1 in the brain cortex were studied in separate cohorts $(n=3-6)$. For all protocols used, see below. 


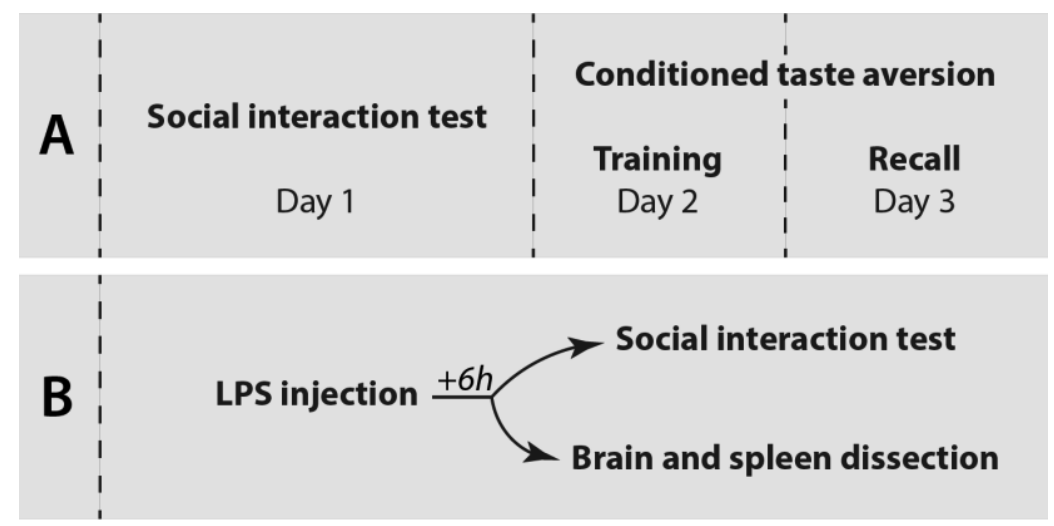

Figure S1. Experimental design of studies with social interaction test. (A) St3gal $5^{-1-}$ and wild-type mice of both sexes were tested in the social test on day 1 , and in the conditioned taste aversion on days 2-3. (B) St3gal5 $5^{--}$and wild-type mice of both sexes with LPS or PBS. After 6 hours post administration, half of the animals was studied in the social interaction test, and other half was killed, their brain and spleen were dissected and were collected for consequent RT PCR assay.

\section{Behavioral tests}

Behavioral tests were carried out during an active period of the animals' light cycle (09:00-21:00) and analyzed offline by the experimenter who was unaware of the genotype of each animal studied. One test was run per day. Mice of both genotypes were tested simultaneously. Behavioural equipment was thoroughly cleaned with water between each test.

\section{Social interaction test}

The social interaction test was adapted from a previously described method (Couch et al., 2016; Gorlova et al., 2020, 2019; Veniaminova et al., 2017). Each mouse was allowed to habituate to a new plastic cage (43 x 27 x $19 \mathrm{~cm}$ ) in which an unfamiliar group-housed naïve juvenile mouse of the same sex, that was five-week-old, was placed for $10 \mathrm{~min}$. the number of rears was scored. The latency, total duration, and number of events of aggressive (attacking) behaviour and dominant-like behaviours: following and mounting, and two forms of neutral social exploration: nose-nose and nose-anal contact were scored. In the study with LPS, the number of mice with the incidence of indicated types of dominant-like 
behaviour and neutral social exploration was scored during two-minute intervals.

\section{Conditioned taste aversion}

During the training session, mice were deprived from water between 17.00 and 14.00 (for $21 \mathrm{~h}$ ) and then were allowed to drink 2.5\% sucrose solution for $30 \mathrm{~min}$ in one-bottle paradigm (Strekalova, 2008, 2009). Thereafter, mice received an i.p. injection with solution of lithium chloride $(\mathrm{LiCl}, 0.24 \mathrm{M})$ at the dose $2 \%$ of body weight or PBS. After injection, animals were allowed to have access to sucrose solution for 1.5 $\mathrm{h}$ and thereafter they were subjected to a water deprivation for $12 \mathrm{~h}$. On the next day, a test for recall was performed. Mice were given a choice between tap water or $1 \%$ sucrose solution in a two-bottles paradigm for $8 \mathrm{~h}$. The amount of consumed liquid was determined by weighing the bottles before and after a drinking session, the preference to sucrose solution was calculated as percentage of consumed sucrose solution from total amount of liquid drunk by following formula:

$$
\text { Sucrose preference }=100 \% \times \frac{\text { Amount of sucrose solution consumed, } g}{\text { Total amount of liquid consumed, } g}
$$

A decrease of sucrose preference during recall session in comparison with a chance level is considered as a sign of taste aversion, i.e., inhibitory associative learning.

Wire test

The Wire test was used to assess motor abilities of mice as described previously (de Munter et al., 2020; Veniaminova et al., 2020). Mice were allowed to grip onto a horizontal hanging wire $(0.3 \mathrm{~cm}$ in diameter at $60 \mathrm{~cm}$ above the surface) using their four limbs, the latency to fall was scored in two consecutive sessions and the mean was calculated. The incidence of falling events was recorded as well.

\section{Pole test}

Mice were placed on top of a vertically standing bar (diameter 1.1 $\mathrm{cm}$, height $60 \mathrm{~cm}$ ) and allowed to climb down to a horizontal surface as described elsewhere (de Munter et al., 2020; Veniaminova et al., 2020). The latency to descend, measured as time spent by an animal to reach 
the ground with all four paws and events of sliding were recorded as measures of motor functions, in two consecutive trials.

Open field test

Mice were placed in the central arena of a customized square open field $(40 \times 40 \mathrm{~cm})$, which was illuminated with a red light. Their behaviour was video recorded for $10 \mathrm{~min}$ as described elsewhere (Lim et al., 2016). The time spent in the central zone $(30 \times 30 \mathrm{~cm})$, and duration of grooming were analysed offline using Any-maze software (Anymaze, Dublin, Ireland).

\section{Real-time polymerase chain reaction (RT-PCR)}

qRT-PCR was performed using the SYBR Green master mix (BioRad Laboratories, Philadelphia, PA, USA). qRT-PCR was performed in a $10 \mu l$ reaction volume containing a SYBR Green master mix (5 ul), RNasefree water $(3 \mu \mathrm{l})$, specific forward and reverse primers used at the concentration $20 \mathrm{pmol} / \mathrm{ul}(1 \mu \mathrm{l})$ and cDNA $(1 \mu \mathrm{l})$. The initial denaturation step for qRT-PCR was at $95^{\circ} \mathrm{C}$ for 5 min followed by 40 cycles of denaturation at $95^{\circ} \mathrm{C}$ for 30 seconds and annealing at $60^{\circ} \mathrm{C}$ for 30 seconds. The sequences of primers used are listed in Table S1 (see below); all primers were purchased from Life Technologies (Carlsbad, CA, USA). All samples were run in triplicate.

\section{Western blot}

Samples of brain cortex ( $0.1 \mathrm{~g}$ of wet tissue) were lysed in $1 \mathrm{ml}$ of lysis buffer (50 mM of Tris- $\mathrm{HCl}(\mathrm{pH}=7.4), 150 \mathrm{mM}$ of $\mathrm{NaCl}, 2 \% \mathrm{SDS}, 1 \%$ Sodium Deoxycholate, 5 mM EDTA, 1\% NP40 (Tergitol Solution, Sigma, St. Louis, MO, USA), and 1:100 protease inhibitor cocktail (cat\#1860932, Thermo Fisher Scientific Hong Kong, Hong Kong), and lysates were passed through $18 \mathrm{G}$ needle 10 times, vortexed for $5 \mathrm{~min}$ and centrifuged at 10,000 rpm for $10 \mathrm{~min}$ at $4 \mathrm{C}$. The supernatant was collected and $5 \mu \mathrm{l}$ of supernatant was mixed with $195 \mu$ l of Laemmli buffer. Then $10 \mu \mathrm{l}$ of samples were resolved on SDS electrophoresis using BoltTM 8\% Bis-Tris Plus Mini Gels (Ref. NW00082BOX, Invitrogen, Thermo Fisher Scientific Hong Kong, Hong Kong) according to manufacturer's recommendations using BoltTM MES SDS Running buffer, voltage of 200V for 25 minutes. 
Table S1. Primer sequence for mRNA expression analysis

\begin{tabular}{|c|c|c|}
\hline Gene & Primer & Sequence \\
\hline \multirow{2}{*}{ Plp1 } & Forward & 5'-CCAGAATGTATGGTGTTCTCCC-3’' \\
\hline & Reverse & 5'-GGCCCATGAGTTTAAGGACG-3’' \\
\hline \multirow{2}{*}{ Mbp } & Forward & 5'- TCACAGCGATCCAAGTACCTG-3' \\
\hline & Reverse & 5'-CCCCTGTCACCGCTAAAGAA-3' \\
\hline \multirow{2}{*}{ Mag } & Forward & 5'-GGTACATGGCGTCTGGTATTTC-3’' \\
\hline & Reverse & 5'-ACTTGTGTGCGGGACTTGAAG-3' \\
\hline \multirow{2}{*}{ Mog } & Forward & 5'-TCATGCAGCTATGCAGGACAA-3' \\
\hline & Reverse & 5'-TTTCGGTAGAGGTGAACCACT-3' \\
\hline \multirow{2}{*}{ Il-1 $\beta$} & Forward & 5'- CTTCCAGGATGAGGACATGAGCAC -3' \\
\hline & Reverse & 5'-TCATCATCCCATGAGTCACAGAGG -3' \\
\hline \multirow{2}{*}{ Il-6 } & Forward & 5'-CCTTCTTGGGACTGATGCTGGTG-3' \\
\hline & Reverse & 5'- AGGTCTGTTGGGAGTGGTATCCTC-3' \\
\hline \multirow{2}{*}{ Tnf } & Forward & 5'-AGCCGATGGGTTGTACCTTG- 3' \\
\hline & Reverse & 5'- GTGGGTGAGGAGCACGTAGTC -3' \\
\hline \multirow{2}{*}{ Gapdh } & Forward & 5'-ATGACCACAGTCCATGCCATC -3' \\
\hline & Reverse & 5'-GAGCTTCCCGTTCAGCTCTG -3' \\
\hline
\end{tabular}

polyvinylidene difluoride (PVDF) membranes (cat\# ISEQ00010, Millipore, Bedford, MA, USA). PVDF membranes were incubated in a 99\%-methanol solution for 1

min (Sigma, St. Louis, MO, USA), then washed with $\mathrm{mQ} \mathrm{H}_{2} \mathrm{O}$ for 5 min, and then incubated in Tris/Glycine transfer buffer (cat\#161-0734, Bio-Rad Pacific Limited, Hong Kong) for $15 \mathrm{~min}$. Transfer was performed on ice using ice-cold transfer buffer with constant voltage $80 \mathrm{~V}$ for $2 \mathrm{~h}$. After transfer, the membrane was treated with a 5\% BSA the TBST, containing

$50 \mathrm{mM}$ Tris- $\mathrm{HCl}$ ( $\mathrm{pH}=8.2$ ), $150 \mathrm{mM} \mathrm{NaCl}, 0.05 \%$ Tween-20 (Sigma, St. Louis, MO, USA) for $1 \mathrm{~h}$ at the room temperature and subsequently incubated with antibodies to PLP1 (1:1000, cat\#ab28486, Abcam, Cambridge, U.K.) and $\beta$-Actin (1: 1000, cat\#4967; Cell Signalling, Beverly, MA, USA) at $4^{\circ} \mathrm{C}$ overnight that was followed by the incubation with secondary horseradish peroxidase-conjugated secondary (HRP) antibodies (1:1000, cat\#7074S, Cell Signaling, Beverly, MA, USA), for $1 \mathrm{~h}$ at room temperature on a rotary shaker. Bands were visualized using Peroxide Detection Reagent from ECL Substrate kit (cat\#ab133406, Abcam, Cambridge, U.K.) according to manufacturer's recommendations. 
$\beta$-Actin was used as a loading control. Quantitative analysis of relative expression levels of PLP1 was normalized to $\beta$-Actin as we reported earlier (Veremeyko et al., 2018).

\section{Results}

\section{Dominant and aggressive behavior}

Statistical values of behavioral analysis are also presented in Table $\boldsymbol{S} 2$. No significant interaction between sex and genotype was found for the latency to following ( $\mathrm{p}=0.34$, two-way ANOVA, Fig. S2). A significant main effect of genotype was observed ( $\mathrm{p}<0.05$, two-way ANOVA). Latency to following in wild-type mice was significantly higher compared to St3gal5 $5^{-/-}$groups irrespectively of the genotype ( $\mathrm{p}=0.02$, unpaired $\mathrm{t}$-test). Two-way ANOVA showed no significant differences in the latency to mounting, number of mounting events, and mounting duration (all $\mathrm{p}>0.05$, two-way ANOVA). In males, no significant differences were found in the latency to attack, number or duration of attacks. 
A

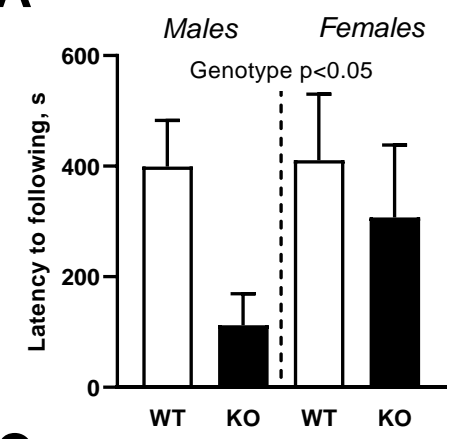

$\mathbf{C}_{\infty 2.5}$ Males, Females

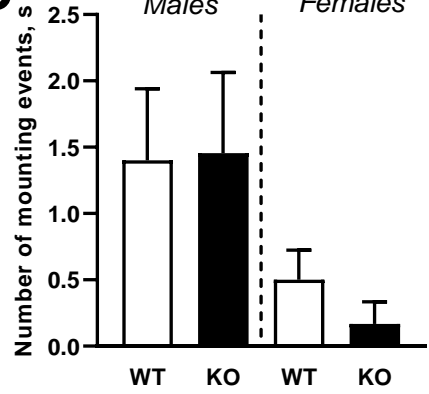

E

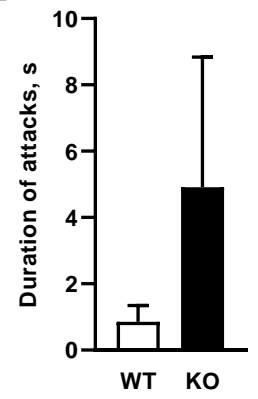

B

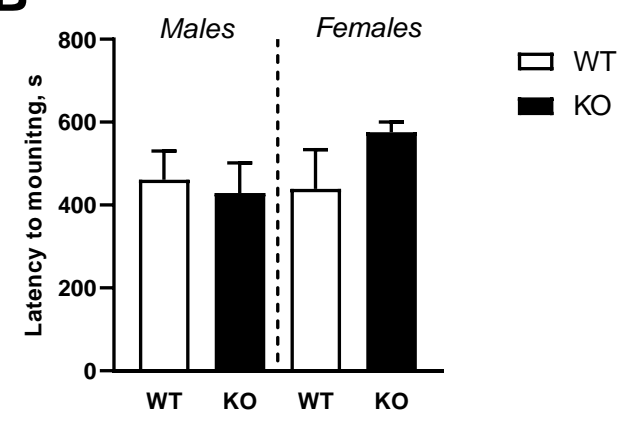

D

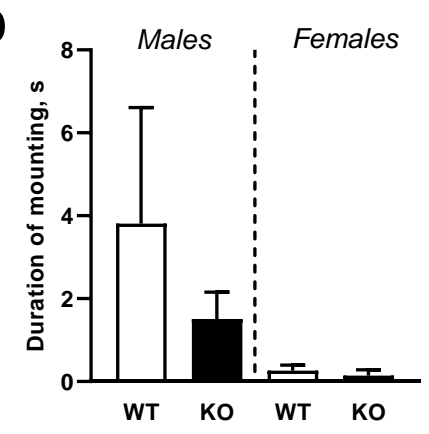

G

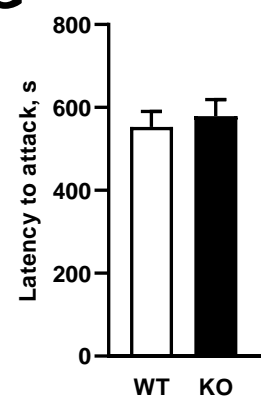

Figure S2. Dominant and aggressive behaviors. (A) Latency to following was significantly lower in St3gal5 $5^{--}$animals irrespective of sex. (B-D) Parameters of mounting and (E-F) parameters of attacks in males were not changed significantly. WT - wild type. $\mathrm{KO}-\mathrm{St} 3 \mathrm{gal5^{-- }}$. Data are presented as Mean \pm SEM. 


\section{Neutral social exploration}

Duration of both nose-anal and nose-nose contacts was affected by the genotype only (both $\mathrm{p}<0.05$, two-way ANOVA, Fig.S3). No significant changes in the latencies to nose-anal and nose-nose contacts were revealed by two-way ANOVA.
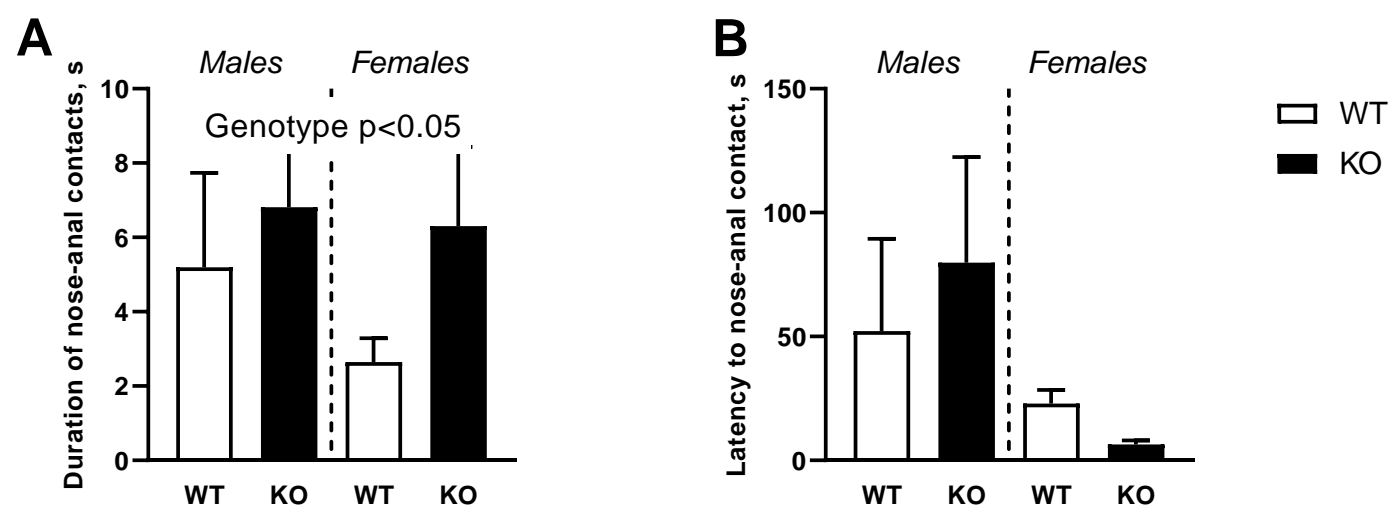

C
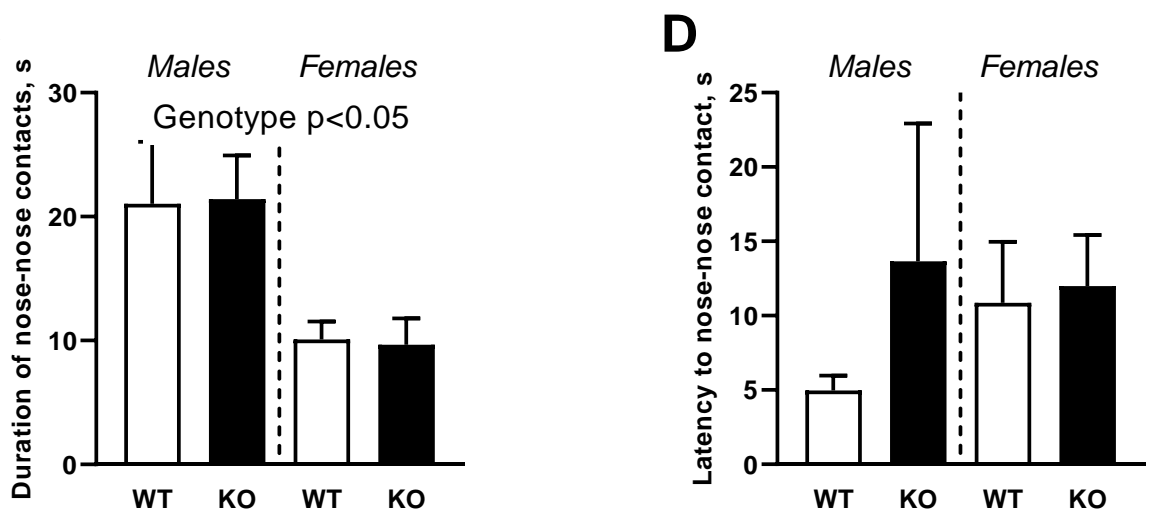

Figure S3. Neutral social exploration in St3gal5 $5^{-/}$mice. (A) Duration of nose-anal contacts. (B) Latency to nose-anal contact. (C) Duration of nosenose contacts. (D) Latency to nose-nose contact. WT - wild type. KO $\mathrm{St}_{\mathrm{gal5}}{ }^{--}$. Data are presented as Mean \pm SEM. 


\section{RT-PCR and Western blot}

Two-way ANOVA did not reveal any significant differences in the expression of $\operatorname{Mog}$ (all p>0.05, two-way ANOVA, Fig.S4A). PLP1 relativefold protein expression was significantly affected by genotype only $(p<0.01$, two-way ANOVA, Fig. S4B). A significant decrease of PLP1 relative-fold protein expression was found in St3gal5 $5^{-/}$mice in comparison to wild-type controls. (Statistical values of Western-blot analysis are also presented in Table S3).

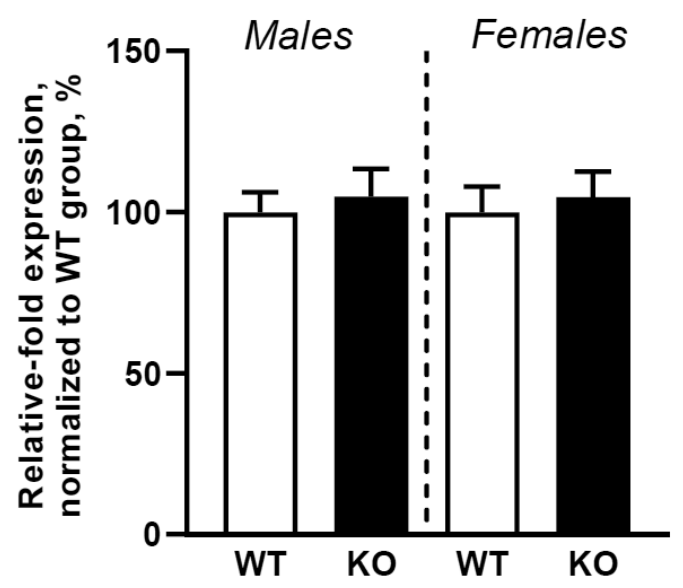

Figure S4. (A) Expression of Mog in the prefrontal cortex of St3gal5 $5^{-1-}$ mice. (B) Western blot analysis of PLP1 expression in the brain of wild-type (WT) and St3gal5-deficient (ST3 ${ }^{-/}$) mice of both sexes. Western blot analysis was performed as described in Methods and representative image for staining with anti-PLP1 antibody is shown. Data are presented as Mean \pm SEM. 


\section{Changes in social behaviors in the LPS-treated mice}

\section{Aggressive and dominant behavior}

Three-way ANOVA found no significant differences in the latency to the following events (all p>0.05, two-way ANOVA, Fig. S5A). For the latency to the mounting events three-way ANOVA revealed a significant sex $\times$ genotype interaction ( $\mathrm{p}=0.01$, Fig. S5B). St3gal5 ${ }^{-1-}$ female mice exhibited a significantly higher latency to mounting events compared to wild-type female group irrespectively of the LPS administration $(p=0.04$, unpaired t-test). Significant main effects of both treatment, genotype, and sex were found for the number of following events (all $p<0.05$, threeway ANOVA. Fig.S5C). Significant sex $\times$ genotype $\times$ treatment interaction was also found for the number of mounting events $(p<0.05$, three-way ANOVA. Fig. S5D). Female LPS-treated wild-type group exhibited a significantly higher number of mounting events than LPS-treated wildtype male group and St3gal5 ${ }^{-1-}$ LPS-treated female group (both $\mathrm{p}<0.05$, Sidak's test). Interaction of treatment and sex significantly affected the duration of following $(\mathrm{p}<0.05$, three-way ANOVA. Fig.S5E). Irrespectively of genotype, LPS-treated female groups exhibited higher duration of following compared to LPS-treated males, and same effect was observed in PBS-treated groups (both $\mathrm{p}<0.05$, Tukey's test). Duration of mounting was significantly affected by the interaction of sex, genotype, and treatment $(\mathrm{p}<0.05$, three-way ANOVA. Fig.S5F). Compared to controlLPS-treated male group and St3gal5 $5^{-/}$-LPS-treated female group, female LPS-treated wild-type group exhibited a significantly higher duration of mounting (both $\mathrm{p}<0.05$, Sidak's test) In male mice, significant differences were found neither in the number of attacks nor in the latency to attack in the social interaction test (all p>0.05, three-way ANOVA, Fig.S5G,H). (Statistical values of behavioral analysis are also presented in Tables $S 5 A, B$.) 
A
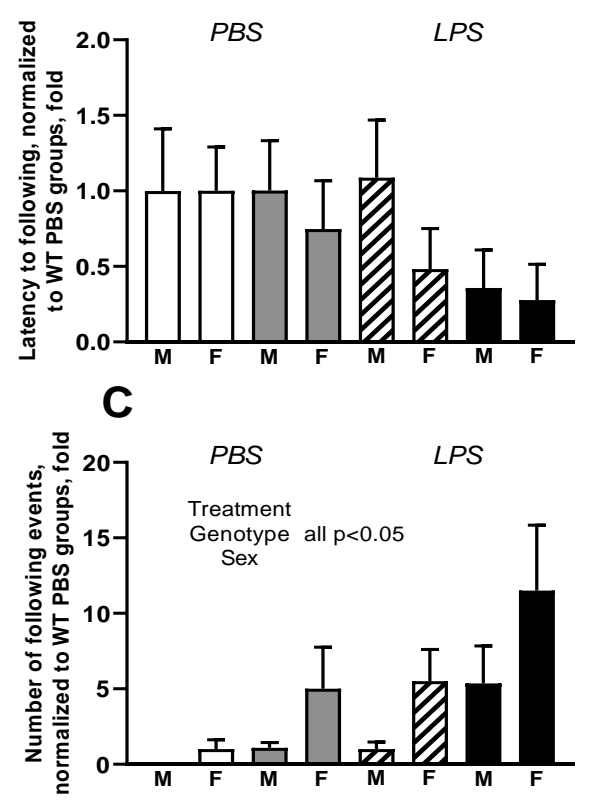

$E$
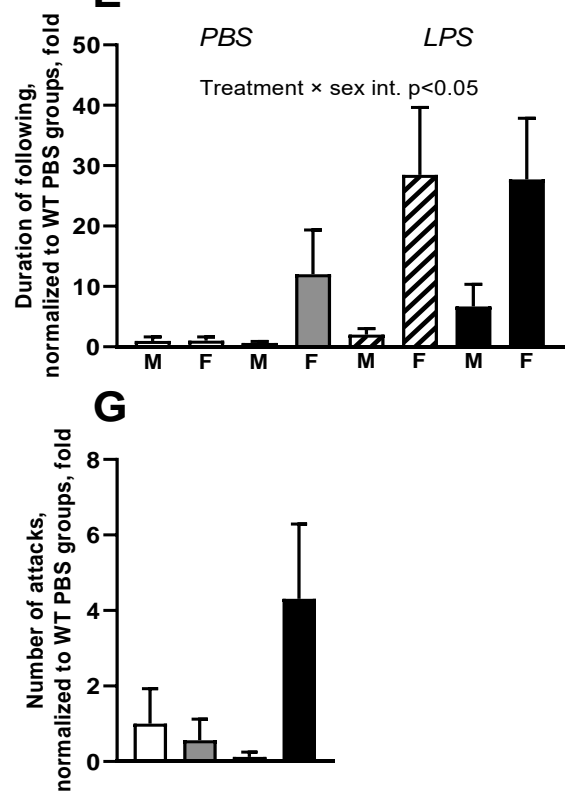

B

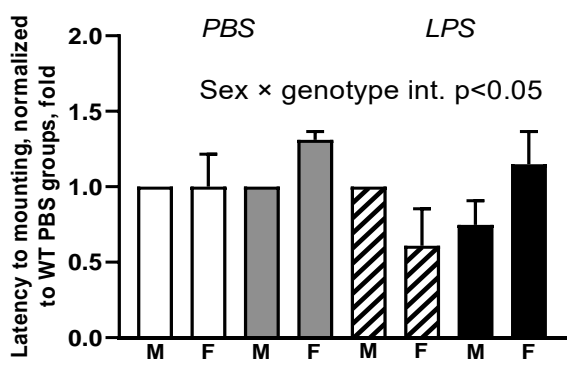

D

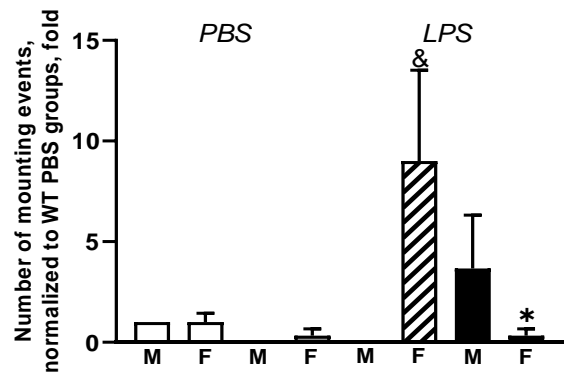

$F$

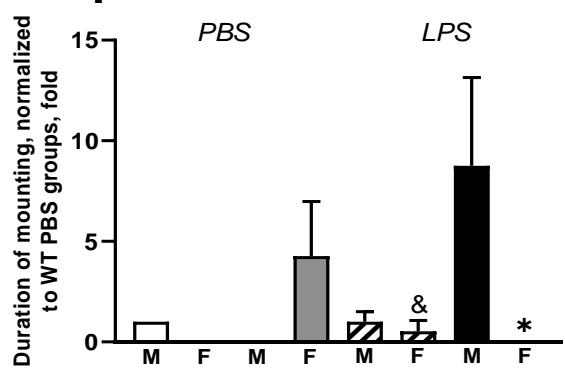

H

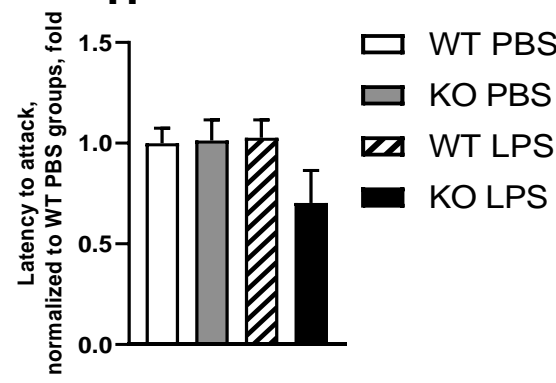


Figure S5. Aggressive and dominant behavior in LPS-treated groups, normalized to the wild-type PBS groups. (A) Latency to following was not affected significantly by any of the factors. (B) Significant sex $\times$ genotype interaction was found for the latency to mounting. (C) Number of following events was significantly affected by the main effects of sex, genotype, and treatment, but not by their interactions. (D) Number of mounting events was higher in LPS-treated wild-type female mice, than in LPS-treated mutant female mice, and LPS-treated wild-type male mice. (E) Duration of following was affected by treatment $\times$ sex interaction. (F) Duration of mounting events was elevated in LPS-treated wild-type female mice than in the LPStreated mutant female mice, and LPS-treated wild-type male mice. (G) Number of attacks and $\mathbf{( H )}$ latency to attack in male were not affected by either genotype, sex, or treatment. WT - wild type. KO - St3gal5 ${ }^{-1}$. Int. interaction. ${ }^{*} p<0.05$ vs. wild type group, $\& p<0.05$ vs. group of males. Data are presented as Mean \pm SEM.

\section{Neutral social exploration}

Statistical values of behavioral analysis are also presented in Tables $S 6 A, B$. No significant differences were found by three-way ANOVA in the latency to nose-anal contacts, and in the latency, duration, and number of nose-nose contacts (all p>0.05, three-way ANOVA. Fig.S6A,B,D,F). For the duration of the nose-anal contacts, three-way ANOVA revealed a significant effect of the genotype ( $p=0.04$. Fig.S6C). Irrespectively of the sex and LPS treatment, St3gal5 $5^{--}$mice showed enhanced duration of the nose-anal contacts. The number of nose-anal contacts also was found to be significantly affected by the genotype only (p<0.05, Fig.S6E). St3gal5 $5^{-1-}$ mice exhibited significantly higher number of the nose-anal contacts compared to wild-type mice irrespectively of sex and treatment. 

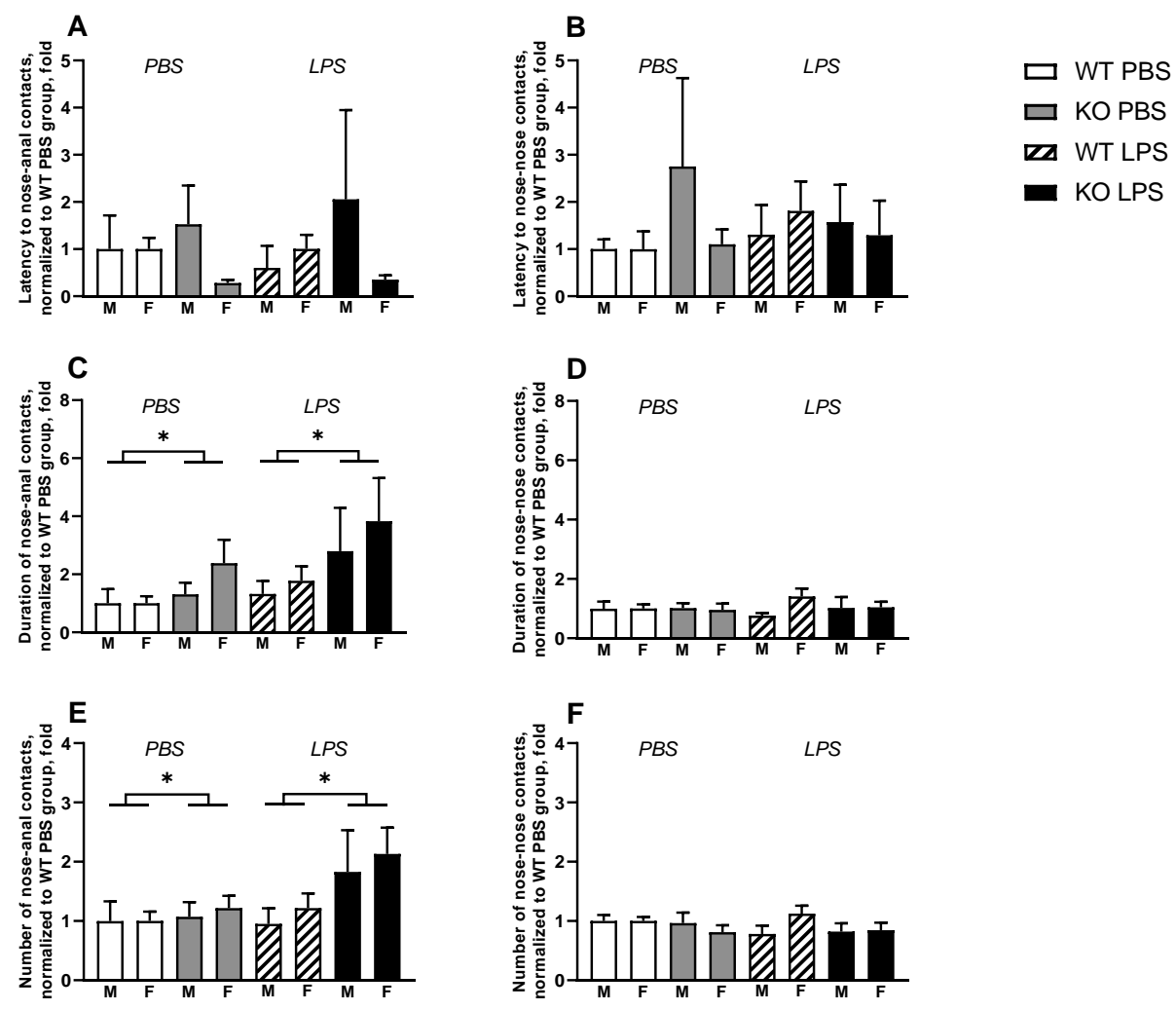

Figure S6. Social interaction in LPS-treated groups. (A, B) No significant differences were found in the latencies to nose-anal or nosenose contacts, as well as in the (D) duration and (F) number of nose-nose contacts. (C, E) In the duration and number of nose-anal contacts, only

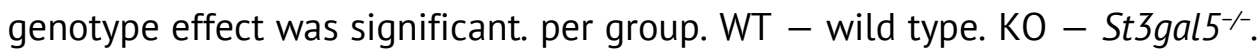
$M$ - male mice, $F$ - female mice. Int. - interaction. ${ }^{*} p<0.05$. Data are presented as Mean \pm SEM.

Expression of the cytokines in the brain and the spleen normalized to sex- and genotype-matched PBS groups

Two-way ANOVA revealed significant sex $\times$ genotype interaction for the normalized to the expression in the sex-and genotype-matched PBS-treated control groups expression of Il-1 $\beta$ mRNA, Il- 6 mRNA, and Tnf mRNA in the brain of LPS-treated mice (all $\mathrm{p}<0.01$, two-way ANOVA. Fig.S7A,B). In both wild-type male and female mice an increase in the concentration of the Il-1 $\beta$ mRNA in the brain after LPS administration 
was significantly higher than in the corresponding St3gal5-1--LPS groups (both $\mathrm{p}<0.05$, Tukey's test). In male wild-type mice, the increase of this measure was significantly higher than in wild-type group of females ( $\mathrm{p}<0.01$, Tukey's test). In St3gal5 ${ }^{-1-}$-LPS-treated mice, an increase in the Il-1 $\beta$ mRNA concentration upon LPS administration was more pronounced in female mice, compared to St3gal5 $5^{-1-}$-LPS-treated males ( $\mathrm{p}<0.01$, Tukey's test). As for $I l-1 \beta$, LPS-induced augmentation of brain concentration of Il-6 mRNA was greater in the wild-type LPS-treated groups than in St3gal5 $5^{--}$animals (both $\mathrm{p}<0.01$, Tukey's test). In both genotypes such increases were significantly higher in male animals than in female groups (both $\mathrm{p}<0.01$ ). Similar increases were found for brain concentration of Tnf mRNA, whose increases were higher in the wildtype groups than in mutants (both $\mathrm{p}<0.05$, Tukey's test). In male wildtype-LPS-treated animals, the elevation in concentration of Tnf mRNA in the brain was higher than in wild-type-LPS-treated female mice $(\mathrm{p}<0.01$, Tukey's test), and opposite changes were found in the $\mathrm{St3gal5}^{-/-}$groups ( $\mathrm{p}<0.01$, Tukey's test). (Statistical values of behavioral analysis are also presented in Table S7).

In the spleen, normalized concentrations of $I l-1 \beta$ mRNA and Il-6 mRNA were significantly affected by the interaction of sex and genotype (both $\mathrm{p}<0.05$, two-way ANOVA. Fig.S7C,D). Elevation of $I l-1 \beta$ mRNA concentration upon LPS administration was significantly higher in wildtype males compared to St3gal5 $5^{--}$males and wild-type females (both $\mathrm{p}<0.01$, Tukey's-test). In wild-type-LPS-treated female group, increase in the Il-6 mRNA concentration was significantly higher in comparison to both male wild-type-LPS group and female St3gal5 ${ }^{-1-}$-LPS-treated animals (both $\mathrm{p}<0.01$, Tukey's-test). For the Tnf mRNA concentration in the spleen, only the main factor of genotype was significant $(p<0.01$, twoway ANOVA). Elevation in the concentration of the Tnf mRNA in the spleen in the St3gal5 ${ }^{-1-}$-LPS-treated groups was significantly higher than in the wild-type-LPS-treated groups irrespectively of the sex. 


\section{Brain}
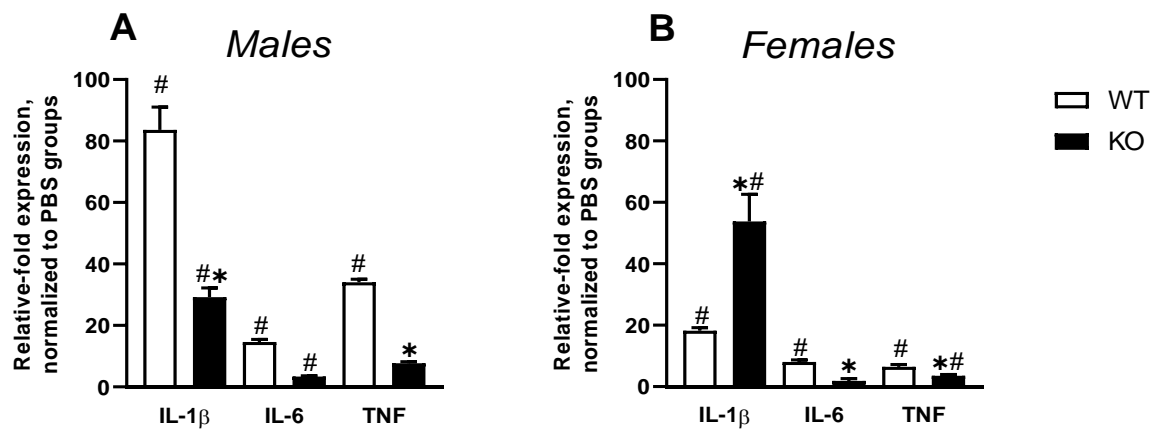

\section{Spleen}
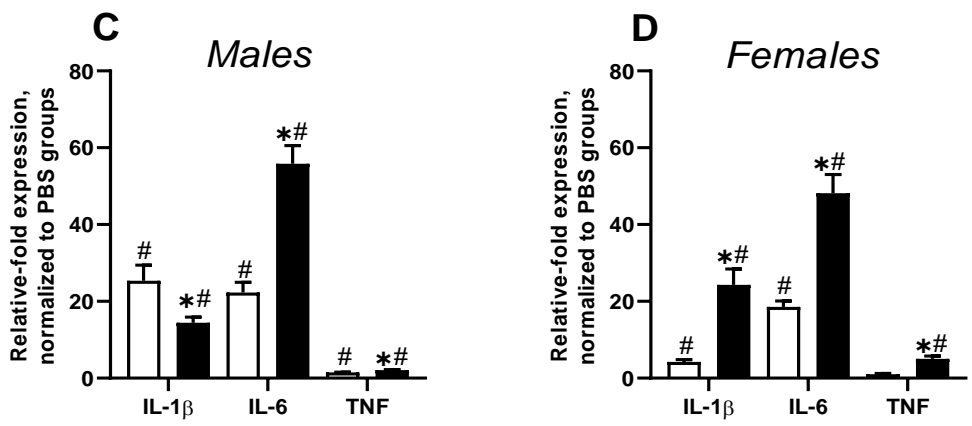

Figure S7. Expression of pro-inflammatory cytokines normalized to sex-and genotype-matched groups. (A, B) All the LPS-treated groups of both sexes showed a significant elevation of the mRNA concentrations of all the analyzed cytokines in the brain. In mutant males, elevation in the concentrations of Il-16 mRNA and Tnf mRNA were lower compared to wildtype males. The same was found for the $l l-6$ mRNA and Tnf mRNA in the female groups. Il-16 mRNA concentration in females showed opposite changes to those in males. (C,D) In the spleen of LPS-treated mice, mRNA concentrations of all the cytokines were elevated significantly in comparison to PBS-treated groups, except Tnf in wild-type females. In male mice, $l l-16$ and Tnf mRNA were elevated significantly higher in wild-typeLPS mice in comparison to the St3gal5 $5^{-1-L P S}$ animals. $1 /-6$ in males and all three cytokines in females were significantly elevated in LPS-treated mutants vs. LPS-treated wild-type animals in the spleen. WT - wild type. KO - St3gal5 $/$. * $p<0.05$ vs. PBS group, ${ }^{*} p<0.05$ vs. wild-type group. Data are presented as Mean \pm SEM. 


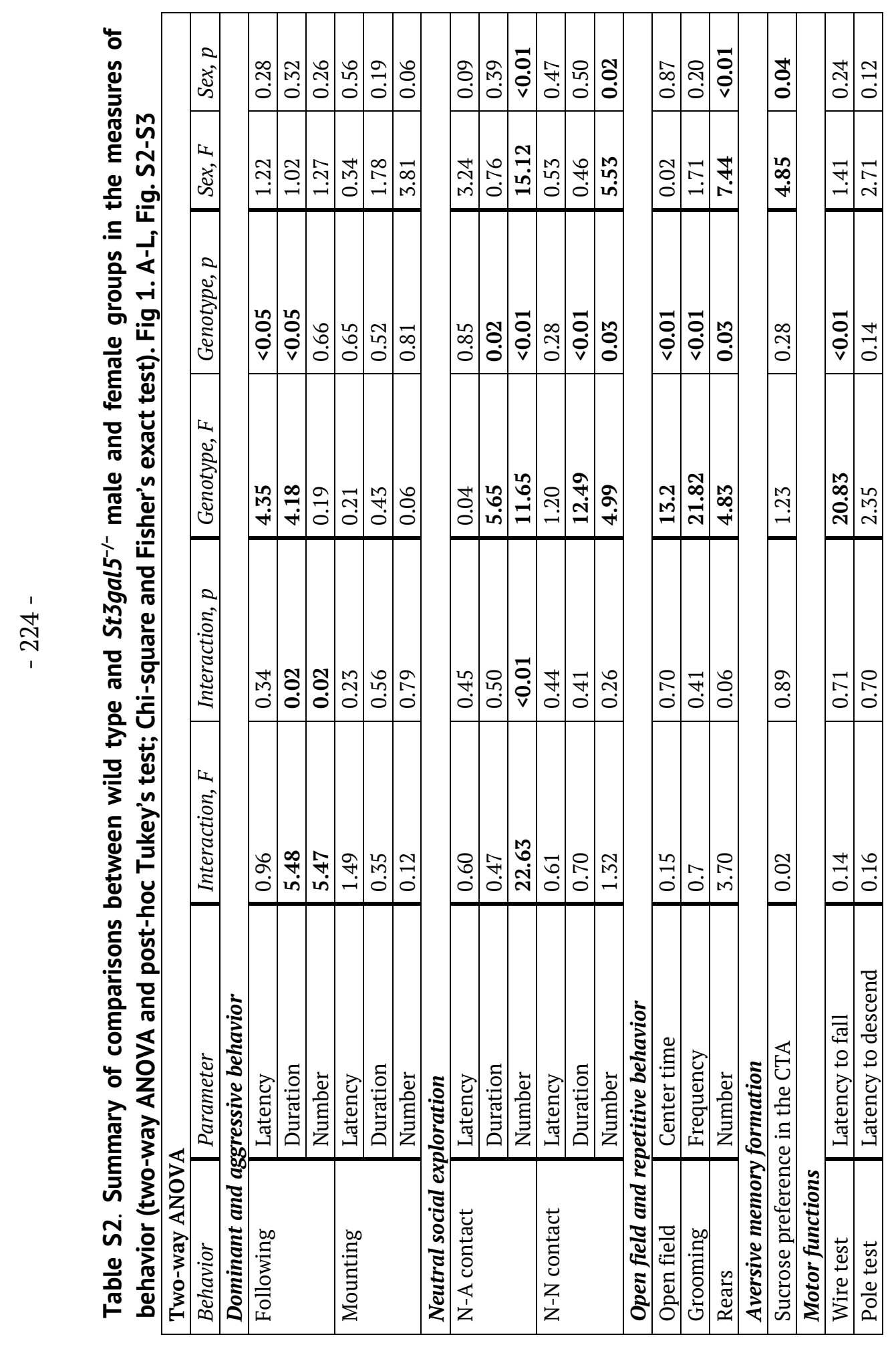




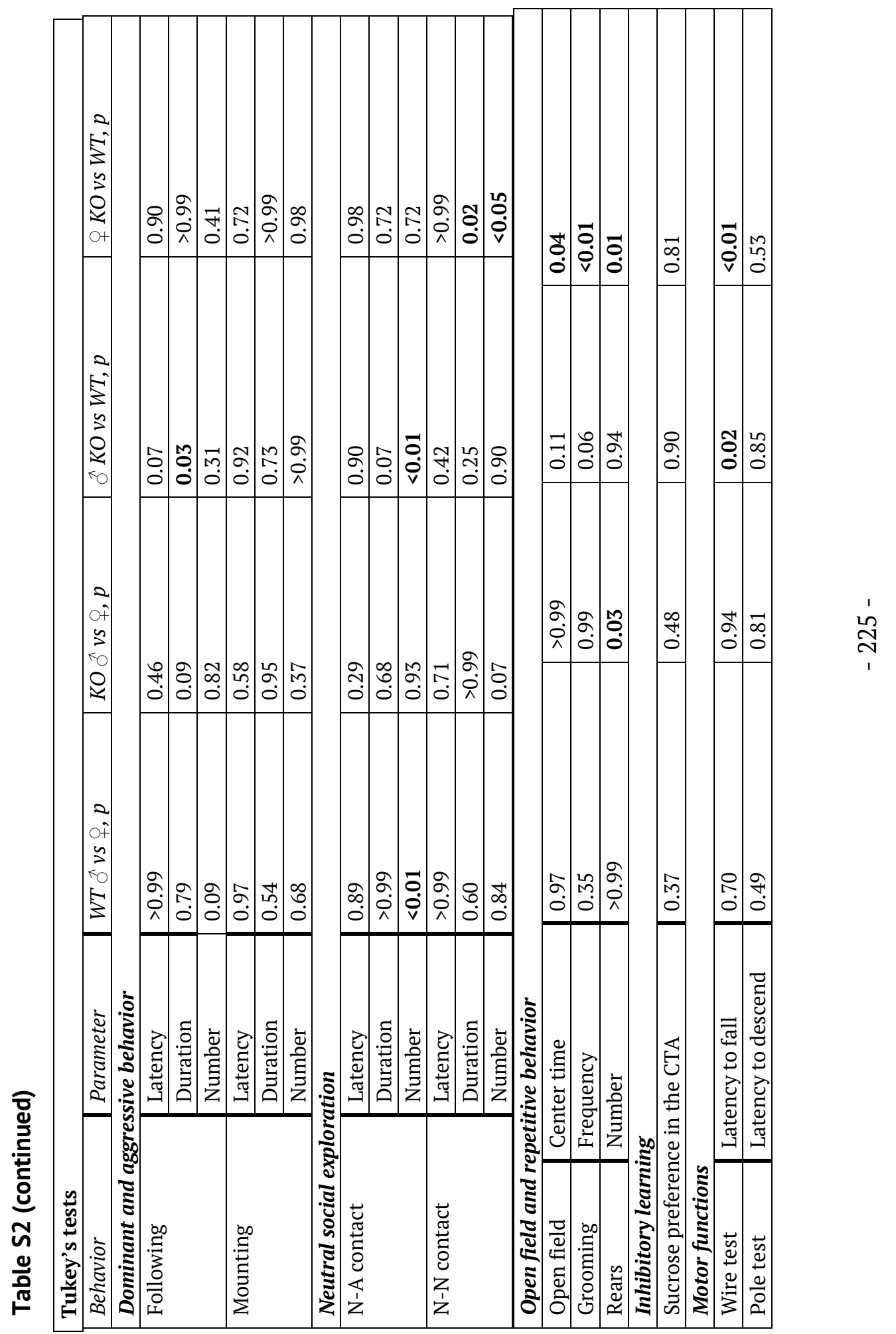




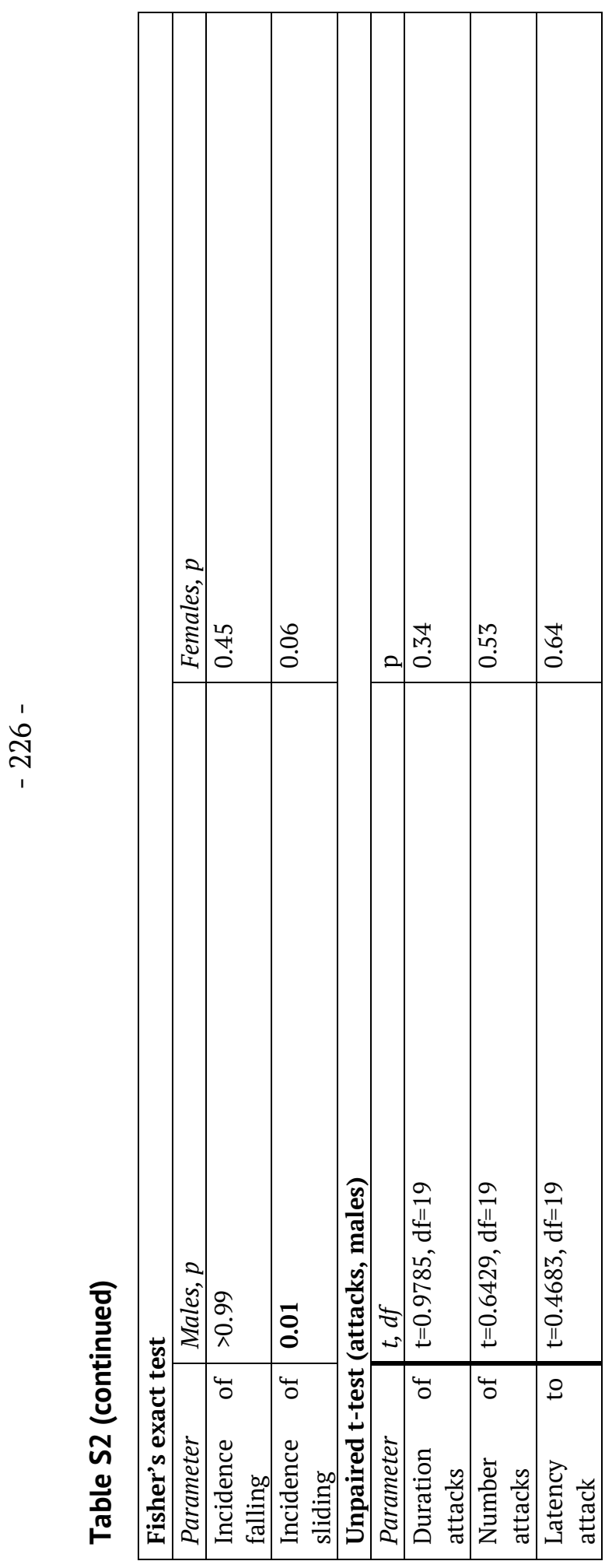




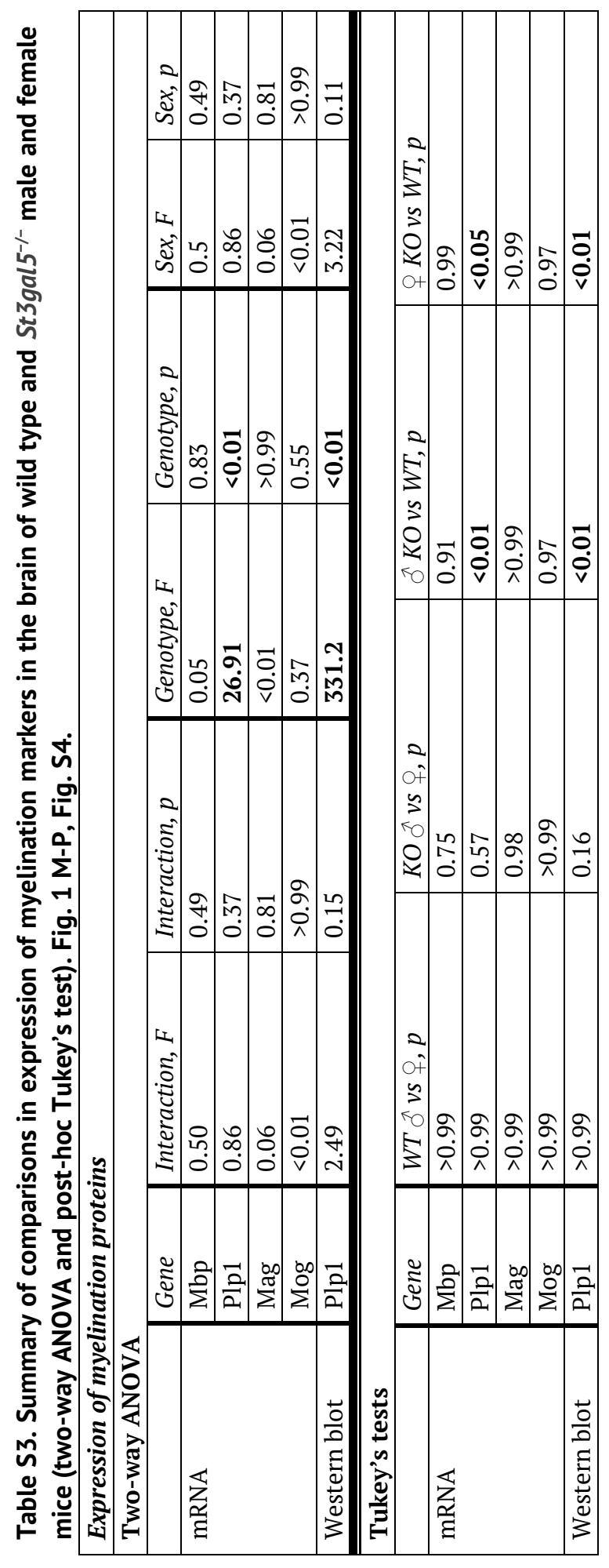




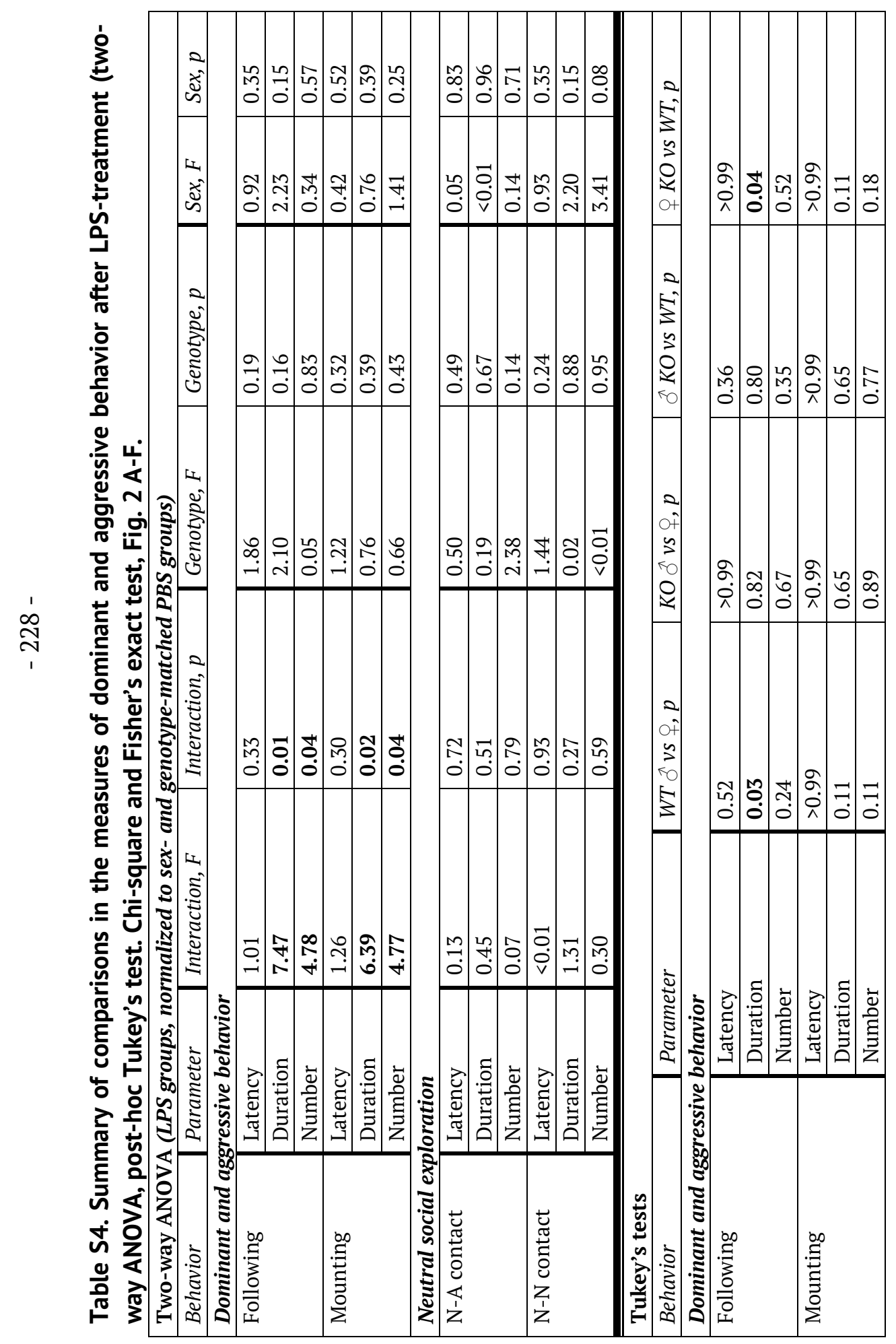




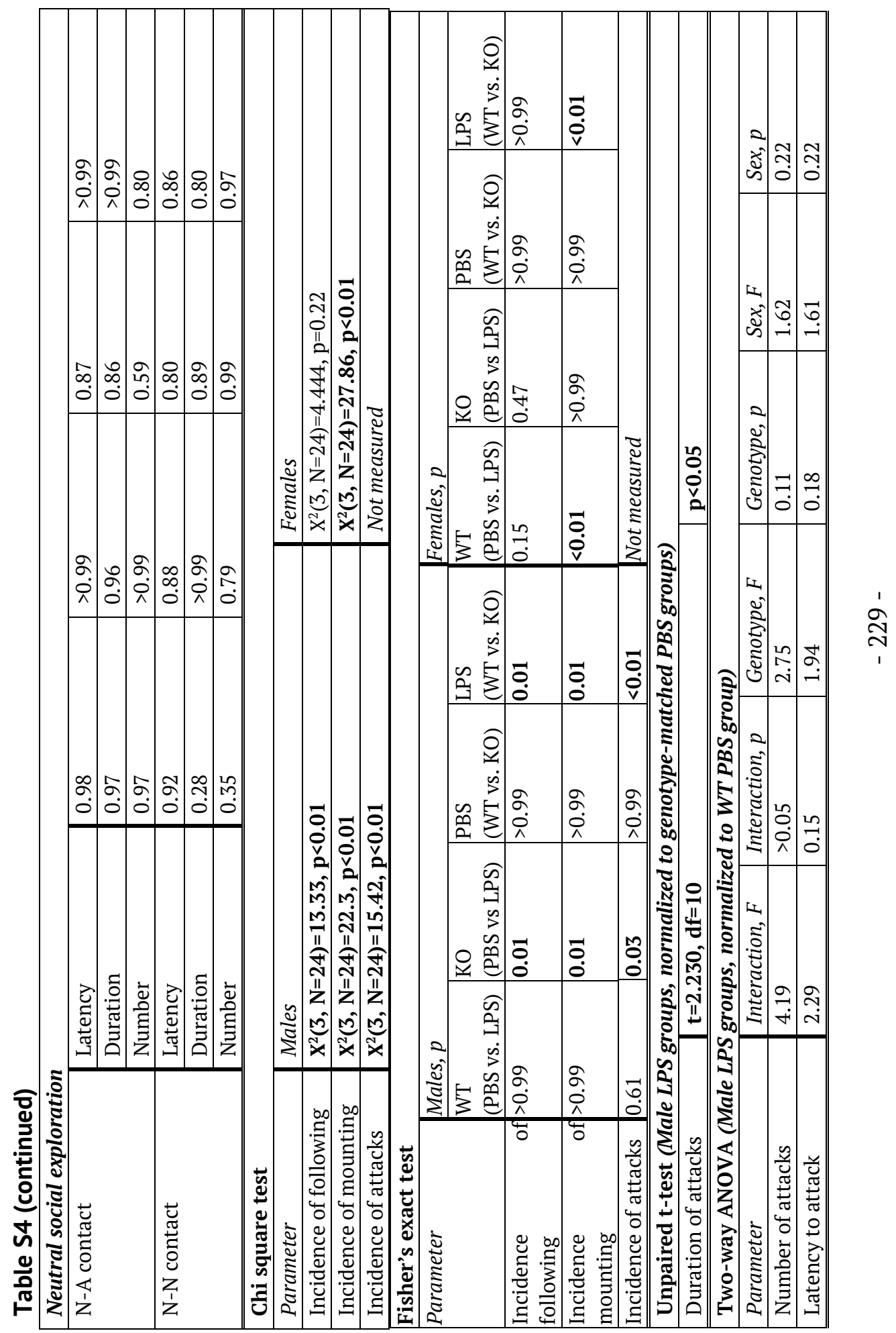




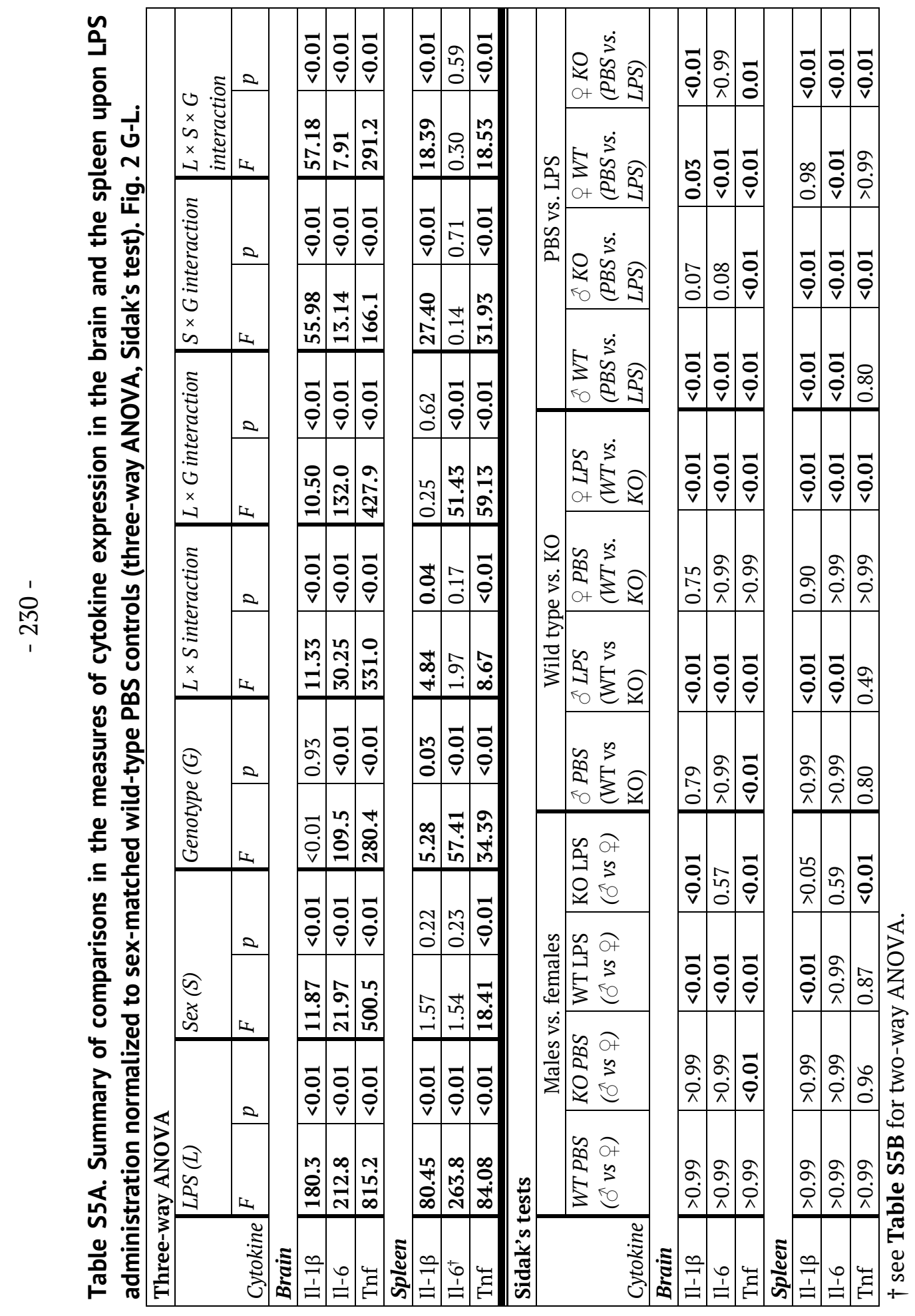



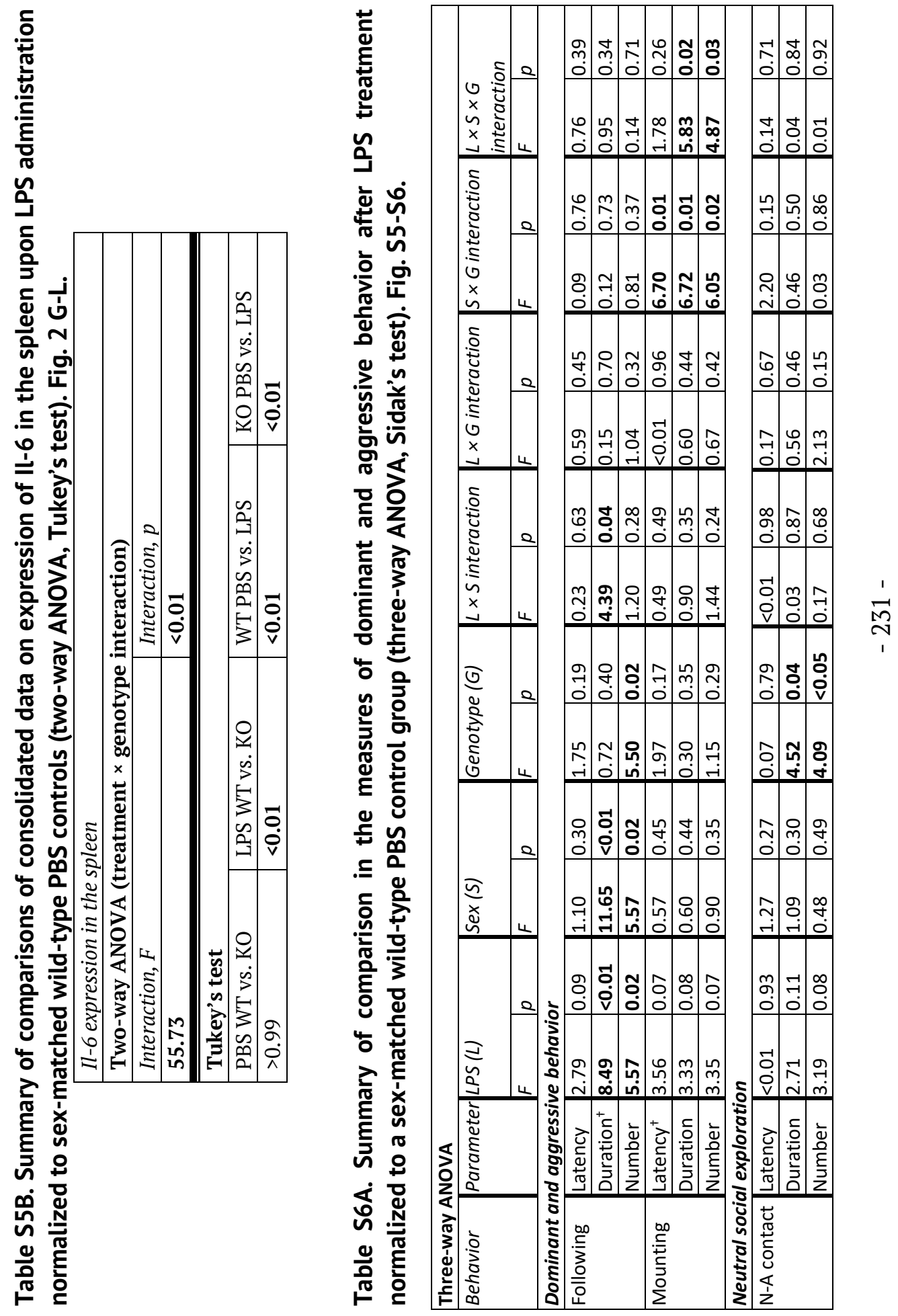


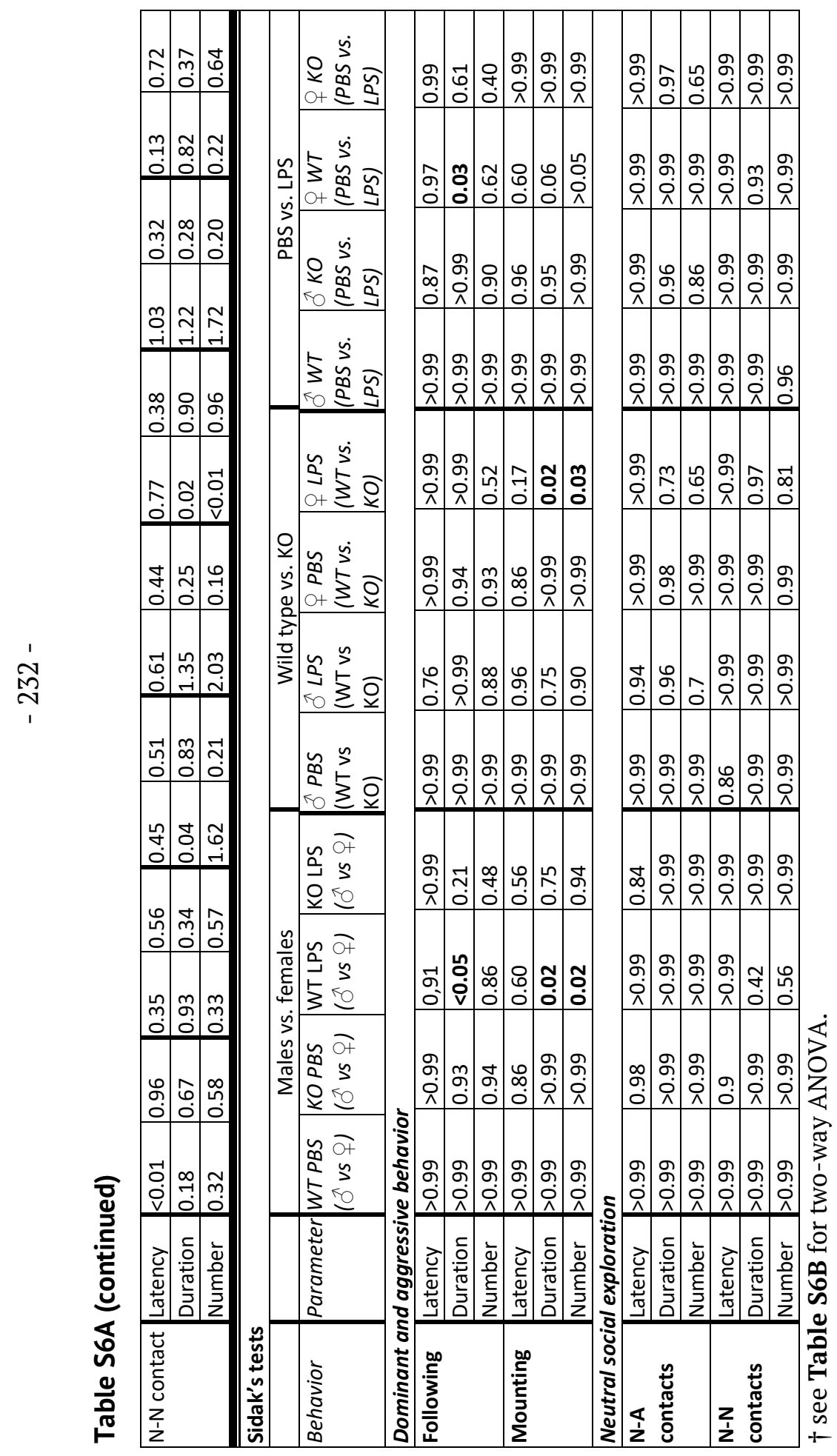




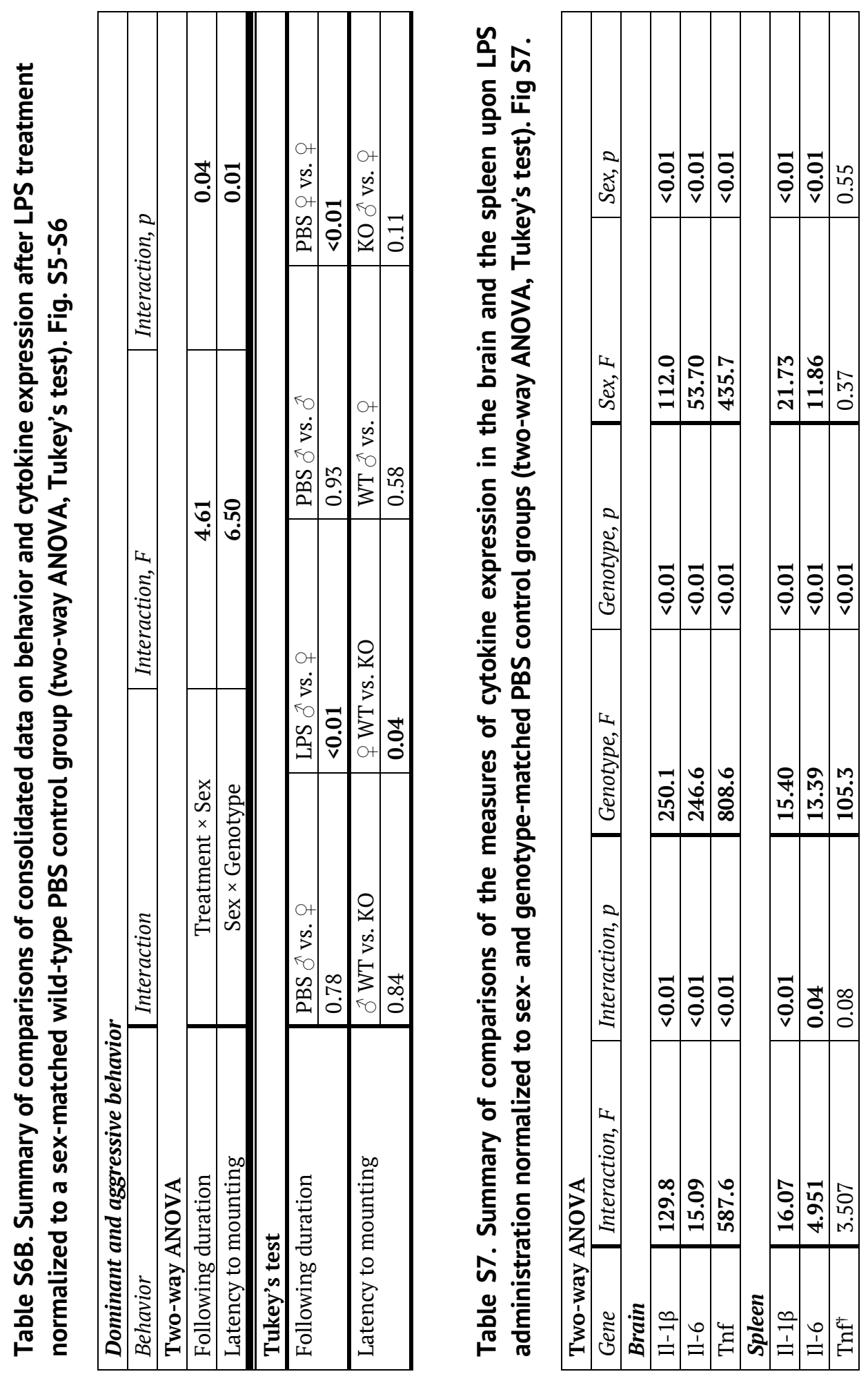




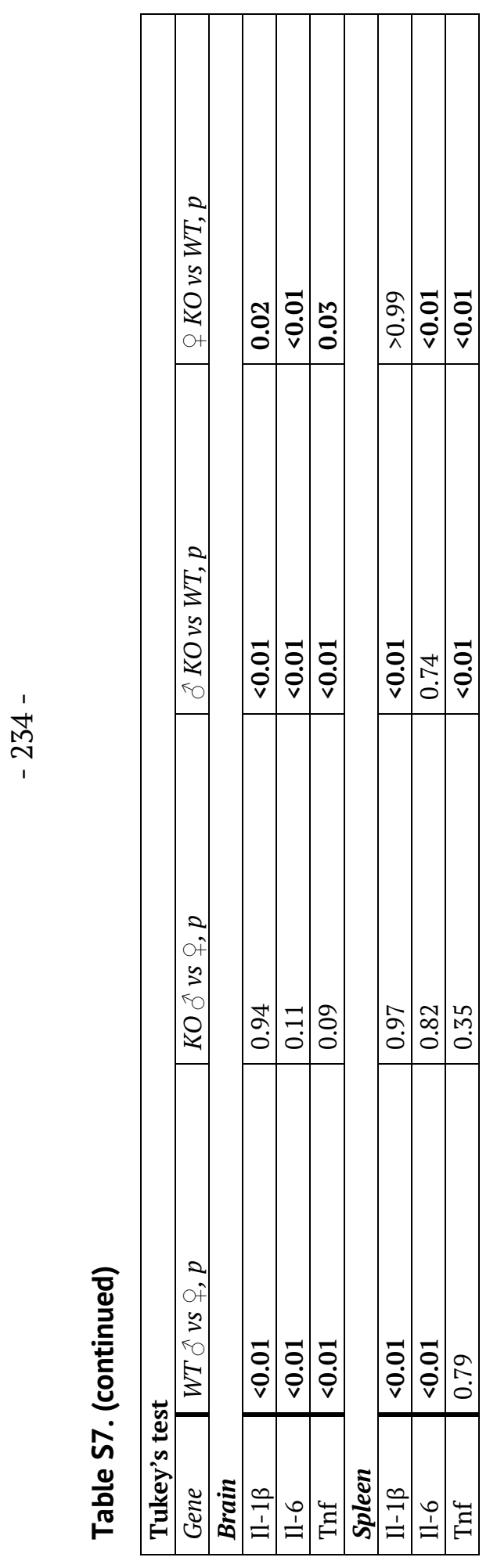




\section{References}

ARRIVE guidelines [WWW Document], n.d. URL https://arriveguidelines.org/ (accessed 6.21.21).

Couch, Y., Trofimov, A., Markova, N., Nikolenko, V., Steinbusch, H.W., Chekhonin, V., Schroeter, C., Lesch, K.P., Anthony, D.C., Strekalova, T., 2016. Low-dose lipopolysaccharide (LPS) inhibits aggressive and augments depressive behaviours in a chronic mild stress model in mice. J. Neuroinflammation 13, 1-17. https://doi.org/10.1186/s12974-016-0572-0

de Munter, J., Schafarevich, I., Liundup, A., Pavlov, D., Wolters, E., Gorlova, A., Veniaminova, E., Umriukhin, A., Kalueff, A., Svistunov, A., Kramer, B.W., Lesch, K.-P., Strekalova, T., 2020. Neuro-Cell therapy improves motor outcomes and suppresses inflammation during experimental syndrome of amyotrophic lateral sclerosis in mice. CNS Neurosci. Ther.

Dukhinova, M., Kuznetsova, I., Kopeikina, E., Veniaminova, E., Yung, A.W.Y., Veremeyko, T., Levchuk, K., Barteneva, N.S., Wing-Ho, K.K., Yung, W.H., Liu, J.Y.H., Rudd, J., Yau, S.S.Y., Anthony, D.C., Strekalova, T., Ponomarev, E.D., 2018. Platelets mediate protective neuroinflammation and promote neuronal plasticity at the site of neuronal injury. Brain. Behav. Immun. 74, 7-27. https://doi.org/10.1016/j.bbi.2018.09.009

Dukhinova, M., Veremeyko, T., Yung, A.W.Y., Kuznetsova, I.S., Lau, T.Y.B., Kopeikina, E., Chan, A.M.L., Ponomarev, E.D., 2019. Fresh evidence for major brain gangliosides as a target for the treatment of Alzheimer's disease. Neurobiol. Aging 77, 128-143. https://doi.org/10.1016/j.neurobiolaging.2019.01.020

Gorlova, A., Ortega, G., Waider, J., Bazhenova, N., Veniaminova, E., Proshin, A., Kalueff, A. V., Anthony, D.C., Lesch, K.P., Strekalova, T., 2020. Stress-induced aggression in heterozygous TPH2 mutant mice is associated with alterations in serotonin turnover and expression of 5HT6 and AMPA subunit 2A receptors. J. Affect. Disord. 272, 440-451. https://doi.org/10.1016/j.jad.2020.04.014 
Gorlova, A., Pavlov, D., Anthony, D.C., Ponomarev, E.D., Sambon, M., Proshin, A., Shafarevich, I., Babaevskaya, D., Lesch, K.P., Bettendorff, L., Strekalova, T., 2019. Thiamine and benfotiamine counteract ultrasound-induced aggression, normalize AMPA receptor expression and plasticity markers, and reduce oxidative stress in mice. Neuropharmacology 156 ,

107543. https://doi.org/10.1016/j.neuropharm.2019.02.025

Kopeikina, E., Dukhinova, M., Yung, A.W.Y., Veremeyko, T., Kuznetsova, I.S., Lau, T.Y.B., Levchuk, K., Ponomarev, E.D., 2020. Platelets promote epileptic seizures by modulating brain serotonin level, enhancing neuronal electric activity, and contributing to neuroinflammation and oxidative stress. Prog. Neurobiol. 188, 101783. https://doi.org/10.1016/j.pneurobio.2020.101783

Lim, L.W., Shrestha, S., Or, Y.Z., Tan, S.Z.K., Chung, H.H., Sun, Y., Lim, C.L., Khairuddin, S., Lufkin, T., Lin, V.C.L., 2016. Tetratricopeptide repeat domain 9A modulates anxiety-like behavior in female mice. Sci. Rep. 6, 37568. https://doi.org/10.1038/srep37568

Sotnikov, I., Veremeyko, T., Starossom, S.C., Barteneva, N., Weiner, H.L., Ponomarev, E.D., 2013. Platelets Recognize Brain-Specific Glycolipid Structures, Respond to Neurovascular Damage and Promote Neuroinflammation. PLOS

One 8. https://doi.org/10.1371/journal.pone.0058979

Strekalova, T., 2008. Optimization of the chronic stress depression model in C57 BL/6 mice: evidences for improved validity, in: J, L. (Ed.), Behavioral Models in Stress Research. Volume I. Nova Science Publishers, NY, USA, pp. 95-139.

Strekalova, T., Steinbusch, H., 2009. Factors of Reproducibility of Anhedonia Induction in a Chronic Stress Depression Model in Mice, in: Gould, T.D. (Ed.), Mood and Anxiety Related Phenotypes in Mice: Characterization Using Behavioral Tests, Neuromethods. Humana Press, Totowa, NJ, pp. 153-176. https://doi.org/10.1007/978-1-60761-303-9_9

Veniaminova, E., Cespuglio, R., Chernukha, I., Schmitt-Boehrer, A.G., Morozov, S., Kalueff, A. V., Kuznetsova, O., Anthony, D.C., Lesch, K.-P., Strekalova, T., 2020. Metabolic, Molecular, and Behavioral Effects of Western Diet in Serotonin Transporter-Deficient Mice: Rescue by 
Heterozygosity?

Front.

Neurosci.

14.

https://doi.org/10.3389/fnins.2020.00024

Veniaminova, E., Cespuglio, R., Cheung, C.W., Umriukhin, A., Markova, N., Shevtsova, E., Lesch, K.P., Anthony, D.C., Strekalova, T., 2017. Autism-Like Behaviours and Memory Deficits Result from a Western Diet in Mice. Neural Plast. 2017. https://doi.org/10.1155/2017/9498247

Veremeyko, T., Yung, A.W.Y., Anthony, D.C., Strekalova, T., Ponomarev, E.D., 2018. Early Growth Response Gene-2 Is Essential for M1 and M2 Macrophage Activation and Plasticity by Modulation of the Transcription Factor CEBP $\beta$. Front. Immunol. 9. https://doi.org/10.3389/fimmu.2018.02515 


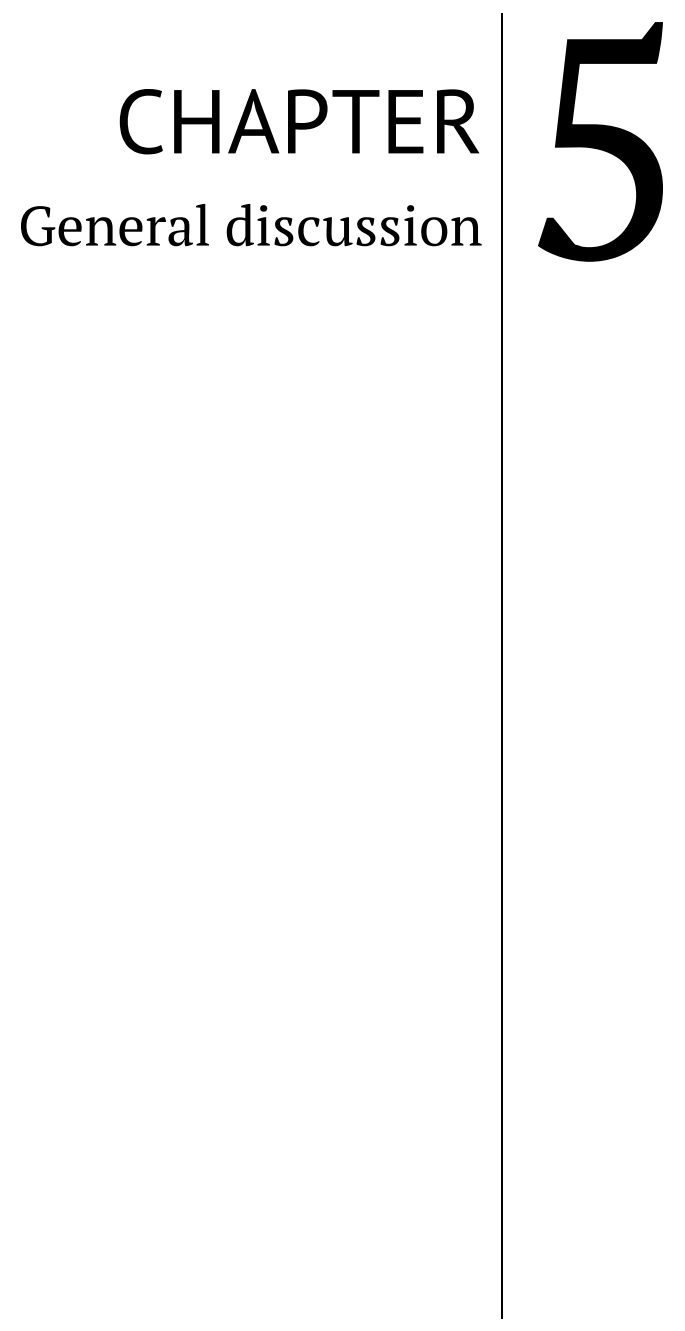




\section{Chapter 5. General discussion}

5.1 Genetic and environmental factors in the pathogenesis of neurodevelopmental disorders and excessive aggression

Family studies suggest that genetic and environmental factors each explain about $50 \%$ of the variance in aggressive behavior (Tuvblad and Baker, 2011). Excessive aggression is often accompanying neurodevelopmental disorders such as ADHD and ASD (Oades et al., 2008; Søndenaa et al., 2014).

Known risk factors for neurodevelopmental disorders include early-life stress such as loss of parents, emotional neglect, child abuse, which all are risk factors for the development of anxiety disorders, depression (Heim and Nemeroff, 2001), and pathologic aggression and violence in adulthood (Carr et al., 2013). Such factors constitute emotional stress, defined as a state primarily triggered by the perception and cognitive evaluation of adverse events rather than disturbances of physical nature (Fontes et al., 2014). This type of stress is of particular significance in the context of social environments and is clinically relevant, as its consequences may have a cumulative effect (Barthas et al., 2020), and the social environment may show as both a risk and a protective factor (Pickett et al., 2009).

Another environmental factor that may contribute to the pathogenesis of neurodevelopmental disorders is inflammation, in particular, that caused by infectious diseases (Debost et al., 2019; Søndenaa et al., 2014). Such diseases suffered during critical periods, e.g., 
during intrauterine and early postnatal development, as well as adolescence, may cause enduring neurodevelopmental abnormalities (Debost et al., 2019; Søndenaa et al., 2014). While severe negative effects caused by infectious disease or maternal immune activation during prenatal development are widely recognized and include disorders such as ASD and schizophrenic psychoses (Estes and McAllister, 2016; Guma et al., 2019; Knuesel et al., 2014), consequences of inflammatory stress during adolescence are often overlooked. However, they may contribute, in addition to prenatal and perinatal inflammation, to the pathogenesis of neurodevelopmental disorders (Chan and Frankovich, 2019).

In most cases, environmental factors should not be regarded as the sole cause of neurodevelopmental abnormalities. Genetic factors, as mentioned above, were shown to increase the risk of neurodevelopmental disorders, and, in particular, explain about $50 \%$ of the variance in aggressive behaviors (Tuvblad and Baker, 2011). Among different genetic factors contributing to the predisposition to neurodevelopmental disorders and associated aggressive behavior, variations in genes related to the brain 5-HT system are considered to be major risk factors (Lesch et al., 2012; Lesch and Merschdorf, 2000). They include genes encoding, e.g., TPH2, SERT, and MAOA (Cupaioli et al., 2021; Homberg and Lesch, 2011; Kolla and Bortolato, 2020). Another gene shown to contribute to the risk of neurodevelopmental disorders, including ADHD and intellectual disability, is ST3GAL3 (Hall et al., 2020; Klein et al., 2020), encoding $\beta$-galactoside- $\alpha 2,3$-sialyltransferase-III, one 
of the enzymes participating in brain ganglioside synthesis (Schnaar, 2016).

Investigation of gene $\times$ environment interaction $(\mathrm{GxE})$ is the approach of choice for studying mechanisms of pathological aggression and neurodevelopmental brain pathology. Thus, valid experimental animal models are needed for such studies. In this work, we used two models of GxE in pathological aggression. In Chapters 2 and 3, $\mathrm{Tph}^{+/-}$ mice of both sexes were studied for aggression after exposure to predation stress. This type of stress reproduces elements of an emotional stress paradigm, as far as it is delivered only by visual and olfactory contact with the predator, without any physical danger to the mouse (Gorlova et al., 2020). This paradigm has been substantiated and is considered ethologically valid, as rats are natural predators for mice, and the presence of predators or their chemical cues negatively affects the neurophysiological state and behavior of rodents (Adamec et al., 2006).

Unlike $T p h 2^{--}$mice, which completely lack neuronal 5-HT and exhibit severe behavioral abnormalities including highly increased aggression (Gutknecht et al., 2015; Mosienko et al., 2012), $T p 2^{+/-}$mice have brain 5-HT levels about 30\% lower than wt controls and do not exhibit explicit behavioral alterations. We showed, however, that after the rat exposure stress, $T p h 2^{+/}$mice of both sexes demonstrate abnormal aggression and decreased neutral social interaction measures (Chapters 2,3 ). Of particular interest is the fact that we found increased aggression in $\mathrm{Tph}^{+ \text {+/ }}$ female mice (Chapter 3), as female aggression is considered to be outside of the normal behavioral repertoire of mice. Of note, in the 
modified swim test $T p h 2^{+/-}$mice of both sexes exhibited signs of higher stress resilience compared to wt controls, which is known to accompany increased aggression and dominance in other aggression studies and was also found in mice with trait aggression (Strekalova et al., 2011).

In Chapter 4, we for the first time investigated the social behavior of male and female mice with a deficiency of major brain gangliosides due to the knockout of the St3gal5 gene. In these mice, we observed altered social and cognitive behavior alongside compromised motor functions. While naïve female St3gal5 $5^{-1-}$ mice showed decreased social interaction and no aggression, increased dominant behavior was evident in naïve male St3gal5 $5^{-/-}$mutants (Chapter 4). After assessment of the baseline behavior, mice were subjected to a model of infectious stress, i.e., systemic inflammation was induced by injections of LPS (Couch et al., 2016, 2013; Trofimov et al., 2017). It led to a significant increase in the aggressive and dominant behavior in male St3gal5 $5^{-1-}$ mice and a decrease in dominant behavior in St3gal5 ${ }^{-/-}$female mutants.

Thus, in both genetic lines, the combination of genetic background and stress of different nature led to abnormal aggression in male mutant mice and altered social behavior in both sexes. These changes resemble features of neurodevelopmental disorders, e.g., ADHD and ASD, and these models could constitute useful paradigms for the investigation of gene $\times$ environment interaction mechanisms in neurodevelopmental disorders. Additionally, female aggression in stressed $T p h 2^{+/-}$mice may be used as a model for research of sex-specific aspects of the neurobiology of aggression. Apart from behavioral 
alterations, we also showed stress-related molecular and neurochemical changes in both models.

5.2 Alterations of monoamine metabolism and changes in the expression of 5-HT receptors, distress and plasticity markers, as well as myelinationrelated proteins in stress-related aggression of Tph2 heterozygous mice

In male $\mathrm{Tph}^{+/-}$mice, we showed stress-related changes in concentrations and turnover of DA and NE in multiple brain structures related to social and emotional behavior, i.e., amygdala and PFC (Chapter 2). Concentrations of 5-HT, its precursor 5-HTP, and its metabolite HIAA were previously assessed in brains of male $T p h 2^{+/-}$mice exposed to the same predation stress paradigm we used in Chapter 2. The study of Gorlova and coworkers (2020) revealed decreased 5-HTP and HIAA concentrations in brains of stressed male $T p h 2^{+/-}$mice with no further stress-related decrease in 5-HT concentration, indicating the existence of certain compensatory mechanisms maintaining normal development and, in particular, brain 5-HT metabolism in naïve $T p h 2^{+/-}$ mice (Gorlova et al., 2020).

However, while under stress conditions the increase of the 5-HT concentration in the PFC and the striatum was evident in wt controls, no such changes were found in Tph2 $2^{+/-}$mutants, possibly due to a ceiling effect of a partial deficiency of Tph2 on 5-HT metabolism. 5-HT system of the brain is in a tight functional connection with DA and NE systems (Chapter 1). 
We showed changes in the brain DA metabolism of stressed male $\mathrm{Tph}^{+/-}$mice (Chapter 2), partly resembling those previously found in the $\mathrm{Tph}^{-{ }^{--}}$mutants. Decreased concentrations of DA in the amygdala and striatum of stressed $T p h 2^{+/-}$mice and enhanced DOPAC/DA turnover in these regions together with strikingly lower DA concentration in the striatum of both stressed and non-stressed $T p h 2^{+/-}$mice provide evidence for massive changes in the DA system of the Tph2-deficient animals. These observations are in accordance with the data on reciprocal modulation of the DA system by the 5-HT system of the brain (De Deurwaerdère et al., 2005; Millan et al., 1998; Rosell and Siever, 2015; Seo et al., 2008).

Modulation of aggression by the DA system and its interaction with the 5-HT system is known also from human studies of aggressive behavior and suicide (Ryding et al., 2008). These two systems regulate frontostriatal and amygdalar activity, which is crucial for impulsivity and aggression control (Chapter 1). Alterations in dopamine system were also found in patients with ASD. Abnormalities in mesocorticolimbic and prefrontal-striatal dopaminergic pathway, which includes DA projections from VTA to striatum and prefrontal cortex, were hypothesized to cause abnormal social behaviors in ASD (Pavăl and Micluția, 2021), which is in accordance with our data. Depressed DA system activity in patients with ADHD was also shown using neuroimaging techniques, suggesting lowered dopaminergic modulation of fronto-striatal networks (Del Campo et al., 2011). 
Interaction between DA and NE systems of the brain and a possible role of NE in ADHD were described in the literature (Del Campo et al., 2011), and we also showed stress-related changes in the NE metabolism. In both genotypes, the rat exposure stress caused an increase of NE concentration in the striatum and NE metabolite MHPG concentration in the hippocampus (Chapter 2). The only genotypespecific change observed was decreased level of MHPG and, subsequently, NE turnover rate in the amygdala. Given the well-known role amygdala plays in the regulation of social cue processing and aggression (Cupaioli et al., 2021), we may suggest the role of NE in the regulation of pathologic aggression in the $T p h 2^{+/-}$mouse line. However, while the role of NE is known in depression, e.g., negative coupling between 5-HIAA and NE concentrations in the CSF known in normal subjects but absent in depressed patients, data on NE participation in the pathogenesis of aggression is scarce and requires further investigation (Geracioti et al., 1997).

The role of different 5-HT receptors in aggression was extensively studied over the past decades. In Chapter 3, we assessed the expression of 5-HT receptor genes Htr1a and Htr2a, encoding 5-HT receptors $1 \mathrm{~A}$ and 2A, respectively. Expression of the Htr1a mRNA was decreased in the PFC of female $T p h 2^{+/-}$mice irrespective of stress. This effect may reflect compensatory changes due to lowered 5-HT baseline concentration observed in $T p h 2^{+/-}$animals (Waider et al., 2019). Previously, no alterations were reported in the Htr1a mRNA expression in $\mathrm{Tph}^{+/-}$males, irrespective of stress (Gorlova et al., 2020). Such discrepancy may reflect 
sex differences in compensatory processes observed in the $T p h 2^{+/-} 5$ - HT system, as sex differences, i.e., higher 5-HT transmission in different brain regions of females compared to males is known both for mice and rats (Carlsson and Carlsson, 1988; Domínguez et al., 2003; Jones and Lucki, 2005).

The concentration of Htr2a mRNA was also decreased in the PFC of female $T p h 2^{+/-}$mice, and, unlike Htr1a, it was significantly increased in both genotypes after stress (Chapter 3). This increase may play a role in abnormal aggression observed in stressed $\mathrm{Tph}^{+/-}$mice, as it was previously shown that upregulation of $5-\mathrm{HT}_{2 \mathrm{~A}}$ receptors in the $\mathrm{PFC}$ (Godar et al., 2019) and administration of 5- $\mathrm{HT}_{2 \mathrm{~A}}$ agonists (Juárez et al., 2013) reduce aggression in mice. Enhanced sensitivity of $5-\mathrm{HT}_{1 \mathrm{~A}}$ receptor

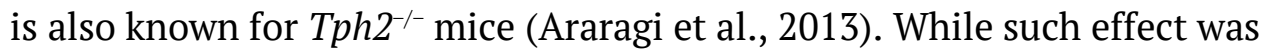
not investigated for $5-\mathrm{HT}_{1 \mathrm{~A}}$ yet, the difference in its sensitivity between genotypes might explain putative differential effects of the stress-related increase of its expression. Given the abovementioned findings, we may speculate that while compensatory changes in the 5-HT, DA, and NE systems of $\mathrm{Tph}^{+/-}$mice enable close to normal function of these mice, decompensation under stress conditions leads to changes resembling features of neurodevelopmental disorders, including aggression. These changes were also accompanied by altered expression of several markers of distress and plasticity.

Baseline expression of Gsk-3 $\beta$ in the PFC of female $\mathrm{Tph}^{+/-}$mice was lowered in comparison to control mice. After stress exposure, the expression increased to the level of control mice. Control mice did not 
show the stress-related change in Gsk-3 $\beta$ expression (Chapter 3). This molecule is known as a marker of distress and is implicated in a wide spectrum of cellular functions, including inflammation (Gocho et al., 2013); in particular, it mediates an increase of pro-inflammatory IL-1 $\beta$ and TNF levels (Green and Nolan, 2012) and inhibits expression of antiinflammatory IL-10 (Jope et al., 2017). GSK-3 $\beta$ was found to participate in the development of affective disorders, including depression (Markova et al., 2017; Pavlov et al., 2017; Strekalova et al., 2016).

Previously, in male mice with lowered TPH2 enzymatic activity due to a knock-in of human R439H mutation, suppression of aggressive behavior was shown upon introduction of $G s k-3 \beta$ heterozygous knockout (Beaulieu et al., 2008). Multiple studies also showed that an inhibitor of GSK-3 $\beta$, lithium, which is widely used for the treatment of neurological and psychiatric disorders, has prominent anti-aggressive and antiinflammatory properties (Beurel and Jope, 2014; Müller-Oerlinghausen and Lewitzka, 2010). Given the well-known association between GSK-3 $\beta$ activity and aggression, the increase of Gsk-3 $\beta$ expression in stressed female $T p h 2^{+/-}$mice may be related to observed aggressive behavior. As in our study expression of Gsk-3 $\beta$ in stressed $T p h 2^{+-}$mice was not significantly different from that of control mice, we speculate that the rise above the baseline level and its interaction with other alterations on a molecular and cellular level rather than the absolute $G s k-3 \beta$ expression level itself may contribute to the behavioral abnormalities (Chapter 3).

Notably, despite observed Gsk-3 $\beta$ expression, we did not find increased expression of the pro-inflammatory cytokine $I l-1 \beta$ in the PFC 
of $\mathrm{Tph}^{+/-}$male and female mice irrespective of stress. Moreover, a trend towards lowered expression in $T p h 2^{+/-}$males and females was observed, (Chapter 3, (Svirin et al., 2021)). As it was discussed in Chapter 1, 5-HT deficiency may shift neuroinflammation towards opposite directions through several pathways. The trend to lower expression of $I l-1 \beta$ in $T p h 2^{+/-}$mice may be explained by decreased microglial activation due to elimination of its stimulation by 5 -HT. No signs of neuroinflammation were reported for $T p h 2^{-/-}$mice as well.

Predation stress also led to a significant increase in the expression of Syp and GluA2 in both genotypes (Chapter 3). Previously, increased GluA2 expression was found in the PFC of male $\mathrm{Tph}^{+/-}$mice and wt controls subjected to predation stress, with no genotype differences (Gorlova et al., 2020). Increased Syp expression was found in the predation stress model in rats, where a significant elevation of Syp mRNA expression was observed in the amygdaloid complex, and a trend towards higher expression was observed in the PFC (Campos et al., 2013). In both cases of Syp and GluA2, the lack of significant expression difference between genotypes in both stress conditions prevents us from concluding their roles in behavioral alterations observed in stressed $T p h 2^{+/-}$mice.

For the first time, we demonstrated changes in the expression of myelination-related proteins in the brain of $\mathrm{Tph}^{+/-}$mice (Chapter 3, (Svirin et al., 2021)). In the PFC of naïve $T p h 2^{+/-}$female mice, we showed a significant increase in $M b p$ and $M a g$ expression as well as a trend in Plp1 expression. These alterations were reverted by stress, while no stress-related changes were found in the PFC of control female mice, and 
only Mog expression was decreased upon stress in both genotypes, with no genotype difference (Chapter 3). Notably, in $\mathrm{Tph}^{+/-}$male mice we did not find significant differences in the expression of Plp1 and Mbp in the PFC, while in the hippocampus mRNA expression of both proteins was decreased in $T p h 2^{+/-}$male mutants (Svirin et al., 2021). These differences between male and female mice are in line with sex differences in myelination previously reported in both mice and rats.

Age-related sex differences in the structure of white matter were found in Long-Evans rats (Yang et al., 2008), and MBP expression was higher in the OFC of adult female Long-Evans rats (Darling and Daniel, 2019). Considerable sex differences in Mbp, Plp1, Mag, and Mog expression were also shown in a rat model of gestational nicotine administration, where these genes were significantly upregulated in adolescent males and, conversely, downregulated in females receiving gestational nicotine (Cao et al., 2013). Remarkably, in the mouse model of prenatal cigarette exposure, increased aggressive behavior was found in male but not female mice (Yochum et al., 2014). In a rat model of adolescent alcohol drinking, myelinated fiber density in the PFC was significantly lowered in male but not in female animals (Tavares et al., 2019). In mice, early weaning was shown to affect white matter structure in the basolateral amygdala only in males, and authors linked the developmentally premature formation of myelin observed in male mice to anxiety-related behavioral changes (Ono et al., 2008).

Thus, there is a considerable body of evidence suggesting that myelination processes are sex-specific both during normal development 
and in pathological conditions, which is in line with our findings in $\mathrm{Tph}^{+/-}$mice (Chapter 3, (Svirin et al., 2021)). As it was discussed in Chapter 1, myelination deficits are increasingly recognized as a common pathology underlying neuropsychiatric and neurodevelopmental disorders, and it is known that dysregulation of myelogenesis in both directions may lead to pathology. Our data suggest that myelination abnormalities may contribute to the behavioral deficits observed in $\mathrm{Tph}^{+/-}$mice; however, further investigation using complementary methods is needed.

5.3 ST3GAL5-deficient mice as a model of neurodevelopmental disorders: social behavior abnormalities, molecular changes, and effects of inflammatory stress

In Chapter 4 we investigated St3gal5 null mutant mice, another model proposed to resemble common features of neurodevelopmental disorders (Niimi et al., 2011). Previously, gene encoding another brain syaliltransferase, St3gal3, was found to be associated with the incidence of ADHD, ASD, and schizophrenia (Hall et al., 2020; Mealer et al., 2020; Zhao et al., 2018b), as well as childhood aggression (Ip et al., 2021). While disruption of brain ganglioside synthesis in humans arising from dysfunction of St3gal5 gene leads to devastating failure of neurodevelopment, St3gal5 ${ }^{-/-}$mice do not show a severe phenotype, possibly due to the existence of a compensatory mechanism, i.e., compensatory synthesis of o-series gangliosides. Thus, we speculate that 
St3gal5 ${ }^{-1}$ mice are a plausible model for partial brain ganglioside deficiency.

We sought to study baseline behavior of St3gal5 ${ }^{-/-}$mice, as no data could be found in the available literature. We showed substantial alterations in the dominant behavior and neutral sociability of St3gal5-mice, as well as other behavioral alterations, resembling ASD-like features, i.e., repetitive behavior (Chapter 4). Naïve St3gal5 ${ }^{-/-}$male mice exhibited a substantial increase in dominant behavior, and a similar trend was also found in St3gal5 ${ }^{-/-}$female mice. However, no significant differences were shown in attacking behavior in naïve St3gal5 mice. Behavioral alterations were accompanied by increased expression of pro-inflammatory cytokines Il-1 $\beta$ and Tnf both in the PFC and the spleen of St3gal5 ${ }^{-/}$animals. Altered systemic immune regulation and neuroinflammatory changes are well-documented in patients with ASD (Thom et al., 2019) and in BTBR mice considered to represent an ASD model (Careaga et al., 2015; Zhang et al., 2019).

As neuroinflammation is one of the common mechanisms of neuropsychiatric disorders, and anti-inflammatory action of major brain gangliosides was shown in many studies (discussed in Chapter 1), we hypothesized that brain ganglioside deficient mice might be susceptible to inflammatory stress. We investigated whether the interaction of genetic background of these mice with environmental adversity such as systemic inflammation aggravates the altered social and aggressive behavior. Additionally, we investigated the expression of proinflammatory cytokines $I l-1 \beta, I l-6$, and Tnf in the brain and in the 
periphery in order to test whether LPS administration causes a different inflammatory response in St3gal5 $5^{-/-}$mice compared to wt controls.

We demonstrated profound sex differences in the behavioral reaction to the LPS administration. While systemic inflammation led to a substantial increase in dominant and aggressive behaviors in St3gal5-1males, in female mice such increase was observed in wt control mice. Sex differences were also found in cytokine expression response to LPS administration. In general, compared to wt controls, St3gal5 $5^{-/-}$mice of both sexes had a lower degree of increase in the expression of the proinflammatory cytokines in the brain and a higher degree in the periphery. However, LPS-induced increase of $I l-1 \beta$ expression both in the brain and in the periphery was significantly higher in St3gal5 ${ }^{-1-}$ females than in wt controls, while in male wt control mice the rise of $I l-1 \beta$ expression was higher than in St3gal5 $5^{--}$males. Thus, there are remarkable sex-specific effects of both the St3gal5 knockout alone and its interaction with inflammatory stress on social and aggressive behavior. Of note, sexspecific differences in the severity of outcomes were shown for many genetic rodent models of neurodevelopmental disorders (Mossa and Manzini, 2021). In most cases, male mice had more severe outcomes, and, in the case of mice with paralogous human truncating variant introduced into the chromodomain-helicase-DNA binding protein 8 (CHD8) gene, male mice exhibited increased anxiety-like behaviors after experiencing stressful events (Jung et al., 2018).

Sex differences in the prevalence and severity of neurodevelopmental disorders are well-known, e.g., ASD and ADHD 
incidence is higher in men [60]. Some authors attribute these differences to sex-specific neuro-immune regulation (Hanamsagar and Bilbo, 2016; May et al., 2019; McCarthy and Wright, 2017), and this explanation would be in line with our findings of differential inflammatory response and changes in aggressive and dominant behaviors in St3gal5 $5^{-/}$mice. Gender differences in aggression were also found in humans: while men are overall more physically aggressive than women, women tend to indulge in more indirect aggression than men (Björkqvist, 2018), and such difference is known, in particular, for patients with ADHD (Rucklidge, 2010).

As there is a substantial body of evidence suggesting links between brain gangliosides and myelination, we also assessed the mRNA expression of myelination-related proteins MBP, PLP1, MAG, and MOG in the PFC of naïve St3gal5 $5^{-/}$mice. In mutants of both sexes, we showed about two-fold decrease of expression of PLP1 both on mRNA and protein levels. No changes in the expression of the other three myelin proteins were found. Interestingly, a mutation in the Plp1 gene leading to its decreased expression was found in rabbits with paralytic tremor disease, and myelin lipid content in these animals was altered (Sypecka and Domańska-Janik, 2005). It was shown that Plp1 knockout $\left(P l p 1^{-/}\right)$ mice, as well as patients with a lack of PLP1, develop length-dependent axonal degeneration progressing with age, with no histological signs of demyelination (Garbern et al., 2002). Local deficits of axonal transport were also found in the internodes myelinated by PLP1-deficient OLs (Gruenenfelder et al., 2011). Given the abovementioned results, we may 
suggest that decreased expression of PLP1 in the PFC of St3gal5 $5^{-/-}$mice may arise from aberrant regulation of OLs in the lack of major brain gangliosides. A decrease in PLP1 may be a factor contributing to white matter abnormalities affecting brain circuits involved in the regulation of social and aggressive behaviors. However, further histological and molecular analysis would be necessary to shed light on the myelination abnormalities suspected in these animals.

5.4 Dysregulated myelination and neuroinflammation as putative common mechanisms of neurodevelopmental disorders and pathologic aggression

In both experimental mouse models of neurodevelopmental disorders used in current research, we showed abnormal aggression and other neurodevelopmental disorder-like behaviors, revealed only by stress, either emotional or infectious. For the first time, such behavioral features were shown for $\mathrm{Tph}^{+/-}$female mice and St3gal5 ${ }^{-/-}$mice. We also showed molecular signs of inflammation and cellular stress in both models and accompanying alterations in the expression of myelinationrelated proteins.

Neuroinflammation is considered one of the substantial mechanisms of neurodevelopmental and neuropsychiatric disorders. Being primarily a normal protective response to infection or tissue injury, abnormal inflammation, which can be caused by stress or infectious agents, may result in cell and tissue damage (Ofengeim and Yuan, 2013; Yuan et al., 2019). In particular, systemic inflammation may cause 
damage to the $\mathrm{BBB}$ and, thus, cause neuroinflammation in the CNS (Banks and Erickson, 2010; Dantzer et al., 2008).

Inflammation and immune system dysfunction were found in ASD, ADHD, depression, schizophrenia, and other disorders (Anand et al., 2017; Dunn et al., 2019; Prata et al., 2017; Robson et al., 2017). There is also a strong link between inflammation and aggression. In patients with depression an association between aggression levels and immune dysregulation was found. Prolonged social stress was shown to enhance both inflammation and depressive and aggressive traits (Takahashi et al., 2018). In addition, in intermittent explosive disorder and psychosis pathological aggression was found to be associated with increased levels of pro-inflammatory cytokines (Coccaro et al., 2015). Moreover, in Alzheimer's disease, in which a marked increase in both systemic and CNS inflammation is present (Forloni and Balducci, 2018), aggression traits are linked to impairments in frontolimbic circuits (Trzepacz et al., 2013). Myelination deficits are found in neurodevelopmental disorders, such as ASD, ADHD, and schizophrenia (Gozzi et al., 2012; Lesch, 2019; Onnink et al., 2015), in which aggression is a frequent comorbidity. Inflammation and myelination abnormalities are in a complex interplay and may contribute to the pathogenesis of neurodevelopmental disorders.

Impairments in myelination of frontolimbic brain circuits may lead to disrupted top-down control which is crucial for the suppression of aggressive behavior and optimal response choice. In the models we used in our work, dysmyelination may arise due to several mechanisms. In the 
$\mathrm{Tph}^{+/-}$mouse model, brain 5-HT deficit may affect oligodendroglia cell lineage both directly, as it was shown in co-cultures of neurons and OLs (Fan et al., 2015), and by regulation of SIRT2 expression which was shown to affect MBP expression, oligodendrocyte differentiation, and axon-myelin interaction (Ji et al., 2011; Li et al., 2007). An increase in the expression of $G s k-3 \beta$ found in $T p h 2^{+/-}$female mice after stress may suppress myelogenesis (Dohare et al., 2018), which is in accordance with the decrease in the expression of myelination-related proteins which we showed in these mice (Chapter 3).

Although we did not find increased expression of proinflammatory $\mathrm{Il}-1 \beta$ in $\mathrm{Tph} 2^{+/-}$mutants, further research will be needed to uncover the neuroinflammatory status of these mice. IL- $1 \beta$ was shown to trigger OL death (Takahashi et al., 2003), and injections of LPS were shown to lead to demyelination in neonatal rats (Singh et al., 2017).

As systemic inflammation and pro-inflammatory cytokines are shown to have a detrimental effect on OLs and myelination, we may speculate that it might be a pathway affecting the expression of PLP1 in St3gal5 ${ }^{--}$mice, which have increased pro-inflammatory cytokine expression both in the periphery and in the CNS (Chapter 4). However, as we showed decreased expression of only the Plp1 gene and not $M b p$, Mag, and Mog, we may suggest that some compensatory mechanism exists. MAG is a protein crucial for the regulation of axon-myelin stability and has highly specific binding to gangliosides GD1a and GT1b which are absent in the brain of St3gal5 ${ }^{-1-}$ mice. Unlike in the brain of B4galnt1 knockout mice, however, o-series ganglioside GD1 $\alpha$, which also 
has a high affinity to MAG (Sawada et al., 1999), is present in the brain of St3gal5 $5^{--}$mutants. This ganglioside may provide a rescue pathway for maintaining axon-myelin stability, and prevent severe phenotype observed in both B4galnt1 and Mag knockout mice (Schnaar, 2010), but such partial compensation may lead to deficient axon-OL interaction mirrored by PLP1 underexpression. Such underexpression, in turn, may lead to axon degeneration and impaired axonal transport disrupting brain connectivity, which, as discussed above, may lead to impaired cognitive control of aggression.

Several mechanisms may underlie the relationship between myelination abnormalities and neuroinflammation (Figure 5.1). In the case of active demyelination, myelin debris activates microglia and macrophages, thus inducing the production of pro-inflammatory cytokines (Murugaiyan et al., 2020). Necroptotic death of axons due to impaired axon-myelin interaction also induces a pro-inflammatory response (Murugaiyan et al., 2020). Last but not least, astrocytes may provide an important interface between neuroinflammation and myelination, as astrocyte-secreted factors regulate oligodendroglia and promote neuronal survival, and, simultaneously, astrocytes regulate microglia and release cytokines and chemokines affecting inflammation (Kiray et al., 2016; Vainchtein and Molofsky, 2020). Astrocytes were shown to be neuronal activity-dependent, and changes in neuronal activity due to altered myelination may affect the above-mentioned astrocyte function. 


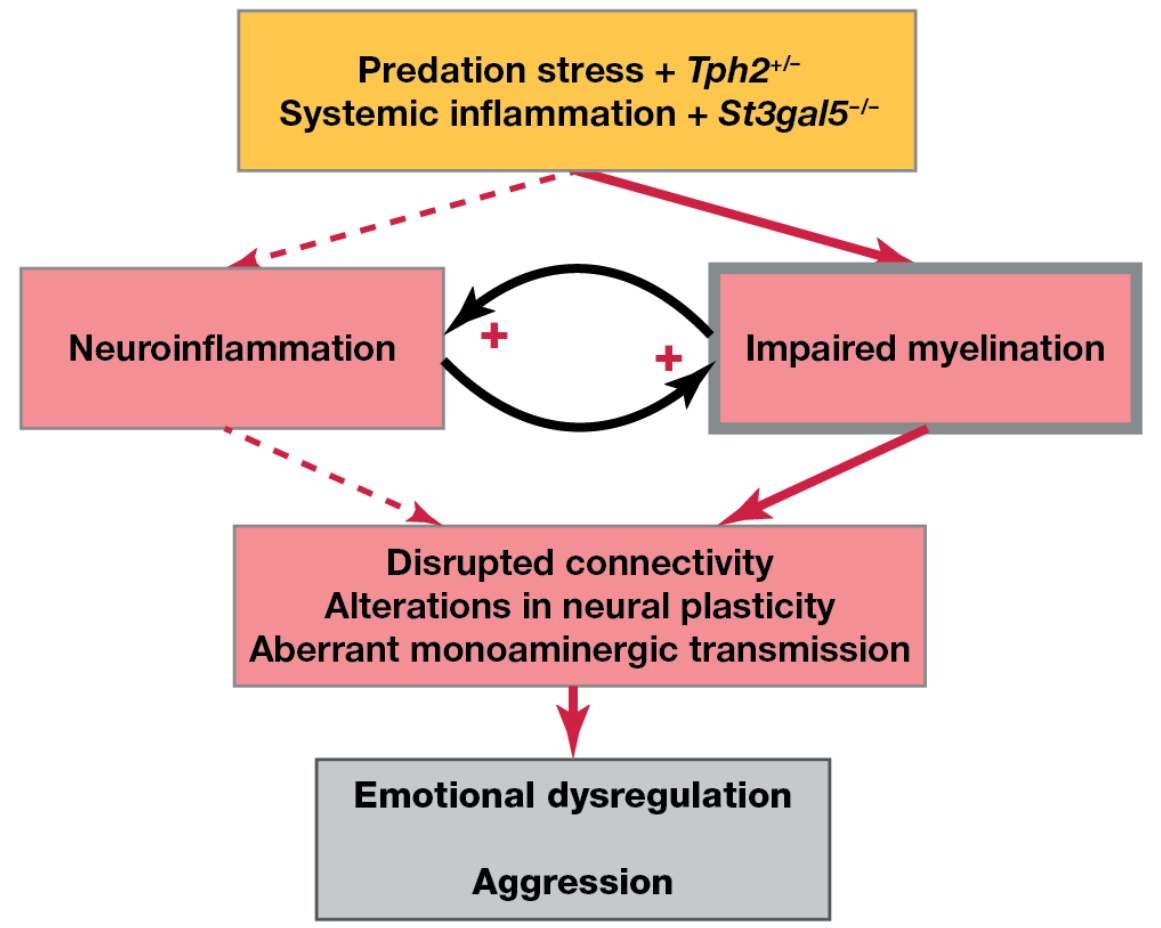

Figure 5.1. Pathological pathways in G×E models of ADHD and ASD. G×E interaction in our models may lead to both neuroinflammation and dysmyelination, which are known to be interrelated. Impairments in myelination may cause neuroinflammation: myelin debris, products of neuron elimination due to necrosis and apoptosis, and dysregulation of activity-dependent astrocytes may activate microglia and macrophages. Proinflammatory cytokines, GSK-3 $\beta$, and dysregulation of glia by inflammation negatively affect myelination. Aberrant signal propagation, axon degradation, and neuronal death due to lack of metabolic support from myelin sheaths disrupt brain connectivity. Additionally, neuroinflammation contributes to alterations in monoaminergic transmission and neural plasticity. Together, these factors lead to behavioral abnormalities resembling endophenotypes of neurodevelopmental disorders, i.e., ADHD and ASD (see the text).

Overall, the complex interplay between neuroinflammation and myelination may affect neuron function and brain functional connectivity both during development and in adult age. Genetic and 
environmental factors and their combination, as in models used in our work, may affect those processes leading to behavioral consequences such as aggression and maladaptive social behavior.

\subsection{Conclusion}

In our work we identified signs of putative common interrelated mechanisms of stress-related aggression in two genetic animal models of neurodevelopmental disorders. Dysregulated immune function and inflammation, neuroinflammation in particular, were shown to play a role in ASD and ADHD (Dunn et al., 2019; Ye et al., 2021), as well as myelination deficits (Gozzi et al., 2012; Lesch, 2019; Onnink et al., 2015).

In a recent analysis of genome-wide association studies of eight psychiatric disorders performed by Cross-Disorder Group of the Psychiatric Genomics Consortium (2019), a high level of pleiotropy was found across multiple genes linking them to two or more psychiatric disorders. Notably, modelling of genetic correlations identified three groups among the eight studied disorders based on their shared genetics. One of them comprises ADHD, ASD, depression, and Tourette's syndrome, that is early-onset neurodevelopmental disorders and disorders with a substantial neurodevelopmental component. Such results led to an idea that multiple pleiotropic genes, acting from early in ontogenesis, contribute to the risk of numerous neurodevelopmental disorders. The authors assumed that alterations in such pleiotropic genes may be translated to discrete psychiatric syndromes by mechanisms involving $\mathrm{G} \times \mathrm{E}$ interactions. 
These ideas are consistent with the hypothesis stating that common nonspecific mechanisms confer broad liability to neurodevelopmental disorders, including ADHD and ASD. These mechanisms may include but are not limited to dysregulated neuroinflammation and aberrant myelination. Notably, the gene for which the most highly pleiotropic locus was found, is Deleted in Colorectal Carcinoma (DCC) gene. This gene was significantly associated with all eight disorders and was shown to be crucial for myelination in the brain (Ye et al., 2021). Null knockout of Dcc in mice is lethal, and conditional knockout in oligodendrocytes leads to disruption in white matter ultrastructure, significant decrease in the protein content of MBP and MAG, and a trend to such decrease in the PLP1 expression (Bull et al., 2014). This finding further links myelination abnormalities with a broad spectrum of neurodevelopmental disorders and underlines the need for additional investigation into the role of myelination, as well as its interaction with neuroinflammation, in pathogenesis of these conditions. 


\section{References}

Adamec, R., Burton, P., Blundell, J., Murphy, D., Holmes, A., 2006. Vulnerability to mild predator stress in serotonin transporter knockout mice. Behav. Brain Res. 170, 126-140. DOI:10.1016/j.bbr.2006.02.012

Anand, D., Colpo, G.D., Zeni, G., Zeni, C.P., Teixeira, A.L., 2017. Attention-Deficit/Hyperactivity Disorder And Inflammation: What Does Current Knowledge Tell Us? A Systematic Review. Front. psychiatry 8, 228. DOI:10.3389/fpsyt.2017.00228

Araragi, N., Mlinar, B., Baccini, G., Gutknecht, L., Lesch, K.P., Corradetti, R., 2013. Conservation of 5-HT1A receptor-mediated autoinhibition of serotonin (5-HT) neurons in mice with altered 5-HT homeostasis. Front. Pharmacol. 4 AUG, 1-11.

DOI:10.3389/fphar.2013.00097

Banks, W.A., Erickson, M.A., 2010. The blood-brain barrier and immune function and dysfunction. Neurobiol. Dis. 37, 26-32. DOI:10.1016/j.nbd.2009.07.031

Barthas, F., Hu, M.Y., Siniscalchi, M.J., Ali, F., Mineur, Y.S., Picciotto, M.R., Kwan, A.C., 2020. Cumulative Effects of Social Stress on Reward-Guided Actions and Prefrontal Cortical Activity. Biol. Psychiatry 88, 541-553. DOI:10.1016/j.biopsych.2020.02.008

Beaulieu, J.M., Zhang, X., Rodriguiz, R.M., Sotnikova, T.D., Cools, M.J., Wetsel, W.C., Gainetdinov, R.R., Caron, M.G., 2008. Role of GSK3 $\beta$ in behavioral abnormalities induced by serotonin deficiency. Proc. Natl. Acad. Sci. U. S. A. 105, 1333-1338. DOI:10.1073/pnas.0711496105

Beurel, E., Jope, R.S., 2014. Inflammation and lithium: Clues to mechanisms contributing to suicide-linked traits. Transl. Psychiatry 4, 17. DOI:10.1038/tp.2014.129

Björkqvist, K., 2018. Gender differences in aggression. Curr. Opin. Psychol. 19, 39-42. DOI:10.1016/j.copsyc.2017.03.030

Bull, S.J., Bin, J.M., Beaumont, E., Boutet, A., Krimpenfort, P., Sadikot, A.F., Kennedy, T.E., 2014. Progressive disorganization of paranodal junctions and compact myelin due to loss of DCC expression by oligodendrocytes. J. Neurosci. 34, 9768-9778. DOI:10.1523/JNEUROSCI.0448-14.2014 
Campos, A.C., Ferreira, F.R., da Silva, W.A., Guimarães, F.S., 2013. Predator threat stress promotes long lasting anxiety-like behaviors and modulates synaptophysin and CB1 receptors expression in brain areas associated with PTSD symptoms. Neurosci. Lett. 533, 34-38. DOI:10.1016/j.neulet.2012.11.016

Cao, J., Wang, J., Dwyer, J.B., Gautier, N.M., Wang, S., Leslie, F.M., Li, M.D., 2013. Gestational nicotine exposure modifies myelin gene expression in the brains of adolescent rats with sex differences. Transl. Psychiatry 3. DOI:10.1038/tp.2013.21

Careaga, M., Schwartzer, J., Ashwood, P., 2015. Inflammatory profiles in the BTBR mouse: HOW relevant are they to autism spectrum disorders Brain. Behav. Immun. 43, 11-16.

DOI:10.1016/j.bbi.2014.06.006

Carlsson, M., Carlsson, A., 1988. A regional study of sex differences in rat brain serotonin. Prog. Neuropsychopharmacol. Biol. Psychiatry 12, 53-61. DOI:10.1016/0278-5846(88)90061-9

Carr, C.P., Martins, C.M.S., Stingel, A.M., Lemgruber, V.B., Juruena, M.F., 2013. The role of early life stress in adult psychiatric disorders: A systematic review according to childhood trauma subtypes. J. Nerv. Ment. Dis. 201, 1007-1020. DOI:10.1097/NMD.0000000000000049

Chan, A., Frankovich, J., 2019. Infections, Antibiotics, and Mental Health Deteriorations. J. Child Adolesc. Psychopharmacol. 29, 647-648. DOI:10.1089/cap.2019.0100

Coccaro, E.F., Fanning, J.R., Phan, K.L., Lee, R., 2015. Serotonin and impulsive aggression. CNS Spectr. 20, 295-302.

DOI:10.1017/S1092852915000310

Couch, Y., Anthony, D.C., Dolgov, O., Revischin, A., Festoff, B., Santos, A.I., Steinbusch, H.W., Strekalova, T., 2013. Microglial activation, increased TNF and SERT expression in the prefrontal cortex define stress-altered behaviour in mice susceptible to anhedonia. Brain. Behav. Immun. 29, 136-146. DOI:10.1016/j.bbi.2012.12.017

Couch, Y., Trofimov, A., Markova, N., Nikolenko, V., Steinbusch, H.W., Chekhonin, V., Schroeter, C., Lesch, K.P., Anthony, D.C., Strekalova, T., 2016. Low-dose lipopolysaccharide (LPS) inhibits 
aggressive and augments depressive behaviours in a chronic mild stress model in mice. J. Neuroinflammation 13, 1-17. DOI:10.1186/s12974-0160572-0

Cupaioli, F.A., Zucca, F.A., Caporale, C., Lesch, K.P., Passamonti, L., Zecca, L., 2021. The neurobiology of human aggressive behavior: Neuroimaging, genetic, and neurochemical aspects. Prog. NeuroPsychopharmacology Biol. Psychiatry 106, 110059. DOI:10.1016/j.pnpbp.2020.110059

Dantzer, R., O’Connor, J.C., Freund, G.G., Johnson, R.W., Kelley, K.W., 2008. From inflammation to sickness and depression: When the immune system subjugates the brain. Nat. Rev. Neurosci. 9, 46-56. DOI:10.1038/nrn2297

Darling, J.S., Daniel, J.M., 2019. Pubertal hormones mediate sex differences in levels of myelin basic protein in the orbitofrontal cortex of adult rats. Neuroscience 406, 487-495.

DOI:10.1016/j.neuroscience.2019.03.041

De Deurwaerdère, P., Moison, D., Navailles, S., Porras, G., Spampinato, U., 2005. Regionally and functionally distinct serotonin3 receptors control in vivo dopamine outflow in the rat nucleus accumbens. J. Neurochem. 94, 140-149. DOI:10.1111/j.1471-4159.2005.03174.x

Debost, J.C., Larsen, J.T., Munk-Olsen, T., Mortensen, P.B., Agerbo, E., Petersen, L.V., 2019. Childhood infections and schizophrenia: The impact of parental SES and mental illness, and childhood adversities. Brain. Behav. Immun. 81, 341-347. DOI:10.1016/j.bbi.2019.06.031

Del Campo, N., Chamberlain, S.R., Sahakian, B.J., Robbins, T.W., 2011. The roles of dopamine and noradrenaline in the pathophysiology and treatment of attention-deficit/hyperactivity disorder. Biol. Psychiatry 69, e145-e157. DOI:10.1016/j.biopsych.2011.02.036

Dohare, P., Cheng, B., Ahmed, E., Yadala, V., Singla, P., Thomas, S., Kayton, R., Ungvari, Z., Ballabh, P., 2018. Glycogen synthase kinase-3 $\beta$ inhibition enhances myelination in preterm newborns with intraventricular hemorrhage, but not recombinant Wnt3A. Neurobiol. Dis. 118, 22-39. DOI:10.1016/j.nbd.2018.06.015 
Domínguez, R., Cruz-Morales, S.E., Carvalho, M.C., Xavier, M., Brandao, M.L., 2003. Sex differences in serotonergic activity in dorsal and median raphe nucleus. Physiol. Behav. 80, 203-210. DOI:10.1016/j.physbeh.2003.07.012

Dunn, G.A., Nigg, J.T., Sullivan, E.L., 2019. Neuroinflammation as a risk factor for attention deficit hyperactivity disorder. Pharmacol. Biochem. Behav. 182, 22-34. DOI:10.1016/j.pbb.2019.05.005

Estes, M.L., McAllister, A.K., 2016. Maternal immune activation: Implications for neuropsychiatric disorders. Science. 353, 772-777. DOI:10.1126/science.aag3194

Fan, L.W., Bhatt, A., Tien, L.T., Zheng, B., Simpson, K.L., Lin, R.C.S., Cai, Z., Kumar, P., Pang, Y., 2015. Exposure to serotonin adversely affects oligodendrocyte development and myelination in vitro. J. Neurochem. 133, 532-543. DOI:10.1111/jnc.12988

Fontes, M.A.P., Xavier, C.H., Marins, F.R., Limborço-Filho, M., Vaz, G.C., Müller-Ribeiro, F.C., Nalivaiko, E., 2014. Emotional stress and sympathetic activity: Contribution of dorsomedial hypothalamus to cardiac arrhythmias. Brain Res. 1554, 49-58.

DOI:10.1016/j.brainres.2014.01.043

Forloni, G., Balducci, C., 2018. Alzheimer's Disease, Oligomers, and Inflammation. J. Alzheimer's Dis. 62, 1261-1276. DOI:10.3233/JAD170819

Garbern, J.Y., Yool, D.A., Moore, G.J., Wilds, I.B., Faulk, M.W., Klugmann, M., Nave, K.A., Sistermans, E.A., Van Der Knaap, M.S., Bird, T.D., Shy, M.E., Kamholz, J.A., Griffiths, I.R., 2002. Patients lacking the major CNS myelin protein, proteolipid protein 1, develop lengthdependent axonal degeneration in the absence of demyelination and inflammation. Brain 125, 551-561. DOI:10.1093/brain/awf043

Geracioti, T.D., Loosen, P.T., Ekhator, N.N., Schmidt, D., Chambliss, B., Baker, D.G., Kasckow, J.W., Richtand, N.M., Keck, P.E., Ebert, M.H., 1997. Uncoupling of serotonergic and noradrenergic systems in depression: preliminary evidence from continuous cerebrospinal fluid sampling. Depress. Anxiety 6, 89-94. 
Gocho, Y., Sakai, A., Yanagawa, Y., Suzuki, H., Saitow, F., 2013. Electrophysiological and pharmacological properties of GABAergic cells in the dorsal raphe nucleus. J. Physiol. Sci. 63, 147-154. DOI:10.1007/s12576-012-0250-7

Godar, S.C., Mosher, L.J., Scheggi, S., Devoto, P., Moench, K.M., Strathman, H.J., Jones, C.M., Frau, R., Melis, M., Gambarana, C., Wilkinson, B., DeMontis, M.G., Fowler, S.C., Coba, M.P., Wellman, C.L., Shih, J.C., Bortolato, M., 2019. Gene-environment interactions in antisocial behavior are mediated by early-life 5-HT2A receptor activation. Neuropharmacology 159.

DOI:10.1016/j.neuropharm.2019.01.028

Gorlova, A., Ortega, G., Waider, J., Bazhenova, N., Veniaminova, E., Proshin, A., Kalueff, A. V., Anthony, D.C., Lesch, K.P., Strekalova, T., 2020. Stress-induced aggression in heterozygous TPH2 mutant mice is associated with alterations in serotonin turnover and expression of 5HT6 and AMPA subunit 2A receptors. J. Affect. Disord. 272, 440-451. DOI:10.1016/j.jad.2020.04.014

Gozzi, M., Nielson, D.M., Lenroot, R.K., Ostuni, J.L., Luckenbaugh, D.A., Thurm, A.E., Giedd, J.N., Swedo, S.E., 2012. A magnetization transfer imaging study of corpus callosum myelination in young children with autism. Biol. Psychiatry 72, 215-220. DOI:10.1016/j.biopsych.2012.01.026

Green, H.F., Nolan, Y.M., 2012. GSK-3 mediates the release of IL$1 \beta$, TNF- $\alpha$ and IL-10 from cortical glia. Neurochem. Int. 61, 666-671. DOI:10.1016/j.neuint.2012.07.003

Gruenenfelder, F.I., Thomson, G., Penderis, J., Edgar, J.M., 2011. Axon-glial interaction in the CNS: What we have learned from mouse models of Pelizaeus-Merzbacher disease. J. Anat. 219, 33-43. DOI:10.1111/j.1469-7580.2011.01363.X

Guma, E., Plitman, E., Chakravarty, M.M., 2019. The role of maternal immune activation in altering the neurodevelopmental trajectories of offspring: A translational review of neuroimaging studies with implications for autism spectrum disorder and schizophrenia. Neurosci. Biobehav. Rev. 104, 141-157. DOI:10.1016/j.neubiorev.2019.06.020 
Gutknecht, L., Popp, S., Waider, J., Sommerlandt, F.M.J., Göppner, C., Post, A., Reif, A., Van Den Hove, D., Strekalova, T., Schmitt, A., Colaço, M.B.N., Sommer, C., Palme, R., Lesch, K.P., 2015. Interaction of brain 5-HT synthesis deficiency, chronic stress and sex differentially impact emotional behavior in Tph2 knockout mice. Psychopharmacology (Berl). 232, 2429-2441. DOI:10.1007/s00213-015-3879-0

Hall, L.S., Pain, O., O’Brien, H.E., Anney, R., Walters, J.T.R., Owen, M.J., O’Donovan, M.C., Bray, N.J., 2020. Cis-effects on gene expression in the human prenatal brain associated with genetic risk for neuropsychiatric disorders. Mol. Psychiatry. DOI:10.1038/s41380-0200743-3

Hanamsagar, R., Bilbo, S.D., 2016. Sex differences in neurodevelopmental and neurodegenerative disorders: Focus on microglial function and neuroinflammation during development. J. Steroid Biochem. Mol. Biol. 160, 127-133. DOI:10.1016/j.jsbmb.2015.09.039

Heim, C., Nemeroff, C.B., 2001. The role of childhood trauma in the neurobiology of mood and anxiety disorders: Preclinical and clinical studies. Biol. Psychiatry 49, 1023-1039. DOI:10.1016/S00063223(01)01157-X

Homberg, J.R., Lesch, K.-P., 2011. Looking on the bright side of serotonin transporter gene variation. Biol. Psychiatry 69, 513-9. DOI:10.1016/j.biopsych.2010.09.024

Ip, H.F., van der Laan, C.M., Krapohl, E.M.L., Brikell, I., Cristina, S.M., Nolte, I.M., St Pourcain, B., Bolhuis, K., et al., 2021. Genetic Association Study of Childhood Aggression across raters, instruments and age. bioRxiv 854927. DOI:10.1101/854927

Ji, S., Doucette, J.R., Nazarali, A.J., 2011. Sirt2 is a novel in vivo downstream target of $\mathrm{Nkx} 2.2$ and enhances oligodendroglial cell differentiation. J. Mol. Cell Biol. 3, 351-359. DOI:10.1093/jmcb/mjr009

Jones, M.D., Lucki, I., 2005. Sex differences in the regulation of serotonergic transmission and behavior in 5-HT receptor knockout mice. Neuropsychopharmacology 30, 1039-1047. DOI:10.1038/sj.npp.1300664 
Jope, R.S., Cheng, Y., Lowell, J.A., Worthen, R.J., Sitbon, Y.H., Beurel, E., 2017. Stressed and Inflamed, Can GSK3 Be Blamed? Trends Biochem. Sci. 42, 180-192. DOI:10.1016/j.tibs.2016.10.009

Juárez, P., Valdovinos, M.G., May, M.E., Lloyd, B.P., Couppis, M.H., Kennedy, C.H., 2013. Serotonin2A/C receptors mediate the aggressive phenotype of TLX gene knockout mice. Behav. Brain Res. 256, 354-361. DOI:10.1016/j.bbr.2013.07.044

Jung, H., Park, Haram, Choi, Y., Kang, H., Lee, E., Kweon, H., Roh, J.D., Ellegood, J., Choi, W., Kang, J., Rhim, I., Choi, S.Y., Bae, M., Kim, S.G., Lee, J., Chung, C., Yoo, T., Park, Hanwool, Kim, Y., Ha, S., Um, S.M., Mo, S., Kwon, Y., Mah, W., Bae, Y.C., Kim, H., Lerch, J.P., Paik, S.B., Kim, E., 2018. Sexually dimorphic behavior, neuronal activity, and gene expression in Chd8-mutant mice. Nat. Neurosci. 21, 1218-1228. DOI:10.1038/s41593-018-0208-z

Kıray, H., Lindsay, S.L., Hosseinzadeh, S., Barnett, S.C., 2016. The multifaceted role of astrocytes in regulating myelination. Exp. Neurol. 283, 541-549. DOI:10.1016/j.expneurol.2016.03.009

Klein, M., Singgih, E.L., van Rens, A., Demontis, D., Børglum, A.D., Mota, N.R., Castells-Nobau, A., Kiemeney, L.A., Brunner, H.G., AriasVasquez, A., Schenck, A., van der Voet, M., Franke, B., 2020. Contribution of intellectual disability-related genes to ADHD risk and to locomotor activity in Drosophila. Am. J. Psychiatry 177, 526-536. DOI:10.1176/appi.ajp.2019.18050599

Knuesel, I., Chicha, L., Britschgi, M., Schobel, S.A., Bodmer, M., Hellings, J.A., Toovey, S., Prinssen, E.P., 2014. Maternal immune activation and abnormal brain development across CNS disorders. Nat. Rev. Neurol. 10, 643-660. DOI:10.1038/nrneurol.2014.187

Kolla, N.J., Bortolato, M., 2020. The role of monoamine oxidase A in the neurobiology of aggressive, antisocial, and violent behavior: A tale of mice and men. Prog. Neurobiol. 194, 101875. DOI:10.1016/j.pneurobio.2020.101875

Lee, P.H., Anttila, V., Won, H., Feng, Y.C.A., Rosenthal, J., Zhu, Z., Tucker-Drob, E.M., Nivard, M.Get al. 2019. Genomic Relationships, Novel Loci, and Pleiotropic Mechanisms across Eight Psychiatric Disorders. Cell 179, 1469-1482.e11. DOI:10.1016/j.cell.2019.11.020 
Lesch, K.P., 2019. Editorial: Can dysregulated myelination be linked to ADHD pathogenesis and persistence? J. Child Psychol. Psychiatry Allied Discip. 60, 229-231. DOI:10.1111/jcpp.13031

Lesch, K.P., Araragi, N., Waider, J., van den Hove, D., Gutknecht, L., 2012. Targeting brain serotonin synthesis: insights into neurodevelopmental disorders with long-term outcomes related to negative emotionality, aggression and antisocial behaviour. Philos. Trans. R. Soc. B Biol. Sci. 367, 2426-2443. DOI:10.1098/rstb.2012.0039

Lesch, K.P., Merschdorf, U., 2000. Impulsivity, aggression, and serotonin: A molecular psychobiological perspective. Behav. Sci. Law 18, 581-604.

DOI:10.1002/1099-0798(200010)18:5<581::AID-BSL411>3.0.CO;2-L

Li, W., Zhang, B., Tang, J., Cao, Q., Wu, Y., Wu, C., Guo, J., Ling, E.A., Liang, F., 2007. Sirtuin 2, a mammalian homolog of yeast silent information regulator-2 longevity regulator, is an oligodendroglial protein that decelerates cell differentiation through deacetylating $\alpha$ tubulin. J. Neurosci. 27, 2606-2616. DOI:10.1523/JNEUROSCI.418106.2007

Markova, N., Bazhenova, N., Anthony, D.C., Vignisse, J., Svistunov, A., Lesch, K.P., Bettendorff, L., Strekalova, T., 2017. Thiamine and benfotiamine improve cognition and ameliorate GSK-3 $\beta$-associated stress-induced behaviours in mice. Prog. Neuro-Psychopharmacology Biol. Psychiatry 75, 148-156. DOI:10.1016/j.pnpbp.2016.11.001

May, T., Adesina, I., McGillivray, J., Rinehart, N.J., 2019. Sex differences in neurodevelopmental disorders. Curr. Opin. Neurol. 32, 622-626. DOI:10.1097/WCO.0000000000000714

McCarthy, M.M., Wright, C.L., 2017. Convergence of Sex Differences and the Neuroimmune System in Autism Spectrum Disorder. Biol. Psychiatry 81, 402-410. DOI:10.1016/j.biopsych.2016.10.004

Mealer, R.G., Jenkins, B.G., Chen, C.Y., Daly, M.J., Ge, T., Lehoux, S., Marquardt, T., Palmer, C.D., Park, J.H., Parsons, P.J., Sackstein, R., Williams, S.E., Cummings, R.D., Scolnick, E.M., Smoller, J.W., 2020. The schizophrenia risk locus in SLC39A8 alters brain metal transport and plasma glycosylation. Sci. Rep. 10, 1-15. DOI:10.1038/s41598-02070108-9 
Millan, M.J., Dekeyne, A., Gobert, A., 1998. Serotonin (5-HT)(2C) receptors tonically inhibit dopamine (DA) and noradrenaline (NA), but not 5-HT, release in the frontal cortex in vivo. Neuropharmacology 37, 953-955. DOI:10.1016/S0028-3908(98)00078-1

Mosienko, V., Bert, B., Beis, D., Matthes, S., Fink, H., Bader, M., Alenina, N., 2012. Exaggerated aggression and decreased anxiety in mice deficient in brain serotonin. Transl. Psychiatry 2, e122-9. DOI:10.1038/tp.2012.44

Mossa, A., Manzini, M.C., 2021. Molecular causes of sex-specific deficits in rodent models of neurodevelopmental disorders. J. Neurosci. Res. 99, 37-56. DOI:10.1002/jnr.24577

Müller-Oerlinghausen, B., Lewitzka, U., 2010. Lithium reduces pathological aggression and suicidality: A mini-review. Neuropsychobiology 62, 43-49. DOI:10.1159/000314309

Murugaiyan, G., Fujiwara, M., Garo, L.P., 2020. RemyelinationPromoting Inflammation: Novel Role for MyD88 Signaling in Microglia/Macrophages. Trends Neurosci. 43, 455-457. DOI:10.1016/j.tins.2020.04.005

Niimi, K., Nishioka, C., Miyamoto, T., Takahashi, E., Miyoshi, I., Itakura, C., Yamashita, T., 2011. Impairment of neuropsychological behaviors in ganglioside GM3-knockout mice. Biochem. Biophys. Res. Commun. 406, 524-528. DOI:10.1016/j.bbrc.2011.02.071

Oades, R.D., Lasky-Su, J., Christiansen, H., Faraone, S. V., SonugaBarke, E.J.S., Banaschewski, T., Chen, W., Anney, R.J.L., Buitelaar, J.K., Ebstein, R.P., Franke, B., Gill, M., Miranda, A., Roeyers, H., Rothenberger, A., Sergeant, J.A., Steinhausen, H.C., Taylor, E.A., Thompson, M., Asherson, P., 2008. The influence of serotonin- and other genes on impulsive behavioral aggression and cognitive impulsivity in children with attention-deficit hyperactivity disorder (ADHD): Findings from a family-based association test (FBAT) analysis. Behav. Brain Funct. 4, 1 14. DOI:10.1186/1744-9081-4-48

Ofengeim, D., Yuan, J., 2013. Regulation of RIP1 kinase signalling at the crossroads of inflammation and cell death. Nat. Rev. Mol. Cell Biol. 14, 727-736. DOI:10.1038/nrm3683 
Onnink, A.M.H., Zwiers, M.P., Hoogman, M., Mostert, J.C., Dammers, J., Kan, C.C., Vasquez, A.A., Schene, A.H., Buitelaar, J., Franke, B., 2015. Deviant white matter structure in adults with attentiondeficit/hyperactivity disorder points to aberrant myelination and affects neuropsychological performance. Prog. Neuro-Psychopharmacology Biol. Psychiatry 63, 14-22. DOI:10.1016/j.pnpbp.2015.04.008

Ono, M., Kikusui, T., Sasaki, N., Ichikawa, M., Mori, Y., MurakamiMurofushi, K., 2008. Early weaning induces anxiety and precocious myelination in the anterior part of the basolateral amygdala of male Balb/c mice. Neuroscience 156, 1103-1110.

DOI:10.1016/j.neuroscience.2008.07.078

Pavăl, D., Micluția, I.V., 2021. The Dopamine Hypothesis of Autism Spectrum Disorder Revisited: Current Status and Future Prospects. Dev. Neurosci. 1-11. DOI:10.1159/000515751

Pavlov, D., Markova, N., Bettendorff, L., Chekhonin, V., Pomytkin, I., Lioudyno, V., Svistunov, A., Ponomarev, E., Lesch, K.P., Strekalova, T., 2017. Elucidating the functions of brain GSK3 $\alpha$ : Possible synergy with GSK3 $\beta$ upregulation and reversal by antidepressant treatment in a mouse model of depressive-like behaviour. Behav. Brain Res. 335, 122-127. DOI:10.1016/j.bbr.2017.08.018

Pickett, W., Iannotti, R.J., Simons-Morton, B., Dostaler, S., 2009. Social environments and physical aggression among 21,107 students in the United States and Canada: Research article. J. Sch. Health 79, 160168. DOI:10.1111/j.1746-1561.2009.00385.X

Prata, J., Santos, S.G., Almeida, M.I., Coelho, R., Barbosa, M.A., 2017. Bridging Autism Spectrum Disorders and Schizophrenia through inflammation and biomarkers - pre-clinical and clinical investigations. J. Neuroinflammation 14, 179. DOI:10.1186/s12974-017-0938-y

Robson, M.J., Quinlan, M.A., Blakely, R.D., 2017. Immune System Activation and Depression: Roles of Serotonin in the Central Nervous System and Periphery. ACS Chem. Neurosci. 8, 932-942. DOI:10.1021/acschemneuro.6b00412

Rosell, D.R., Siever, L.J., 2015. The neurobiology of aggression and violence. CNS Spectr. 20, 254-279. DOI:10.1017/S109285291500019X 
Rucklidge, J.J., 2010. Gender Differences in AttentionDeficit/Hyperactivity Disorder. Psychiatr. Clin. North Am. 33, 357-373. DOI:10.1016/j.psc.2010.01.006

Ryding, E., Lindström, M., Träskman-Bendz, L., 2008. The role of dopamine and serotonin in suicidal behaviour and aggression. Prog. Brain Res. 172, 307-315. DOI:10.1016/S0079-6123(08)00915-1

Sawada, N., Ishida, H., Collins, B.E., Schnaar, R.L., Kiso, M., 1999. Ganglioside GD1 $\alpha$ analogues as high-affinity ligands for myelinassociated glycoprotein (MAG). Carbohydr. Res. 316, 1-5. DOI:10.1016/S0008-6215(99)00081-6

Schnaar, R.L., 2016. Gangliosides of the Vertebrate Nervous System. J. Mol. Biol. 428, 3325-3336. DOI:10.1016/j.jmb.2016.05.020

Schnaar, R.L., 2010. Brain gangliosides in axon-myelin stability and axon regeneration. FEBS Lett. 584, 1741-1747.

DOI:10.1016/j.febslet.2009.10.011

Seo, D., Patrick, C.J., Kennealy, P.J., 2008. Role of serotonin and dopamine system interactions in the neurobiology of impulsive aggression and its comorbidity with other clinical disorders. Aggress. Violent Behav. 13, 383-395. DOI:10.1016/j.avb.2008.06.003

Singh, K., Patro, N., Pradeepa, M., Patro, I., 2017. Neonatal lipopolysaccharide infection causes demyelination and behavioral deficits in adult and senile rat brain. Ann. Neurosci. 24, 146-154. DOI:10.1159/000477152

Søndenaa, E., Rasmussen, K., Helverschou, S.B., Steindal, K., Nilson, B., Nøttestad, J.A., 2014. Violence and sexual offending behavior in people with autism spectrum disorder who have undergone a psychiatric forensic examination. Psychol. Rep. 115, 32-43. DOI:10.2466/16.15.PR0.115c16z5

Strekalova, T., Couch, Y., Kholod, N., Boyks, M., Malin, D., Leprince, P., Steinbusch, H.M.W., 2011. Update in the methodology of the chronic stress paradigm: Internal control matters. Behav. Brain Funct. 7, 1-18. DOI:10.1186/1744-9081-7-9

Strekalova, T., Markova, N., Shevtsova, E., Zubareva, O., Bakhmet, A., Steinbusch, H.M., Bachurin, S., Lesch, K.-P., 2016. Individual 
Differences in Behavioural Despair Predict Brain GSK-3beta Expression in Mice: The Power of a Modified Swim Test. Neural Plast. 2016, 5098591. DOI:10.1155/2016/5098591

Svirin, E., Gorlova, A., Lim, L.W., Veniaminova, E., Costa-Nunes, J., Anthony, D., Lesch, K.-P., Strekalova, T., 2021. Sexual bias in the altered expression of myelination factors in mice with partial genetic deficiency of tryptophan hydroxylase 2 and pro-aggressive effects of predation stress, in: IBNS 30th Annual Meeting.

Sypecka, J., Domańska-Janik, K., 2005. Rabbit paralytic tremor phenotype - A plp1 gene mutation as a model of human PelizaeusMerzbacher disease. Acta Neurobiol. Exp. (Wars). 65, 221-229.

Takahashi, A., Flanigan, M.E., McEwen, B.S., Russo, S.J., 2018. Aggression, social stress, and the immune system in humans and animal models. Front. Behav. Neurosci. 12. DOI:10.3389/fnbeh.2018.00056

Takahashi, J.L., Giuliani, F., Power, C., Imai, Y., Yong, V.W., 2003. Interleukin-1 $\beta$ promotes oligodendrocyte death through glutamate excitotoxicity. Ann. Neurol. 53, 588-595. DOI:10.1002/ana.10519

Tavares, E.R., Silva-Gotay, A., Riad, W.V., Bengston, L., Richardson, H.N., 2019. Sex differences in the effect of alcohol drinking on myelinated axons in the anterior cingulate cortex of adolescent rats. Brain Sci. 9. DOI:10.3390/brainsci9070167

Thom, R.P., Keary, C.J., Palumbo, M.L., Ravichandran, C.T., Mullett, J.E., Hazen, E.P., Neumeyer, A.M., McDougle, C.J., 2019. Beyond the brain: A multi-system inflammatory subtype of autism spectrum disorder. Psychopharmacology (Berl). 236, 3045-3061.

DOI:10.1007/s00213-019-05280-6

Trofimov, A., Strekalova, T., Mortimer, N., Zubareva, O., Schwarz, A., Svirin, E., Umriukhin, A., Svistunov, A., Lesch, K.-P., Klimenko, V., 2017. Postnatal LPS Challenge Impacts Escape Learning and Expression of Plasticity Factors Mmp9 and Timp1 in Rats: Effects of Repeated Training. Neurotox. Res. 32, 175-186. DOI:10.1007/s12640-017-9720-2

Trzepacz, P.T., Yu, P., Bhamidipati, P.K., Willis, B., Forrester, T., Tabas, L., Schwarz, A.J., Saykin, A.J., 2013. Frontolimbic atrophy is associated with agitation and aggression in mild cognitive impairment 
and Alzheimer's disease. Alzheimer's Dement. 9, S95-S104.e1. DOI:10.1016/j.jalz.2012.10.005

Tuvblad, C., Baker, L.A., 2011. Human aggression across the lifespan. Genetic propensities and environmental moderators, 1st ed, Advances in Genetics. Elsevier Inc. DOI:10.1016/B978-0-12-3808585.00007-1

Vainchtein, I.D., Molofsky, A. V., 2020. Astrocytes and Microglia: In Sickness and in Health. Trends Neurosci. 43, 144-154. DOI:10.1016/j.tins.2020.01.003

Waider, J., Popp, S., Mlinar, B., Montalbano, A., Bonfiglio, F., Aboagye, B., Thuy, E., Kern, R., Thiel, C., Araragi, N., Svirin, E., SchmittBöhrer, A.G., Corradetti, R., Lowry, C.A., Lesch, K.-P., 2019. Serotonin Deficiency Increases Context-Dependent Fear Learning Through Modulation of Hippocampal Activity. Front. Neurosci. 13, 1-12. DOI:10.3389/fnins.2019.00245

Yang, S., Li, C., Zhang, W., Wang, W., Tang, Y., 2008. Sex differences in the white matter and myelinated nerve fibers of LongEvans rats. Brain Res. 1216, 16-23. DOI:10.1016/j.brainres.2008.03.052

Ye, J., Wang, H., Cui, L., Chu, S., Chen, N., 2021. The progress of chemokines and chemokine receptors in autism spectrum disorders. Brain Res. Bull. DOI:10.1016/j.brainresbull.2021.05.024

Yochum, C., Doherty-Lyon, S., Hoffman, C., Hossain, M.M., Zelikoff, J.T., Richardson, J.R., 2014. Prenatal cigarette smoke exposure causes hyperactivity and aggressive behavior: Role of altered catecholamines and BDNF. Exp. Neurol. 254, 145-152. DOI:10.1016/j.expneurol.2014.01.016

Yuan, J., Amin, P., Ofengeim, D., 2019. Necroptosis and RIPK1mediated neuroinflammation in CNS diseases. Nat. Rev. Neurosci. 20, 19-33. DOI:10.1038/s41583-018-0093-1

Zhang, Q., Wu, H., Zou, M., Li, L., Li, Q., Sun, C., Xia, W., Cao, Y., $\mathrm{Wu}$, L., 2019. Folic acid improves abnormal behavior via mitigation of oxidative stress, inflammation, and ferroptosis in the BTBR $\mathrm{T}+\mathrm{tf} / \mathrm{J}$ mouse model of autism. J. Nutr. Biochem. 71, 98-109. DOI:10.1016/j.jnutbio.2019.05.002 
Zhao, Y., Liang, X., Zhu, F., Wen, Y., Xu, J., Yang, J., Ding, M., Cheng, B., Ma, M., Zhang, L., Cheng, S., Wu, C., Wang, S., Wang, X., Ning, Y., Guo, X., Zhang, F., 2018. A large-scale integrative analysis of GWAS and common meQTLs across whole life course identifies genes, pathways and tissue/cell types for three major psychiatric disorders. Neurosci. Biobehav. Rev. 95, 347-352. DOI:10.1016/j.neubiorev.2018.10.005 


\section{Summary}

In our work, we investigated the mechanisms underlying human neurodevelopmental brain pathology associated with abnormal aggression and accompanying emotional abnormalities that are related to endophenotypes of developmental neuropsychiatric disorders. Specifically, we used genetically modified mice deficient for tryptophan hydroxylase-2 (TPH2), the rate-limiting enzyme of neuronal serotonin (5-HT) synthesis, and mice deficient in lactosylceramide alpha-2,3sialyltransferase (ST3GAL5), also called GM3 synthase, which synthesizes ganglioside GM3, the precursor of major brain gangliosides.

Genetic variation in the TPH2 gene and ST3GAL5 gene-dependent alterations in ganglioside synthesis and catabolism in humans were shown to contribute to neurodevelopmental disorders. Both TPH2- and ST3GAL5-deficient mice share features of neurodevelopmental and psychiatric disorders, including attention-deficit/hyperactivity disorder (ADHD) and autism spectrum disorders (ASD), such as hyperactivity as well as increased impulsivity and aggression. In addition, they display compromised cognitive control and signs of impaired brain myelination. Apart from genetic predisposition, environmental challenges, such as emotional stress or inflammatory stress caused by infectious diseases, are known to contribute to the pathogenesis of these disorders.

To investigate the contribution of environmental challenges in these experimental mouse models of disease, we used exposure to a predator or induction of inflammatory stress. In light of current views suggesting that genetic influence on psychiatric disorders involves genes 
acting at early stages of neurodevelopment and the establishment of brain circuitry and, thus, conferring broad liability to psychiatric disorders, we sought to investigate two genetic models exhibiting partly similar behavioral phenotypes in order to facilitate identification of putative common neurobiological mechanisms leading to behavioral alterations, including increased aggression.

First, we used mice with a partial genetic deficiency of Tph2. In line with previously demonstrated abnormal aggression in male heterozygous Tph2 $\left(\mathrm{Tph}^{+/-}\right)$mice subjected to environmental stressors, we showed increased aggression and dominant behavior, as well as deficits in neutral social behavior in both male and female mutants following rat exposure stress. Naïve $T p h 2^{+-}$male mice challenged with novelty exhibited increased exploratory activity and less behavioral despair in the modified swim test than wildtype (wt) control mice. Decreased floating was also found in naïve $T p h 2^{+/-}$female mice, indicating stress resilience and locomotor hyperactivity which are a prominent feature of neurodevelopmental disorders. Thus, in both sexes in $\mathrm{Tph}^{+/-}$mice we observed increased stress resilience and stressinduced aggression.

We suggest similarities in neurobiological mechanisms of behavioral changes in male and female mice. Following previous research that found alterations in 5-HT metabolism, we used male mice for highperformance liquid chromatography (HPLC) assay of brain dopamine and norepinephrine. Stress-induced changes of dopamine and norepinephrine metabolism were most pronounced in the amygdala, 
where dopamine concentration was drastically reduced and its turnover was heightened in stressed $\mathrm{Tph}^{+/-}$mice compared to wt controls and non-stressed mutants. Norepinephrine turnover in the amygdala was reduced in mutant mice. In the PFC of stressed $T p h 2^{+-}$mice we found strongly decreased dopamine concentration and elevated dopamine turnover compared to wt control mice, which may alter PFC activity and, thus, affect top-down control of impulsive aggression. We speculate that the observed neurochemical differences between wt controls and $T p h 2^{+/-}$ mice are implicated in the deficits of cognitive control dependent on the functional interplay between the PFC and amygdala.

RT-qPCR showed increased expression of $5-\mathrm{HT}_{2 \mathrm{~A}}$ in the PFC accompanying behavioral changes in stressed female $T p h 2^{+/-}$mice of both genotypes. In $\mathrm{Tph}^{+/-}$female mice, $5-\mathrm{HT}_{1 \mathrm{~A}}$ receptor expression was downregulated. Together, these findings suggest stress $\times$ genotype interaction affecting the 5-HT system of the brain, which is essential for cognitive control. Expression of glycogen synthase kinase 3 beta gene $(G s k-3 \beta)$ in the PFC was decreased in non-stressed $T p h 2^{+/-}$female mice. GSK-3 $\beta$ is considered a molecular hub of distress and is a wellestablished physiological mediator of elevated synthesis of proinflammatory cytokines. Together with decreased behavioral despair in the modified swim test, lowered Gsk-3 $\beta$ expression may indicate reduced susceptibility of $\mathrm{Tph}^{+/-}$mutants to stress.

For the first time, we found elevated mRNA expression of four major myelin structural proteins: myelin basic protein (MBP), proteolipid protein 1 (PLP1), myelin-associated glycoprotein (MAG), and myelin 
oligodendrocyte glycoprotein (MOG), in the PFC of non-stressed Tph2 $2^{+-}$ female mice. Stress lowered the expression level of these proteins in $T p h 2^{+/-}$mice. Changes in the expression of myelination-related peptides were reciprocal to the changes in the $G s k-3 \beta$ expression, which is in accordance with the literature. In non-stressed male $T p h 2^{+-}$mice we found lowered expression of Plp1 and Mbp in the hippocampus. Taken together, these changes indicate the possibility of compromised myelination of neurons, which may contribute to the observed behavioral alterations, as dysregulated myelin formation disrupts conductivity and, thus, connectivity in the brain.

Overall, in $T p h 2^{+/-}$mice of both sexes, we found a stress-induced increase in aggression, as well as decreased stress susceptibility and anxiety in naïve mice, the behavioral features similar to those observed in Tph2 knockout mice $\left(T p h 2^{---}\right)$. We also showed signs of altered myelination and altered catecholamine metabolism in the brain regions implicated in aggression and emotional regulation.

Secondly, we used mice of both sexes with GM3 synthase knockout $\left(\right.$ St3gal5 $\left.^{-/}\right)$, which are lacking major brain gangliosides. Disruption in ganglioside metabolism in humans leads to devastating neurological impairments, but more subtle alterations may contribute to an increased risk of neurodevelopmental disorders, including ADHD. However, the role of ST3GAL5 in endophenotypes of ADHD and ASD has been poorly investigated and no data are available in the corresponding knockout mouse model. Our studies demonstrated elevated measures of aggressive and dominant behavior in mutants of both sexes. Notably, we 
found decreased expression of PLP1 in the cerebral cortex of St3gal5 ${ }^{-/}$ mice at both gene and protein levels, suggesting compromised myelination. As there is an established link between neurodevelopmental disorders and infectious diseases suffered in a broad time window from the prenatal period to adolescence, we challenged St3gal5 $5^{-/-}$mice with a model of infectious disease causing inflammatory stress. It led to an aggravation of changes in the behavior of $\mathrm{St}_{\mathrm{gal}} \mathrm{g}^{-/-}$mice, and an aberrant inflammatory response to systemic inflammation was found in the CNS and in the periphery. Altogether, our findings support the view that ganglioside deficiency, dysmyelination, and neuroinflammation are interrelated, which may underlie neurodevelopmental disorders of various genetic origins.

Thus, in both Tph2 and St3gal5 mouse lines, we found signs of inflammation and altered myelination. Our data has led us to hypothesize that impaired myelination and neuroinflammation may be sharing mechanisms leading to disrupted brain connectivity and subsequent aggressiveness, hyperactivity, and other behavioral alterations that are characteristic of ADHD- and ASD-like features. Based on our results, we speculate that these mechanisms are common for different genetic aberrations. Our results further support the findings from recent genome-wide association studies, suggesting that variation in multiple pleiotropic genes interacting with environmental challenges may cause similar dimensions of symptoms in neurodevelopmental psychiatric disorders. 


\section{Samenvatting}

In ons werk onderzochten we de mechanismen die ten grondslag liggen aan menselijke neurologische ontwikkelingsstoornissen die gekenmerkt worden door abnormale agressie en emotionele afwijkingen, gerelateerd aan endofenotypen voor neuropsychiatrische ontwikkelingsstoornissen. Hiervoor zijn genetisch gemodificeerde muizen gebruikt met een gebrek aan tryptofaanhydroxylase-2 (Tph2), betrokken bij de synthese van serotonine $(5-\mathrm{HT})$, en muizen met een gebrek aan lactosylceramide-alfa-2,3-sialyltransferase (ST3GAL5, ookwel bekend als GM3-synthase), verantwoordelijk voor de synthese van de precursor van de belangrijkste gangliosiden in de hersenen, GM3. Genetische variatie in het TPH2-gen en veranderingen in de synthese en afbraak van gangliosiden door het ST3GAL5-gen dragen bij aan neurologische ontwikkelingsstoornissen bij mensen. Zowel TPH2- als ST3GAL5-deficiënte muizen vertonen kenmerken van neurologische en psychiatrische ontwikkelingsstoornissen, zoals aandachtstekorthyperactiviteitstoornis (attention-deficit hyperactivity disorder [ADHD]) en autismespectrumstoornissen (ASS), met kenmerken als hyperactiviteit, verhoogde impulsiviteit en agressie. Daarbij vertonen zij verminderde executieve functionaliteit en zijn er aanwijzingen voor achterblijvende myelinisatie van de hersenen. Naast genetische aanleg kunnen omgevingsfactoren, zoals emotionele stress en inflammatoire stress door infecties, bijdragen aan de pathogenese van deze stoornissen.

Om de bijdrage van omgevingsfactoren in experimentele muismodellen te onderzoeken, is gebruik gemaakt van blootstelling aan 
een roofdier en geïnduceerde inflammatoire stress. De genetische invloed op psychiatrische stoornissen betreft volgens de huidige opvattingen genen die betrokken zijn bij de vroege neurologische ontwikkeling en de opbouw van hersencircuits, die bij deze processen een belangrijke rol spelen in de ontwikkeling van psychiatrische stoornissen. In dit licht hebben we twee genetische modellen gebruikt die gedeeltelijk vergelijkbare gedragsfenotypen vertonen, om de mogelijk gemeenschappelijke neurobiologische mechanismen te identificeren die leiden tot afwijkend gedrag, zoals verhoogde agressie.

Ten eerste hebben we muizen met een genetische gedeeltelijke deficiëntie van Tph2 gebruikt. In overeenstemming met eerder aangetoonde abnormale agressie bij mannelijke heterozygote Tph2 $\left(T p h 2^{+/-}\right)$muizen die onderworpen werden aan omgevingsstressoren, vonden we na stressvolle blootstelling aan ratten zowel bij mannelijke als vrouwelijke mutanten een toename van agressie en dominant gedrag, en een gebrek aan neutraal sociaal gedrag. Naïeve mannelijke $\mathrm{Tph}^{+/-}$-muizen die werden uitgedaagd met onbekende omstandigheden vertoonden verhoogde exploratieve activiteit en minder hulpeloos gedrag dan wildtype (wt) controle-muizen in een aangepaste Porsolt zwemtest. Verminderde immobiliteit werd ook waargenomen bij naïeve vrouwelijke Tph2 $2^{+-}$-muizen, hetgeen duidt op verminderde stressgevoeligheid en locomotorische hyperactiviteit. Dit is een belangrijk kenmerk van neurologische ontwikkelingsstoornissen. Bij beide geslachten van $\mathrm{Tph}^{+/-}$-muizen werden dus verhoogde stressbestendigheid en stressgeïnduceerde agressie waargenomen. 
We suggereren overeenkomsten in de neurobiologische mechanismen achter gedragsveranderingen bij mannelijke en vrouwelijke muizen. In navolging van eerder onderzoek dat veranderingen in het 5HT-metabolisme aantoonde, gebruikten we high-performance liquid chromatography (HPLC) om het gehalte van dopamine en noradrenaline in de hersenen van mannelijke muizen te bepalen. Stress-geïnduceerde veranderingen in het dopamine- en noradrenaline-metabolisme waren het meest uitgesproken in de amygdala. Daar waren bij gestreste Tph2 ${ }^{+/-}$muizen de dopamineconcentraties drastisch verlaagd en de dopamineturnover verhoogd, in tegenstelling tot wt-controles en nietgestreste mutanten. De turnover van noradrenaline in de amygdala was juist verlaagd bij de mutant-muizen. In de prefrontale cortex (PFC) van de gestreste $T p h 2^{+/-}$-muizen vonden we een sterk verlaagde dopamineconcentratie en een verhoogde turnover, in vergelijking met wt-controlemuizen. Deze veranderingen zouden de activiteit van de PFC kunnen veranderen en zo de top-down controle van impulsieve agressie kunnen beïnvloeden. We speculeren dat de waargenomen neurochemische verschillen tussen wt-controlemuizen en $T p h 2^{+/-}$ muizen betrokken zijn bij de gebreken in executieve functionaliteit, die afhankelijk is van de functionele interactie tussen de PFC en de amygdala bij mutanten.

Bij gestreste vrouwelijke Tph2-muizen van beide genotypen, toonde RT-qPCR een verhoogde expressie van $5-\mathrm{HT}_{2 \mathrm{~A}}$ in de PFC die gepaard ging met gedragsveranderingen. Bij vrouwelijke $T p h 2^{+/-}$-muizen was de expressie van de $5-\mathrm{HT}_{1 \mathrm{~A}}$-receptor gedownreguleerd. Samen 
suggereren deze twee bevindingen een interactie tussen stress en genotype, die het 5-HT-systeem in de hersenen beïnvloedt, wat gevolgen heeft voor de executieve functionaliteit. De expressie van glycogeensynthase-kinase-3-beta $(G s k-3 \beta)$ in de PFC was verlaagd bij niet-gestreste vrouwelijke $T p h 2^{+/-}$-muizen. GSK-3 $\beta$ wordt beschouwd als een moleculair knooppunt van angst en nood, en is een bekende fysiologische mediator van verhoogde synthese van pro-inflammatoire cytokines. Samen met de verminderde hulpeloosheid in de gemodificeerde zwemtest, kan de verlaagde $G s k-3 \beta$ wijzen op een verminderde gevoeligheid van $T p h 2^{+/-}$-mutanten voor stress.

Voor het eerst vonden we in de PFC van niet-gestreste vrouwelijke $T p h 2^{+/-}$-muizen een verhoogde expressie van vier belangrijke eiwitten voor de myelinestructuur: basisch myeline-eiwit (MBP), proteolipide-eiwit 1 (PLP1), myeline-geassocieerd glycoproteïne (MAG) en myeline-oligodendrocyt glycoproteïne (MOG). Stress verlaagde het expressieniveau van deze eiwitten in $T p h 2^{+/-}$-muizen. In overeenstemming met de literatuur was er een verband tussen veranderingen in de expressie van myelinisatie-gerelateerde peptiden en veranderingen in de $G s k-3 \beta$-expressie. In niet-gestreste mannelijke $\mathrm{Tph}^{+/-}$-muizen vonden we een verlaagde expressie van Plp1 en $\mathrm{Mbp}$ in de hippocampus. Samen wijzen deze bevindingen op de mogelijkheid van gecompromitteerde myelinisatie van neuronen. Dit kan bijdragen aan de waargenomen gedragsveranderingen, aangezien ontregelde myelinevorming de geleiding, en dus de connectiviteit, in de hersenen verstoort. 
Over het geheel vonden we bij $T p h 2^{+/-}$-muizen van beide geslachten een stress-geïnduceerde toename van agressie, en een afname van stressgevoeligheid en angst bij naïeve muizen. Deze gedragskenmerken zijn vergelijkbaar met het waargenomen gedrag van Tph2-knockout-muizen $\left(T p h 2^{-/-}\right)$. Daarnaast vonden we aanwijzingen voor veranderingen in de myelinisatie en het catecholaminemetabolisme, in de hersengebieden die betrokken zijn bij agressie en emotieregulatie.

Ten tweede hebben we muizen van beide geslachten gebruikt met GM3-synthase-knockout (St3gal5 ${ }^{-/}$), die daardoor belangrijke hersengangliosiden missen. Verstoring van het ganglioside-metabolisme bij mensen leidt tot verwoestende neurologische stoornissen, maar subtielere veranderingen kunnen bijdragen aan een verhoogd risico op neurologische ontwikkelingsstoornissen, waaronder ADHD. Echter, de rol van ST3GAL5 in endofenotypen van ADHD en ASS is slecht onderzocht en er zijn geen gegevens beschikbaar van het corresponderende knockout-muismodel. Onze studies toonden verhoogde maten van agressief en dominant gedrag aan bij mutanten van beide geslachten. In het bijzonder vonden we een verminderde expressie van PLP1 in de hersenschors van St3gal5 ${ }^{-/-}$-muizen op zowel gen- als eiwitniveau, hetgeen wijst op een verminderde myelinisatie. Omdat er een verband bestaat tussen neurologische ontwikkelingsstoornissen en infectieziekten optredend tussen de prenatale periode tot aan adolescentie, hebben we St3gal5 $5^{-1-}$-muizen geconfronteerd met een modelziekte waardoor inflammatoire stress werd veroorzaakt. Dit leidde 
tot een verergering van het afwijkende gedrag van $S t 3 g a l 5^{-1-}$-muizen. Een afwijkende ontstekingsreactie op systemische ontstekingen werd gevonden in het centraal zenuwstelsel en in de periferie. Onze bevindingen ondersteunen de opvatting dat ganglioside-deficiëntie, dysmyelinisatie en neuro-inflammatie met elkaar in verband staan, wat ten grondslag kan liggen aan neurologische ontwikkelingsstoornissen van verschillende genetische oorsprong.

We vonden dus zowel bij Tph2- als bij St3gal5-muizenlijnen aanwijzingen voor inflammatie en veranderde myelinisatie. Onze gegevens hebben geleid tot de hypothese dat verminderde myelinisatie en neuro-inflammatie mechanismen kunnen delen die leiden tot verstoorde hersenconnectiviteit en daaropvolgend agressiviteit, hyperactiviteit en andere gedragsveranderingen die kenmerkend zijn voor ADHD- en ASS-achtige beelden. Op basis van onze resultaten speculeren wij dat gemeenschappelijke mechanismen betrokken zijn bij verschillende genetische afwijkingen. Onze resultaten ondersteunen verder de bevindingen van recente genoomwijde associatiestudies, die suggereren dat een variatie van meerdere pleiotrope genen, in wisselwerking met omgevingsfactoren, vergelijkbare symptoomdimensies van neurologische ontwikkelingsstoornissen kan veroorzaken. 


\section{Impact}

Neurodevelopmental disorders include, for example, attentiondeficit/hyperactivity disorder (ADHD) with prevalence estimates ranging from 5 to $12 \%$ and autism spectrum disorders (ASD) with estimated prevalence from 0.6 to $2.3 \%$. Marked aggression is one of the common symptoms: according to epidemiological research, the prevalence of abnormal aggression is estimated in the range from 5.7\% in ADHD to about 68\% in ASD. The World Health Organization categorizes aggression and violence among the top 20 causes of disability, so there is an evident need to understand the neurobiology of aggressive behavior with a view to developing new treatments.

In the present study, we aimed to investigate the impact of environmental adversities on neurobiological correlates of two experimental genetic animal models and study the validity of these models as models of gene $x$ environment interaction in neurodevelopmental disorders. Genes affected in these models were shown to be the risk factors for neurodevelopmental disorders.

The interaction of an individual's genetic background with adverse environmental experiences (gene $\times$ environment interaction) is one of the main pathogenic factors for these disorders, but not many models are available to mimick this situation experimentally.

We used mice with a genetic decrease in neuronal serotonin, a model of gene $\times$ environment interaction in male aggression. Mutation in the gene, which is partially inactivated in these mice, was associated with neurodevelopmental disorders, including ADHD and ASD. We showed 
that in these mice emotional stress-related aggression is accompanied by substantial changes in the brain neurochemistry of the regions crucial for aggressive, emotional, and social behavior. For these mice, no data on the behavior of females was previously available. Surprisingly, although aggression is thought to be outside of the natural behavioral repertoire of female mice, we found aggressive behavior in female mice with deficiency of brain serotonin after emotional stress.

This behavior was accompanied by prominent changes in brain molecular markers, which were previously shown to be involved in aggression and depressive behavior. One of these markers is also implicated in inflammation. Notably, in both male and female mice with a serotonin deficiency we found signs of alteration in myelination, a neurodevelopmental process ensuring proper signal propagation in the nervous system, and, thus, functional connectivity, which was shown to be affected in many psychiatric disorders.

Secondly, for the first time, we studied the social behavior of mice with a genetic deficit of major brain gangliosides - ubiquitous molecules playing various roles in the CNS. In humans, lack of brain gangliosides leads to devastating neurodevelopmental deficits, accompanied by severe intellectual disability, growth retardation, and seizures. These mice, however, do not mirror these deficits completely due to compensatory mechanisms. Thus, these mice are considered as a model of more subtle neurodevelopmental anomalies linked to brain gangliosides. Genetic variants of one of the genes involved in brain ganglioside synthesis were found to be associated with ADHD and ASD. 
In ganglioside-deficient mice we have found aberrant social and dominant behaviors, as well as signs of repetitive behaviors, which are reminiscent of ASD-like syndrome. These findings were complemented by increased inflammatory markers, which are also known to be increased in patients with ASD. Additionally, as in the case with the first mouse model, we found signs of altered myelination in both sexes of ganglioside-deficient mice. We also found an altered response to inflammatory stress accompanied by increased aggression and aberrant social behavior in these mice, thus underpinning the importance of gene $\times$ environment interaction in the pathogenesis of excessive aggression.

Thus, in both mouse lines we found abnormal aggression and other alterations in social behavior as a consequence of environmental stressors, which suggests them as promising models for studies of the gene $\times$ environment interaction in ADHD and ASD.

Our work also offers a new model of female aggression. Such models are very scarce, and female aggression demonstrated in serotonin-deficient mice may also prove itself useful as a tool for studies of gene $\times$ environment interaction in female aggression.

We also are the first to report signs of alterations in myelination in these models. Myelination and neuroinflammation are interrelated processes, and with our results we may set the direction for further investigations, as the data on the role of alterations in myelination and brain connectivity in neurodevelopmental disorders such as ADHD and ASD are scarce. Overall, we assume that our work provides further addition to the idea that the interaction between various genetic and 
environmental factors may affect converging mechanisms leading to neurodevelopmental pathologies such as ADHD and ASD.

We consider our primary target group to be researchers working in the field of neurobiology of aggression and neurodevelopmental disorders; however, our results are relevant also for the medical community, as they provide data for the development for new pharmacological treatments. The data will be published in peer-reviewed journals and presented at national and international conferences. 


\section{Acknowledgements}

First of all, I would like to thank Prof. Klaus-Peter Lesch for general supervision of my work that was a joint research project between Maastricht University, Department of Neuroscience, Würzburg University Clinic, and the I.M. Sechenov First Moscow State Medical University. During my $\mathrm{Ph}$. D. years, I had an exceptional chance to take part in numerous projects, during which I was able to learn new methods and gain experience for my studies. All of this would not be possible without the invaluable contribution of Prof. Lesch. I am very thankful for the opportunity to work in his division of Molecular Psychiatry, where I received training from the very beginning of my $\mathrm{Ph}$. D., and for his help with DAAD fellowship. I am also incredibly grateful for the warmest welcome I had at his house in Würzburg, where I had the pleasure of staying during the months of my work in Germany. Prof. Lesch's attention to detail and gentle criticism helped a great deal to improve my writing and reporting skills. I am especially thankful for important discussions and feedback regarding my research throughout the $\mathrm{Ph}$. $\mathrm{D}$. training period.

I express my special gratitude to Prof. Tatyana Strekalova, my day-to-day supervisor, who introduced me to the work with animal models and coached me since the start of my Ph. D. project. She provided me with a unique opportunity to join the project supported by the ' $5-100$ Russian Excellence Project' and taught me the highest standards of research work, study design, planning and organization of experiments, and quality control of behavioral experiments on mice. She also 
extensively trained me to analyze and present my data. With her invaluable organizational help and support, I was able to attend important international meetings and undertake traineeships in the most prominent laboratories in Europe. During these joint activities and traineeships arranged by Prof. Strekalova, I acquired valuable behavioral and molecular techniques and carried out important experiments for my thesis. The defense of my $\mathrm{Ph}$. D. thesis would not be possible without her pivotal contribution to this process.

I sincerely thank Dr. Joao Costa-Nunes for productive discussions, his practical contribution to my papers, and his warm hospitality during my stay at Lisbon University, as well as his help with my receipt of the FELASA certification training. I thank researchers from Würzburg: Dr. Sina Kollert and Katharina Gerber, for teaching me electrophysiological and cell culture methods and instructing me during my first months in Würzburg; Dr. Angelika G. Schmitt-Boehrer for helping me master animal manipulations and for participation in experimental planning; Gabriela Ortega, who taught me the details of RT-PCR and was helping me whenever I had any questions about literally any laboratory methods; Dr. Andrea Forero and Hsing-Ping $\mathrm{Ku}$, who kindly helped me to learn immunohistochemistry, as well as Dr. Jonas Waider for his invaluable help in the HPLC analysis; Maria Vitale and Johanna Zöller, who helped me a great deal to become a part of the team.

I thank Prof. Eugene Ponomarev and Prof. Lee Wei Lim for providing mouse lines for the study and for the help with molecular and behavioral assessments. I would also like to sincerely thank Prof. Daniel 
Anthony for the oysters and, of course, a detailed explanation of how the statistical analysis should look like. Special thanks to Dr. Johannes de Munter for the encouragement and Bloody Marys.

I am very grateful to Prof. Alexei Umrukhin from the Sechenov University for providing me continuous help with research facilities throughout my Ph. D. training. I am especially pleased to thank Prof. Andrey Svystunov, Prof. Denis Butnaru, Prof. Andrey Zamyatnin, and Elina Vinogradova from the I.M. Sechenov First Moscow State Medical University, as well as Prof. Sergey Morozov from the Institute of General Pathology and Pathophysiology, for their help and support provided over the years in my work in Moscow.

I express my gratitude to Prof. David Linden, head of School for Mental Health and Neuroscience, Faculty of Health, Medicine and Life Sciences, Prof. Jos Prickaerts, head of Division III; and administration of Maastricht University, and the Ph. D. office for their general support and help in the organization of the defense of my $\mathrm{Ph}$. D. Thesis, as well as for the opportunities to present my data at the MHeNs Research Days.

On a separate note, I would like to thank my peers and colleagues Dr. Anna Gorlova, Dr. Ekaterina Veniaminova, Dr. Dmitrii Pavlov, Dr. Natalia Markova, Dr. Alexander Trofimov, Diana Babevskaya, Margarita Oplatchikova, who were among the first members of the Laboratory of Psychiatric Neurobiology. During these years we were participating in numerous experiments, training events, and conferences, sharing the experiences. They have provided me with all kinds of practical assistance, 
moral support, and wonderful companionship. Many thanks to Paul Smiths and Yulia Sudarikova for their help with Dutch and English text.

Last but not least, I would like to cordially thank my dear parents and grandparents for supporting me across all these years and making me believe in my success, despite all the challenges that came across. I especially thank my dear Anastasia Belova for her infinite patience and support spreading across thousands of kilometers during my long stays abroad.

I thank my dearest friends for their sensitive attention and for being discreet enough not to ask me TOO often whether I am going to finish my thesis soon. 


\section{About the author}

Evgeniy Svirin was born on January $30^{\text {th }}, 1991$, in Moscow, USSR (now Russia). In 2010 - 2015 he studied physiology at the Biological Faculty of Lomonosov Moscow State University. During his undergraduate studies, he was involved in research on electroencephalographic features of schizophrenia under the supervision of Dr. Zhanna Garakh at the Laboratory of Human Higher Nervous Activity, Institute of Higher Nervous Activity and Neurophysiology of Russian Academy of Sciences, and later on EEG- and eye-tracking-based brain-computer interfaces at the Department of Cognitive Neurotechnologies, National Research Center "Kurchatov Institute”.

After graduating in 2015 with MS in physiology, Evgeniy studied magnetoencephalographic correlates of intention in a joint research project between Kurchatov Institute and Moscow State University of Psychology and Education under supervision of Dr. Sergei Shishkin. In October 2016 after finishing the project, he started started to work as a junior researcher under the supervision of Prof. Tatyana Strekalova and Prof. Klaus-Peter Lesch at the Laboratory of Psychiatric Neurobiology in the I.M. Sechenov First Moscow State Medical University (Sechenov University). In 2017 he was appointed as an external Ph.D. student at the Department of Neuroscience, School for Mental Health and Neuroscience, Maastricht University, Netherlands. He was doing his PhD research on mouse models combining both genetic and environmental factors of pathogenesis of neurodevelopmental disorders and excessive aggression, under the immediate supervision of Prof. Tatyana Strekalova 
and general supervision of Prof. Klaus-Peter Lesch (University of Würzburg and University of Maastricht).

In 2016 - 2019, he undertook multiple travels to Germany, where he was trained in research methods at the Division of Molecular Psychiatry of Würzburg University Clinic with a grant support of German Academic Exchange Service (DAAD). During this traineeship, Evgeniy learned methods of immunohistochemical assays under supervision of Dr. Andrea Forero and Hsing Ping $\mathrm{Ku}$, cell and slice electrophysiology under supervision of Prof. Erhard Wichmeyer and Dr. Sina Kollert, mammal cell cultures under supervision of Katharina Gerber, RNA extraction under supervision of Dr. Natalia Markova, RT-PCR under supervision of Gabriela Ortega. Evgeniy had an opportunity to undertake training on animal research and manipulations according to FELASA category B at the University of Lisbon and participated in workshops at the Würzburg University Graduate School of Life Sciences.

In between travels, Evgeniy participated in animal experiments in Moscow, gaining a sound experience in practical running of tests for anxiety and depressive-like behaviour, social, motor, and cognitive functions and stress models, brain dissection and surgery under supervision of Prof. Strekalova. He attended international and local conferences, such as FENS Forum of Neuroscience in Berlin, Germany; Göttingen Meeting of the German Neuroscience Society in Göttingen, Germany; Inflammation and oxidative stress in translational research workshop in Estoril, Portugal; and numerous other conferences, where he gave in total 4 oral presentations and presented 8 posters. He contributed 
to 11 papers with cumulative impact factor 43.67 in the following international peer-reviewed journals: Frontiers in Neuroscience; Neurotoxicity Research; Stem Cell Research; Progress in NeuroPsychopharmacology and Biological Psychiatry; Brain, Behavior and Immunity - Health; Molecular Psychiatry; Biomolecules, as well as to 2 papers in Russian journals. His current h-index is 6.

Tel: +7-968-734-01-04

E-mail: jogikint@gmail.com 


\section{Employment:}

March 2021 - present, Junior researcher, Laboratory of Cognitive Dysfunctions, Research Institute of General Pathology and Pathophysiology, Moscow, Russia

October 2016 - present, Junior researcher, Laboratory of Psychiatric Neurobiology, Institute of Molecular Medicine, I.M. Sechenov First Moscow State Medical University, Moscow, Russia.

September 2015 - October 2016, Research engineer, Department of Neurocognitive Technologies, Complex of NBICS Technologies, National Research Center «Kurchatov Institute», Moscow, Russia.

\section{Presentations at domestic and international conferences:}

- Svirin E., Veniaminova E., Costa-Nunes J., Anthony D., Lim L.W., Walitza S., Lesch K.-P., Strekalova T. "Predation stress causes excessive aggression in female mice with partial genetic inactivation of tryptophan hydroxylase 2: neurochemical and behavioral correlates”, WASAD Congress 2021 “Anxiety, Stress and Disease” 20-22 September, Vienna, Austria (oral presentation)

- Svirin E., Gorlova A., Lim, L. W., Veniaminova E., Costa-Nunes J., Anthony D., Lesch K.-P., Strekalova T. "Sexual bias in the altered expression of myelination factors in mice with partial genetic deficiency of tryptophan hydroxylase 2 and pro-aggressive effects of predation stress”, IBNS 30th Annual Meeting, 01-05.06.2021 (poster presentation).

- Gorlova A., Rogachev R., Svirin E., Pomytkin I., Moskvin O., Veniaminova E., Fedulova L., Chernukha I., Lim L. W., Strekalova T., 
Lesch K.-P. "Compromised glucose metabolism and altered gene expression of gut regulatory pathways in female mice deficient for neuronal serotonin synthesis", Eat2BeNice 4th GA Meeting, 05 06.11.2020 (oral presentation).

- Svirin E., Kollert S., Wischmeyer E., Strekalova T., Lesch K.-P. "Dysmyelination in the CNS of tryptophan hydroxylase 2 knockout mice”, Poster session at the department of Normal Physiology, I.M. Sechenov First Moscow State Medical University, 29.01.2020 (poster presentation in Russian)

- Svirin E. “Dysmyelination in tryptophan hydroxylase 2 knockout mouse model: electrophysiological assessment", Inflammation and oxidative stress in translational research: new models and treatments, Estoril, Portugal, 19 - 22.08.2019 (oral presentation)

- Svirin E., Kollert S., Jansch C., Wischmeyer E., Strekalova T., Lesch K.-P. “Assessment of electrophysiological properties of human iPSC-derived serotonergic neuron model”, 13th Göttingen Meeting of the German Neuroscience Society, Göttingen, Germany, 20 - 23.03.2019 (poster presentation)

- Svirin E., Kollert S., Jansch C., Wischmeyer E., Strekalova T., Lesch K.-P. Electrophysiological assessment of human induced pluripotent stem cells-derived serotonergic neurons”, 11th FENS Forum of Neuroscience, Berlin, Germany, 09.07.2018 (poster presentation)

- Svirin E., Kollert S., Strekalova T., Lesch K.-P. “Genetic deficiency of the cell adhesion molecule $\mathrm{CDH} 13$, a risk factor for neurodevelopmental disorders, and plasticity of PV+ hippocampal 
interneurons: a study in a new mouse model”, Evaluation Conference, Laboratory of Psychiatric Neurobiology, I.M. Sechenov First Moscow State Medical University, Moscow, Russia, 06.04.2017 (poster presentation)

- Medyntsev A., Nuzhdin Y., Svirin E. Fedorova A., Shishkin S. "The effect of vibrotactile feedback on the rate of commands issued using consecutive eye fixation", The Seventh International Conference on Cognitive Science, Svetlogorsk, Russia, 20-25.06.2016. (poster presentation)

- Shishkin S., Nuzhdin Y., Svirin E., Trofimov A., Fedorova A., Dubynin I., Velichkovsky B. "Semi-direct mind-to-machine interface using gaze and intention markers", The Seventh International Conference on Cognitive Science, Svetlogorsk, Russia, 20 - 25.06.2016 (poster presentation)

- Shishkin S., Svirin E., Nuzhdin Y., Fedorova A., Trofimov A., Slobodskoy-Plusnin Y., Vasilyevskaya A. "Be Patient! Can contingent negative variation help to issue eye movement-based commands?", Conference "Cognitive science in Moscow: new studies", Moscow, Russia, 16.06.2015 (poster presentation)

- Svirin E., Nuzhdin Y., Fedorova A. "A preliminary study of fixation-related potentials during gaze-fixation controlled gaming", XVIII School and Conference of Young Scientists on Physiology of Higher Nervous Activity and Neurophysiology, Moscow, Russia, 29-30.10.2014. (oral presentation) 


\section{List of publications}

- Svirin E., Veniaminova E., Costa-Nunes J., Gorlova A., Umriukhin A., Kalueff A.V., Proshin A., Nedorubov A., Tse A.C.K., Walitza S., Lim L.W., Lesch K.-P., Strekalova T. "Predation stress causes excessive aggression in female mice with partial genetic inactivation of tryptophan hydroxylase-2: evidence for altered myelination-related processes”, Cells, under revision

- Strekalova T., Veniaminova E., Svirin E., Kopeikina E., Veremeyko T., Yung A.W.Y., Proshin A., Kai T.S.Z., Khairuddin S., Lim L.W., Lesch K.-P., Walitza S, Anthony D., Ponomarev E.D. 2021. “Sexspecific ADHD-like behavior, altered insulin receptor expression, and metabolic functions, and increased EEG activity in sialyltransferase ST3GAL5-deficient mice”, Biomolecules, 11(12), 1759. DOI: 10.3390/biom11121759

- Strekalova T., Svirin E., Veniaminova E., Kopeikina E., Veremeyko T., Yung A.W.Y., Proshin A., Walitza S., Anthony D., Lim L.W., Lesch K.-P., Ponomarev E.D. 2021. “ASD-like behaviours, dysregulated inflammatory response and decreased expression of PLP1 characterise mice deficient for sialyltransferase ST3GAL5", Brain Behav Immun Health 27;16:100306. DOI:10.1016/j.bbih.2021.100306

- Strekalova, T., Svirin, E., Waider, J., Gorlova, A., Cespuglio, R., Kalueff, A., Pomytkin, I., Schmitt-Boehrer, A.G., Lesch, K.-P., Anthony, D.C. 2021. “Altered behaviour, dopamine and norepinephrine regulation in stressed mice heterozygous in TPH2 gene”, Progress in 
Neuropsychopharm and Biol Psychiatry 108:110155. DOI:10.1016/j.pnpbp.2020.110155

- Waider J., Popp S., Mlinar B., Montalbano A., Bonfiglio F., Aboagye B., Thuy E., Kern, R., Thiel, C., Araragi, N., Svirin, E., SchmittBöhrer, A.G., Corradetti, R., Lowry, C.A., Lesch, K.-P. 2019. “Serotonin Deficiency Increases Context-Dependent Fear Learning Through Modulation of Hippocampal Activity”, Frontiers in Neuroscience 13 (April). DOI:10.3389/fnins.2019.00245.

- Corominas J., Klein M., Zayats T., Rivero O., Ziegler G., Pauper M., Neveling K., et al. 2018. "Identification of ADHD Risk Genes in Extended Pedigrees by Combining Linkage Analysis and Whole-Exome Sequencing”, Molecular Psychiatry, August. DOI:10.1038/s41380-0180210-6.

- Jansch C., Günther K., Waider J., Ziegler G., Forero A., Kollert S., Svirin E., et al. 2018. “Generation of a Human Induced Pluripotent Stem Cell (IPSC) Line from a 51-Year-Old Female with AttentionDeficit/Hyperactivity Disorder (ADHD) Carrying a Duplication of SLC2A3”, Stem Cell Research 28 (April): 136-40. DOI:10.1016/j.scr.2018.02.005.

- Trofimov A., Strekalova T., Mortimer N., Zubareva O., Schwarz A., Svirin E., Umriukhin A., Svistunov A., Lesch K.-P., Klimenko V. 2017. "Postnatal LPS Challenge Impacts Escape Learning and Expression of Plasticity Factors Mmp9 and Timp1 in Rats: Effects of Repeated Training”, Neurotoxicity Research 32 (2): 175-86. DOI:10.1007/s12640017-9720-2. 
- Nuzhdin Y., Shishkin S., Fedorova A., Trofimov A., Svirin E., Kozyrskiy B., Medyntsev A., Dubynin I., Velichkovsky B. 2017. “The Expectation Based Eye-Brain-Computer Interface”, In Proceedings of the 2017 ACM Workshop on An Application-Oriented Approach to BCI out of the Laboratory - BCIforReal '17, 39-42. New York, New York, USA: ACM Press. DOI:10.1145/3038439.3038446.

- Shishkin S., Nuzhdin Y., Svirin E., Trofimov A., Fedorova A., Kozyrskiy B., Velichkovsky B. 2016. "EEG Negativity in Fixations Used for Gaze-Based Control: Toward Converting Intentions into Actions with an Eye-Brain-Computer Interface”, Frontiers in Neuroscience 10 (November). DOI:10.3389/fnins.2016.00528.

- Shishkin, S., Kozyrskiy B., Trofimov A., Nuzhdin Y., Fedorova A., Svirin E., Velichkovsky B. 2016. "Improving Eye-Brain-Computer Interface Performance by Using EEG Frequency Components.” Bulletin of Russian State Medical University, no. 2: 36-41. DOI:10.24075/brsmu.201602-05. 